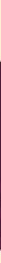

Einfühlen, Unbewußtes, Symptom, Hysterie, Sexualität, Übertragung, Perversion 
Einführungen in die Psychoanalyse I 

Karl-Josef Pazzini, Susanne Gottlob (Hg.)

\section{Einführungen in die Psychoanalyse I}

Einfühlen, Unbewußtes, Symptom, Hysterie, Sexualität, Übertragung, Perversion 
Bibliografische Information der Deutschen Bibliothek:

Die Deutsche Bibliothek verzeichnet diese Publikation in der Deutschen Nationalbibliografie; detaillierte bibliografische Daten sind im Internet über http://dnb.ddb.de abrufbar.

\footnotetext{
(c) $\$$ This work is licensed under a Creative Commons

BY NC ND Attribution-NonCommercial-NoDerivatives 3.0 License.
}

(C) 2005 transcript Verlag, Bielefeld

Lektorat \& Satz: Susanne Gottlob, Hamburg

Layout: Jeannie Moser, Torsten Meyer, Hamburg

Umschlaggestaltung: Kordula Röckenhaus, Bielefeld

Druck: Majuskel Medienproduktion, Wetzlar

ISBN 3-89942-348-8 


\section{Inhalt}

Karl-Josef Pazzini | Susanne Gottlob

Vorwort

\section{Claus-Dieter Rath}

>Einfühlen` und >Erschließen

Max Kleiner

Die Bildungen des Unbewußten

Peter Müller

Was sagt das Symptom?

Ulrike Oudée Dünkelsbühler

Hysterie: »... sagte ich mir, der Fall könne

keine Hysterie sein« (Freud)

Edith Seifert

Zum Mißverständnis der weiblichen Sexualität bei Freud.

Kastrationswahrnehmung als symbolische Matrix

Johanna Drobnig-Naumann

Zur Übertragung - Der Analytiker als Schatzkästchen

Günther X. Frank

Perversion: Savoir-faire und Monotonie.

Versuch einer Strukturanalyse 



\section{Vorwort}

$»$ Ich weiß nicht«, sagt Sigmund Freud zu Beginn seiner ersten Vorlesung in einem Hörsaal der Wiener psychiatrischen Klinik im Wintersemester 1915/16, »wieviel die einzelnen von Ihnen aus ihrer Lektüre oder vom Hörensagen über die Psychoanalyse wissen. Ich bin aber durch den Wortlaut meiner Ankündigung - Elementare Einführung in die Psychoanalyse - verpflichtet, Sie so zu behandeln, als wüßten Sie nichts und bedürfen einer ersten Unterweisung «. ${ }^{1}$ Vor einem gemischten Auditorium aus Hörern aller Fakultäten weiß Freud nicht, was die Zuhörer wissen und diese wissen nicht, was ihnen zu Ohren kommen wird, sie ahnen vielleicht unbewußt etwas. Für Freud entsteht daraus eine Verpflichtung, die einzelnen Zuhörenden so zu behandeln, als wüßten sie nichts, einen Stil der Rede an den anderen zu finden, der einem, und genau genommen einem vielseitigen, >ich weiß nicht`statt gibt. Es geht dabei um ein Nicht-Wissen, das nicht das Umfeld der Dummheit oder Klugheit meint, sondern einen Zwischenraum an Unwissenheiten darüber annimmt, was sich durch Lektüre und Hörensagen an Bezügen zum psychoanalytischen Verfahren bereits eingeschrieben hat.

Die rhetorische Geschicklichkeit der Freudschen Rede unternimmt so gelesen mit den anfänglichen Worten bereits eine erste Unterweisung in der Psychoanalyse: Zwischen dem, der spricht und dem, der hört, wirkt ein prinzipieller, uneinholbarer Hiatus von Nicht-Wissen, der als Voraussetzung für den Impuls zu sprechen und zu hören in der Kur und zu lehren in der Universität lesbar ist. Gibt es hier wie da einen Austausch von Worten, so bleibt (zumindest) ein Unterschied zwischen der Institu- 
tion Universität und der Kur. Erstere lebt von einem mehr oder minder öffentlichen diskursiven Austausch, letztere verträgt keinen dritten $\mathrm{Zu}$ hörer. Der intime Sprachort zwischen Analytiker und Analysant »läßt sich nicht demonstrieren «. ${ }^{2}$ Anders als ein medizinisch-psychiatrisches Deskriptionsverfahren mit einer Nosologie, so Freud etwas später in dieser Vorlesung, entzieht sich das psychoanalytische Verfahren einer Evidentia übers Auge und der Logik des Beweisens. Nicht das visuelle Abbilden, nicht das Lernen an Patienten wird die Technik der Vermittlung sein, das Hören auf das Wort, dem »Zauber« des Wortes ${ }^{3}$ nachzulauschen, bleibt das grundlegende psychoanalytische Verfahren. Es bahnt den Weg zum Unbewußten, es läßt, im Hören des Wortes, und zwar auf der Schwelle vom Sprechen zur »Sprache unserer Wahrnehmungen ${ }^{4}$ Unbewußtes, Geschichtlichkeit auftauchen.

Dieser komplexen Ausgangssituation, vor der Freud stand, haben wir, über hundert Jahre nach den Anfängen der Psychoanalyse, auf noch einem anderen Niveau von Unwissenheit und Wissen über die Psychoanalyse versucht, in der Konzeption der Vorlesung Einführungen in die Psychoanalyse nachzukommen. Jede Vorlesung bezog sich auf ein paar Textstellen bei Freud und Lacan, die den Hörern zugänglich gemacht wurden. Die Vorlesung war als Lektüre, Auslegung, Übersetzung und Performanz gedacht vom Ort der jeweiligen Praxis der Psychoanalyse her, und zwar punktuell.

In diesem Buch sind die Vorträge in der Reihenfolge, in der sie als Ringvorlesung unter dem gleichnamigen Titel an der Universität Hamburg im Sommersemester 2004 gehalten wurden, transkribiert. Der Schritt vom Vortragen, dem immer auch Schriftakte vorausgehen, zur Niederschrift ist nicht nur ein weiterer in einer Prozedur, das gesprochene Wort einer anderen Öffentlichkeit, hier also dem Leser, zuzutragen. Die Publikation der Vorlesungen ist auch als Niederschlag einer unabgeschlossenen Fragestellung lesbar, die wir einmal mehr in Umlauf bringen möchten: Wie verlaufen die Grenzen, wo entwerfen sie sich, wenn psychoanalytische Diskurse in die Institution Universität, die als ein Ort von Bildung und Wissensproduktion anerkannt ist, hineingetragen werden? Immer wieder von neuem erfahren wir, daß die Psychoanalyse eine andere Form des Wissens produziert als es die Universität tun kann. Psychoanalyse ist ja nicht zuletzt als Kritik an der Versicherung des Wissens über Sichtbarkeit und Ableitungen daraus entstanden. Wäre aber das, was sich im analytischen Hören zuträgt, überhaupt Wissen zu nennen? Und wie ließe sich dieses andere artikulieren, darstellen? Die hier 
versammelten Vorlesungen sind Anwendungen der Psychoanalyse - mit all den Widerständen, die sich an die Vorstellung einer Anwendbarkeit heften -, es sind also auch Hinwendungen zur und Abwendungen von der Psychoanalyse, kurzum, es sind Zeugnisse dieser Praxis, auch der Praxis des Theoretisierens.

Indem die Psychoanalyse ein Denken und Sprechen vom Unbewußten her zuläßt, das sich einer Dialektik von Wissen und Nicht-Wissen entzieht und flüchtig, als ausweichendes, unzeitiges Moment aufflackert und wirkt, trägt sie einen Mangel ins Denkbare und erinnert an einen der Sprache konstitutiven und unhintergehbaren Verlust. Von diesem dunklen Punkt her, der je nach spezifischem Kontext von woanders her Geschichten schreibt, kommt etwas in die Sprache und im vorliegenden Buch in die Schrift. Man könnte auch sagen, daß sich die unterschiedlichen Vortragsstile einer Krisis der Rede über die Psychoanalyse verdanken. Ihnen noch einmal anders Gehör zu geben und auch dem Leser, der nicht in dem Hörsaal war, Gelegenheit zu einer Aufnahme zu geben, ist unser Anliegen.

Gerade weil es nicht >die Psychoanalyse $<$ gibt, genausowenig wie >die Einführung in die Psychoanalyse, haben wir Psychoanalytiker aus verschiedenen Praxen (nicht nur der klinischen) eingeladen, zu elementaren Begriffen wie »Einfühlen«, »Unbewußtes«, »Symptom«, »Hysterie«, »Sexualität«, »Übertragung« und »Perversion« vor einem öffentlichen Forum zu sprechen. Eine Fortsetzung der Publikation der Vorlesungen ist geplant, da im darauf folgenden Wintersemester eine zweite Vorlesungsreihe mit Themen zum »Setting«, zur »Traumdeutung«, »Sublimierung«, »Angst«, zum »Lehren«, zur »Psychoanalyse als Kritik normativen Denkens« und zur Frage »Was wirkt?« stattgefunden hat.

Die Vorlesungsreihe wurde gemeinsam konzipiert von Kollegen und Freunden, die im Rahmen von der Assoziation für die Freudsche Psychoanalyse (AFP), dem Lehrhaus der Psychoanalyse Hamburg und der Le[ ]r- und Forschungsstelle: Kunst, Pädagogik und Psychoanalyse (Fakultät für Bildungswissenschaften, Universität Hamburg) arbeiten, diskutieren, denken. Insbesondere danken wir Hartmut Freese von der Arbeitsstelle für wissenschaftliche Weiterbildung der Universität Hamburg für seine aufmerksame Kooperation bei der Organisation der Vorlesungen. Weiter danken wir dem Lehrhaus der Psychoanalyse Hamburg, der AFP und der Universität Hamburg auch für finanzielle Unterstützung bei der Durchführung und Publikation der Vorlesungsreihe.

Karl-Josef Pazzini und Susanne Gottlob 


\section{Einführungen in die Psychoanalyse}

\section{Anmerkungen}

1 Gehalten im Wintersemester 1915/16 an der Universität Wien, veröffentlicht in drei Teilen von 1916 bis 1917. Vgl. Sigmund Freud: »Vorlesungen zur Einführung in die Psychoanalyse«, in: ders., Gesammelte Werke, I-XVIII Bde., London 1940, Frankfurt am Main ${ }^{2} 1999$, hier Bd. XI, 7.

2 Ebd. 10.

3 Ebd.

4 Jutta Prasse: Sprache und Fremdsprache. Psychoanalytische Aufsätze, herausgegeben von Claus-Dieter Rath, Bielefeld 2004, bes. $106 f$. 
Claus-Dieter Rath

\section{`Einfühlenı und ıErschließen` bei Freud}

»Wir müssen herausfinden: Wie geht es denen und was wollen die?«, das sagt die Geschäftsführerin einer Hamburger Werbeagentur; gemeint sind die deutschen Klein- oder Durchschnittsbürger. Und so ersannen ihre Mitarbeiter eine besondere Forschungsvorrichtung: sie halten ihre Konferenzen in einem nachgebauten deutschen Standardwohnzimmer $\mathrm{ab}$, dessen Parameter sie aus Marktforschungen, Statistiken und Beobachtungen bei `Durchschnittsbürgern` gewonnen hatten. Sie müssen ja "so nah wie möglich an die Zielgruppe herankommen" und versuchen nun, sich in andere Bürger hineinzuversetzen, indem sie sich in deren Interieur hineinsetzen. ${ }^{1}$

Die Idee der Einfühlung meint das Eindringen ins Innenleben, in die Seele des Anderen. Im alltäglichen Wortgebrauch bedeutet Einfühlung meist eine bestimmte Nähe, Affinität oder Seelenverwandtschaft: >In diesen Menschen, in dieses Kunstwerk kann ich mich einfühlen; bei jenem anderen gelingt es mir nicht $\iota$. In Kunst und Literatur ist dies die Fähigkeit des Künstlers oder Autors, sich in seine Protagonisten hineinzuversetzen, aber auch des Kunstrezipienten, Lesers, Hörers oder Zuschauers, Figuren und Figurationen zu verstehen und darüber zu einem Verständnis seiner selbst zu gelangen. Von einem Pädagogen erwartet man, daß er sich in seine Schüler hineinversetzen kann. Auch in anderen Bereichen ist solch ein Sich-identifizieren-Können gefordert: Regierende sollten spüren, wo der Bevölkerung »der Schuh drückt $\ll^{2}$, und der Zahnarzt, wo es wehtut, wo etwas sich so merkwürdig anfühlt. Manch einer enttäuscht solche Erwartungen; so meldet die Presse, daß der Fußballtrainer Berti Vogts bei seiner schottischen Mannschaft nicht besonders beliebt sei, weil es ihm an Einfühlungsvermögen fehle. ${ }^{3}$ 
Viele Psychotherapeuten legen Wert auf die Schaffung einer verständnisinnigen Atmosphäre - >Hier werden Sie verstanden Fähigkeit, in die Seele des fremden Patienten hineinzublicken. Sich auf Einfühlung zu berufen, klingt wie eine weder verifizierbare noch falsifizierbare Glaubensüberzeugung, die aus einer Stimmung, einem Gefühl der Stimmigkeit, Harmonie oder Affektgewißheit hervorgeht. Doch welchen anderen Zugang zum Anderen sollte es denn sonst geben? Wiewohl die Psychoanalyse nichts von paranoischen Gedankenleser-Figuren hält, verzichtet auch sie nicht auf den Begriff. Freud, der einmal geäußert hatte: »Es ist mir unheimlich, wenn ich das Gemütsleben eines andern nicht auf Grund des eigenen begreifen kann ${ }^{4}$, unterscheidet mehrere Arten von Einfühlung. Eine davon gehört für ihn zu den Erkenntnisinstrumenten des Psychoanalytikers. Doch dient dieses nicht zur Herstellung eines Bildes der fremden Person $->$ Wer ist das wohl? Kann ich mir das vorstellen, kann ich ihn verstehen?^-, sondern richtet sich auf die fremde Wahrheit des Subjekts.

Einfühlung interessiert Freud zunächst im Zusammenhang mit unserem Lachen über einen naiven Ausspruch, wie zum Beispiel:

"Ein 3-jähriges Mädchen warnt seinen Bruder: ১Du, iß nicht soviel von dieser Speise, sonst wirst du krank werden und mußt Bubizin nehmen.` 'Bubizin? fragt die Mutter, swas ist denn das? ' Wie ich krank warı, rechtfertigt sich das Kind, shabe ich ja auch Medizin nehmen müssen. Das [österreichische] Kind ist der Meinung, daß das vom Arzt verschriebene Mittel Mädi-zin heißt, wenn es für das Mädi bestimmt ist, und schließt, daß es Bubi-zin heißen wird, wenn das Bubi es nehmen soll. [Freud kommentiert:] Dies ist nun gemacht wie ein Wortwitz, der mit der Technik des Gleichklangs arbeitet [Medi - Mädi], und könnte sich ja auch als wirklicher Witz zugetragen haben, in welchem Falle wir ihm halb widerwillig ein Lächeln geschenkt hätten. Als Beispiel einer Naivität scheint es uns ganz ausgezeichnet und macht uns laut lachen. ${ }^{5}$

Ausschlaggebend für diese Affektreaktion sei unser »Sichhineinversetzen [...] in den psychischen Vorgang bei der produzierenden Person«. Wir nehmen entweder an, der Witz sei beabsichtigt (worauf wir lau reagieren), oder daß das Kind »im guten Glauben auf Grund seiner unkorrigierten Unwissenheit einen ernsthaften Schluß habe ziehen wollen «. ${ }^{6}$ »Aus solchem Sichhineinversetzen und Vergleichen resultiert eine Ersparung von Aufwand, die wir durch Lachen abführen. ${ }^{7}$ Das Kind hat nämlich im Fall von Medi-zin, Mädi-zin, Bubi-zin »eine Identität gefunden« und zugleich »eine Schranke überwunden [...], die für uns besteht«. Da wir uns beim Verstehen des Gehörten »den Aufwand für die Einhal- 
tung dieser Schranke ersparen « können, ja müssen, kommt es zum Lachanfall. ${ }^{8}$ Einfühlung ist hier eine Vergleichungsarbeit und nicht lediglich ein Gleichempfinden (wie wenn zwei über dasselbe lachen). Hingegen beschäftigt Freud der Vorgang, der das Gefühl hervorruft, "gleich zu empfinden", schon in seinen ersten psychoanalytischen Arbeiten, etwa 1895 im »Entwurf einer Psychologie« im Zusammenhang mit den Äußerungen des Kleinkinds, das sich nicht selbst helfen kann das nicht aus eigenen Kräften eine Reizzufuhr dauerhaft beseitigen $\mathrm{kann}^{9}$ - und das folglich versucht, den Anderen herbeizurufen. Da ihm die »spezifische Aktion« einer »Veränderung in der Außenwelt« nicht gelingt, vollzieht das Kind eine »innere Veränderung«: es führt seine Erregung in Form eines Affekts ab, es verschafft seinen Gemütsbewegungen Ausdruck, beispielsweise in Gestalt einer Angstreaktion, etwa durch Schreien, Gefäßinnervation, die durch Erröten, heftig gehenden Puls, Schwitzen usw. wahrnehmbar wird. ${ }^{10}$ Dieser Weg des Appells an den Anderen ist lebensnotwendig, denn das Baby vermag sich nicht alleine zu ernähren, sich die Windeln zu wechseln, sich gegen Kälte, Hitze usw. zu schützen. ${ }^{11}$ »Der menschliche Organismus ist zunächst unfähig, die spezifische Aktion herbeizuführen. Sie erfolgt durch fremde Hilfe, indem durch die Abfuhr auf dem Wege der inneren Veränderung ein erfahrenes Individuum auf den Zustand des Kindes aufmerksam gemacht« wird. Und dann kommt etwas für mein Thema $>$ Einfühlen und ErschlieBen< Bedeutsames: »Diese Abfuhrbahn gewinnt so die höchst wichtige Sekundärfunktion der Verständigung, und die anfängliche Hilflosigkeit des Menschen ist die Urquelle aller moralischen Motive. ${ }^{12}$ Der kleine Mensch wendet sich also an einen großen Anderen, versucht ihm etwas $\mathrm{zu}$ verstehen zu geben. Was das Kind selbst von dem versteht, was es gerade umtreibt, und wie sein Appell verstanden wird, bleibt dabei offen. Übrigens sind für Freud alle Symptomäußerungen auf den Anderen berechnet. ${ }^{13}$ Das Kind gibt etwas von sich, das beim Anderen hoffentlich ankommt. Dieser kann aufgrund eigener Körpererfahrungen - und mit Hilfe seiner Kultur - diesem Appell Verständnis entgegenbringen. Und das Kind wiederum erfährt etwas durch dessen Reaktionen auf seine verschiedenen Formen der Abfuhr. ${ }^{14}$

Doch hat diese »Verständigung« etwas mit Einfühlung zu tun? Sie kann ja sowohl `Einfühlung in den psychischen Vorgang`als auch `Einfühlung in die Person`, eine Art Mitfühlen (Mitempfinden, gemeinsam empfinden), ein Sich-Gleichmachen sein. Verstehen, Erklären und SichIdentifizieren werden oft verwechselt, etwa wenn man behauptet, die 
Erörterung der Motive eines straffälligen Menschen bedeute, man wolle dessen Taten verharmlosen und ihn dementsprechend nachsichtig behandeln.

Das Sich-Einfühlen wird meist nicht als eine zerlegende, analytische Tätigkeit aufgefaßt, sondern als die Schaffung einer >guten Gestaltı oder als das Einswerden mit der anderen Person; man fühlt sich dann befriedigt, wenn das Verstehensgefühl eine Ganzheit ergibt, was jedoch keineswegs bedeutet, daß man etwas kapiert hat.

Die bis hier genannten Überlegungen Freuds wären eher von allgemein sozialpsychologischem und weniger von psychoanalytischem Interesse, wenn er nicht Anfang der zwanziger Jahre auf die Einfühlung zurückgekommen wäre, diesmal als ein Element der Massenbindung und - der Arbeit des Psychoanalytikers. Für beide spiele die »ursprünglichste Form der Gefühlsbindung an ein Objekt « ${ }^{15}$, nämlich die Identifizierung, eine entscheidende Rolle. Freud unterscheidet drei Formen:

1. Die Identifizierung mit einem Vorbild. Das Kind möchte so werden wie ein Größerer, Vollkommenerer, etwa der Vater, und an seine Stelle treten. ${ }^{16}$ Dieses Vorbild ist nicht dasselbe wie ein Liebesobjekt bzw. Objekt der Sexualtriebe. Die »Identifizierung strebt danach, das eigene Ich ähnlich zu gestalten wie das andere, zum >Vorbild genommene ${ }^{17}$, das Ich-Ideal.

2. Die Identifizierung mit einer geliebten Person, die man verloren hat. Man übernimmt, kopiert einen bestimmten Zug von ihr. Dieses Objekt einer unmöglich gewordenen Liebe wird dann nicht mehr sinnlich begehrt und ersatzweise ins eigene Ich introjiziert. Die Identifizierung wird hier »auf regressivem Wege zum Ersatz für eine libidinöse Objektbindung [...] gleichsam durch Introjektion des Objekts ins Ich «. ${ }^{18}$ Die Selbstvorwürfe des Melancholikers ${ }^{19}$ sind somit Vorwürfe gegen den verlorenen Anderen, nachdem er introjiziert worden ist.

3. Bei der dritten Art von Identifizierung, die auch die hysterische genannt wird, greift man den Gefühlszustand eines Mitmenschen auf, der weder Objekt noch Vorbild ist. Dabei will man weder den anderen haben noch will man wie er sein, sondern man will etwas auch haben. $\mathrm{Zu}$ dieser dritten Art zählt Freud die Einfühlung. Das Besondere an ihr stellt er folgendermaßen dar:

„Wenn zum Beispiel eines der Mädchen im Pensionat einen Brief vom geheim Geliebten bekommen hat, der ihre Eifersucht erregt und auf den sie mit einem hysterischen 
Anfall reagiert, so werden einige ihrer Freundinnen, die darum wissen, diesen Anfall übernehmen [...]. Dies geschehe "auf dem Wege der psychischen Infektion ${ }^{20}{ }^{20}$

Dieser Vorgang beruhe darauf, daß die Freundinnen sich »in dieselbe Lage« versetzen können oder wollen. »Die anderen möchten auch ein geheimes Liebesverhältnis haben und akzeptieren unter dem Einflu $\beta$ des Schuldbewußtseins auch das damit verbundene Leid«, also das Leiden an dem übernommenen hysterischen Symptom, dem Anfall. Freud entwickelt dies nun theoretischer:

»Es wäre unrichtig zu behaupten, sie eignen sich das Symptom aus Mitgefühl an. Im Gegenteil, das Mitgefühl entsteht erst aus der Identifizierung, und der Beweis hiefür ist, daß sich solche Infektion oder Imitation auch unter Umständen herstellt, wo noch geringere vorgängige Sympathie zwischen beiden anzunehmen ist, als unter Pensionsfreundinnen zu bestehen pflegt. [Ansteckung und Imitation also schon ohne Mitgefühl; CDR] Das eine Ich hat am anderen eine bedeutsame Analogie in einem Punkte wahrgenommen, in unserem Beispiel in der gleichen Gefühlsbereitschaft, es bildet sich daraufhin eine Identifizierung in diesem Punkte, und unter dem Einfluß der pathogenen Situation verschiebt sich diese Identifizierung zum Symptom, welches das eine Ich produziert hat. Die Identifizierung durch das Symptom wird so zum Anzeichen für eine Deckungsstelle der beiden Ich, die verdrängt gehalten werden soll.."1

Im Zuge dieser Verdrängung verschiebt sich also etwas. Der durch Infektion übernommene hysterische Anfall der Freundinnen indiziert eine Deckungsstelle der beiden Ich, hier die Neigung, »auch ein geheimes Liebesverhältnis haben« zu wollen. Auf dieses unstatthafte Verhältnis bezieht sich dann das »Schuldbewußtsein«, das eine »pathogene Situation« erzeugt. Dieses Geschehen zwischen den Pensionatsmädchen ist selbstverständlich mehrfach determiniert. Freuds Beispiel soll hier nur zeigen, daß für diesen massenhaft auftretenden Fall von Symptombildung eine einzige Deckungsstelle genügt. ${ }^{22}$

Die dritte Form von Identifizierung entsteht »bei jeder neu wahrgenommenen Gemeinsamkeit mit einer Person, die nicht Objekt der Sexualtriebe ist [...]. Je bedeutsamer diese Gemeinsamkeit ist, desto erfolgreicher muß diese partielle Identifizierung werden können und so dem Anfang einer neuen Bindung entsprechen «. ${ }^{23}$

Die »gegenseitige Bindung der Massenindividuen« sei »von der Natur einer solchen Identifizierung durch eine wichtige affektive Gemeinsamkeit«. Freud vermutet, »diese Gemeinsamkeit liege in der Art der Bindung an den Führer «. ${ }^{24}$ Dieser Fall könnte sich mit dem ersten (»gleiche 
Gefühlsbereitschaft «) darin verbinden, daß die Suche nach einem Führer einen Liebesanspruch enthält; es geht dann um den großen Anderen. ${ }^{25}$

Einfühlung ist für Freud nichts Unmittelbares, sondern etwas Vermitteltes. Sie setzt nämlich eine Identifizierung voraus. Wir wissen ja, daß unser Mitgefühl Grenzen kennt: auch wer ein Herz für Tiere hat, macht Unterschiede zwischen bevorzugten, als nahestehend empfundenen Tierarten und anderen, deren Schicksal ihn nicht so sehr rührt. ${ }^{26}$ Auch mit Menschen haben wir nicht unterschiedslos Mitgefühl. Der andere muß uns nahe stehen. (Katastrophe im Ausland: >Wie viele Deutsche befinden sich unter den Opfern?〈) Es muß zumindest in einem Punkt eine Gemeinsamkeit, eine Verbindung geben. Da Gesellschaft kein Naturzustand ist, bedarf es symbolischer Akte, die sie konstituieren. Ein solcher ist das von Freud in der Massenpsychologie erwähnte Totemmahl als gemeinsame Inkorporierung. ${ }^{27}$ Mahlrituale bekräftigen die symbolische Identifizierung derjenigen, die etwas Drittes miteinander teilen. Derjenige, mit dem ich das Brot teile, wird mein Kumpan (cum-panis, compagno, copain ...). Das Mahl trennt Tischgenossen von den Ausgeschlossenen, >Unreinen`, mit denen es nicht geteilt wird. Eine Form dieses magischen Rituals ist das christliche Abendmahl, die Kommunion, bei der sowohl eine vertikale Identifizierung (mit dem symbolischen Jesus) als auch eine horizontale Identifizierung (mit den anderen, mit denen man die idealisierte Speise teilt) stattfindet.

Auch die Hypnose und das delegierte Ichideal ordnet Freud der Bindungsthematik $\mathrm{zu}^{28}$, beläßt es jedoch bei der Bemerkung, man sei »weit davon entfernt [...], das Problem der Identifizierung erschöpft zu haben«, und kommt überraschend auf die Arbeit des Psychoanalytikers zu sprechen: es sei nämlich zu ahnen, »daß wir vor dem Vorgang stehen, den die Psychologie >Einfühlung rem Verständnis für das Ichfremde andrer Personen hat «. ${ }^{29}$ Verständnis wofür? Manchmal kann ein Blick auf Übersetzungen solche Formulierungen erhellen - selbst wenn sie Fehlübersetzungen sind. So wird in französischen Freud-Ausgaben das »Ichfremde andrer Personen« zu »ce que l'autre a d'étranger à notre moi«, und in englischen zu »our understanding of what is inherently foreign to our ego in other people $\ll^{30}-$ als stünde bei Freud: das uns am Ich andrer Personen Fremde. In der italienischen Ausgabe findet man: »d'intendere 1'Io estraneo di altre persone« (»das fremde Ich anderer Personen verstehen«). Vor diesem Hintergrund erkennt man deutlicher: es geht um das, was dem Ich des anderen an ihm selbst fremd bleibt: das Unbewußte, das Unheimliche, das Ur- 
verdrängte. Dazu gehört nicht allein das, was man nicht tut, man nicht sagt oder das, was zu denken verboten ist, das, was das Ich des anderen nicht anerkennen kann (Spiegel-Ich; eine Frage des Narzißmus, Image, Imaginären; Ich als Ort der Verkennung: »Das kann doch gar nicht sein, daß ich so etwas getan, gesagt, gedacht habe; so etwas gehört nicht $\mathrm{zu}$ mir, paßt nicht zu mir ${ }^{31}$ ). Denn wesentlich geht es um das, was das Ich prinzipiell nicht kennen und nicht erkennen kann (Reales, Es; um das Nachdrängen des - nie offenzulegenden - Urverdrängten. Grenzen des Ich als Wahrnehmungsorgan).

Ohne diese Zusammenhänge weiter auszuführen, bemerkt Freud an dieser Stelle, die Identifizierung beschränke sich nicht auf die »nächsten affektiven Wirkungen«, sondern habe auch »für unser intellektuelles Leben« Bedeutung. Einfühlen betrifft also nicht ausschließlich das Gefühlsleben. Und aus der folgenden Fußnote ersieht man, daß sie für ihn nicht irgendeine psychotherapeutische Technik, sondern ein Fundament der psychoanalytischen Arbeit ist: »Von der Identifizierung führt ein Weg über die Nachahmung zur Einfühlung, das heißt zum Verständnis des Mechanismus, durch den uns überhaupt eine Stellungnahme zu einem anderen Seelenleben ermöglicht wird «. ${ }^{32}$ Der Ausgangspunkt ist also eine Identifizierung; auf diese folgt eine Nachahmung bzw. Imitation oder Infektion, von denen es zwei Varianten gibt: 1. einfaches Gleichtun (in einem Punkt) und 2. Verschiebung der Identifizierung zum Symptom, welches das eine Ich produziert hat. Erst infolge dieser Vorgänge findet Einfühlung statt.

Einfühlung gilt oft als ein verständnisinniges Sich-in-den-anderen-Hineinfühlen, als Durchdrungenwerden eines Ichs durch ein anderes. Man spricht davon, der eine könne sich in den anderen (nicht) einfühlen, oder Männer könnten sich nicht in Frauen einfühlen usw. Es wird dabei stets das Überwinden einer lästigen Fremdheit angestrebt. Freuds Einfühlung hingegen erhält eine erfrischende, erhellende Fremdheit aufrecht. Im Unterschied $\mathrm{zu}$ einem Anschmiegungs- und Gleichwerdungsvorgang nähert diese psychoanalytische Einfühlung sich dem Ichfremden im anderen, und zwar unter Aufrechterhaltung der Verschiedenheit. Insofern unterscheidet sich ihr Mechanismus von dem der Massenhysterie: bei dieser entsteht aus einer »bedeutsame[n] Analogie in einem Punkt« bzw. einer "gleichen Gefühlsbereitschaft« die Gewißheit einer Gleichheit oder zumindest einer Gefühlsgleichheit. Der Analytiker weiß, daß man die psychischen Akte, die man der anderen Person zuschreibt, nur vermuten, also aus ihren Äußerungen und Handlungen erschließen, überset- 
zen, erraten kann, und daß >Gefühl etwas Bewußtes - etwas Sich-zuFühlen-Gebendes - und somit etwas Verschobenes ist, das stets auf seinen unbewußten Gehalt hin befragt werden muß.

Der sich einfühlende Analytiker ist in einer anderen Position als eine der >infizierten` Freundinnen des Internatsmädchens. Das Mädchen, das das Gefühl hat: >Wir sind gleich ২, weiß nicht, daß es sich mit dem Begehren des anderen identifiziert, wenn es dessen Symptom übernimmt. Für die Freundinnen muß die »Deckungsstelle der beiden Ich [...] verdrängt gehalten werden $«{ }^{33}$ Der Analytiker hingegen weiß, daß das Unbewußte im Spiel ist, und deshalb kommt keine Massenbildung zustande. Die Kur - oder der Kurs des analytischen Diskurses - ist ja auf das Begehren des Einzelnen ausgerichtet und verträgt kein >ich auch`, kein `wir beide verstehen uns doch`, keine Vereinigung.

$\mathrm{Oft}$ - etwa in manchen Konzeptionen der Gegenübertragung ${ }^{34}$ - wird aus Freuds Konzeption des Einfühlens ein Verstehen gemacht oder die Einfühlung in den psychischen Vorgang verwechselt mit einer Einfühlung in die andere Person oder mit einer Gefühlsgleichheit. Freud jedoch spricht gerade in Bezug auf die Arbeit des Psychoanalytikers davon, daß die Identifizierung sich nicht auf die "nächsten affektiven Wirkungen« beschränke, sondern auch »für unser intellektuelles Leben« Bedeutung habe.

Die praktische Relevanz der Einfühlungsthematik besteht für den Analytiker darin, daß er durch die Symptomäußerungen und andere Bildungen des Unbewußten hindurch genügend von dem latenten Diskurs erfährt bzw. diesen den Analysanten selbst erfahren läßt. Insofern betreffen die unterschiedlichen Arten, Einfühlung zu denken, d.h. zu theoretisieren, die Ausrichtung der analytischen Tätigkeit, die Ideal- oder Normforderungen bei der Ausbildung von Psychoanalytikern (〉Fühle Dich ein!^) und schließlich auch den Umgang des Analytikers mit sich selbst. Der Analytiker identifiziert sich nicht mit dem Begehren des Analysanten und bildet mithin nicht dasselbe Symptom aus - hoffentlich! ${ }^{35}$ Welche Folgen hätte eine kopierende Art der Nachahmung für ihn? Er übernähme unbewußt von seinen Analysanten nicht nur allerlei Gemütszustände (eventuell täglich mehrmals wechselnd), sondern auch Symptomhandlungen und körperliche Symptomäußerungen: Weinen, Migräneanfälle, Ohrensausen, Herzbeschwerden, Taubheit an allen möglichen Gliedern ... Er steckte sich mit diesen Symptomen an, auch wenn sie bei ihm sich anders zusammensetzten, in seiner Psyche anders determiniert wären. 
Noch mal: »Das Ichfremde« kann man lesen als »das Unbewußte«. Doch auf welchen Wegen geht dessen Erkundung vor sich? Manche stellen sich Einfühlung vor wie eine Direktverbindung zwischen einem Unbewußten und einem zweiten Unbewußten, gleichsam eine ÜberspielVerkabelung zweier Apparate. In dem Science-Fiction-Film Projekt Brainstorm von Douglas Trumbull (1982) nutzt ein Wissenschaftler die Entdeckung, daß menschliche Empfindungen aufgezeichnet und auf andere Personen übertragen werden können, um mit Hilfe einer Maschinerie in die Träume eines anderen einzutauchen. Ich glaube, der Wissenschaftler versucht, jemanden auf diesem Wege zu retten und muß beim Durchqueren seiner Alpträume furchtbare Qualen leiden. Mit einem ähnlichen Bild illustriert Freud in seinen »Ratschlägen für den Arzt bei der psychoanalytischen Behandlung« dessen Verbindung zum Unbewußten des Patienten. Er warnt dort zunächst vor den Gefahren des »therapeutischen Ehrgeizes«: Der Arzt solle sich in den Stand setzen,

»alles ihm Mitgeteilte für die Zwecke der Deutung, der Erkennung des verborgenen Unbewußten zu verwerten, ohne die vom Kranken aufgegebene Auswahl durch eine eigene Zensur zu ersetzen, in eine Formel gefaßt: er soll dem gebenden Unbewußten des Kranken sein eigenes Unbewußtes als empfangendes Organ zuwenden, sich auf den Analysierten einstellen wie der Receiver [d.h. Hörmuschel, CDR] des Telephons zum Teller [d.h. Sprechmuschel, CDR] eingestellt ist. Wie der Receiver die von Schallwellen angeregten elektrischen Schwankungen der Leitung wieder in Schallwellen verwandelt, so ist das Unbewußte des Arztes befähigt, aus den ihm mitgeteilten $A b$ kömmlingen des Unbewußten dieses Unbewußte, welches die Einfälle des Kranken determiniert hat, wiederherzustellen ${ }^{36}{ }^{36}$

Jahrelang wurde von Freuds Schülern diese einfach scheinende, jedoch rätselhafte Äußerung zur Arbeitsgrundlage des analytischen Vorgangs verstanden als eine Art Gedankenübertragung bzw. direkter Kommunikation zweier Systeme $U b w$, obwohl in Freuds Text unklar bleibt, was das Unbewußte hier sein soll ${ }^{37}$ : die Instanz $U b w$ (systematisch), unbewußtes Material (deskriptiv) oder aber ein unbewußter Vorgang beim Analytiker. Ludwig Binswanger kam schließlich auf die Idee, den Autor selbst um Klärung zu bitten:

"Von jeher hat mich Ihre Bemerkung frappiert, der Analysator habe dem Analysanden sein Unbewußtes nur so passiv entgegenzuhalten wie der Receiver sich zum Teller verhält usw. [...]. [...] denn entweder muß man hier rein rationalistisch eine in jedem Menschen wirksame, allen gemeinsame ১Organisation der Vernunftı annehmen oder aber 
zu einer mystischen oder zum mindesten romantischen Auffassung von dem geistigen Wechselverkehr der Menschen gelangen [...] . $^{38}$

Freuds Replik:

"Selbstverständlich beantworte ich gern Ihre wissenschaftlichen und persönlichen Anfragen. Den Satz, man müsse das Unbewußte des Analysierten mit seinem Unbewußten erfassen, ihm gewissermaßen das unbewußte Ohr als receiver entgegenhalten, habe ich in einem bescheidenen und rationalistischen Sinne ausgesprochen, obwohl ich nicht verkenne, daß sich hinter der Formulierung auch weitergehende Probleme verbergen. Ich meinte zunächst nur, man müsse sich frei halten von der bewußten Steigerung gewisser Erwartungen und also denselben Zustand in sich herbeiführen, den man vom Analysierten selbst verlangt. Jede Unklarheit verschwindet, wenn Sie annehmen, daß das Unbewußte in jenem Satze nur deskriptiv gemeint ist. In systematischer Ausdrucksweise sollte es lauten: vorbewußt anstatt unbewußt «. ${ }^{39}$

Der receiver ist also das »unbewußte Ohr«, das mit Sprache und Sprechen des Analysanten umzugehen hat, und im Unterschied zu einer Telefonhörmuschel nicht lediglich elektrische Impulse in Schallwellen umwandelt. Das Ohr als receiver kann beispielsweise den Empfang verweigern, ohne deshalb schon kaputt zu sein. Die Begriffe »Kommunikation« oder »kommunizieren«, die diese Differenzen eher verhüllen, verwendet Freud übrigens nie für den Verkehr zwischen Personen, sondern stets für die Beziehungen zwischen Neuronen, Partialtrieben oder Systemen der Psyche. Auch der Zusammenhang des Teller-ReceiverBildes von 1912 wird in dem Brief an Binswanger nochmals hervorgehoben: es geht darum, sich von bestimmten Erwartungen frei zu machen und seine Aufnahmefähigkeit zu maximieren. Man kann dabei auch an den Vergleich mit der Funktionsweise des »Wunderblocks« denken ${ }^{40}$, anhand dessen Freud (1924/25) das Verhältnis von Wahrnehmung und Erinnerung illustriert. Die Aufnahmefläche muß immer frisch sein, das Ohr muß immer frei sein. Es handelt sich da um eine besondere Art produktiven kreativen Vergessenkönnens: ignorantia docta.

Die Einfühlung als »Stellungnahme zu einem anderen Seelenleben« kann man auch ein Erschließen eines »vermuteten realen Sachverhalts« nennen. In einem seiner letzten Texte grenzt Freud die »Realität«, als etwas sinnlich Wahrnehmbares, gegen das »Reale« ab, das sich der Wahrnehmung und der Darstellbarkeit entziehe, aber dennoch Wirkungen zeitige. Die Psychoanalyse habe »die Lücken unserer Bewußtseinsphänomene«, unserer »bewußten Selbstwahrnehmung« »auszufüllen«; 
wie eine Naturwissenschaft decke sie »hinter den unserer Wahrnehmung direkt gegebenen Eigenschaften (Qualitäten) des Forschungsobjektes« anderes auf. Es gelte also »eine Anzahl von Vorgängen, die an und für sich >unerkennbar sind «, zu »erschließen«; wir »schalten sie in die uns bewußten ein und wenn wir z.B. sagen, hier hat eine unbewußte Erinnerung eingegriffen, so heißt das eben: Hier ist etwas für uns ganz Unfaßbares vorgefallen, was aber, wenn es uns zum Bewußtsein gekommen wäre, nur so und so hätte beschrieben werden können «. ${ }^{41}$ Unsere Sinnesorgane könnten den »vermuteten realen Sachverhalt« nicht wahrnehmen. Freud formuliert an dieser Stelle, als nähme er ein Lacansches Diktum vorweg: »Das Reale wird immer >unerkennbar bleiben «. ${ }^{42}$ Seine Feststellung, die Psychoanalyse betreibe die »Erschließung des Unbewußten ${ }^{43}$, bezieht sich auf Vorgänge und Inhalte sowie auf psychische Gebiete und Strukturen. Beispielsweise sagt er: »Die Bearbeitung der Einfälle, welche sich dem Patienten ergeben, wenn er sich der psychoanalytischen Hauptregel unterwirft, ist nicht das einzige unserer technischen Mittel zur Erschließung des Unbewußten. Dem gleichen Zwecke dienen zwei andere Verfahren, die Deutung seiner Träume und die Verwertung seiner Fehl- und Zufallshandlungen «. ${ }^{44}$ Und gleichermaßen: »Aus der Zwangsvorstellung läßt sich das ursprüngliche Ereignis leicht erschließen «. ${ }^{45}$ Oder er spricht von den »einzelnen latenten Seelenvorgänge[n], die wir erschließen « ${ }^{46}$ An anderer Stelle heißt es: $»$ Das Über-Ich ist eine von uns erschlossene Instanz «. ${ }^{47}$ Da das Reale sich der Wahrnehmung entzieht, müssen wir »alles, was wir neu erschlossen haben, doch wieder in die Sprache unserer Wahrnehmungen übersetzen [...], von der wir uns nun einmal nicht frei machen können «. ${ }^{48}$ Wir haben also etwas »Unfaßbares« anzuerkennen und uns diesem Realen auf zwei Wegen zu nähern: indem wir an der Aufnahmefähigkeit unserer Sinnesorgane arbeiten - hören lernen -, und indem wir das Erschließen des »vermuteten realen Sachverhalts« üben.

Der Psychoanalytiker betreibt keine Hellseherei und verläßt sich auch nicht auf übersinnliche Phänomene. Er ist auf Sinnesdaten angewiesen, von denen aus er Rückschlüsse zieht. ${ }^{49}$ Seiner Wahrnehmung sind dabei ebenso Grenzen gesetzt wie der Selbstwahrnehmung des Subjekts infolge der »Zerlegung der psychischen Persönlichkeit«. An einer berühmten Stelle seiner gleichnamigen Vorlesung erklärt Freud, er könne sich vorstellen, $\gg d a ß$ es gewissen mystischen Praktiken gelingen mag, die normalen Beziehungen zwischen den einzelnen seelischen Bezirken umzu- 
werfen, so daß z.B. die Wahrnehmung Verhältnisse im tiefen Ich und im Es erfassen kann, die ihr sonst unzugänglich waren. ${ }^{50}$

Diesen Bezug auf Mystiker (neben Laienärzten, Naturheilkünstlern, Dichtern und Naturphilosophen) verwendet Freud mehrfach ${ }^{51}$, um dem Ärztepublikum die Lücken in einem rein anatomisch, chemisch, physikalisch und biologisch orientierten Wissen zu verdeutlichen, welches das psychische Leben außer acht läßt. (Übrigens sollte man die Anschauungen bestimmter Mystiker nicht verwechseln mit mystischer Weltanschauung, etwa dem Okkultismus, in der Freud den Hauptfeind der Wissenschaftlichkeit sieht. ${ }^{52}$ ) Den mystischen Praktiken setzt Freud eine gleichsam wissenschaftliche Erweiterung des Wahrnehmungsfeldes entgegen, denn die »therapeutischen Bemühungen der Psychoanalyse« hätten »sich einen ähnlichen Angriffspunkt gewählt [...]. Ihre Absicht ist ja, das Ich zu stärken, es vom Über-Ich unabhängiger zu machen, sein Wahrnehmungsfeld zu erweitern und seine Organisation auszubauen, so daß es sich neue Stücke des Es aneignen kann. Wo Es war, soll Ich werden. Es ist Kulturarbeit etwa wie die Trockenlegung der Zuydersee. ${ }^{53}$

Diese überraschende Verbindung von »therapeutischen Bemühungen der Psychoanalyse« und Kulturarbeit erweitert den Sinn des >Erschließens um die `Erschließung` eines Gebiets - es geht also um ein logisches wie um ein kolonisierendes Erschließen.

Mir scheint, daß die unterschiedlichen Auslegungen des berühmten Mottos auf verschiedenen Auffassungen des \Aneignens〈 (»daß es sich neue Stücke des Es aneignen kann«) beruhen. Eine verbreitete, ichpsychologische, Lesart dieses Bilds von der Trockenlegung lautet: das Es soll zurückgedrängt, sein Gebiet soll annektiert werden, gleichsam nach der Art eines >Anschlusses` an das Ich, das nicht länger ein bloßes Anhängsel des Es bleiben soll. Das Es wird dabei der Zuydersee gleichgesetzt - als läse man `Es ist ... Zuydersee < - und das hinter dem 1932 vollendeten Damm liegende Meer, die Nordsee, wird gar nicht mehr zur Kenntnis genommen.

Andere Akzente setzt Jacques Lacan: Im Gegensatz zu einer gängigen französischen Übersetzung - »Le moi doit déloger le ça« (»Das Ich soll das Es verscheuchen «) - unterzieht er das Freudsche Motto seit den frühen fünfziger Jahren einer Deutungsarbeit, die den Aspekt des Werdens hervorhebt und sich hauptsächlich auf die Tatsache stützt, daß Freud dort »Es« und »Ich« ohne Artikel schreibt; so gelangt Lacan zu Formulierungen wie: »Wo es war, soll ich werden « $^{54}$, wobei »es« das Trauma oder der Urverlust (und die Urverdrängung) sein könnte, von dem aus- 
gehend das Subjekt - »ich « - entstehen soll. Psychoanalytische Kulturarbeit wäre hier das Werden eines begehrenden Subjekts, also eines Subjekts, das aus einem bloßen strial und error oder bloßer Ansprüchlichkeit (Kriegenwollen) herausfindet. Unter dem Gesichtspunkt der Kulturarbeit sollte festgehalten werden, daß Freud in seiner Vorlesung das 1932 höchst aktuelle Bild von der Trockenlegung der Zuydersee im theoretischen Zusammenhang des Wahrnehmens, des Erschließens und des Ausbaus einer Organisation heranzieht. Das berechtigt zur Annahme, daß »aneignen « dort nicht als ein Zurückdrängen (Wegnehmen, Enteignen) zu verstehen ist, sondern als ein Erfassen oder Begehbarmachen unzugänglicher Verhältnisse. Ziel der Kulturarbeit wäre also nicht das Verstummen oder Verschwinden des Objekts der Aneignung, sondern die Erweiterung eines Wahrnehmungsfelds. ${ }^{55}$

Genauso wesentlich ist es, dessen Beschränktheit anzuerkennen, denn:

»In den bestgedeuteten Träumen muß man oft eine Stelle im Dunkel lassen, weil man bei der Deutung merkt, daß dort ein Knäuel von [latenten; CDR] Traumgedanken anhebt, der sich nicht entwirren will, aber auch zum Trauminhalt keine weiteren Beiträge geliefert hat. Dies ist dann der Nabel des Traums, die Stelle, an der er dem Unerkannten aufsitzt. Die Traumgedanken, auf die man bei der Deutung gerät, müssen ja ganz allgemein ohne Abschluß bleiben und nach allen Seiten hin in die netzartige Verstrikkung unserer Gedankenwelt auslaufen. Aus einer dichteren Stelle dieses Geflechts erhebt sich dann der Traumwunsch wie der Pilz aus seinem Mycelium «. ${ }^{56}$

Aus dem Unergründlichen, dem Pilzgeflecht, ragt also etwas sinnlich Wahrnehmbares hervor: der Pilz - es ist ein komplexeres Bild als das von der Spitze eines Eisbergs. Für Freud steht fest: »Jeder Traum hat mindestens eine Stelle, an welcher er unergründlich ist, gleichsam einen Nabel, durch den er mit dem Unerkannten zusammenhängt «. ${ }^{57}$ Lacan forciert dieses »Unerkannte« und erklärt, es sei nicht bloß das Nochnicht-Erkannte, sondern das prinzipiell Unerkennbare, das Urverdrängte bzw. das Unmögliche oder Reale, das niemals gesagt werden kann. ${ }^{58}$ Ein Loch. Diese Lesart kann sich auf die oben erwähnte Freudsche Figur des »unerkennbaren Realen« stützen (die Lacan übrigens nie wörtlich zitiert hat).

Aufgabe des Analytikers ist es, dieses Loch offenzuhalten und dafür zu sorgen, daß der Analysant weitere Bildungen des Unbewußten produzieren und somit von diesen Rändern des Wahrnehmbaren her das Reale etwas weiter erschlossen werden kann. Lacans Operation »cerner le 
réel«, das Einfassen, Konturieren oder auch Ausleuchten des Realen, entspricht insofern der Freudschen »Trockenlegung der Zuydersee«.

Dennoch ist ein Psychoanalytiker immer wieder versucht, dieses Loch mit seinen Phantasien und seinem gesammelten Wissen zu stopfen, etwa mit Hilfe einer Symboldeutung (bsp. Traumbücher), einer Sinndeutung (〉welche aggressive Bedeutung hat das?^) oder einer intuitiven Deutung ( $\$ Ich habe das Gefühl, daß ....८). Eine als Gleichwerdung mit dem anderen verstandene Einfühlung ist im Hinblick auf das Reale, das Unbewußte, das Urverdrängte, fehl am Platz. Sie kann nur Verkennung sein. Die Berufung auf Intuition klingt zwar sympathisch, doch führt sie in diesem Zusammenhang zu einer Willkürherrschaft des Analytikers, der sich von irgendwelchen Gestalt-Vorstellungen leiten läßt.

In der alten französischen Ausgabe der Massenpsychologie wurde Einfühlung mit sympathie übersetzt; später verwendete man, wie auch an einigen Stellen der englischen Ausgabe, empathie. Setzt man diese beiden Begriffe in den ursprünglichen Freud-Text ein, ergibt sich etwas ganz anderes. ${ }^{59}$ Das ...pathie steht für >fühlen`; Sympathie für >Mitleid, übereinstimmende Empfindung`, Empathie für 〉in den anderen Hineinfühlen . Das Freudsche Einfühlen ist - auch in seinen Überlegungen zur Komik - nichts Pathetisches, nicht das starke Mitgefühl, das wir im Sinn haben, wenn wir von >einfühlsam` als Gegensatz zu >gefühllos` sprechen. Übrigens bedeutet seine berühmte Empfehlung, der Analytiker möge sich die gefühlskalte Haltung des kunstgerecht arbeitenden Chirurgen zueigen machen, nicht: Verleugne Dich, sei abweisend oder gar taktlos!, sondern: Konzentriere Dich ganz auf Deine Aufgabe, auf die Arbeitsweisen des Unbewußten im allgemeinen und auf das Ichfremde der anderen Person, des Analysanten, im besonderen!

Dem Einwand, mit der Betonung des intellektuellen Aspekts der Einfühlung werde den Affekten der Patienten auf >rationalistische< Weise begegnet, wo sie doch ermutigt werden sollten, ihre Emotionen überhaupt erst zu spüren und zu äußern, ist entgegenzuhalten, daß jeder Affekt - ausgenommen die Angst - Resultat einer Verschiebung ist. Psychoanalytische Arbeit hat es mit vielen und heftigen Affekten allein schon deshalb zu tun, weil mit einer Aneignung neuer Stücke des Es dem Subjekt nicht nur etwas geschenkt, sondern auch etwas genommen wird. Man kann diesen Vorgang, der zugleich die Kultivierung eines lebenslangen Umwegs ist, >symbolische Kastration`nennen. Die sich in der Psychoanalyse vollziehende Arbeit ist eine Trauerarbeit, eine Arbeit am Verlust, am verlorenen Objekt. Sie begnügt sich nicht mit der Fest- 
stellung der Existenz oder der Abwesenheit bestimmter Gefühle, also $d a \beta$ der einzelne etwas verloren hat und $d a \beta$ er sich traurig fühlt, sondern erforscht, was er verliert, worin sein Verlust besteht und wie er mit diesem Verlust bzw. mit dem Mangel umgeht. Die psychoanalytische Erschließung des Unbewußten ist nicht dasselbe wie ein Wiedererleben oder ein Rekonstruieren. Die immer wieder notwendigen Historisierungen sind Konstruktionen. Insofern ist der psychoanalytische Prozeß nicht eine Reproduktion, sondern eine Produktion. Und insofern ist das Erschließen - als ein cooles Sich-Einfühlen - etwas anderes als die Vorstellung, die man sich von der anderen Person machen kann.

Die Validität der Einfühlung liegt bei Freud nicht in dem Vorgang selbst. Er legt vielmehr an ihn im Prozeß der Wahrheitsfindung ein externes Kriterium an: ob der jeweilige analytische Akt beim Patienten neues Material zum Vorschein gebracht hat, das eine bessere Konstruktion gestattet. ${ }^{60}$ Lacan hebt das Moment der Überraschung hervor, wie schon Theodor Reik. Lucien Israël tut das ebenfalls; und er fügt noch einen besonderen Indikator hinzu: das überraschte Lachen des Analysanten. Ist der Bezug auf ein Lachen nicht ein lächerliches Kriterium? Nein, denn wir können es, im Rückgriff auf Freuds Untersuchungen zum Witz und zur Komik, die ich im Beispiel »Medizin - Bubizin« erwähnt habe, einen Abfuhrvorgang nennen, der von dem Überwinden einer Schranke zeugt. In solchen Momenten blitzt, manchmal nachhaltig, etwas von der Überwindung des trop de mal (zu viel Mühe, zu viel Weh) auf, in dem - wie Lacan es einmal formuliert hat - »bis zu einem gewissen Grad [...] die einzige Berechtigung für unser Eingreifen « liegt. ${ }^{61}$

Ich fasse zusammen: Der Begründer der Psychoanalyse geht davon aus, daß Einfühlung »den größten Anteil an unserem Verständnis für das Ichfremde andrer Personen hat«. Anders als man sich diesen - auch Empathie genannten - Vorgang gemeinhin vorstellt, ist er für Freud aber nicht die 〉Einfühlung einer Person in eine andere Person<. Der »Mechanismus, durch den uns überhaupt eine Stellungnahme zu einem anderen Seelenleben ermöglicht wird «, ist nämlich notwendigerweise über das Un-Heimliche vermittelt. Die spezifische Freudsche Einfühlung ist kein `Sich-Gleichmachen immer unerkennbar bleibenden Realen.

Statt sich mit dem Analysanten zu identifizieren ( $>$ Ich empfinde, was Du meinst $\varsigma$ ), sorgt der Psychoanalytiker Freud für genügend Fremdheit, die jenem erst die Begegnung mit dem eigenen unbewußten Begehren ermöglicht. 
Aus den theoretischen Auffassungen der >Einfühlung « folgen also unterschiedliche technische Konzeptionen in der Praxis (auch hinsichtlich der $>$ Gegenübertragung $`$ ). Da die Psychoanalyse eine praktische Theorie und eine theoretische Praxis ist, sind die Verfeinerungen des Wahrnehmungs- und Erschließungsvermögens des Analysanten mit denen des psychoanalytischen Forschers und seiner Gemeinschaft vermittelt. Dabei sind auf beiden Seiten Widerstände im Spiel. Und auf diese Widerstände hat Freud sich bezogen, als er von der Notwendigkeit sprach, "sich frei [zu] halten von der bewußten Steigerung gewisser Erwartungen«.

Die Werbeleute, die herausfinden wollen, >wie es denen geht und was die wollen`, möchten dies nachempfinden, indem sie sich an den Platz des anderen begeben. Und von da aus versuchen sie, die Ware zu (er)finden, die für genügend kurze Zeit und auf profitable Weise das Loch des anderen zu stopfen scheint: >Wir wissen, was Ihnen fehlt und wir hätten da was für Sie!

Der Psychoanalytiker hingegen versucht dem Analysanten bei seiner eigenen Forschungsarbeit zu helfen, indem er für ihn den Platz des Dritten, des Anderen, freihält. Deshalb kann er dem anderen weder Waren noch Wahrsagungen unterjubeln noch sich als idealen Wunscherfüller anbieten. Und er kann nicht an der Stelle des Analysanten etwas bewirken wollen. Er behauptet nicht, in den anderen wie mühelos hineinzuschlüpfen (wie es das »Mutabor« in Hauffs Kalif Storch ermöglicht), sondern er versucht, den latenten Diskurs des Anderen zu erschließen dank der uns gemeinsamen Sprache. Das Verfahren heißt talking cure. Ich hoffe, daß meine Ausführungen dazu beitragen konnten, daß sich dieses Feld Ihnen weiter erschließt.

\section{Anmerkungen}

1 »Auf der Couchgarnitur mit Jägermeister und Reiseführer«, in: Der Tagesspiegel, 7. März 2004.

2 »Wo uns der Schuh drückt« hieß eine 1951 eingeführte Radiosendung des RIAS, in der der Regierende Bürgermeister von (West-)Berlin zu aktuellen Problemen der Stadt Stellung nahm.

3 Der Tagesspiegel, 31. März 2004.

4 Freud an seine Verlobte Martha Bernays am 13. Juli 1882; zit. bei Ernest Jones: Das Leben und Werk Sigmund Freuds, München 1984, Bd. I, 374.

5 Sigmund Freud (1905c): »Der Witz und seine Beziehung zum Unbewußten«, in: ders., Studienausgabe [StA] Bde. I-X u. Ergänzungsband, Frankfurt am Main 1982, hier Bd. IV, $170 \mathrm{f}$.

6 Ebd.

7 Ebd., $173 \mathrm{f}$.

8 Ebd., 174. 
9 Reiz ist hier nicht etwas angenehm >Reizvolles`, sondern etwas Lästiges, eine zu stark gewordene Erregung, die nach einer Abfuhr drängt, etwa Husten in Falle von >Reizhusten<.

10 Sigmund Freud (1950 c [1895]): »Entwurf einer Psychologie«, in: ders., Gesammelte Werke [GW], Bde. I-XVIII u. Nachtragsband, Frankfurt am Main 1968, hier Nachtragsband, 410 .

11 Im Fall des Hustenreizes geht es ja darum, dauerhaft den Reiz zu bannen, also nicht bloß zu husten, sondern etwas an der Hustenursache zu ändern.

12 Ebd., 410f., Herv. von Freud.

13 Vgl. Sigmund Freud (1985c [1887-1904]): Briefe an Wilhelm Fließ 1887-1904. Ungekürzte Ausgabe, Frankfurt am Main 1986, 112. Brief, 223.

14 Damit befaßt sich Theodor Reik in seiner Arbeit von 1925 Wie man Psychologe wird, im gleichnamigen Buch, Wien 1927, 7-33, hier 16f.

15 Freud (1921c), »Massenpsychologie und Ich-Analyse«, StA IX, 100.

16 Ebd., 98 und 100.

17 Ebd., 99.

18 Ebd., 100.

19 Ebd., 102.

20 Ebd., 100, Herv. CDR.

21 Ebd., Herv. CDR.

22 Die Überdeterminiertheit psychischer Phänomene ist für Freud selbstverständlich. Beispielsweise sagte er in einer Diskussion in seinem Wiener Kreis: »Wer immer dem Menschen das Kausalitätsbedürfnis eingegeben hat, hat etwas Wichtiges vergessen. Die Menschen fragen immer nur nach einer Kausalität. Man muß immer mit einer Überdeterminierung rechnen«. Richard F. Sterbas Bericht über Freuds Äußerungen bei den Wiener Mittwochabenden. In: ders., (1974): »Unpublizierte Diskussionsbemerkungen Sigmund Freuds«, in: Harald Leupold-Löwenthal, Inge Scholz-Strasser (Hg.): Sigmund Freud Vorlesungen 1970-1988, Wien, Köln 1990, 36.

23 Freud, »Massenpsychologie und Ich-Analyse«, StA IX, 100, Herv. CDR.

24 Ebd.

25 Die konkrete Art der Bindung hat etwas mit dem Objekt - Brust, Stimme, Kothäufchen, Blick - und mit der Triebposition zu tun: Fressen, gefressen werden, füttern ..., schauen, sich zeigen, scheißen, hören, appellieren ....

26 Nahe sind Haustiere oder Totemtiere wie bspw. in Deutschland das Pferd (als germanischem Kulttier).

27 Ebd., Fußnote 2, 103.

28 Vgl. ebd., Kapitel: Verliebtheit und Hypnose, StA IX, 104-108.

29 Freud, »Massenpsychologie und Ich-Analyse«, StA IX, 101.

30 Sigmund Freud (1921c): Group Psychology and the Analysis of the Ego, London 1985, Penguin, Pelican-Ausgabe, Bd. XII, 137.

31 Nietzsche: »)Das habe ich getan〈, sagt mein Gedächtnis. `Das kann ich nicht getan haben < - sagt mein Stolz und bleibt unerbittlich. Endlich - gibt das Gedächtnis nach.« Nur müssen wir hier für Gedächtnis einsetzen: das Erinnern gibt nach, denn das im Gedächtnis Aufgezeichnete wird ja beim Vergessen keinesfalls vernichtet. Friedrich Nietzsche: »Jenseits von Gut und Böse«, IV. Hauptstück. Sprüche und Zwischenspiele, hier Nr. 68, in: Karl Schlechta (Hg.), ders., Werke in drei Bänden. München 1973 (7. Aufl.), 625.

32 Freud, »Massenpsychologie und Ich-Analyse«, StA IX, 103 Fußnote 2. Es ist hier nicht ganz klar, ob Freud mit diesem »Weg« das Begreifen des Einfühlungs-Mechanismus meint oder das Begreifen mittels Einfühlung.

33 Ebd., 100

34 Z.B. bei Franz Wellendorf: »Jenseits der Empathie«, in: Forum der Psychoanalyse 1999, Vol. 15, 9-24, hier 21.

35 Und wo es doch passiert, kann er sie selbst an sich erkennen, da sie bei ihm in der Regel ohne Verschiebung, d.h. Verdrängung der Deckungsstelle, bleiben müßte.

36 Freud (1912e), »Ratschläge für den Arzt bei der psychoanalytischen Behandlung«, StA Ergänzungsband, 175f., Herv. CDR.

37 Freud 1915 zur Übertragung, Lesbarkeit von unbewußten Gedanken und Tendenzen zwischen zwei Subjekten: »Es ist sehr bemerkenswert, daß das $U b w$ eines Menschen mit Umgehung des $B w$ auf das $U b w$ eines anderen reagieren kann«. Vgl. Freud, »Das 
Unbewußte«, StA III, 153. Die Frage sei, »ob sich vorbewußte Tätigkeit dabei ausschließen läßt«. Ebd.; vgl. auch, »Die Disposition zur Zwangsneurose«, StA VII, $112 \mathrm{f}$.

38 Ludwig Binswanger an Sigmund Freud, Brief vom 15. Februar 1925, in: Gerhard Fichtner (Hg.) Sigmund Freud - Ludwig Binswanger. Briefwechsel 1908-1938, Frankfurt am Main 1992, 198f.

39 Ebd., Freud an Binswanger, Brief vom 22. Februar 1925, 202.

40 Freud (1925a [1924]), »Notiz über den >Wunderblock««, GW XIV, 3-8.

41 Freud (1940a [1938]), »Abriss der Psychoanalyse«, GW XVII, 127, Herv. CDR.

42 Ebd. Übrigens ist »das Reale« in den französischen und englischen Editionen des »Abriss« fälschlich als réalité bzw. reality übersetzt und somit die hier vorgenommene Unterscheidung ignoriert worden.

43 Freud (1933a [1932]), »Neue Folge der Vorlesungen zur Einführung in die Psychoanalyse $«, \mathrm{GW}$ XV, 34.

44 Freud (1910a [1909]), »Über Psychoanalyse«, GW VIII, 31, Herv. CDR.

45 Freud (1895g), »Über Hysterie«, GW Nachtragsband, 338.

46 Freud (1915e), »Das Unbewußte«, GW VIII, 269.

47 Freud (1930a [1929]), »Das Unbehagen in der Kultur«, GW XIV, 496.

48 Freud (1940a [1938]), »Abriss«, GW XVII, 126, Herv. CDR. An anderer Stelle heißt es im »Abriss«: die »psychische[n] Vorgänge, Inhalte« des Unbewußten »haben keinen so leichten Zugang zum Bewusstwerden, sondern müssen auf die beschriebene Weise erschlossen, erraten und in bewussten Ausdruck übersetzt werden« (Ebd., 82). Auf die Unterschiede zwischen diesen Tätigkeiten bin ich in meiner Arbeit »Übersetzen und Erschließen in der Psychoanalyse« eingegangen, in dem Band: »Rücksicht auf Darstellbarkeit« (Bielefeld, im Druck).

49 Bestimmte Relationen sind »nicht direkt aufzuzeigen, nur auf dem Wege des Rückschlusses faßbar«. Freud (1926d [1925]), »Hemmung, Symptom und Angst«, GW XIV, 186.

50 Freud, »Neue Folge der Vorlesungen, GW XV«, 86.

51 Vgl. Freud (1916-17a [1915-17]), »Vorlesungen zur Einführung in die Psychoanalyse «, StA I, 45f.

52 Richard Sterba erinnert sich an Freuds Äußerungen dazu bei den Wiener Mittwochabenden (Dezember 1928): »Die Menschen sagen: >Die psychologische Erkenntnis einer Weltanschauung macht für ihren Wert nichts aus.` Aber das ist nicht wahr. Die Wissenschaft bringt die anderen Weltanschauungen um. Nur bei der mystischen Weltanschauung nützt keine Erklärung, sie ist der Feind der Zukunft. Wir sind derzeit ohnmächtig gegen sie. Die Menschen reservieren sich ein Stück mystischer Weltanschauung. Die parapsychischen Wissenschaften wollen die wissenschaftliche Weltanschauung in die mystische umschmelzen. « Sterba, Unpublizierte Diskussionsbemerkungen Sigmund Freuds, 35-37 (vgl. hier Anm. 22).

53 Freud (1933a [1932]), »Neue Folge der Vorlesungen«, GW XV, 86.

54 Jacques Lacan: »La chose freudienne«, in: ders., Écrits, Paris 1966, 416f. Zu den verschiedenen Variationen bei Lacan, vgl. Susanne Hommel: »Les interprétations lacaniennes du >Wo Es war soll Ich werden««, in: Analytica, Vol. 41 (Paris 1977) »La place du psychanalyste«, 87-93. Etwa: »Là ou c'était / s'était, là c'est mon devoir que je vienne à être«, oder »Là ou c'était, Je doit advenir«, oder »Là ou était la chose, je dois advenir«.

55 Einiges von dem in den letzten Absätzen Dargestellten habe ich eingehender behandelt vgl. Claus-Dieter Rath: »Übertragungsgefahr. Herausforderungen psychoanalytischer Kulturtheorie heute«, in: Georg C. Tholen, Manfred Riepe, Gerhard Schmitz (Hg.), Übertragung - Übersetzung - Überlieferung, Bielefeld 2001, 395-432.

56 Freud (1900a) »Die Traumdeutung«, StA II, 503.

57 Ebd., 130, FN 2.

$58 \mathrm{Vgl}$. »Réponse de Jacques Lacan à Marcel Ritter« (April 1975) in: Lettres de l'École freudienne. Journée des cartels. Introduction aux séances de travail. Vol. 18, Strasbourg 1976.

59 Empathy ist der Titel eines neueren Doku-Fiktion-Films über einige amerikanische Analytiker/Therapeuten.

60 Freud (1937d), »Konstruktionen in der Analyse«, StA Ergänzungsband, 399.

61 Jacques Lacan: Die vier Grundbegriffe der Psychoanalyse. Seminar Buch XI, Textherstellung durch Jacques-Alain Miller; Norbert Haas, Joachim Metzger (Hg.), übersetzt von Norbert Haas, Olten, Freiburg 1978, 175. 


\section{Die Bildungen des Unbewußten}

Unter diesem Titel möchte ich von Erscheinungen sprechen wie dem Traum, dem psychischen Symptom, dem Witz sowie von den sogenannten Fehlleistungen: dem Versprecher, der als `Freudscher bekannt geworden ist, dem mehr als zufälligen Vergessen von Namen, Terminen, Daten etc., dem Vergreifen, Verlesen und Ähnlichem. Der Begriff der Bildungen ist dabei auch zu hören im Sinne der Geologie (Freud liebte geologische und archäologische Vergleiche): als geologische Formationen, Schichtungen. In den aufgezählten, scheinbar banalen Phänomenen können die großen und alten, in unserer Psyche wirksamen Kräfte deutlich zutage treten. So, wie Ihnen ein Kieselstein, den Sie an einem bestimmten Ort finden, sehr viel über den großräumigen geologischen Aufbau, über Schichtung und Geschichte, verraten kann.

\section{Der Witz}

Im Jahr 1905 veröffentlicht Freud Der Witz und seine Beziehung zum Unbewußten $^{1}$ - eines der, wie ich meine, nach der Traumdeutung (1899/1900) persönlichsten Werke Freuds. Diese Schrift sagt einiges über Freuds Beziehung zu seinem gesellschaftlichen Umfeld aus, die durch seine Stellung als assimilierter Jude geprägt wird. Sie handelt damit auch von seiner eigenen Beziehung zum Unbewußten.

Freud verwendet im Verlauf des Buches eine Reihe von Zitaten von Heinrich Heine; an einer Stelle wird aus den Reisebildern zitiert, dem III. Teil, der mit Die Bäder von Lucca betitelt ist und 1829 veröffentlicht wurde. Es ist dies eine Stelle, in der Heines witzsprühende und geistrei- 
che Prosa sehr dicht wird, eine Stelle voller Ironie und auch Bitterkeit, und zwar hinsichtlich sowohl der politischen Verhältnisse in Europa wie auch der gesellschaftlichen und finanziellen des Autors Heine. In den Mund gelegt sind die Pointen vor allem der buffoartigen Figur des Hirsch-Hyazinth, der sich über das identische Monogramm als eine Ersetzung des Autors verrät (Heine bekam von den Eltern den Namen >Harry< und hat sich mit der Taufe einen neuen Vornamen gegeben, jedoch ohne damit sein Monogramm verändern zu müssen). HirschHyazinth nun erweist sich als das Zerrbild seines Herrn, eines gewissen Markese Christoforo Gumpelino, vulgo Christoph Gumpel, eines neureichen, gar zum Katholizismus konvertierten Juden. Dieser klagt dem Erzähler folgendes:

"'Sie haben keinen Begriff davon, Herr Doktor, wie viel Geld ich ausgeben muß, und dabei behelfe ich mich mit einem einzigen Bedienten, und nur wenn ich in Rom bin, halte ich mir einen Kapellan für meine Hauskapelle. Sehen Sie, da kommt mein Hyazinth.r

Die kleine Gestalt, die in diesem Augenblick bei der Windung eines Hügels zum Vorschein kam, hatte vielmehr den Namen einer Feuerlilje verdient. Es war ein schlotternd weiter Scharlachrock, überladen mit Goldtressen, die im Sonnenglanze strahlten, und aus dieser roten Pracht schwitzte ein Köpfchen hervor, das mir sehr wohlbekannt zunickte. Und wirklich, als ich das bläßlich besorgliche Gesichtchen und die geschäftig zwinkenden Äuglein naher betrachtete, erkannte ich jemanden, den ich eher auf dem Berg Sinai als auf den Apenninen erwartet hätte, und das war kein anderer als Herr Hirsch, Schutzbürger in Hamburg, ein Mann, der nicht bloß immer ein sehr ehrlicher Lotteriekollekteur gewesen, sondern sich auch auf Hühneraugen und Juwelen versteht, dergestalt, daß er erstere von letzteren nicht bloß zu unterscheiden weiß, sondern auch die Hühneraugen ganz geschickt auszuschneiden und die Juwelen ganz genau zu taxieren weiß.

ıch bin guter Hoffnungı, sprach er, als er mir näher kam, ১daß Sie mich noch kennen, obgleich ich nicht mehr Hirsch heiße. Ich heiße jetzt Hyazinth und bin der Kammerdiener des Herrn Gumpel.ı 'Hyazinth!ı rief dieser in staunender Aufwallung über die Indiskretion des Dieners. ${ }^{2}$

Doch Gumpelino ist bald wieder besänftigt:

»Es ist ein treuer Mensch - sagte der Markese - ssonst hätte ich inn längst abgeschafft, wegen seines Mangels an Etikette. Vor Ihnen hat das nichts zu bedeuten. Sie verstehen mich. Wie gefällt Ihnen seine Livree? Es sind noch für vierzig Taler mehr Tressen dran als an der Livree von Rothschilds Bedienten. Ich habe innerlich mein Ver- 
gnügen, wie sich der Mensch bei mir perfektioniert. Dann und wann gebe ich ihm selbst Unterricht in der Bildung. Ich sage inm oft: Was ist Geld? Geld ist rund und rollt weg, aber Bildung bleibt. ॥ $^{3}$

Schließlich kommt Hirsch-Hyazinth wieder selbst zu Wort, um von seinen Erfahrungen mit den Reichen und Mächtigen zu berichten:

»Es ist mir aber immer nur um die Ehre zu tun - setzte Hyazinth hinzu - sund das habe ich auch dem Baron Rothschild gesagt, als ich die Ehre hatte, ihm die Hühneraugen zu schneiden. Es geschah in seinem Kabinett; er saß dabei auf seinem grünen Sessel, wie auf einem Thron, sprach wie ein König, um ihn herum standen seine Courtiers, und er gab seine Ordres, und schickte Stafetten an alle Könige; und wie ich ihm während dessen die Hühneraugen schnitt, dacht ich im Herzen: du hast jetzt in Händen den Fuß des Mannes, der selbst jetzt die ganze Welt in Händen hat, du bist jetzt ebenfalls ein wichtiger Mensch, schneidest du ihn unten ein bißchen zu scharf, so wird er verdrießlich, und schneidet oben die größten Könige noch ärger - Es war der glücklichste Moment meines Lebens!

ıch kann mir dieses schöne Gefühl vorstellen, Herr Hyazinth. Welchen aber von der Rothschildschen Dynastie haben Sie solchermaßen amputiert? War es etwa der hochherzige Brite, der Mann in Lombardstreet, der ein Leihhaus für Kaiser und Könige errichtet hat?

,Versteht sich, Herr Doktor, ich meine den großen Rothschild, den großen Nathan Rothschild, Nathan den Weisen, bei dem der Kaiser von Brasilien seine diamantene Krone versetzt hat. Aber ich habe auch die Ehre gehabt, den Baron Salomon Rothschild in Frankfurt kennen zu lernen, und wenn ich mich auch nicht seines intimen Fußes zu erfreuen hatte, so wußte er mich doch zu schätzen. Als der Herr Markese zu ihm sagte, ich sei einmal Lotteriekollekteur gewesen, sagte der Baron sehr witzig: ılch bin ja selbst so etwas, ich bin ja der Oberkollekteur der rothschildschen Lose, und mein Kollege darf bei Leibe nicht mit den Bedienten essen, er soll neben mir bei Tische sitzen - Und so wahr wie mir Gott alles Guts geben soll, Herr Doktor, ich saß neben Salomon Rothschild, und er behandelte mich ganz wie seines Gleichen, ganz famillionär.ıi"

In bittere Ironie hüllt Heine hier die Verletzungen, die ihm von seinem reichen Onkel, dem Hamburger Bankier Salomon Heine, zugefügt worden sind; die Geringschätzung, die dem Dichter von Seiten seines Onkels entgegengebracht wurde, gipfelte anscheinend in dessen Verweigerung der Zustimmung zur Vermählung Heinrich Heines mit seiner großen Jugendliebe, die eine Tochter jenes Onkels war. 
An solchen Stellen wie dem »famillionär« verdichtet sich etwas, und aus dieser Verdichtung entspringt im Text der Witz. Die Verdichtung kann dabei als eine extreme Verkürzung verstanden werden, als die Abkürzung eines Gedankenganges. Plötzlich taucht aus der eher gemächlich dahinfließenden Erzählung ein anderer, ein >unangebrachter` Ausdruck auf. Durch die Plötzlichkeit des Auftauchens wird auf dem Hintergrund einer Geschichte ein Abgrund spürbar - hier Heines abgrundtiefe Verzweiflung über die durch den Millionär der Familie erlittene Behandlung (man könnte so weit gehen, ein direktes Verhältnis von >Abgründigkeit $\mathrm{zu}>$ Witzigkeit $<\mathrm{zu}$ behaupten ...). Zu beachten ist dabei auch das Verhältnis des Witzes zum Adressaten, der rhetorische Aspekt - Heines Witze scheinen besonders witzig für Freud gewesen zu sein, was aus den Ähnlichkeiten beider Lebensumstände als assimilierte Juden im Bürgertum erklärlich wird. Übrigens verwendet Freud in seinem Witzbuch mit Vorliebe jüdische Witze.

Die Struktur eines Witzes oder auch nur einer witzigen Bemerkung, eines Bonmots, erstreckt sich nun anscheinend in zwei Dimensionen: zunächst gibt es so etwas wie den Fluß der Erzählung, die Prosa, in der Umstände beschrieben oder evoziert werden, wo Personen beschrieben werden und eine Atmosphäre entsteht; in diesem Fluß oder Gewebe taucht plötzlich etwas auf, das erratische einzelne Wort, hier das »famillionär«. Die zuvor ausgebreiteten Gedankenstränge und Geschichten scheinen sich an einem Punkt zu verdichten. Freud beschreibt das Geschehen folgendermaßen:

»Famili är

Milion är

Familion är

Den Vorgang aber, welcher den Gedanken in den Witz übergeführt hat, kann man sich in folgender Weise darstellen, die zunächst recht phantastisch erscheinen mag, aber nichtsdestoweniger genau das wirklich vorhandene Ergebnis liefert:

$\checkmark R$. behandelte mich ganz familiär,

d.h. soweit ein Millionär es zu stande bringt.،

Nun denke man sich eine zusammendrängende Kraft auf diese Sätze einwirken und nehme an, daß der Nachsatz aus irgend einem Grunde der weniger resistente sei. Dieser wird dann zum Schwinden gebracht werden, der bedeutsame Bestandteil desselben, das Wort `Millionärı, welches sich gegen die Unterdrückung zu sträuben vermag, wird gleichsam an den ersten Satz angepreßt, mit dem ihm so sehr ähnlichen Element dieses Satzes ıfamiliärı verschmolzen, und gerade diese zufällig gegebene Möglichkeit, 
das Wesentliche des zweiten Satzes zu retten, wird den Untergang der anderen unwichtigeren Bestandteile begünstigen. So entsteht dann der Witz:

`R. behandelte mich ganz famili on är.s

(mili) (är) $\varkappa^{5}$

Die beschriebene »Technik des Witzes« bezeichnet Freud als eine »Verdichtung mit Ersatzbildung « ${ }^{6}$. Diese ist auch in dem folgenden Beispiel am Werk, dem Bonmot eines zur damaligen Zeit wohl bekannten Lästermauls der Wiener Gesellschaft, eines gewissen Herrn N.:

»Herr N. wird eines Tages auf die Person eines Schriftstellers aufmerksam gemacht, der durch eine Reihe von wirklich langweiligen Aufsätzen bekannt geworden ist, welche er in einer Wiener Tageszeitung veröffentlicht hat. Die Aufsätze behandeln durchweg kleine Episoden aus den Beziehungen des ersten Napoleon zu Österreich. Der Verfasser ist rothaarig. Herr N. fragt, sobald er den Namen gehört hat: Ist das nicht der rote Fadian, der sich durch die Geschichte der Napoleoniden zieht? «?

Die Verdichtung geschieht hier mit den beiden Schichten:

- das Sich-Ziehen des roten Fadens,

- das fade Sich-Ziehen des roten X

und ergibt den »Fadian« als Ersatzbildung. Freud unterscheidet eine Reihe weiterer Witztechniken, die gewissermaßen absteigend hinsichtlich ihres Grades an Verdichtung vorgestellt werden. Eine Technik, bei der die Verdichtung nicht in einem Punkt als Ersatzbildung kulminiert, sondern bei der die beiden Sinnschichten noch getrennt sind, ist die »mehrfache Verwendung des gleichen Materials mit kleiner Modifikation«, wie sie in einem anderen Witz des Herrn N. gebraucht wird: »Er hört von einem Herrn, der selbst als Jude geboren ist, eine gehässige Äußerung über jüdisches Wesen. >Herr Hofrat,^ meint er, >Ihr Antesemitismus war mir bekannt, Ihr Antisemitismus ist mir neu. « ${ }^{8}$

Ein weites Feld schließlich öffnet sich bei der »Verwendung des gleichen Ausdrucks im doppelten Sinn«, die oft als einfaches »Wortspiel« daherkommt. Hier ein Witz, den Freud als einen »geradezu diabolisch guten« bezeichnet, und der deutlich macht, wie abhängig die verborgene Abgründigkeit von den Lebens- und Zeitumständen doch ist: »Das Ehepaar X lebt auf ziemlich großem Fuße. Nach der Ansicht der einen soll der Mann viel verdient und sich dabei etwas zurückgelegt haben, nach anderen wieder soll sich die Frau etwas zurückgelegt und dabei viel verdient haben. ${ }^{9}$ 
Ähnlich ist der folgende Witz gebaut: »Zwei Juden treffen in der Nähe des Badehauses zusammen. > Hast du genommen ein Bad? fragt der eine. >Wieso?` fragt der andere dagegen, >fehlt eins? « ${ }^{10}$ Schließlich nochmals ein Heinesches Bonmot:

"Man erzählt von Heine, daß er sich eines Abends in einem Pariser Salon mit dem Dichter Soulié befunden und unterhalten habe, unterdessen tritt einer jener Pariser Geldkönige in den Saal, die man nicht bloß um des Geldes willen mit Midas vergleicht, und sieht sich bald von einer Menge umringt, die ihn mit größter Ehrerbietung behandelt. ISehen Sie doch, , sagt Soulié zu Heine, swie dort das neunzehnte Jahrhundert das goldene Kalb anbetet.ı Mit einem Blick auf den Gegenstand der Verehrung antwortet Heine, gleichsam berichtigend: `Oh, der muß schon älter sein ‘...].."11

Ein Beispiel nun, bei dem es nicht mehr den einen Ausdruck gibt, der im doppelten Sinne zu verstehen wäre, ist das folgende, laut Freud ein »Judenwitz«:

")Ein Verarmter hat sich von einem wohlhabenden Bekannten unter vielen Beteuerungen seiner Notlage $25 \mathrm{fl}$. [Gulden] geborgt. Am selben Tage noch trifft ihn der Gönner im Restaurant vor einer Schüssel Lachs mit Mayonnaise. Er macht inm Vorwürfe: `Wie, Sie borgen sich Geld von mir aus und dann bestellen Sie sich Lachs mit Mayonnaise. Dazu haben Sie mein Geld gebraucht? । Ich verstehe Sie nicht, digte, swenn ich kein Geld habe, kann ich nicht essen Lachs mit Mayonnaise, wenn ich Geld habe, darf ich nicht essen Lachs mit Mayonnaise. Also wann soll ich eigentlich essen Lachs mit Mayonnaise?«"12

Hier ist also nicht mehr ein Wort oder eine Wendung verschieden zu verstehen, sondern es ist die ganze Situation, die von dem »Beschuldigten« in einem zweiten, gewissermaßen skandalösen Sinne gedeutet wird. Es gibt dabei keine Verdichtung mehrerer Ebenen an einer Stelle im Text, sondern hier wird - und zwar wiederum plötzlich - offenbar, daß das Ganze anders gemeint war, von vorneherein. Bei dieser Art von

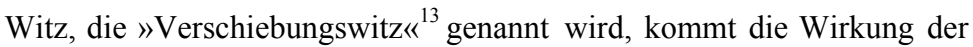
>Abgründigkeitく mit dem Gewahrwerden einer ganz anderen Sinnebene zustande. Unvermutet wird deutlich, daß der Andere Absichten hegt, die unlauter sind oder obszön oder feindselig ...

Zusätzlich noch, und auch grundsätzlich, wird an dieser Stelle das prinzipielle Nichtverstehenkönnen des Anderen offenbar, d.h. die grundsätzliche Andersheit des Anderen ${ }^{14}$, da bei ihm stets die Möglichkeit einer anderen, verborgenen, unlauteren Absicht besteht. 
Diese Möglichkeit ist es, die Freud dem Gefühl des »Unheimlichen « ${ }^{15}$ zu Grunde gelegt hat. Der Eindruck des Unheimlichen antwortet bei mir auf die Frage: >Was will der Andere eigentlich (von mir)?` Das heißt, ich vermute irgendwelche Absichten bei ihm, die er mir verbirgt - und diese Absichten verknüpfe ich mit Wünschen bei mir, die ich mir selbst verberge. Deshalb kann Freud behaupten, das Unheimliche sei eigentlich das Heimliche. Und dieses Heimliche ist nichts anderes als der vorher beschriebene Abgrund des Witzes, der sich damit als der Abgrund des Grauens und der Angst erweist.

Jedoch nicht nur im Text des Witzes taucht diese Abgründigkeit auf, sondern auch im Akt des Witze Erzählens selbst wird sie spürbar: der Andere wird als der Adressat des Witzes lachen gemacht, damit ich beruhigt sein kann, daß er mir nichts tun wird. Ein Beleg für diesen $\mathrm{Zu}$ sammenhang liefert Heinz Erhards Diktum: »Einen hab’ ich noch!«, das prägnant die Taktik der Scheherazade gegenüber dem Sultan bezeichnet. In einer Art Verschränkung mache ich mich gemein mit dem Anderen, meinem Gegenüber, um damit umso gemeiner gegen den Anderen im Text meines Witzes sein zu können. Ich lache mit dem Anderen gegen den Anderen - wobei letzterer auch ich selbst sein kann, wie es im jüdischen Witz häufig der Fall ist. Aus dieser Umlenkung stammt ein Großteil der Energie des Witzes, die im Lachen frei wird. Dadurch, daß ich den Zuhörer auf meine Seite ziehe, kann ich gefahrlos gegen eine Regel verstoßen; ich kann etwas sagen, was ich sonst nicht dürfte, ich überliste die Zensur. Die List des Witzes bedient sich einer Technik, deren Zweck Freud in der Ersparung von psychischem Aufwand identifiziert. Der Witz muß dem Anderen eine Verlockungsprämie bieten, und diese besteht in der Lust, die frei wird, sobald der Text des Witzes eine Abkürzung einschlägt. Der Zuhörer erspart sich dabei ein Quantum von Anstrengung, die benötigt wird, um zum Beispiel beim Verstehen die Regeln der Logik zu beachten (der scheinlogische oder der Nonsens-Witz), oder auch die Regeln der Moral (der zynische, böse Witz). Die Mechanismen der Witztechnik sind die Verdichtung und die Verschiebung. Sie machen, auf der Textebene des Witzes, vermittels der Verlockung der Abkürzung, einen Abgrund gegenwärtig, indem sie zunächst ein Sinngewebe erzeugen (das kann ganz schnell gehen, wenige >Regieanweisungen r reichen - es kann sich aber auch lange, quälend lange hinziehen, was die Spannung steigert), in dem plötzlich und unversehens ein Riß erscheint. 


\section{Die Traumarbeit ${ }^{16}$}

Freuds Schema der Bildung eines Traums ist, sehr verkürzt dargestellt, das folgende: es gibt zunächst einen Wunsch, der kraft der ihm eigenen Energie danach drängt, bewußt zu werden und erfüllt zu werden. Hat der Wunsch jedoch einen verbotenen, verpönten oder konfliktträchtigen Inhalt, so wird er von der Erfüllung, oder sogar vom Bewußtsein abgehalten. Er wird zensiert. Im Schlafzustand nun ist die seelische Instanz der Zensur abgeschwächt, und der Wunsch kann, indem er sich >verkleidet`, die Zensur überwinden und bewußt werden. Als Verkleidung sind entweder die sogenannten Tagesreste, d.h. Eindrücke des vorigen Tages, oder weiter zurückliegende, aber banale Erinnerungen geeignet. Der Mechanismus der Verschiebung sorgt im wesentlichen für die Assoziierung des Wunsches zu dem unverdächtigen Material, wie den Tagesresten, während die Verdichtung bei der Umformung des Gedankenmaterials zum konkreten Traum die größere Rolle spielt. Zwei Ebenen sind es, die Freud bei der Deutung eines Traum unterscheidet: zunächst trifft man auf den manifesten Trauminhalt, den es zu analysieren gilt, um zu den latenten Traumgedanken zu gelangen. Bei der Deutung wird der Weg der Traumarbeit zurückverfolgt. An der dem Traum gewidmeten Stelle in der Arbeit über den Witz drückt Freud die Zusammenhänge folgendermaßen aus:

"Im ganzen wären also bei der Traumbildung, grob genommen, drei Stadien zu unterscheiden: erstens die Versetzung der vorbewußten Tagesreste ins Unbewußte, woran die Bedingungen des Schlafzustandes mitbeteiligt sein müßten, sodann die eigentliche Traumarbeit im Unbewußten, und drittens die Regression des so bearbeiteten Traummaterials auf die Wahrnehmung, als welche der Traum bewußt wird.

Als Kräfte, welche bei der Traumbildung beteiligt sind, lassen sich erkennen: Der Wunsch zu schlafen, die den Tagesresten nach der Erniedrigung durch den Schlafzustand noch verbliebene Energiebesetzung, die psychische Energie des traumbildenden unbewußten Wunsches und die widerstrebende Kraft der im Wachleben herrschenden, während des Schlafes nicht völlig aufgehobenen ıZensurı. Aufgabe der Traumbildung ist es vor allem, die Hemmung der Zensur zu überwinden, und gerade diese Aufgabe wird durch die Verschiebungen der psychischen Energie innerhalb des Materials der Traumgedanken gelöst. «17

Die innerhalb des Materials, nämlich der (Traum-)Gedanken, wirkenden Mechanismen der Verschiebung und Verdichtung stellt Freud folgendermaßen dar: 
»Das Material der Traumgedanken erfährt während der Traumarbeit eine ganz außerordentliche Zusammendrängung oder Verdichtung. Ausgangspunkte derselben sind die Gemeinsamkeiten, die sich zufällig oder dem Inhalt gemäß innerhalb der Traumgedanken vorfinden; da dieselben für eine ausgiebige Verdichtung in der Regel nicht hinreichen, werden in der Traumarbeit neue, künstliche und flüchtige, Gemeinsamkeiten geschaffen, und zu diesem Zwecke werden mit Vorliebe selbst Worte benützt, in deren Laut verschiedene Bedeutungen zusammentreffen. Die neugeschaffenen Verdichtungsgemeinsamen gehen wie Repräsentanten der Traumgedanken in den manifesten Trauminhalt ein, so daß ein Element des Traumes einem Knoten- und Kreuzungspunkt für die Traumgedanken entspricht und mit Rücksicht auf die letzteren ganz allgemein ıüberdeterminiertı genannt werden muß. Die Tatsache der Verdichtung ist dasjenige Stück der Traumarbeit, welches sich am leichtesten erkennen läßt; es genügt, den aufgeschriebenen Wortlaut eines Traumes mit der Niederschrift der durch Analyse gewonnenen Traumgedanken zu vergleichen, um sich von der Ausgiebigkeit der Traumverdichtung einen guten Eindruck zu holen. Minder bequem ist es, sich von der zweiten großen Veränderung, welche durch die Traumarbeit an den Traumgedanken bewirkt wird, zu überzeugen, von jenem Vorgang, den ich die Traumverschiebung genannt habe. Dieselbe äußert sich darin, daß im manifesten Traum zentral steht und mit großer sinnlicher Intensität auftritt, was in den Traumgedanken peripherisch lag und nebensächlich war; und ebenso umgekehrt. Der Traum erscheint dadurch gegen die Traumgedanken verschoben, und gerade durch diese Verschiebung wird erreicht, daß er dem wachen Seelenleben fremd und unverständlich entgegentritt. Damit solche Verschiebung zustande kam, mußte es möglich sein, daß die Besetzungsenergie von den wichtigen Vorstellungen ungehemmt auf die unwichtigen übergehe, was im normalen bewußtseinsfähigen Denken nur den Eindruck eines `Denkfehlersı hervorrufen kann. ${ }^{18}$

Während die Verdichtung der Gedanken an einzelnen Kreuzungs- oder Knotenpunkten erkennbar wird, zeigt sich die Verschiebung als eine von »Besetzungsenergie «, d.h. von Bedeutungen, erst mit Blick auf den größeren Zusammenhang der Gedanken. Hier erweist sich die Strukturähnlichkeit des Traums mit dem Witz, der ebenso aus dem ausgebreiteten Gewebe des von ihm hergestellten Sinnzusammenhanges den plötzlichen Riß, der ja immer eine mehrdeutige Verdichtung ist, entspringen läßt. Das Wirken von Verdichtung und Verschiebung findet einigermaßen ungehemmt nur unter den Bedingungen des unbewußten Denkens statt. Deswegen legt Freud sein Augenmerk auf den >topischen`Aspekt, wenn er die Gemeinsamkeit von Traum und Witz zusammenfaßt: »Ein vorbewußter Gedanke wird für einen Moment der unbe- 
wußten Bearbeitung überlassen, und deren Ergebnis alsbald von der bewußten Wahrnehmung erfaßt. " ${ }^{19}$ Der größte Unterschied zwischen beiden liegt nicht in ihrem Aufbau, sondern ihrer »Darbietung« (wie Lacan sagen würde: nicht in der Aussage, sondern im Aussagen). Denn während sich der Witz an den Anderen wendet, ist der Traum »asozial $\aleph^{20}$. Der Witz will verstanden werden, wenn auch falsch, der Traum hingegen will nicht verstanden werden, »er muß sich sogar hüten, verstanden zu werden, da er sonst zerstört würde; er kann nur in der Vermummung bestehen ${ }^{21}{ }^{2}$. Denn vor allem ist der Traum »ein, wiewohl unkenntlich gemachter, Wunsch; der Witz ist ein entwickeltes Spiel«. ${ }^{22}$

\section{Fehlleistungen}

Jacques Lacan kennzeichnet das, was wir als Fehlleistung kennen, damit, daß »im Lauf einer intentionalen Rede« (oder Handlung) »etwas geschieht, das das Wollen [des Subjekts] überschreitet «. ${ }^{23}$ Dieses Geschehen ist die »Erzeugung eines Sinns ${ }^{24}$ und verweist auf eine Wahrheit, die als solche unsagbar wäre. Sigmund Freud widmet den Fehlleistungen eine doch recht umfängliche Schrift, betitelt Zur Psychopathologie des Alltagslebens, Untertitel: Über Vergessen, Versprechen, Vergreifen, Aberglaube und Irrtum, die 1904 erschienen ist. ${ }^{25}$ Die Einleitung dazu bildet die Besprechung eines Falles des Vergessens eines Eigennamens, womit Freud einen eigenen Aufsatz wieder aufgreift, den er schon 1898 unter dem Titel Zum psychischen Mechanismus der Vergesslichkeit veröffentlicht hat. ${ }^{26}$ Die Schilderung des Zusammenhanges, in dem sich das Vergessen ereignet, fällt in der frühen Version ausführlicher aus:

"Während der Sommerferien unternahm ich einmal von dem schönen Ragusa aus eine Wagenfahrt nach einer benachbarten Stadt in der Herzegowina; das Gespräch mit meinem Begleiter beschäftigte sich, wie begreiflich, mit dem Zustand der beiden Länder (Bosnien und Herzegowina) und mit dem Charakter ihrer Einwohner. Ich erzählte von verschiedenen Eigentümlichkeiten der dort lebenden Türken, wie ich sie vor Jahren von einem lieben Kollegen hatte schildern hören, der unter ihnen lange Zeit als Arzt gelebt hatte. Eine Weile später wandte sich unsere Unterhaltung auf Italien und auf Bilder, und ich hatte Anlass, meinem Gesellschafter dringend zu empfehlen, einmal nach Orvieto zu gehen, um sich dort die Fresken vom Weltuntergang und letzten Ge- 
richt anzusehen, mit denen ein grosser Maler eine Kapelle im Dom ausgeschmückt. Der Name des Malers aber entfiel mir und war nicht wieder zu haben. Ich strengte mein Gedächtnis an, liess alle Details des in Orvieto verbrachten Tages vor meiner Erinnerung vorüberziehen, überzeugte mich, daß nicht das Mindeste davon verlöscht oder undeutlich sei. Im Gegenteile, ich konnte mir die Bilder sinnlich lebhafter vorstellen, als ich es sonst vermag; und besonders scharf stand vor meinen Augen das Selbstbildnis des Malers, - das ernste Gesicht, die verschränkten Hände, - welches er in die Ecke des einen Bildes neben dem Portrait seines Vorgängers in der Arbeit, des Fra Angelico da Fiesole, hingestellt hat; aber der mir sonst so geläufige Name des Künstlers verbarg sich hartnäckig. Mein Reisegefährte konnte mir nicht aushelfen; meine fortgesetzten Bemühungen hatten keinen anderen Erfolg als den, zwei andere Künstlernamen auftauchen zu lassen, von denen ich doch wusste, daß sie nicht die richtigen sein könnten: Botticelli und in zweiter Linie Boltraffio. ${ }^{27}$

Hier fügt Freud in einer Fußnote an, daß der erste dieser Namen ihm »sehr vertraut, der zweite dagegen kaum geläufig « ${ }^{28}$ sei. Schließlich führt ihn die Reise Tage später mit einem »gebildeten Italiener« zusammen, »der mich durch die Mitteilung des Namens: Signorelli befreite. Ich konnte dann aus Eigenem den Vornamen des Mannes, Luca, hinzufügen. Die überdeutliche Erinnerung an die Gesichtszüge des Meisters auf seinem Bilde verblasste bald. ${ }^{29}$ Freud fügt 1904 hinzu, es sei »der Name des Meisters ${ }^{30}{ }^{30}$ gewesen, »welcher im Dom von Orvieto die großartigen Fresken von den >letzten Dingen` geschaffen«. Bei der Untersuchung des Entfallens arbeitet Freud fünf Gesichtspunkte heraus: »Der Grund für das Entfallen des Namens Signorelli ist weder in einer Besonderheit dieses Namens selbst, noch in einem psychologischen Charakter des Zusammenhanges zu suchen, in welchen derselbe eingefügt war.« Ein anderer Zusammenhang, nicht jener der Aussage, sondern jener des Aussagens, erscheint ihm ebenfalls »zunächst harmlos«: »Ich machte mit einem Fremden eine Wagenfahrt« usw.

Eine Erklärung bahnt sich an, wenn sich Freud »an das in jener Unterhaltung unmittelbar vorhergehende Thema erinner[t]《. Er hatte sich nämlich mit seinem Reisegefährten »über die Sitten der in Bosnien und in der Herzegowina lebenden Türken unterhalten« (womit wohl in der heutigen Terminologie die bosnischen Moslems gemeint sind). Freud hatte darüber geplaudert, was ihm ein dort praktizierender Kollege (in der ersten Version war das noch ein »lieber Kollege« gewesen) über »diese Leute« erzählt hatte: »daß sie sich voll Vertrauen in den Arzt und voll Ergebung in das Schicksal zu zeigen pflegen. Wenn man ihnen an- 
kündigen muß, daß es für den Kranken keine Hilfe gibt, so antworten sie: >Herr, was ist da zu sagen? Ich weiß, wenn er zu retten wäre, hättest du ihn gerettet!«« Freud verweist auf die hier auftauchenden Worte. »Bosnien, Herzegowina, Herr«, die »sich in eine Assoziationsreihe zwischen Signorelli und Botticelli - Boltraffio einschalten lassen $\ll$.

Warum aber kann dieses vorher geführte Gespräch über die »Türken« die Verknüpfung von Freuds Gedanken mit dem Namen »Signorelli« stören? Freud braucht eine Zusatzannahme: er nimmt an, daß der erwähnten »Gedankenreihe« »die Fähigkeit, einen nächsten Gedanken zu stören, darum zukam, weil ich ihr meine Aufmerksamkeit entzogen hatte, ehe sie noch zu Ende gebracht war.« Eigentlich hatte er noch Interessanteres erzählen wollen: »Diese Türken schätzen den Sexualgenuß über alles und verfallen bei sexuellen Störungen in eine Verzweiflung, welche seltsam gegen ihre Resignation bei Todesgefahr absticht. « So hatte einer der Patienten seinem Kollegen einmal gesagt: »>Du weißt ja, Herr, wenn das nicht mehr geht, dann hat das Leben keinen Wert.« Aber dieses Thema wollte Freud dann doch »nicht in einem Gespräch mit einem Fremden berühren«. Er »lenkte« darüber hinaus seine »Aufmerksamkeit auch von der Fortsetzung der Gedanken ab«, die sich »an das Thema >Tod und Sexualität hätten knüpfen können«, da er noch von einer Nachricht berührt war, die er wenige Wochen zuvor in Trafoi erhalten hatte: »Ein Patient, mit dem ich mir viele Mühe gegeben, hatte wegen einer unheilbaren sexuellen Störung seinem Leben ein Ende gemacht.« Hier hebt Freud die »Übereinstimmung Trafoi - Boltraffio « hervor.

Nun sieht sich Freud genötigt, dem Vergessen ein Motiv zu unterstellen: »Ich wollte also etwas vergessen, ich hatte etwas verdrängt.« Eigentlich wollte er aber etwas anderes als den Namen Signorelli vergessen; »dieses andere brachte es zustande, sich mit dessen Namen in assoziative Verbindung zu setzen, so daß mein Willensakt das Ziel verfehlte und ich das eine wider Willen vergaß, während ich das andere mit Absicht vergessen wollte«. Die »Ersatznamen«, die ihm statt Signorelli eingefallen sind, »mahnen« ihn »(nach Art eines Kompromisses) ebensosehr an das, was ich vergessen, wie an das, was ich erinnern wollte«.

In einem letzten Schritt faßt Freud seine Ergebnisse in einem Schema zusammen, das er schon in der ersten Version so gezeichnet hatte. 


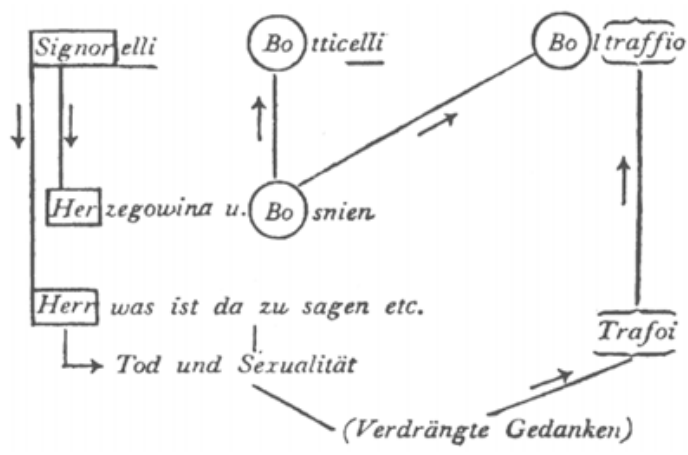

Abb.: Schema von Sigmund Freud, Zur Psychopathologie des Alltagslebens, GW IV, 9.

$\mathrm{Zu}$ ergänzen wären in diesem Schema vielleicht noch der zweite »türkische Spruch«, nämlich: »Herr, wenn das nicht mehr geht ... « sowie die Verbindung von »Signorelli« über das Wort »Meister« zum Herrn und zum Tod. Freud geht bei der Beschreibung des Vorgangs von »Signorelli« aus, der als Name »in zwei Stücke zerlegt« worden ist. Das »elli« kehrt in »Botticelli« wieder, das andere wurde durch Übersetzung zum »Herrn« und hat dadurch »mehrfache und verschiedenartige Beziehungen zu den im verdrängten Thema enthaltenen Namen gewonnen, ist aber dadurch für die Reproduktion verloren gegangen.« Dabei hat »eine Verschiebung längs der Namenverbindung >Herzegowina und Bosnien«« stattgefunden, ohne Rücksicht auf Sinn und Silbenabgrenzung. Die Elemente wurden wie »Buchstabenfolgen« in einem »Rebus« genommen. Die wirkende Kraft für den gesamten Ablauf geht nicht von dem Thema »Tod und Sexualität« aus, da dieses zu allgemein wäre und einen zu weiten Bedeutungsumfang hätte. Dem Thema zugrunde liegen vielmehr die im Schaubild in Klammern gesetzten »verdrängten Gedanken«, d.h. besondere, individuelle unbewußte Elemente - die im hier vorliegenden Fall vielleicht mit der Bedeutung zu tun haben, die der erwähnte Suizid des Patienten für Freud gehabt hat.

\section{Theorie}

Die einer Fehlleistung zugrundeliegenden Vorgänge erweisen sich nach der Art eines Rebus strukturiert. Diesen Aufbau hatte Freud auch in der Traumarbeit festgestellt. Wie Champollion bei der Entzifferung der ägyptischen Hieroglyphen war er auf die Idee gekommen, die Elemente 
des Traumes nicht in erster Linie als Bilder, sondern als Schriftzeichen zu begreifen, die einen Lautwert haben. Die Verbindungen im Unbewußten können somit durch Verschiebungen von Silben oder, wie im Signorelli-Beispiel, von Buchstabenfolgen hergestellt werden.

An dieser Stelle zeigt sich die grundsätzliche Bedeutung des häufig zitierten Lacanschen Diktums: »Das Unbewußte ist strukturiert wie eine Sprache.« Sofern irgendetwas aus dem Unbewußten heraus aktiv wird, muß es durch das Gitter der sprachlichen Strukturen gehen.

Um diese Strukturen aufzuzeigen, verwendet Lacan die Linguistik eines Ferdinand de Saussure und eines Roman Jakobson. Von Saussure stammt die Verwendung des Begriffs des Signifikanten: Das linguistische Zeichen hat zwei Seiten, das Signifikat, wörtlich: das Bezeichnete, also Begriff, Konzept, Vorstellung, sowie eben den Signifikanten, wörtlich: den/das Bezeichnende(n), was Saussure mit dem Lautbild identifiziert. Zwischen Signifikant und Signifikat steht »la barre«: die Schranke, der Trennstrich, der deutlich macht, daß es keine direkte Verbindung zwischen den beiden Teilen des Zeichens gibt. Durch diese grundsätzliche Trennung gibt es keine snatürliche` Bedeutung eines Zeichens, jede Bedeutung kommt nur durch einen komplexen Vermittlungsprozeß zustande. Auf jeder Seite der Schranke gibt es eigenständige Strukturen. Lacan legt viel Betonung auf die Autonomie der >Ordnung〈 des Signifikanten; sie ist es, die die Struktur des Unbewußten bestimmt.

Laut Jakobson lassen sich die Beziehungen innerhalb der Struktur der Signifikanten nach zwei Achsen ordnen: es gibt die Achse der Ersetzung, der Substitution, deren Vorgehen Lacan beschreibt mit »ein Wort für ein anderes $\aleph^{31}$, und die etwa im Wörterbuch vorherrscht. Daneben gibt es die Achse der Verkettung, der Kontiguität, der Reihung, die von Lacan als »Wort an Wort ${ }^{32}$ beschrieben wird. Diese sorgt für die Erzeugung von Sätzen, von größeren Strukturen und Zusammenhängen. Die beiden Sprachachsen zeigen sich auf dem Gebiet der Rhetorik in Gestalt zweier exemplarischer Figuren: der Metapher und der Metonymie. Die Metapher vollzieht sich vor allem auf der Achse der Ersetzung, sie ist »ein Wort für ein anderes«. Die Metonymie geschieht auf der Bahn der Verkettung des »Wort an Wort«. Dabei ist es wichtig zu sehen, daß sich die Metapher in der Kette der Signifikanten ereignet, innerhalb der metonymischen Verknüpfung. Denn in der Metapher ersetzt ja ein Wort ein anderes, und zwar an seinem Platz, der erst durch die Signifikantenkette vorgegeben wird. Es gibt einerseits Ersetzung eines Signifikanten durch einen anderen an einem Platz, aber der ersetzte Signifikant 
bleibt als unterdrückter wirksam durch seine metonymische Verkettung mit dem Rest der Signifikanten des Satzes oder des größeren Zusammenhangs.

Um diese Struktur der Metapher zu zeigen, möchte ich Ihnen ein Beispiel aus dem Bereich der Poesie geben. Es handelt sich um das erste Gedicht aus Ingeborg Bachmanns Zyklus Anrufung des Großen Bären, überschrieben mit Das Spiel ist aus. Die ersten Worte lauten: »Mein lieber Bruder, wann bauen wir uns ein Floß und fahren den Himmel hinunter? « ${ }^{33}$ Der Signifikant »Himmel« ersetzt hier einen anderen, der sich aus dem Zusammenhang des Satzes als »Fluß« aufdrängt. Nach den Gesetzen der metonymischen Reihung wäre »Fluß« (oder der Name eines Flusses) zu erwarten; denn die Metonymie fügt ein Bild aus erwarteten und bekannten Elementen. Das erwartete Bild reißt an der Stelle der metaphorischen Ersetzung auf und durch den Riß schimmert gewissermaßen eine andere Welt hindurch. Zugleich bleibt aber auch das Ersetzte wirksam, das Bild des Flusses verschwindet nicht, sondern wird überlagert. Es entsteht ein Mischgebilde wie ein doppelt belichtetes Foto oder ein Vexierbild. Dies Ganze geschieht auf der Grundlage der metonymischen Verkettung, innerhalb derer sich das Neue und Schöpferische der Metapher ereignen kann.

Die beiden Koordinatenachsen der Ordnung des Signifikanten, wie sie durch die Bewegungen der Metapher und der Metonymie deutlich werden, können auch den Vorgängen zugeordnet werden, die bei Freud als Verdichtung und Verschiebung bezeichnet sind. Die Verdichtung spielt sich auf der Ebene der Metapher ab, während die Verschiebung der Metonymie entspricht.

Die Zusammenhänge seien nun noch einmal anhand des SignorelliBeispiels, das als eine verunglückte Metapher bezeichnet werden kann, erläutert:

a) Das Vergessen des Namens ereignet sich innerhalb eines Gesamtzusammenhanges; dieser ist in der weitesten Perspektive: Freuds damalige Lebenssituation; dann, etwas enger gefaßt, der Sommerurlaub in Dalmatien, in der Herzegowina usw., in den auch die in Trafoi erhaltene Nachricht fällt; weiter herangezoomt dann die Wagenfahrt und das Gespräch mit dem Fremden; schließlich der Satz im Gespräch, der in etwa so gelautet haben könnte: »Waren Sie eigentlich schon einmal in Orvieto und haben Sie die berühmten Fresken gesehen, von ... wie heißt er noch gleich? « In den Verschiebungen der Aufmerksamkeit innerhalb des situativen Zusammenhanges, weg von Gedanken des Selbstzweifels, des 
sexuellen Versagens, der Todesangst, hin zu Themen wie Italienreisen und Kunst, macht sich die Wirkweise der metonymischen Verkettung kenntlich.

b) In diesem Gewebe aber ereignet sich etwas, es holpert, die bis dahin glatte Verschiebung reißt; denn ein Element fällt aus: »Signorelli«. Weil ein Teil davon, »Signor«, eine Ersetzung des Elementes »Herr« ist, das selbst wieder für etwas steht, das nicht bewußtseinsfähig ist. Dieses »Stehen-für« bedeutet hier: der Signifikant steht im aktuellen metonymischen Zusammenhang (für Freud) am gleichen Platz. Deshalb ist die Ersetzung möglich. Lacan schreibt sie folgendermaßen ${ }^{34}$ :

$$
\text { " } \frac{\mathrm{X}}{\text { Signor }} \cdot \frac{\text { Signor }}{\text { Herr }} \text { " }
$$

eine Formel, die noch um einen Ersetzungsschritt zu ergänzen wäre:

$$
" \frac{\mathrm{X}}{\text { Signor }} \cdot \frac{\text { Signor }}{\text { Herr }} \cdot \frac{\text { Herr }}{(\mathrm{a})} \text { " }
$$

wobei (a) das unsagbare Objekt bzw. in Freuds Schema die »verdrängten Gedanken« bezeichnet. In seiner Analyse rekonstruiert Freud die Entsprechung von »Signor« und »Herr«. »Herr« wiederum steht für etwas, das nur spekulativ erschlossen werden kann; das mag hier Freuds befürchtetes Scheitern als Arzt sein, mit den Gedanken um den Suizid des Patienten, ein ruinierte Ansehen, wirtschaftliche Not, ein gescheiterter »Lebensentwurf« usw.; ein anderer verdrängter Bereich zentriert sich vielleicht um die Bedrohung der Männlichkeit, die Furcht vor Impotenz; schließlich mögen Todesängste und die Angst vor Krankheiten ihre Macht ausüben. Lacan weist darauf hin, daß sich die Ersetzungen voneinander unterscheiden: so wird »Signorelli« vergessen, während »Signor« verdrängt und »Herr« unterdrückt wird.

c) Der Riß der ersten metonymischen Verkettung an der Stelle »Signorelli« wird auch bedingt durch andere metonymische Zusammenhänge dieses Elements, von denen wiederum Verbindungen zu anderen unterdrückten Bereichen abzweigen. Schon erwähnt wurde die Verknüpfung der Bezeichnung Signorellis als »Meister« mit dem Element »Herr«. Daneben handelt es sich ja um den Maler einer Eschatologie oder, mit Freuds Worten, der »letzten Dinge« (Tod und Verdammnis). Schließlich aber gibt es noch eine Verbindung, die Freud an den betreffenden Stellen nicht erwähnt, die aber in der »Traumdeutung « angesprochen ist. ${ }^{35}$ Es geht um den Ort: Orvieto war auf Freuds Italienreise 1897 der südlichste von ihm erreichte Ort, das heißt, es war ihm wieder nicht gelun- 
gen, nach Rom zu kommen. Diese Hemmung, das mehrmalige Umkehren kurz vor diesem Ort seiner größten Sehnsüchte, bringt Freud mit seiner jugendlichen Identifizierung, dem semitischen Feldherrn Hannibal, in Zusammenhang, der es ja auch rätselhafterweise versäumt hatte, nach seinem Triumph bei Cannae in Rom einzumarschieren. Freud gelang das endlich im Jahr 1901.

d) Nachdem also die erste metonymische Kette gerissen ist und sich die an dieser Stelle wirksame Metapher nicht vollziehen konnte, führen weitere metonymische Bewegungen entlang der Verschiebungslinien von »Her(r)« über die Zusammensetzung »Herzegowina und Bosnien« $\mathrm{zu}$ den Ersatznamen »Botticelli« und »Boltraffio«. Wäre »Botticelli« sofort an der Stelle von »Signorelli« aufgetaucht, dann hätte es sich um eine geglückte Metapher gehandelt, um eine, mit den Termini aus dem Witzbuch gesprochen, »Verdichtung mit Ersatzbildung«. Statt einer Hemmung, wie sie in dem Moment des Aussetzens der Namenfindung wirksam war, hätte sich ein Symptom gebildet. Dieses entsteht nun erst im Verlaufe der Analyse und weist gewissermaßen als passageres Symptom den Weg zum Unbewußten. Dabei zeigt sich auch der Kompromiß-Charakter des Symptoms ganz deutlich: durch diverse metonymische und auch metaphorische Verflechtungen steht es auf halbem Wege zwischen dem zu ersetzenden wie auch dem ersetzenden Zusammenhang.

\section{Schluß}

Auch in der psychoanalytischen Praxis geht es darum, eine Sprechsituation zu schaffen, in der sich die Bildungen des Unbewußten ereignen können. Dabei muß der Analytiker darauf achten, daß sich der Riß im metonymischen Gewebe des Sprechens nicht sogleich wieder schließt das »Wort an Wort« der Metonymie würde dafür sorgen. An den Stellen, wo ein >dahinter durchscheint, da muß innegehalten werden, damit für den Sprechenden ein Anderes hörbar wird. Dieses Innehalten und Hinweisen ist die Deutung. Sie hat die Aufgabe, das bewußte, sinn-volle Sprechen zu einem Unsinn hin zu öffnen, der den Anstoß zu einem anderen Sinn gibt. Jedoch ist das Unbewußte >selbst nicht sagbar; es ist immer das dahinter Liegende. Wie ein Gedicht, läßt es sich, so Lacan, nur »halb-sagen«; und wie der Witz ist es verschwunden, wenn man es erklärt. 


\section{Anmerkungen}

1 Sigmund Freud: „Der Witz und seine Beziehung zum Unbewußten«, in: Sigmund Freud, Gesammelte Werke [GW], Bde. I-XVIII, hier GW VI, London 1940, Frankfurt am Main ${ }^{2} 1999$.

2 Heinrich Heine: »Reisebilder«, in: Klaus Briegleb (Hg.), Heinrich Heine. Sämtliche Schriften, Bde. I-XII, München, Wien 1976, hier Bd. III, 401f.

3 Ebd., 404.

4 Ebd., 424f.

5 Freud, »Witz«, GW VI, 17f.

6 Ebd., 18.

7 Ebd., 21.

8 Ebd., 33.

9 Ebd., 32.

10 Ebd., 50.

11 Ebd., $48 f$.

12 Ebd., 51.

13 Ebd., 53.

14 Es ist dieses fundamentale Anderssein, welches Jacques Lacan damit ausdrückt, daß er den Anderen oder auch das Andere als »l'Autre « mit einer Majuskel versieht.

15 Freud, »Das Unheimliche«, GW XII, 227-268.

16 Dies ist der Titel des zentralen 6. Kapitels von Freuds Traumdeutung. Vgl. Freud, »Die Traumdeutung«, GW II/III, 283-512.

17 Freud, »Witz«, GW VI, 188.

18 Ebd., $186 \mathrm{f}$

19 Ebd., 189.

20 Freud: »Der Traum ist ein vollkommen asoziales seelisches Produkt [...].« Ebd., 204.

21 Ebd.

22 Ebd., 204f.

23 Jacques Lacan: Le Séminaire Livre V. Les formations de l'inconscient, 1957-58, Paris 1998, 51 (Zitat von mir übersetzt).

24 Ebd.

25 Freud, »Zur Psychopathologie des Alltagslebens. Über Vergessen, Versprechen, Vergreifen, Aberglaube und Irrtum«, GW IV.

26 Freud, »Zum psychischen Mechanismus der Vergesslichkeit«, GW I, 517-527.

27 Ebd., 520f.

28 Ebd., Fußnote.

29 Ebd.

30 Dieses wie auch die folgenden Zitate aus Freud, »Zur Psychopathologie des Alltagslebens«, GW IV, 6-10.

31 Jacques Lacan: Écrits, Paris 1966, 507. Die angerissenen Zusammenhänge führt Lacan in seinem Aufsatz »L'instance de la lettre dans l'inconscient« [»Das Drängen des Buchstaben im Unbewußten«] aus, in: ders., Écrits, 493-528.

32 Ebd., 506.

33 Ingeborg Bachmann: Sämtliche Gedichte, München 1998 (1978), 92.

34 Lacan, Le Séminaire Livre V. Les formations de l'inconscient 1957-58, 59.

35 Freud, »Traumdeutung«, GW II/III, 199ff. 


\section{Was sagt das Symptom?}

\section{Sagen}

Ausgehend vom Boden des medizinischen Wissens seiner Zeit entwikkelte Freud den psychoanalytischen Begriff des Symptoms aus dem, was die Träger dieses Symptoms selbst dazu sagten. Diesem Ansatz folgt mein Vortrag.

Definierte man heute das Symptom als objektives Anzeichen einer Pathologie, so müßte man viele Zeitgenossen, die sich keineswegs krank fühlen, in die Praxen von Psychiatern und Therapeuten schicken. Aber wie man weiß, kann das Subjekt »unter Martyrien leiden ohne irgendwelche Anstalten zu machen, sich davon zu befreien « ${ }^{1}$. Auch >objektive Symptome - von Schweißausbrüchen bis zu bizarrem Verhalten - sind psychoanalytisch nur zugänglich, wenn sie in gewissem Maße vom Subjekt als eigene Produktion oder Kreation begriffen werden. Dann können sie als dessen Botschaft ankommen. Kann man das Symptom anders als von seiner Adresse - vom Anderen - her erfassen?

Wie Sie vielleicht wissen, hat Freud in dem, was man seine zweite Topik nennt, den Begriff des Es entwickelt. Lacan hat das aufgegriffen und gedeutet: es spricht. Im Menschen spricht es. Er hat nicht gesagt: Das Es spricht, Herr oder Frau Es. Es spricht bereits, bevor jemand Ich sagen kann. Und in seinem Vortrag über das Symptom ${ }^{2}$ sagt Lacan, daß es merkwürdigerweise wenigen einleuchtet, daß der Mensch im Geplapper aufwächst. »Ein Symptom konstruiert man nicht allein. - Es ist eine Konstruktion, die von mehreren Personen fabriziert wird - um festzuhalten, daß etwas nicht ausgedrückt werden konnte. ${ }^{3}$

Kurz: Wenn es zur Sprache kommt, dann ist eine Dynamik im Spiel, die nicht nur Symptome hervorbringt, sondern auch unsere gewohnte Auffassung vom Sprechen durcheinanderbringt. 


\section{Die Grundregel}

Warum legen Psychoanalytiker soviel Wert auf das Sprechen? Beschränken wir uns auf eine der vielen Begründungen: Weil das Sprechen gerade dann den größten Wert hat, wenn wir nicht wissen, was wir sagen. Mit dieser Tatsache sind wir alle in wechselndem Maße konfrontiert. Das Ich ist nicht Herr im eigenen Haus, darin sah Freud eine der drei großen Kränkungen der Menschheit. Es ist nicht Herr dessen, was es sagt. Der Mensch ist krank an der Sprache.

Aber haben wir nicht unsere Vokabeln gelernt, wir haben doch eine Muttersprache! Wieso hapert es mit ihr? Das reicht von den vielen Formen der Artikulationsstörungen, die anscheinend immer häufiger zu Behandlungen führen, bis zu den Bildungen des Unbewußten: den Fehlleistungen, Träumen und eben den Symptomen. Wir möchten nichts von diesem Durcheinander wissen - das >durch einen Anderen` in uns spricht.

>Alles sagen!^, so lautet die Gebrauchsanweisung für die Analyse. Dieses >Alles sagen nimmt natürlich seinen Ausgang vom dem, was jemand an Symptomen vorbringt. >Sprechen Sie über das, weswegen Sie gekommen sind, von Ihren Symptomen, von dem, was Ihnen dazu einfällt, sagen Sie einfach alles, auch wenn es Ihnen blöde erscheint, belanglos oder anstößig usw., auch wenn es Ihnen fremd erscheint, als ob es überhaupt nicht zu Ihnen gehörte .... $4^{4}$

Freud geht mit der Mitteilung dieser Regel eine Wette ein. >Alles` bis zum Ende der Analyse Gesagte wird, insofern es sich an den Anderen wendet, nicht auf eine Information reduziert, sondern als Anspruch auf alles Mögliche und Unmögliche gehört, als Bitte, Verlangen, Wunsch, Begehren. Und das heißt für den Analytiker, sich a priori nicht als denjenigen zu betrachten, der den Anspruch nach diesem oder jenem >Objekt $\measuredangle \mathrm{zu}$ befriedigen oder zu erfüllen hätte. Denn dem Symptom liegt (wie jedem Sprechen) ein Begehren zugrunde, das nach Anerkennung sucht. Diese findet das Subjekt nur über die Deutung.

Ist das Symptom zunächst der Anlaß der Konsultation, so wird es sich im Laufe der Analyse als außerordentlich verdichtete Form herausstellen. Das Subjekt umkreist sprechend seine Beziehung zum 〉Objekt`, eine unweigerlich phantasmatische Beziehung, in der sich das Subjekt unablässig durch seine Objekte zu bestimmen sucht. Und es versucht seine Beziehung zum Kostbarsten in jene Worte zu fassen, die es von Kindheit 
an vom Anderen geliehen hat. ${ }^{5}$ Diese Beziehung kann das Subjekt nur über den Anderen wiederbeleben.

Diese Prozedur, die man Analyse nennt, ist also bestimmten methodischen Bedingungen unterworfen. Sie richten sich weder nach den Spielregeln der Wissenschaft, noch nach den Launen oder Gefühlen des Analytikers, sondern nach den universellen Gesetzen der Sprache, in denen das eine Form findet, was eine Generation an die nächste weitergibt und worin z.B. das Verhältnis zwischen Anspruch und Begehren seinen Ausdruck findet. Diese Beziehung zur Weitergabe von einer Generation zur nächsten ist in der Struktur des Symptoms enthalten. So ist Symptom das, was von einer zur nächsten Generation weitergegeben wird, ohne verstanden worden zu sein. ${ }^{6}$

\section{Sprechen und Körper}

Mit dem, was wir sagen, sagen wir also mehr und anderes als wir meinen. Wir hören zwar selbst, was wir sagen, aber erst, wenn wir es gesagt haben, ist es uns überhaupt möglich, etwas vom Gesagten mitzubekommen. Es entgeht uns dabei immer etwas. In einer Psychoanalyse geht es nicht so sehr darum, sich auszusprechen, zu erklären, was man fühlt usw., nicht um eine Art Tonwiedergabe unserer Gedanken. Auch nicht der heimlichsten. Eine solche passive Vorstellung vom Aussprechen der Gedanken läßt den schöpferischen Aspekt des Sprechens beiseite. Sagen ist finden, wiederfinden, erfinden, und eine Psychoanalyse, die nicht auf dieser erfindenden Aktivität des Sprechens aufbaut oder sie als Nebensächlichkeit einstuft, verdiente nicht, sich auf ihren Begründer zu berufen. Das Intendierte kann sich nachträglich als etwas anderes erweisen. Freuds Grundlagenwerke über das Unbewußte: Traumdeutung, Psychopathologie des Alltagslebens und Der Witz und seine Beziehung zum Unbewußten enthalten dazu Beispiele in Hülle und Fülle. Hier eines aus der Praxis.

Eine Lateinlehrerin hatte, unter anderem wegen heftiger Kopfschmerzen, den Analytiker aufgesucht. Sie >kommuniziert` in einer Sitzung, wie sehr sie sich über Handwerker im Haus aufgeregt hat. Sie wollte diesen gegenüber nicht herrisch und grob auftreten, sondern verbindlich und weiblich. Sie betont mehrfach, wie kaputt sie das gemacht habe, sich so zusammennehmen zu müssen. Aber es war ihr gelungen. Es war das Ende der Sitzung. Die nächste Sitzung sagt sie: Auf der Treppe ist mir nach 
dem letzten Mal das Wort kaputt nachgeklungen, und schlagartig mußte ich an caput (lat.: Haupt) denken. Dies erlaubte ihr, eine Verbindung zu ihren Kopfschmerzen ebenso wie zu ihrer problematischen Beziehung zum Familienoberhaupt, zu ihrem Vater herzustellen. Man sieht, wie hier die informatorische Seite des Sagens hinter die evokative zurücktritt. Erst nachträglich, als sie gesprochen hatte, konnte sie das Gesagte so hören.

Diese Entdeckung eines anderen Sprechens ist in der psychoanalytischen Kur oft mit einem veränderten Erleben, einer anderen Beziehung zum Körper verbunden. Wenn die beabsichtigte Rede vom Unbewußten durchkreuzt wird, wenn der Mensch erfährt, daß er mehr gesprochen wird, als daß er spricht, dann ist er auch nicht in der ihm bekannten Weise in seinem Körper (... zu Hause).

>Es ist doch unmöglich, alles zu sagen`, könnte man gegen die psychoanalytische Grundregel einwenden. Aber wenn dieses >Alles« auch das Unmögliche einschließt, so bezieht sich die Regel nicht auf die Summe des Gesprochenen, sondern darauf, daß das Subjekt immer schon ein >Gesprochenes` ist. Der oft vorgebrachte Einwand, die Praxis der Psychoanalyse schließe den Körper aus, trifft ebensowenig zu wie die Reduktion des Sprechens auf die Summe der gesprochenen Worte. Die Analyse ist eine körperliche Angelegenheit, auch wenn wir das als $>\mathrm{Au}-$ ßenstehende< nicht mitbekommen. Was soll denn dieses >Außen deuten, wenn nicht außerhalb des Körpers dessen, der spricht?

Freud schreibt 1905, daß verdrängte Vorstellungen im Körper sprechen. Wie ist das zu verstehen? Er vergleicht die hysterischen Symptome auch mit Hieroglyphen. Inschriften, Niederschriften im Körper. Ist der Körper nicht auch eine Vielfalt von Spuren und Einschreibungen? Vielleicht ist dies einer der Punkte, an dem der Psychoanalytiker Jacques Lacan bei Freud angeknüpft hat. Wir rühren hier an eine Grundfrage der Psychoanalyse, sowohl praktisch als auch theoretisch. Und es war vor allem eine Frage der Hysterikerinnen, die Freud zur Entdeckung der Psychoanalyse geführt haben: Wie können Sprache und Körper zusammen gedacht werden? Aber so frug die Wissenschaft seit jeher. Nur ist dies aber keine Sache des Denkens, zumindest nicht des Denkens allein. Lange bevor das Kind denkt, wird es in vielfältiger Weise bedacht, bedeutet, gedacht, besprochen. Zunächst durch die Umgebung und in erster Linie durch die Mutter. Durch den mütterlichen Diskurs. ${ }^{7}$ Es ist eine Passage, die der Mensch immer wieder durchläuft, die sich nur unzureichend mit dem erfassen läßt, was wir `lernen` nennen. Denn ehe wir die Sprache 
lernen, lehrt sie uns. Nirgendwo wird das deutlicher als bei den hysterischen Symptomen. In einem frühen Alter bildet das Kind Phantasien aus »Gesehenem «, »Gehörtem « und »nachträglich Verstandenem «". Diese in die Struktur eingeschriebenen Phantasien sperren die Erinnerung. Sie scheinen einen Sinn und eine subjektive Geschichte zu bilden, die etwas anderes ist, als eine Aneinanderreihung von historischen Fakten. Mit Lacans Spiegelstadium könnte die subjektive Geschichte auf der Basis der Phantasiebildung mit der Einheit des Spiegelbildes zusammenfallen. Vorstellungen aber können unbewußt sein von dem Moment an, wo ein einheitliches Körperbild aus all den Fragmenten entsteht, in die der Mensch von Geburt an eingetaucht ist. Sind es nicht Szenen, in denen sich das Subjekt stets am Rande befindet, wie ausgeklammert und bei denen es zugleich in massiver Weise beteiligt ist?

Mit der freien Assoziation wird ein Rand betreten und in einer Analyse kann man diesen Rand sehr gut kennenlernen. Im Zuge eines Sprechens, das sich an einen Unbekannten wendet und das nicht gezielt geschieht, wird die Beziehung zum eigenen Körperbild belebt. Es entsteht eine Beziehung, die auch den Körper sprechen läßt. Die Situation des Kindes, auf das eingesprochen wurde, dreht sich quasi um: Was damals eingesprochen wurde, bekommt nun der Analytiker verschlüsselt zu hören.

Der Körper, das ist nicht nur eine Summe von Regungen und Funktionen, unterteilt, wie etwa die verschiedenen Abteilungen eines Krankenhauses. Der Körper hat ein Spiegelbild, und das war ein wesentlicher Ausgangspunkt für Jacques Lacan. Eine Lektüre seines Aufsatzes über das Spiegelstadium ${ }^{9}$ würde den Rahmen dieses Vortrags überschreiten. Ich begnüge mich mit einigen Hinweisen. Lacan sagt ungefähr folgendes: Was dem Menschenkind eine Einheit verleiht, ist ihm selbst nicht von Anfang an gegeben. »Das Menschenjunge erkennt [...] sein Bild als solches « (Hervorhebung P.M.). Es erkennt diese Einheit im >Spiegelstadium $<$. Dieses Bild der Einheit ist nur vermittels des Anderen möglich. Man kann hier von einem existentiellen Moment sprechen, in dem dieses Bild im Augenblick, da es vom Subjekt erkannt wird, auch mit dem zusammentrifft, was man den Namen nennen kann, und was weit über die paar Buchstaben hinausgeht, mit dem man das Kind ruft. Diese Buchstaben sind eher eine Verdichtung all dessen, was den Namen ausmacht. So z.B. die Beziehung zum Geschlecht. Denn dieser Moment der Verknüpfung zwischen dem Bild, dem Körper und dem Namen ist auch der Moment der größten Entfremdung, denn alles, was hier zu einer Einheit gefaßt wird, bezeichnet zugleich das, was das Subjekt für die 
Umgebung, für die Eltern, ist. >Sein` wird zu >Was sein?«, zu dem, was das Subjekt für den Anderen ist. Und genau diese Frage nach dem Sein wird wieder belebt, wenn jemand wegen eines Symptoms den Psychoanalytiker aufsucht. Dieses >Alles` der Grundregel bezieht sich ebenfalls auf die Totalität des Körpers, es schließt logisch ein Jenseits mit ein, Jenseits des aktuellen, des Sagbaren, der `Gefühleく. Bezieht man sich vorwiegend auf diese, so kann das der Errichtung einer Schranke gleichkommen, die das Subjekt vor diesem Jenseits des Lustprinzips errichtet. >Alles` bezieht sich auch auf die Geschichte dessen, was die Eltern unter dem Namen ihres Kindes gewünscht haben, besonders auf das, was sie davon nicht wissen wollten. In diesem Begriff des Spiegelstadiums findet also eine Verknüpfung der drei Register statt, innerhalb derer sich die psychische Struktur entwickelt: der Name und seine Geschichte, das Bild, das vom Subjekt als sein eigenes identifiziert wird und worüber es sich identifiziert, und der reale Körper. Es ist das Zusammentreffen des Symbolischen, Imaginären und Realen, wie Lacan diese Register entwickelt hat, und mit deren Hilfe er die Freudsche Theorie neu geschrieben hat. Man kann das auch so ausdrücken: In diesem Moment, wo sich das Kind mit seinem Bild identifiziert und damit zum Träger seines Namens wird, verkennt es sich. Diese Verkennung ergibt sich notwendigerweise, da es nicht weiß, woher die Bedeutung der Worte kommt, was die Worte für den Anderen bedeuten. Diese Frage, diese Situation eines radikalen >Nicht-Wissens` über das Sein, wird durch das Symptom erneut aufgeworfen.

Das Spiegelbild ermöglicht Identifizierung, aber wenn diese Verknüpfung gelungen ist, gibt es kein Zurück zu einem >Vorher`. Man kann bei dieser Struktur auch von einer zeitlichen Geburt oder einer Geburt der symbolischen Zeit sprechen. Von nun an wird es für den Menschen immer ein X geben, eine Leerstelle (vgl. ausführlicher hier im letzten Abschnitt zur Vatermetapher), ausgelöst durch die nie ganz beantwortbare Frage nach seinem Ursprung. Es wird ein Vorher durch die Struktur des Spiegelstadiums geschaffen und zugleich ein für immer Unerkanntes, Unaussprechliches. Dieses X kann man als den Motor der Befragung durch das Symptom wie auch durch die analytische Arbeit verstehen.

Diese Skizze des Spiegelstadiums soll verdeutlichen, daß jede Vorstellung oder Darstellung des Sprechwesens, wie Lacan das menschliche Subjekt bezeichnet, einen ursprünglichen Verlust voraussetzt. Was hat dieser Verlust mit dem Symptom zu tun? Erstens, daß sich die Symptome, die zur Konsultation auf dem Gebiet des Psychischen führen, um 
einen (imaginären) Verlust drehen. Zweitens, daß eine glatte Darstellung des Psychischen nicht zu haben ist. Das gilt zuerst dem Analytiker: er möge keine Übereinstimmung zwischen der Darstellung und dem Dargestellten erwarten. Nicht nur, weil auch bei der Darstellung immer ein Wunsch im Spiel ist und in die Quere kommt, sondern, weil wir es mit unbewußten Vorgängen zu tun haben. Zu diesen unbewußten Vorgängen zählt Freud neben der Verschiebung und der Verdichtung einen dritten Mechanismus, die Rücksicht auf Darstellbarkeit. Freud schreibt in seiner Traumdeutung, »daß ein farbloser, abstrakter Ausdruck des [latenten] Traumgedankens gegen einen bildlichen und konkreten eingetauscht wird « ${ }^{10}$. Daß dieser Tausch sich im Unbewußten vollzieht, heißt, daß wir darüber nur etwas wissen können, nachdem das Subjekt dazu etwas gesagt hat und eben nicht vorher. Was Freud über den Traum sagt, ließe sich auch über das Symptom sagen: Das Symptom ist alles andere als eindeutig, es ist nicht mit sich selbst identisch und nicht wie in der Medizin als Zeichen einer Krankheit definierbar. Gerade darin besteht seine Einzigkeit. Wenn der Traum der »Hüter des Schlafs« ist, d.h. zu einem gewissen Gleichgewicht beiträgt, insofern er nicht, wie z.B. der Angsttraum zum Aufwachen führt und sich damit dem Symptom nähert, so ist das Symptom der »Ladenhüter«, den wir nicht loswerden und der bewirkt, »daß die Dinge nie genauso laufen, wie wir sie gerne hätten « ${ }^{11}$. Dieser Störenfried widersetzt sich der Auflösbarkeit und der glatten Übersetzbarkeit, was die Theorie der Kommunikation oft vernachlässigt.

\section{Medizinisches und psychoanalytisches Symptom}

In der Sprechstunde hören wir immer öfter: `Ich habe Panikattacken, ... Allergie, ... Depressionen, ... eine Zwangsstörung, ... ein ADS-Syndrom, ich habe Probleme mit der Kommunikation ...< Dem minimalen Aussagewert solcher >Botschaften $`$ steht eine maximale performative Funktion entgegen: Sie passen sich an den Katalog des Psychiaters an, sind ein Versuch, das störende Unbekannte aus dem Gespräch fernzuhalten, sie dienen dazu, dieses $\mathrm{X}$ vorschnell mit dem Ich verträglich $\mathrm{zu}$ machen und den Patienten mit seinem eigenen Bild zu versöhnen. Dergleichen kann nicht im Interesse des Psychoanalytikers liegen. Und doch ist es nicht immer vermeidbar, daß das Streben nach `Kommunikation das erwähnte $\mathrm{X}$ ausschließt. Bestätigt der Analytiker (oder der Arzt) die Einverleibung des Symptoms in ein Fachwissen, so mag dies einen vo- 
rübergehenden Beruhigungseffekt haben, das Sprechen in seiner schöpferischen Dimension wird dabei aber zurückgedrängt oder ver-drängt. Dies kommt oft vor, wenn sich medizinischer und psychoanalytischer Diskurs überschneiden:

Einen 30jährigen Ingenieur plagt wiederholte Unlust, die ihn aggressiv macht und ihn oft bei seinen täglichen Verrichtungen hindern. Er möchte verstehen, was es mit diesen lästigen Erscheinungen auf sich hat. Subtil versucht er die Konfrontation mit dem Fremdartigen seiner Symptome zu umgehen, indem er sie inszeniert und sich an Schreckensmeldungen in den Medien ergötzt. Vielleicht um sich dabei in der Phantasie zu befriedigen. Mehr noch aber, um das, was er passiv in den Symptomen als Einbruch von etwas Fremdem unerträglich empfindet, nun selbst willkürlich hervorzurufen. Diese Dimension entgeht ihm vollständig. Nach und nach kommt heraus, daß er solche Inszenierungen seit der Kindheit praktiziert. Diese Inszenierungen seiner Symptome erlauben ihm eine Kontrolle. In seiner Kindheit hätte er auf ziemlich raffinierte Art Vögel und Fliegen getötet ${ }^{12}$, was er dann so zu arrangieren und vor den Eltern darzustellen verstand, daß die Tiere wie zufällig gestorben seien. Was der hochintelligente Mann dabei nicht bemerkt, ist, daß er so tut, wie wenn er den Zufall willentlich herbeiführen könnte. Genauso sucht er nun die Herrschaft über sein Verhalten wiederzuerlangen. Aber eine Verhaltenstherapie erfüllt seine Erwartungen nicht: »Je technischer ich vorgehe, um so weniger komme ich voran.«

Sein größtes Unbehagen scheint, daß er sich nicht selbst behandeln kann. Der Psychoanalytiker ist Zeuge eines ständigen Kampfes zwischen seiner Selbstkontrolle und seiner Abgrenzung durch Wissen mit seinen sich endlos wiederholenden Täuschungen, Überraschungen, Einbrüchen und ihm fremd erscheinender Neigungen und Reaktionen. Seine Handlungsfreiheit schlägt stets in eine extreme Unfreiheit um. Auch seine Einfälle gehorchen nicht seinen selbstgeschmiedeten Vorstellungen. Er bietet so zwei Arten von Symptomen, zwei Lektüren des Symptoms: eine, die man >objektiv` nennen könnte und die er als Abweichung von der Norm beseitigt wissen möchte, und eine >subjektive`, die auf Widersprüche und Fremdkörper in seinem Denken stößt. Und sein Kampf besteht darin, die Kontrolle zu bewahren. Als ob er beanspruchte, daß die Welt wie auch der Andere, die Geschichte wie die Sprache eindeutig seien. Findet er in diesem Anspruch auf Eindeutigkeit eine Sicherheit, so ist es gerade dieser Anspruch, an dem er scheitert. Denn er sieht sich von fremden Mächten gelebt, anstatt über sein Leben verfügen zu kön- 
nen. Als er zur Konsultation kam, legte er mit dem Bericht über seine aggressiven Gedanken und Taten eine Visitenkarte vor. Die Illusion, daß dies alles nur ein Spuk sei, der ihn letztlich nichts angehe, wurde durch seine Erfahrung widerlegt, denn er spürte, wie sehr diese unlustvollen Momente an ihm klebten: Jenseits des Lustprinzips... Fast könnte man sagen, daß er von diesem Jenseits heimgesucht wird und es wie etwas betrachten möchte, das ihn letztlich nichts angeht. Eine solche Auffassung vom Symptom mag mit der Medizin verträglich sein, nicht aber mit der Psychoanalyse.

Man kann auch den Werdegang Freuds aus dieser Perspektive betrachten. Er begann als Arzt und Neurologe. Stück für Stück hat ihn seine Erfahrung von diesem vertrauten Boden der Medizin und der Psychiatrie entfernt. Heute haben wir sein gesamtes Werk in den Händen. Dies versichert uns aber nicht Freuds Entwicklung als abgeschlossen betrachten zu können, indem wir die Gesammelten Werke als Lexikon gebrauchen. Ebensowenig wie die Lektüre eines Werkes nicht ohne eigenes Erfinden möglich ist, d.h. nicht ohne Verlust, hängt auch der Ausgang einer Analyse davon ab, wie sich der Analytiker mit dergleichen Verlust auseinandersetzen konnte. Anerkennung des Verlusts kindlicher Objekte gewiß. Wie zeigt sich diese Anerkennung? Besteht sie nicht in einem radikalen Verzicht darauf, daß das, was uns vom Anderen zukommt, mit dem übereinstimmt, was wir wissen und was wir erwarten?

Der Arzt ordnet die Symptome der Krankheit zu, d.h. seinem Wissen. Als ob es die Krankheiten wären, die in der Sprechstunde zu uns sprechen. Was schon eine Rolle spielt, wenn wir unterscheiden, was der Patient hat oder was ihm fehlt. Was ihm fehlt ist natürlich die Gesundheit, die Normalität, das Wissen, das Benennen können.

Hier trennen sich die Wege zwischen Medizin und Psychoanalyse. Ein Leiden ist vor allem ein Zustand gesteigerter Spannung im Organismus und muß nicht unbedingt eine existentielle Bedrohung bedeuten. Wie oft beruhigt es den Neurotiker, wenn ihn eine überschaubare körperliche Krankheit ereilt, für die er eine Zuständigkeit des Arztes ausmachen kann. Doch berührt eine Krankheit letztlich immer die Frage danach, was unseren Körper zusammenhält. Sie konfrontiert damit, daß wir nicht Herr über unseren Körper, über unser Leben sind. Definiert man die Gesundheit als das `Schweigen der Organe〈, so heißt das nicht, daß sprechende Organe von Krankheiten erzählen.

Die Krankheit, zumindest die körperliche, konfrontiert uns damit, daß wir uns das Leben nicht selbst gegeben haben, daß wir einst hilflose, auf 
den anderen angewiesene Wesen waren. Längst vergessene Spuren drängen sich wieder in den Vordergrund. Der Arzt schenkt diesem Thema kaum die notwendige Aufmerksamkeit und sieht seine Aufgabe eher darin, diesen Zustand zu beseitigen. Kann er als konkret helfender anderer die traumatische Erinnerung an die uranfängliche Hilflosigkeit überhaupt gestatten?

Wird uns der andere, hier in Gestalt des Arztes, die bedrohte oder verlorene Verfügung über unseren Körper zurückgeben? Aber diese Verfügung über den Körper ist eine Illusion, ein frommer Wunsch. Schweigen die Organe der Gesunden etwa in der sexuellen Erregung oder wenn wir Hunger haben?

Redensarten, wie z.B. es liegt etwas im Magen, man hat etwas auf dem Herzen, etwas ist einem an die Nieren gegangen usw., machen weniger darauf aufmerksam, daß die Organe sprechen, sondern, daß etwas in den Körper eingedrungen ist gleich einer Inschrift, daß sich die Organe >melden`, weil etwas - meist durch andere oder den Anderen - durch Worte oder Handlungen - auf sie einwirkt. Die Medizin besteht in einem langen Prozeß, sich diesen Gedanken systematisch abzugewöhnen ...

Wenn es auch in dieser skizzenhaften Andeutung der Krankheitserfahrung gewisse Gemeinsamkeiten zur Psychoanalyse gibt, so läßt sich doch ein wesentlicher Unterschied erkennen. Es war erstens von der Beziehung des Subjekts des Patienten zum Arzt die Rede und zweitens vom medizinischen Wissen. Als ob das Subjekt hier nur die Informationen zu liefern hätte über seinen kranken Körper oder seine Empfindungen, Gefühle, Eindrücke usw., die ihm in dem Maße enteignet werden, wie der Arzt seine Zuständigkeit davon abhängig macht, ob die Information des Patienten zum Katalog der Medizin paßt. Aber es fehlt etwas, das immer im Spiel ist, wenn Menschen zusammentreffen. Und die Hysterikerin ist die erste, die daran appelliert: Wie steht es mit der Beziehung des Patienten zu seinen Symptomen, zu seinem Sprechen? M.a. W. mit dem Verhältnis zu seinem Begehren?

Die Spur, der Freud folgte, war die des Begehrens, das sich in den Symptomen seiner ersten Patienten ausdrückte: Dabei war er sich seiner ärztlich-therapeutischen Aufgabe durchaus bewußt:

"[...] man kann in jeder Hinsicht die von allen Beimengungen gereinigte Hysterie selbständig abhandeln, nur nicht in Hinsicht der Therapie. Denn bei der Therapie handelt es sich um praktische Ziele, um die Beseitigung des gesamten leidenden Zustandes, [...] ähnlich wie bei den Mischinfektionen, wo die Erhaltung des Lebens sich als Aufga- 
be stellt, die nicht mit der Bekämpfung der Wirkung des einen Krankheitserregers zusammenfällt. ${ }^{13}$

Hier die Bekämpfung der Krankheitsursache dort die Beseitigung des gesamten leidenden Zustands. Hier die medizinische Aufgabe, dort das, was den Patienten in die Sprechstunde führt: ein Anspruch und ein Begehren.

Aber, man bekümmert sich doch heute außerordentlich darum, wie die Menschen leben! Sicher. Aber es gibt da eine Grenze, und an dieser Grenze steht ein Schild und darauf steht >privat $<$. Heute hat sich eine bestimmte Beziehung zwischen >öffentlich` und >privat` herausgebildet, die zur Zeit Freuds nicht so in der Gesellschaft verankert war. Ich erwähne als Beispiel etwa den Massenkonsum von Talk-Shows, in denen so getan wird, als handele es sich um einen Einblick ins Private. Die Imaginarisierung, die Veröffentlichung des Privaten. Lesen Sie heute eine Krankengeschichte Freuds, so werden Sie sehen, welche außerordentliche Rolle das Private dort spielte. Das Private ist heute zu einer Art öffentlichem Konsumgegenstand geworden. Das verändert auch etwas an den Sprechstunden. Geht die Psychoanalyse stets von der Singularität des Patienten aus, so muß dieses kostbare Prinzip mehr und mehr dem Diagnoseschema und den Therapieprogrammen weichen, und dies oft aus fragwürdigen oder kurzschlüssigen ökonomischen Erwägungen. Dies gilt besonders für Patienten, die nicht den Erwartungen des Arztes entsprechen. Und doch könnte der Arzt gerade von diesen Kranken, von den Zwischenfällen, die das Subjekt hervorbringt, von denen, die sich nicht auf den Katalog der Symptome und der Krankheiten beschränken, profitieren. Hier steht an erster Stelle die Hysterie. Warum hat man sie aus dem internationalen diagnostischen Katalog entfernt?

\section{Hysterie und Normalität}

Freuds Studien über Hysterie können aus mehreren Gründen als Nullpunkt des psychoanalytischen Symptombegriffs angesehen werden: Wie bereits oben dargestellt sprachen die Symptome (wenn dieses Sprechen weit genug vorangetrieben werden konnte, verschwanden die Symptome). Ging Freud dem Faden der rein subjektiven Erinnerung nach, so beschränkte sich die Entstehungsgeschichte der Symptome nicht auf eine biographische Rekonstruktion - »auch wenn sich diese [subjektive 
Erinnerung] als sehr lückenhaft herausstellt« ${ }^{14}$. Erst durch das Sprechen der Patienten wurde erkennbar, daß ihre Symptome nicht durch Persönlichkeitsdefekte bedingt waren, sondern einen sehr fein und kunstvoll konstruierten Sinn hatten. Damit holte Freud sie aus dem Ghetto des Abnormen heraus: Die Vorstellungen, die man bis dahin von der Normalität hatte, waren nun in Frage gestellt. Dem Leser Freuds stellte sich nun die Aufgabe, nicht länger einen Widerspruch darin zu sehen, daß jemand zugleich hysterisch (neurotisch) und normal sei.

Die Wirkung von Normvorstellungen ist nicht allein Sache der Soziologie. Jeder von uns stößt in sich selbst auf Abweichungen von dem, was die Umgebung als Norm vorgibt, wenn er sich nicht vollständig seiner Zensur beugt. Es geht hier um einen Widerspruch im Subjekt, einen Einriß im Ich. Worin besteht dieser Widerspruch? Erst die Lockerung der Zensur - z.B. in einer Analyse bringt ihn ans Licht. Mit den unwichtigen, nebensächlichen, sonderbaren oder anstößigen Gedanken geht der Einzelne nämlich so um, wie der Diskurs der Normalität mit den Abweichlern, Randfiguren, Unverständlichen usw. Verlangte der Erfinder der gleichschwebenden Aufmerksamkeit bei der Analyse seiner Träume nicht die gleiche Unvoreingenommenheit gegenüber sich selbst und der Sexualität wie der Forscher gegenüber seinem Gegenstand?

Hysterie, griech.: hustera. Der im Körper wandernde Uterus. Im antiken Ägypten lockte man dieses widerspenstige Tier mit Parfüms an die Stelle des Geschlechts, um es dort zu fixieren. Fixieren, weil nichts so verschiebbar, nichts so sehr zum Ersatz geeignet ist, wie die Sexualtriebe. Fixierung aber auch, um der Sexualität den Platz zu geben, mit dem sie der Kultur dienstbar gemacht werden soll. Verschiebung und Unruhestiftung zugleich. Fixierung als kulturelle Leistung? Der wandernde Uterus der Antike war ein Vorläufer der Freudschen Idee der sich im Körper verschiebenden Sexualität. Aber ist es die Sexualität selbst, die unterdrückt werden soll, oder nicht vielmehr die Fragen, die sie uns stellt? Fragen, für die es unter allen menschlichen Handlungen am allerwenigsten vorgefertigte Antworten gibt. Die diesbezüglichen zahlreichen Vorschläge, die uns ständig in der Gesellschaft präsentiert werden, bieten vielleicht mehr oder weniger nachahmenswerte Praktiken an, kaum aber befriedigende Antworten auf unsere Fragen. Stets konfrontiert uns die Sexualität mit dem Unerledigten in unserer Geschichte, stets verlangt sie von uns, daß wir uns nicht mit dem Gewohnten begnügen und zwingen uns zur Revision unserer Konsumvorstellungen. 
Über den unterdrückten Affekt, der das Symptom hervorruft, fand Freud den Zugang zu dieser >Unterwelt $<$ : Ein schmerzlicher Affekt, der während des Essens entsteht, aber unterdrückt wird und dann Übelkeit und Erbrechen erzeugt und dieses als hysterisches Erbrechen monatelang andauert«. Freud spricht hier von einer symbolischen Beziehung zwischen der Veranlassung und dem pathologischen Phänomen. Es »bedient sich« einer Neuralgie so, wie der moralische Ekel im Erbrechen seinen Ausdruck findet. Symbolisch: ein »seelischer« Schmerz! Das ist vielleicht ein erster Ansatz zur Formel des Symptoms als Metapher. Und mit der Entdeckung dieser symbolischen Beziehung, der Metapher, taucht die Sexualität als Ursache der Symptome auf. Die metaphorische Beziehung - die »symbolische Begegnung ${ }^{15}$ - war die Voraussetzung für die Entdeckung, da $\beta$ die psychischen Prozesse überdeterminiert sind und daß sich das Symptom nicht auf eine einzige biographische Ursache zurückführen läßt. Determinierung anstatt Definition. Freud betont, daß die Ursache der Symptome nicht äußerlich ist, kein »agent provocateur«, sondern wie ein Fremdkörper wirkt. Es ist etwas ins Innerste Aufgenommenes. Ins Innerste eines Subjekts, das keineswegs autonom ist: »[...] die anfängliche Hilflosigkeit des Menschen ist die Urquelle aller moralischen Motive $\aleph^{16}$. Auf der einen Seite dieser Hilflosigkeit ist das Subjekt überwältigenden Erregungen in seinem Körper ausgeliefert, auf der anderen Seite ist es auf einen helfenden anderen angewiesen. Von dieser Seite des Anderen wird sich ihm auch der Zugang eröffnen, etwas zu seiner Lage und zu seiner Herkunft artikulieren zu können.

Ausgelöst werden die Symptome durch einen Einbruch des narzißtischen Bildes: Verlust einer Liebe, einer bedeutenden Stellung, aber dieser Verlust allein macht noch nicht notwendig ein Symptom. Hinter der dramatischen Aktualität klopfen vorausgegangene Ereignisse an, die stets auf frühere verweisen und das Subjekt zum Einsatz seiner Phantasie und zur Erfindung nötigten.

Dieser durch die Symptome eingeschlagene Weg führt zurück, wie gesagt, nicht auf eindeutige Ursachen, auf eine in der Tiefe schlummernde Bedeutung. Sie drehen sich um die gesamte Beziehung zum Anderen, zur Sprache: So kann Freud sagen, daß die Deutung des Traums zu einer »Umwertung aller Werte $\aleph^{17}$ führt.

Mit der Grundregel, seine belanglosesten Einfälle auszusprechen, empfahl er eine Arbeit an der Oberfläche, dem Rand, dort, wo das Subjekt gegenüber einem unbekannten Anderen in seinen Einfällen eine Beziehung zum Neuen herstellt und die Chance ergreift, sich neu auf die Be- 
ziehung zur Sprache einzulassen. Mit dem Neuen kommt das Reale ins Spiel, das sich jeder Beherrschung entzieht. Seltsam, dieser unmittelbar erscheinende Widerstand, die belanglosesten Einfälle zu sagen. Eher eine Situation, die dem Analysanten aus den Händen gleitet, als daß es sich darum handelte, ein Geheimnis zu hüten. Sollte es nur die Kränkung sein, erneut an vergangene Peinlichkeiten erinnert zu werden? War dies das sogenannte »Trauma«, das ein so heftiges »Nicht wissen wollen« rechtfertigt? Wohl kaum. Eher ist das Sprechen selbst ein Vorgang, dem ein Widerstand innewohnt. Es gibt Vorstellungen, die ein Fremdkörper in der Vorstellungsmasse des Ichs sind. Die Verdrängung dieser Vorstellungen gelingt nicht und sie kehren in isolierter, unkenntlich gemachter Form im Symptom wieder. Das Subjekt will von diesen Vorstellungen nichts wissen. Das beschreibt Freud zunächst als Willensakt. Später wird er sagen, daß er der festen Überzeugung ist, daß das Subjekt die Szenen, die zu den Symptomen gehören, weiß. Es ist also nicht so, daß das Subjekt sich nicht zu erkennen geben will, es ist ein struktureller Widerspruch im Subjekt selbst.

Freud führt die Symptome anfangs auf traumatische Szenen zurück. Bald werden sie als sexuell präzisiert. Später wird er das Phantasma als Schlüssel für die Symptome entdecken. Symptome sind Ersatzbefriedigungen für unerfüllte sexuelle Wünsche. Ist die Sexualität der Schlüssel für alle Symptome? Ist das der sogenannte Pansexualismus, den man Freud vorwarf? Aber was heißt bei Freud »sexuell«?

\section{Die Sexualität und das Spiel}

Der Chemiker aus der Traumdeutung, der von seiner »häuslichen Sexualbefriedigung« (der Masturbation) loskommen möchte und doch im Traum vor der Gelegenheit eines Rendez-vous mit der Dame ausweicht. Oder Freud selbst, der von einer Formel der Sexualchemie träumt und darin seinen Wunsch erfüllt sieht, daß ihm eine Schrift der Sexualität gelänge, womit er diese metaphorisiert. Die Zwangskranke aus den Vorlesungen zur Einführung in die Psychoanalyse, die ein peinliches sexuelles Versagen ihres Mannes in der Hochzeitsnacht durch ihre Zwangshandlung kaschieren möchte. Dora mit ihrer hysterischen Aphonie, der nach oben verschobenen Sexualität, die Herrn K abwehrt, und dabei nach dem Rätsel der Weiblichkeit sucht ... In den Symptomen 
steht das Subjekt stets zwischen seinen konservativen Trieben und dem Einbruch von etwas Fremdem, dessen Handhabung nie glatt geht.

Die Analysen Freuds führen nicht zu einer Sexualität, die paßt. Man könnte eher von einer verpaßten Sexualität sprechen. Eine, die man verpaßt oder eine, die man verpaßt bekommt. Keine `natürlicheく Sexualität, die von dem frei wäre, was wir vom Anderen mitbekommen haben. Gleich, was alle möglichen Befreiungsapostel uns weismachen wollen. Die natürliche Sexualität wäre nur eine, die nach dem Bild einer Auffüllung eines Mangels oder einer Entledigung von chemischem Druck gleich einer >Entschlackung « verliefe, worin wir nur das Phantasma am Werke sehen. Frei von dem zu sein, was wir für uns als vorherbestimmt glauben, wäre nur ein anderes, vielleicht anziehenderes Phantasma. Nirgendwo ist der Glaube an einen Sinn mehr von Phantasmen bestimmt als in der Sexualität. Darin nimmt der Träger des Symptoms einen bestimmten Platz ein, an den er mehr oder weniger fixiert ist oder den er mehr oder weniger zugewiesen bekommt. Sexueller Sinn? Je weiter die Analyse fortschreitet, um so mehr tauchen die Koordinaten auf, die diesen Platz bestimmen, an den sich jemand in seinem Phantasma gestellt sieht. Und als Freud selbst seiner Patientin Dora einen bestimmten Platz zu geben versucht, daß sie doch einen Herrn liebe und auf ihn bezogen sei, bricht sie die Analyse ab. Freud erkennt nachträglich seinen Irrtum. Der Sinn der Symptome lautet der Titel der XVII. Vorlesung zur Einführung in die Psychoanalyse. Auch hier ist von Sexualität die Rede. Vor allem aber von dem Platz, den eine Zwangskranke jahrelang eingenommen hatte, und an dem sie weiß Gott keine befriedigende Sexualität hatte. $\mathrm{Ob}$ sie meint, diesen Platz willentlich eingenommen zu haben oder nicht, das ist nicht entscheidend. Entscheidend ist, daß sie von einem Platz bestimmt ist, der ihr völlig entgeht. Das unbewußte Subjekt ist kein >zweites Ich . Es ist das Hypokeimenon (griech.: das Zugrundeliegende, Unterworfene), das der Sprache insofern unterworfen ist, als etwas in ihr begehrt und schon in ihr begehrt hat, bevor sie darüber irgendeine Idee haben konnte. In ihrem Zwangsritual des zwischen zwei Zimmern hin und her Laufens »spielte« sie unwissentlich die Geste ihres Mannes in der Hochzeitsnacht nach. Freud hütet sich, von einer männlichen Identifizierung zu sprechen, er sagt, »sie spielt ihn ja, indem sie sein Laufen aus einem Zimmer ins andere nachahmt $\ll^{18}$. Sie ist nicht bestimmt durch irgendeine obskure Neigung, den Mann zu spielen, sondern sie folgt einem signifikanten Schema, das sich ihr aufdrängt und das durch seine auffällige Sinnlosigkeit symptomatisch ist. Das ist mit 
Platz gemeint. Ein Platz gegenüber dem Anderen, um dort eine Bedeutung zu inszenieren. Freud beobachtet - eigentlich ist es die Schilderung der Beobachtung der Patientin, der er zuhört - und läßt den Sinn der Symptomhandlung bis zu dem Punkt offen, an dem die Bestimmung durch den Anderen im Netz ihrer eigenen Artikulierung an die Oberfläche gelangt. Oberfläche insofern, als aus dem Sprechen des Analysanten ein anderer Zusammenhang hörbar wird. In diesem anderen Zusammenhang kommt dem Analysanten ein Platz zu.

Den Mann spielen. Freuds Patientin mag das, in dieser leidenschaftlichen Praxis ihres Symptoms, wohl nicht so spielerisch vorgekommen sein. Aber die Analyse ist das. Die Aufgabe des Analytikers ist genau diese: Dieses Spiel im Sprechen des Analysanten zu hören. Ein Spiel in der Rede, das dem sprechenden Subjekt entgeht.

Dieses Spiel in der Sprache folgt bei genauerer Betrachtung Regeln, die Freud vor allem in den Primärvorgängen gefunden hat, in den unbewußten Mechanismen: Verschiebung, Verdichtung, Rücksicht auf Darstellbarkeit. »Das Gegenteil von Spiel ist nicht Ernst sondern Wirklichkeit « ${ }^{19}$, sagt Freud. Der Ernst ist ein viel zu wenig beachtetes Symptom. Bei vielen Patienten, die zum Psychoanalytiker kommen, ist er ihrer Wirklichkeitsferne proportional. ${ }^{20}$

\section{Die Vatermetapher als Leerstelle}

Ist der Vater in den vorherigen Kapiteln untergegangen? - Freud spricht vom Untergang des Ödipuskomplexes. Oder handelt es sich dabei um eine stillschweigende, latente Anwesenheit?

Ausgehend vom Symptom gelangt Freud zum verführenden Vater. Dieser durchzieht seine Krankengeschichten wie auch sein gesamtes Werk. Vom Entwurf über die Studien zur Hysterie, die Zwangsneurosen, den Fall Schreber. Vom >Vater der Vorzeit` über Totem und Tabu bis zum Mann Moses. Der Vater wird als Ursache der Symptome benannt. Er wird ersehnt, als Verführer beschuldigt, auf- oder abgewertet, es wird um seine Anerkennung gerungen, schließlich wird er erschlagen. Aber was wäre ein stillschweigend anwesender Vater? Ein >toter Vater? Als Name in die Struktur eingeschrieben? Im Werk Freuds ist er ein Angelpunkt. Dies in dreierlei Hinsicht: der genießende Vater (der Urhorde), der Vater der Liebe (im Ödipuskomplex) und der Vater des Gesetzes (als Name im Mann Moses). ${ }^{21}$ Dieser >Vaterfigur $<$ hat sich nach Freud 
kein anderer Psychoanalytiker so sehr angenommen wie Jacques Lacan. Aber um was für eine Figur handelt es sich?

Lacan hat den eben skizzierten Vaterfunktionen eine wesentliche Bedeutung für das Symptom gegeben. Weder bei Freud noch bei Lacan geht es nur um die >Vaterrolle in Familie und Gesellschaft, wie sie etwa die Soziologie studiert. In den Sprechstunden hören wir zwar meist davon, wie der Vater war: gewalttätig, tyrannisch, autoritär, despotisch ... Weniger lautstark hören wir vom schwachen, abwesenden Vater. Und manchmal hören wir gar nichts von ihm. Oder er reduziert sich auf eine farblose Person an der Seite der Mutter. Wird der Vater etwa weniger beachtet als die Mutter? Bei den Psychoanalytikern hat man manchmal den Eindruck. Weil seine Funktion schwerer zu begreifen zu sein scheint als die ihre? Auch der Gesetzgeber scheint seine Funktion schwer bestimmen zu können. Das Pater semper incertus, was im Rom der Antike eine Art Adoptionserklärung notwendig machte, kann heute als unsicherer Vater gelesen werden. Der Vaterschaftsnachweis unserer Tage hat weder die Beurteilung der Vaterfunktion sicherer gemacht, noch seine Stellung verbessert. Im Gegenteil. Je realistischer man seine Aufgabe begreift, um so weniger scheint man einen Schimmer von seiner symbolischen Funktion zu verstehen. Reduziert er sich heute auf den Erzeuger und den Helfer bei der Kindererziehung? »Die Praxis lehrt uns«, so die Kinderanalytikerin Eva-Marie Golder ${ }^{22}$, »daß die Aufgabe, einen Vater zu finden, immer mehr auf den Kindern lastet«.

»Was für das Kind in bezug zum Vater wichtig ist, ist die Tatsache, daß der Vater derjenige ist, der die Mutter sexuell genügend befriedigt - eine Lappalie Lacans « $?^{23}$ Für Freud ist der Ödipuskomplex das Schibboleth, das die Anhänger von ihren Gegnern unterscheidet. Manche mögen hier nur den Appell an die starke Hand sehen, um aus ängstlichen Weichlingen ganze Kerle zu machen. Aber eine solche >Vererbungstheorie ২ unterscheidet sich nicht grundlegend von der alten Degenerationslehre. Die obskure Schwäche wäre nur eine Generation zurück verlagert. Kein Familienroman, in dem der Vater >starkı genug oder einfach nur genügend anwesend gewesen wäre. Welche Funktion hat diese Charakterisierung der väterlichen Person? Und inwiefern können wir heute die Symptome auf den Vater zurückführen? In der obigen »Lappalie« wird deutlich:

- Die väterliche Funktion ist eine über die Mutter vermittelte.

- Die sexuelle Befriedigung der Mutter ist mit ihrer Beziehung zum Kind verbunden. 
- Wie sich die Abwesenheit der Mutter (ihre An- und Abwesenheit) in die kindliche Psyche einschreibt, hängt so mit der Sexualität zusammen.

Schon in seinen ersten psychoanalytischen Schriften beschreibt Freud einen psychischen Apparat, der durch Hemmung entsteht. Dieser Apparat dient der Verarbeitung der »anfänglichen Hilflosigkeit«. Seine Struktur selbst ist eine Reaktion des Menschenkindes auf diese Hilflosigkeit gegenüber mannigfachen Erregungen. Alles kommt vom Anderen. Am Anfang stehen »nicht die kindlichen Triebschicksale, sondern das symbolische Register, von woher diese ausgelöst werden und woher das Kind entweder einen Platz bekommt oder nicht. Was am Anfang steht, ist nicht das Begehren des Kindes gegenüber der Mutter, sondern ihr eigenes Begehren ${ }^{24}$. Ebenso wie dieser Apparat Wahrnehmung, Einschreibung und Verarbeitung in sich vereinigt, ermöglicht er auch die Auffassung der Sprache.

Diese Auffassung der Sprache steht in enger Beziehung sowohl zum Vater als auch zum Symptom. Die Analyse des Symptoms deckt nicht nur das Symbolische seiner Beschaffenheit auf, sie verändert notwendigerweise auch die Beziehung zur Sprache. Warum?

Allzu oft trifft man auf die Vorstellung, daß es sich beim Symbolischen um eine Art Lexikon oder System handelte, und daß man nur dieses Wörterbuch genügend kennen müßte, um es zu übersetzen. Genauso wie man den Vater auf jene Person mit ihren Eigenschaften reduziert. Diese Auffassung führt in die Irre. Sie verwechselt die Vorstellung vom Vater, den imaginären Vater, mit seiner symbolischen Funktion. Der Namedes-Vaters - muß daran erinnert werden? - ist weder der Familienname, der Name des rechtmäßigen Vaters, noch die Doppelsilbe $\mathrm{Pa}-\mathrm{Pa}$, sondern der Signifikant dessen, was ausgehend vom Signifikant des Begehrens der Mutter, will sagen, dem symbolischen Phallus, dem Kind Bedeutung vermittelt ${ }^{25}{ }^{25}$ Das Symbolische ist das, was jemandem einen Platz gibt. So ist für das Kind und vor allem im Unbewußten des Kindes der Platz, den die Mutter dem Vater gibt, ein symbolischer Platz insofern, als es ein leerer Platz ist, ein noch auszufüllender Platz oder zumindest sollte er leer sein. Wir treffen hier wieder auf dieses X im Symptom, von dem oben die Rede war. Denn wenn er allzu >voll ist oder allzu fehlend, dann ist dieser Platz kein Platz mehr, sondern eine Definition, ein Schicksal und es gibt an diesem Platz nichts mehr zu wünschen, nichts mehr zu entdecken. 
Die Wichtigkeit dieser Leerstelle hängt damit zusammen, daß sich das kindliche Subjekt über eine >demandeく, einen Anspruch, eine Frage konstituiert: Was ist der Andere, was begehrt die Mutter in ihm?

Diese Andeutung zur psychischen, d.h. ödipalen Struktur dient nur der Hervorhebung eines einzigen Punktes, in dem vielleicht eine Ähnlichkeit zwischen der Funktion des Vaters und der des Symptoms erscheint, nämlich in der Funktion der Leerstelle. Begegnet man in der psychoanalytischen Praxis nicht Patienten, die auffallend an ihrem Symptom festhalten, vielleicht deshalb, weil dies für lange Zeit die einzige Möglichkeit darstellt, eine Leerstelle, eine Frage oder ein Rätsel offenzuhalten? In jeder Analyse geht es um die Anerkennung der väterlichen Funktion, der Leerstelle. Der Frage, was es eigentlich mit dem stets vorausgegangenen, nie einholbaren Begehren des Anderen auf sich hat. Diese ist immer erst möglich, wenn das Subjekt gewagt hat, etwas auszusprechen, mehr noch, etwas vom Unbewußten sprechen zu lassen. Die Mindestvoraussetzung dafür ist, daß das Subjekt es wagt, bei seinem Assoziieren gewohnte Zusammenhänge zu verlassen, sagen wir, sich in seinem Sprechen zu verausgaben. Dann entsteht ein anderer Bezug zur Sprache, der nicht erklärt, sondern in dem Lücken, Leerstellen erscheinen können, an denen »der Andere«, anknüpfen kann. »Falsche Verknüpfung « ${ }^{26}$ war eine der ersten Bezeichnungen Freuds für das hysterische Symptom. Was aber keinesfalls bedeutet, daß sich der Analytiker hier selbst mit der »richtigen« Verknüpfung unterzubringen hätte. Damit kehren wir zurück zur Grundregel. Sie ist eine notwendige, aber keine ausreichende Bedingung für die Analyse. Sie ist wirksam, wenn die Rede des Analysanten von Leerstellen, oder besser gesagt von der Leerstelle markiert ist. Diese väterliche Leerstelle macht es möglich, daß sich in jeder Psychoanalyse die ödipale Struktur wiederholt.

Nichts, was nicht über das Sprechen zu laufen hätte. Diese negative Formulierung der Regel, alles zu sagen, drückt vielleicht besser als die positive aus, daß diese Regel von vornherein ein Nichts einführt, und sei es nur im Ausruf des Analysanten: Das ist doch nicht möglich, alles zu sagen! Dieses Nichts kann eine Form sein, in der sich die Leerstelle ausdrückt, auswirkt und womit sich die Umwertung im Psychischen vollzieht.

Wie in der Kindheit werden in einer Analyse Ansprüche artikuliert, wiederholt, manchmal auch geweckt. Diese Ansprüche durchlaufen das Sprechen gemäß den Primärprozessen von Verschiebung und Verdichtung. Damit tritt eine Anerkennung in Funktion, die nicht bestimmten 
Ansprüchen gilt. Findet die Analyse in der >Versagung < statt, so kann die Leerstelle wiederbelebt werden und beim Analysanten zur Anerkennung nicht seiner Ansprüche, sondern des Begehrens als Ursache führen. Die väterliche Instanz in der Sprachfunktion macht im Laufe einer Analyse deutlich, in welcher Weise die letztere geeignet ist, kindliche Erfahrungen wieder zu beleben. Alles, was von der Ordnung des Wortes ist, alles Symbolische erscheint dann insofern deutbar, als es vor dem Hintergrund von etwas stets Rätselhaftem, Unerreichbarem, Abwesendem, Verlorenem erscheint und zur Benennung drängt.

\section{Anmerkungen}

1 Jean-Marie Jadin: Côté divan, côté fauteuil, Paris 2003, 110 (Übersetzung P.M.).

2 Jacques Lacan: »Vortrag in Genf über das Symptom«, in: RISS. Zeitschrift für Psychoanalyse, No. 1, 1986, 5-43.

3 Lucien Israël: »Qu'est-ce que ça vous rapporte au wattman«, Vorlesung vom 03. 02. 1986, Universität Straßburg, unveröffentlicht.

4 Vgl. Sigmund Freud: »Zur Einleitung der Behandlung«, in: ders., Gesammelte Werke [GW], Bde. I-XVIII, Frankfurt am Main 1968, hier: GW VIII, 453-478, 468.

5 Etwas verkürzt sei darauf hingewiesen, daß Lacan diese Beziehung als Grundformel des Phantasmas aus drei Elementen entwickelt hat: Dem sprechenden Subjekt, dem realen, nicht auf eine symbolische oder imaginäre Weise faßbaren Objekt und einem variablen Element, das beide verbindet.

6 Daniel Michel: »Der hinkende Bote«, in: Arbeitshefte Kinderpsychoanalyse 2003, 55.

7 Freud, »Der Dichter und das Phantasieren«, GW VII, 214.

8 Freud, Briefe an Wilhelm Fließ, GW Ergänzungsband, 255.

9 Jacques Lacan: »Das Spiegelstadium als Bildner der Ich-Funktion«, in: ders., Schriften $I$, Norbert Haas (Hg.), übersetzt von Rodolphe Gasché, Norbert Haas, Klaus Laermann et al., Olten 1973, 61-70.

10 Freud, »Die Traumdeutung«, GW II/III, 345.

11 Marcel Ritter: »Das Symptom von Freud bis Lacan«, in: Jahrbuch für klinische Psychoanalyse. Das Symptom, Tübingen 2000, Bd. 2, 35.

12 Hier liegt nicht nur die Verdichtung nahe, die von Fliegen - fliegen - vögeln reicht, sondern auch der diesen Metaphern nicht fernliegende Mädchenname der Mutter.

13 Freud, »Studien über Hysterie«, GW I, 259.

14 André Michels: »Zur Frage der Kausalität«, in: Jahrbuch für klinische Psychoanalyse. Das Symptom, Tübingen 2000, Bd. 2, 69.

15 Lucien Israël: Boiter n'est pas pècher, Paris 1989, 285.

16 Freud, »Entwurf einer Psychologie«, GW Ergänzungsband, 411.

17 Freud, »Die Traumdeutung«, GW II/III, 345.

18 Freud, »Vorlesungen zur Einführung in die Psychoanalyse«, GW XI, 270.

19 Freud, »Der Dichter und das Phantasieren«, GW VII, 214.

20 »Sind wir alle vermuttert?«, lautet der Titel einer zum Muttertag 2004 erschienen Satire in Die Zeit. Dort wurde vom ständigen Anstieg des »Mutterquotienten« gewarnt. Zu viele Mütter, immer weniger Kinder. Das einzig wertvolle Gut, von dem es in Deutschland pausenlos immer mehr gibt, ist Mutter [...]. Männer mit enger Mutterbeziehung werden häufig sonderlich. In 30 Jahren sitzen in der U-Bahn nur noch Sonderlinge. Ihre uralten Mütter bringen sie ins Büro. [...] der Ödipuskomplex hat sich auf eine Weise radikalisiert, die niemand auszusprechen wagt. [...] Frauen, die in letzter Zeit Mutter geworden sind. [...] Mit tiefem Décolleté lassen sie sich vor der Geburt fotografieren, wo sie auf Parties einen draufmachen. Einen Tag nach der Geburt mit einem Bündel im Arm, schwenkend, das später einmal sonderlich werden wird. 14 Tage nach 
der Geburt im Bikini Squash spielen, mit Leonardo di Caprio nackt an der Costa smeralda bungee jumpen. Zum Muttertag bekommen sie von ihrem Mann einen Satz japanischer Wurfmesser, von ihrem Fitnesstrainer ein mit Brillanten besetztes Kondom. Vor solchen Müttern habe ich Angst.«

21 François Balmes: Le nom, la loi, la voix. Freud et Moïse: écritures du père 2, Toulouse 1997.

22 Eva-Marie Golder: »Vatermetapher-Ort des Subjekts-Fragen zur Übertragung«, in: Diskurier. Zeitschrift für Psychoanalyse, No. 6, 1996, 18.

23 Ebd.

24 Philippe Julien: »L'amour du père chez Freud«, in: Littoral No. 11/12, Toulouse 1984, 156.

25 Philippe Julien: »Die drei Dimensionen der Vaterschaft in der Psychoanalyse «, in: Edith Seifert (Hg.), Perversion und Philosophie. Lacan und das unmögliche Erbe des Vaters, Berlin 1992, 170.

26 Freud, »Studien über Hysterie«, GW I, 121. 



\section{Hysterie: "... sagte ich mir, der Fall könne keine Hysterie sein« (Freud)}

\section{Punkt: Doppelpunkt Zitat: »Hieroglyphen der Hysterie»}

Zwei Metaphern, zwei Übersetzungen, Wiederholungen, am Anfang: Die erste, »Hieroglyphen«, ist ins Griechische, die zweite, »Hysterie«, aus dem Griechischen übersetzt. Wiederholungen als Anfang, nach dem unmöglichen Anfang. ${ }^{1}$ Hinzu kommt, daß weder die Hieroglyphen noch die Hysterie gerade das wären, was man einen Neologismus nennt. Nichts Neues unter der Sonne also, kein Novum scheint in Sicht, von dem ein incipit hätte aus- oder losgehen können. Dies wird der Anfangohne-Anfang gewesen sein, denn er ist schon passiert, schon wiederholt, überholt und er wird etwas anderes zurückgelassen haben. »Hieroglyphen der Hysterie«, sagte namentlich Lacan und begründete damit den Rat an sein psychoanalytisches Seminar, der da lautete, ich zitiere: »Lösen Sie Kreuzworträtsel!«

Es geht hier um den Versuch, im Text und Kontext der Hysterie - was immer das Wort »Hysterie« heißen und um wessen Text und Kontext es dabei gehen mag - nach dem strukturellen Zusammenhang von Metapher und Nachträglichkeit zu fragen. Metaphern: Das, was als Ersetzung gehandelt wird, als die Zwei einer Substitution, aber ohne die Eins. Genauer: Das, was sich immer erst nachträglich als immer schon wiederholendes Ersetzt- und Verdichtetsein darstellt, mithin, was sich allererst als immer schon übersetzt und übergesetzt zeigt. Metaphern indes, die etwas wie eine Kluft verraten: Eine Kluft, die sich nicht darstellt, sondern die wirkt. Die wirkt, insofern ihr Effekt die Metapher ist. Denn diese Kluft, dieser Zwischenraum, dessen es im Zuge der metaphorisierenden Verschiebung bedarf, kann nur dadurch zum Tragen kommen, daß 
etwas bereits woanders hin verschoben, übertragen, "verrückt« wurde: Das Nichts einer Leerstelle nicht ersetzend sondern supplementierend, wird etwas an eine andere Stelle gesetzt worden sein, das nachträglich als anderes, neues, dasteht und dargestellt ist, differierterweise. Anders gesagt: Durch das aktiv-passive (Über-)Tragen und Schieben, das metaphorein heißt und betreibt, kommt diese Kluft - eine konstitutive Lücke, die Metapher gemacht haben wird - nie zum Vorschein einer Präsenz, sondern als Zug eines (nicht) repräsentierten anderen zum Tragen. Etwas zieht, transportiert und wird von dem gezogen und betrieben, was sich nicht repräsentieren läßt. Eine Kluft also, die Differenz nicht ist, sondern durch ihr verschiebendes Verschobensein Differenz gemacht haben wird. Kluft durch Schub, Differenz als Spur ohne Tinte, wenn Sie so wollen, sans encre. Und, da ohne Anfang, auch ohne Anker, sans ancre. Wenn Sie die Spur dieser Kluft aufspüren, war sie immer schon (nie) da, das heißt fort, weil anders eröffnend als das, was sich da dann aufzeigend eröffnet hat. Lassen wir die Metapher - Metapher der Metapher der Nachträglichkeit - sich wenigstens andeutungsweise noch einen einzigen kleinen, wenngleich diffizilen, Schritt weiterschieben.

Denn später - »später« heißt griechisch husteros - und das heißt hier: Nach und dank Freuds eröffnender Einsicht in diese rückwärts qua vorwärts katapultierende Logik der Nachträglichkeit, nach diesem darstellungskonstitutiven Umkehr- oder Konvertierungs-Salto (später wird man sagen können, die Hysterie schlüge Purzelbäume) - und vielleicht gerade weil sie bei Freud ohne Definition blieb - wird sie namentlich als différance $^{2}$ neu $\mathrm{zu}$ lesen aufgegeben worden sein: verschoben geschrieben, ein »e« durch ein gewisses klein a ersetzend, verschoben verschrieben. Die différance metaphorisiert Freuds Nachträglichkeit nachträglich, sie konstituiert sie differiert, (v)ersetzt, ein weiteres erstes Mal, anders: Derridas différance ist nichts, mithin kein Begriff, sondern ein "provisorisches Stratagem«, das sich ohne Präsenz und ohne Repräsentierbarkeit als das schreibt, wonach sich Differenz (das, was differiert: diffère) im und als Aufschub gibt und - ineins - als das, wonach sich Aufschub (das, was aufschiebt: diffère) in der und als Differenz gibt. Umgekehrt und verboten überstürzt formuliert: Schrift - ob als mündliches oder schriftliches Zeugnis von Sprache als Zug: wir kommen darauf zurück wäre eine Metapher für jene Differenz, die dieser konstitutiven Verspätung unterliegt, und das heißt hier: einem gewissen husteros unterliegt. Verspätung vor allem, als Matrix oder mater, die darunter, dahinter und danach - husteros - kommt, verschwindet, wirkt. 
Zurück zu den »Hieroglyphen der Hysterie«: sagte Lacan, nach Freud. (Klammer auf: Klammern gehören, wie Sie wissen, jenen supplementären Schriftzügen ohne Sinn an, die Sie nicht hören können und die dem Raum eines Zwischen (in den Klammern) statt geben: In dieser Klammer sei angemerkt, daß der Ausdruck »Lacan nach Freud « beinahe ein Beispiel dafür ist, was in der Rhetorik einer Figur entspricht, die sich durch eine zeitliche Umkehrung hervortut. Ihr Name lautet »HysteronProteron «, zu deutsch, »das Spätere als Früheres«. Goethe wird ja immer gern zitiert, und das meistbemühte Beispiel für ein solches $»$ HysteronProteron« lautet denn auch: »Ihr Mann ist tot und läßt Sie grüßen!«, natürlich aus Faust. Im Unterschied zur Rhetorik erfährt die temporale Umkehrung des »Hysteron-Proteron« in der Logik nun aber wiederum eine Umwertung. Denn in der Logik gilt ein »Hysteron-Proteron« als "Scheinlogik« oder »Zirkelbeweis«, d.h. es ist der Name für das, was gegen eben die Logik verstößt, die diese Figur im Sinn und als Diagnose, wenn Sie so wollen, auf Unlogik, d.h. als ihr Negativum zu bestimmen weiß.

Es ist nicht klar, ob ich diese Klammer rechtzeitig schließen werde, indes scheint klar, daß die Hysterie - ob es sie gibt oder nicht, wird vielleicht aus sehr guten Gründen nicht zu klären sein - alles mit Umkehrung und Unlogik zu tun hat. Das heißt, sofern man den Darstellungen über sie Glauben schenken will. Denn, ich sage es gleich, ich werde Ihnen die Hysterie nicht erschließen, zumindest nicht bewußt, und alles, was Sie hier in Form von nurmehr fragmentarischen Nachträgen oder post scripta vorgetragen bekommen, hat mit dem zu tun, was über sie zu lesen ist. Was über sie, die Hysterie, zu lesen ist, sind - wie sollte es anders sein - Darstellungen von Lektüren ihrer Darstellungen. Und nichts spricht dagegen, daß auch ihre Darstellungen - die der Hysterie - auf Lektüren beruhen: Auf beunruhigend prägenden Wahrnehmungen, die in dem Maß Leiden schaffen und leiden machen, wie ihre Darstellung sagen wir eine gewisse Handhabung des Metaphorischen - auf dem Spiel steht. Dessen Einsatz ihr Körper ist.

$\mathrm{Zu}$ lesen ist - folgt man den theoretischen Darstellungen über die der Hysterien - vor allem diese Warnung: Man dürfe, heißt es, das Wort $»$ Hysterie« - aus griechisch hustera (Achtung: feminin!), das später im Lateinischen zu uterus und im Zuge einer mir rätselhaften Geschlechtsumwandlung maskulin wurde - man dürfe also hustera, die Gebärmutter oder Matrix, keinesfalls verwechseln mit dem Adjektiv husteros: dieses heißt indes nicht nur »später«, »nach« und, Konsequenz dieser Sequenz, 
»Zweitrangig «, sondern auch, ich wiederhole mich, »dahinter« und »darunter«. Dem Späteren ist hier also unterstellt, daß es darunter liegt oder unterliegt. Der Grund - zum Schluß?

Bleibt, daß es in der Hysterie - oder aber eben in den Theorien über sie - buchstäblich drunter und drüber geht: Krankheiten von unten steigen zu Kopfe, überschlagen und widersprechen sich, drehen Fragezeichen in allen Posen der Schrift. Um die Klammer schließlich zu schließen, mag eine Hypothese oder Unter-Stellung hier angebracht sein: Und wenn, et si: Was wäre, wenn die Hysterie - als Frage und als Rätsel, als die sie einzig Bestand und Konstanz zu haben scheint - sich genau nicht auf die Alternative begrenzen ließe, nach der sie entweder von hustera oder aber von husteros ausgehend zu denken sei, sondern als das, was sich dazwischen (zwischen hustera/uterus und husteros/später), zwischen beiden und beide berührend, aufspannte? Und damit erneut, verspätet und anders - en différance - die alte Frage des Zwischen, chora, die Frage dieses anderen, des dritten Raums, der nicht zuletzt den des Denkens und der Theorie des Nichttheoretisierbaren eröffnet haben, in Anschlag gebracht und in Gang gehalten haben könnte? Das anzuerkennen könnte eine Chance für Theorie sein, nicht im Entweder-Oder zu verkommen, mithin, eine Chance von Theorie nicht versus, sondern - en différance - als Hysterie und vice versa. Theorie (nach) der Hysterie, Hysterie (nach) der Theorie: Aber wie ist der doppelte Genitiv zu lesen? Wer wird wen gelesen haben, metaphorisiert, dargestellt, theoretisiert? Will fragen: Wer wird als wessen Symptom zu lesen sein? Klammer zu, da capo:)

\section{Punkt: Geschichten}

»Mach doch keine Geschichten!«, wie es heißt, aber nein, es ist wie bei Kant, nämlich »gerade umgekehrt«: Die Hysterie macht Geschichten. Und um sie ist es der Psychoanalyse, deren Praxis nicht zuletzt eine mündliche Kunst oder Technik ist, wesentlich zu tun. Hier findet das Erzählen - und dessen sprachlose Ränder - von Geschichten statt, in Gesprächen à deux. Lateinisch verseutscht heißen solche und andere Gespräche namentlich »Konversationen«, was sich wörtlich mit »Zusammen- oder Umwendungen oder -drehungen« rückübersetzen läßt. Konversation wird hier in dem gepflegt, was Freud denn auch die Kur nennt. Thema und Material der Gespräche im Setting der Psychoanalyse bilden 
also Geschichten - mitsamt den ebenso impliziten wie konstitutiven Brüchen und Unterbrechungen, Lücken, Klüften, Zäsuren und Zensuren, Aufschüben. Geschichten, sagt Kluge - Wortgeschichten und Wortfamilien zähle ich dazu -, seien der Herkunft nach, ihrer Geschichte nach also, »Geschehnisse ${ }^{3}$ und er verweist von dort zurück auf »schicken« und »Geschick». Geschicke finden, wie wir wissen, nie ursprünglich und nie in der Gegenwart statt, sondern sie sind das, was immer schon geschickt, geschehen und vergangen ist, »vorüber«: Es sind Geschehnisse, die nie geschehen, sondern immer erst qua Darstellung als Geschichte(n) über sie, nach ihnen, en différance und metaphorisierterweise, ergehen: Erzählungen indes, die selbst oder deren Modi der Darstellung - und das ist das Novum seit Freud - symptomatologisch gelesen werden können. Des weiteren: Die zu erzählenden Geschehnisse sind das, was wiederum Goethe »Begebenheiten« nennt: ein Gegebenes indes, das sich nur als schon Gegebenes und zugleich nie Dagewesenes gibt. Es sind Gaben, die geprägt sind von einer wesentlich temporalen Abwesenheit oder zumindest von Nichtpräsenz. Weshalb, wie man nachträglich riskieren könnte zu setzen, Goethe - und man möchte fast sagen Freud zuliebe oder genauer: Weshalb Eckermann in seinen Gesprächen mit Goethe (englisch Conversations, versteht sich) sie auf den Nenner des Genres »Novelle« als einer »sich ereigneten unerhörten Begebenheit« bringen konnte. Eine solche Begebenheit wird erst durch die nachträgliche Darstellung zum sich als unerhört er- oder begeben habenden Ereignis, und wir werden noch versuchen zu hören, warum. Ereignis: Etwas, das, wie Musil sagt, unerwartet auf einen hereinbricht, und vermutlich eben deshalb auf Äußerung drängt. Was einbricht, wird oder kann indes Effekte gezeitigt haben und sich gemäß derselben Logik nur und erst en différance als Effekt zeigen, nie als es selbst und nie im Jetzt. Ich unterstreiche »zeitigen«, weil die Mehrdeutigkeit dieses Verbs eben jene Verschiebung, Intensivierung und Suspendierung von Zeit - Aufschub von und als Differenz - andeutet. Übrigens benennt Freud Mehrdeutigkeiten oder Polysemien mit dem wiederum mehrdeutigen Wort »Wechsel«. Was einbricht, stellt sich nicht im Präsens dar, sondern »wechselt« die Abfolge der Zeitlichkeit selbst, indem die Gegenwart nicht nur als Gebrochene, sondern als nie Gewesene, nachträglich eingeführt wird. Was einbricht, hinterläßt stimmlose Spuren einer Differenz als différance. Und »zeitigt« nicht dieser Wechsel innerhalb der différance - Effekt des Bruchs im Ereignis - den Widerstand, der sich, vergleichbar dem Schmerz, dem Schock und der Lust, qua Grenze der Darstellbarkeit ent- 
zieht und den Fluß im Erzählen unterbricht? A propos: Just in seiner Darstellung mit dem Titel »Bruchstück einer Hysterie-Analyse«, bekannt als Dora-(Fall-)Geschichte, überschlägt sich Freud an einigen Stellen geradezu mit Metaphern von Fluß, Strom, Strombett gar, Strömungen und nicht zuletzt ist dabei die Rede von deren »Schiffbarkeit« als negierter. Wir kommen darauf zurück.

Zurück zur Geschichte des Ereignisses, jener »unerhörten Begebenheit«, deren erzählerische Lücken und Brüche in Fluß und Logik dem Hörer Freud zur symptomatologischen Lektüre gereichen werden. Denn gewisse Unlogiken fallen ihm auf, »zerrissene Zusammenhänge«, sagt Freud, denn:

»In Wirklichkeit sind die Kranken unfähig, derartige Berichte über sich zu geben. Sie können zwar [...] ausreichend und zusammenhängend informieren, dann aber folgt eine Periode, in der ihre Auskünfte seicht werden, Lücken und Rätsel lassen, und ein andermal steht man wieder vor ganz dunkeln, durch keine brauchbare Mitteilung erhellten Zeiten. Die Zusammenhänge, auch die scheinbaren, sind meist zerrissen, die Aufeinanderfolge verschiedener Begebenheiten unsicher; [...].. ${ }^{4}$

Von Lücken und Brüchen ist die Rede, die Rätsel lassen, von »zerissenen Zusammenhängen«, gleichsam vom Riß eines gewissen Fadens, der das Erzählte doch hätte zusammenhalten sollen, anstatt »die Aufeinanderfolge verschiedener Begebenheiten unsicher« zu machen. Sodann tauchen auffällig viele zeitliche Begriffe wie »Periode«, »dann«, »ein andermal«, »wieder«, »meist « und »Zeiten« auf. Wie Sie erraten haben mögen, betreffen diese »Unsicherheiten«, die Freud zeitweise »vor ganz dunkeln [...] Zeiten« stehen lassen, nicht zuletzt die Figur des HysteronProteron.

Entscheidend wird spätestens hier, daß Freuds Beschreibung der Beschreibung der »Kranken« - oder seine Erzählung über ihre Erzählung zumindest die Frage erlaubt, um wessen logische Unsicherheiten, Brüche und Rätsel es sich handelt, wirft Freuds Text doch nicht minder eben solche auf. Hinzu kommt, daß das Verfahren der Psychoanalyse durchweg im Modus just jener Figur der temporalen Inversion verläuft, die woanders Hysteron-Proteron heißt. Ein wie beiläufiger Nebensatz von Freud sagt es in aller Gelassenheit:

»In dieser, der Reihe nach zweiten, der Zeit nach früheren Szene ist das Benehmen des 14-jährigen Kindes bereits ganz und voll hysterisch« (VI, 106; Herv. U.D.). 
Nicht »voll und ganz«, sondern »ganz und voll hysterisch«. Ein Freudscher Dreher? Eine Version des »vertierenden« Hysteron-Proteron? Sei’s drum. Zurück zu den Geschichten, die Freud gern »Mitteilungen« nennt:

Wie die nachträgliche Darstellung der Begebenheiten - d.h. erst das (Preis-)Geben der Geschichte - die Begebenheiten zu eben solchen (anderen) macht, so läßt erst das Teilen der darstellenden Mitteilung, soweit sie möglich ist, aus dem, was sich ereignet hat, ein Ereignis zum Ereignis werden. Qua notwendiger Mit-Teilung ist ein Ereignis damit nie ein Eignis, nie ein Eigenes, sondern es berührt es nur, und zwar vom Anderen her, von dem/der her, mit dem/der es geteilt wird. Das heißt von dem her, der oder die adressiert wurde, von dem her, woran das Sprechen sich wendet. Denn erst das bezeugende Hören des Anderen läßt aus dem Ereignis ein Ereignis werden, genauer: Es läßt es zum geteilten Enteignis werden. Wobei die Aufnahme oder Rezeption dessen, an den oder an die man sich wendet, nie gesichert ist. Das heißt, der Bruch kann doppelt sein. Und wie Sie vielleicht wissen, kann es immer zum Vorkommnis des Nichtankommens eines Briefs oder Buchstabens kommen. Der Möglichkeit nach bleibt das Ereignis, die Geschichte, weil sie immer nur (anders) passiert und beim anderen (nicht) angekommen sein kann, folglich die Möglichkeit einer doppelten Unmöglichkeit - ohne jede Paradoxie.

Wenn das Teilen, das Äußern und Weitertragen hingegen ein Stück weit glückt, wird aus dem Unerhörten jedoch nicht ein Gehörtes, sondern ein als Unerhörtes hörbares Unerhörtes. Was eine Metapher sein könnte für ein Subjekt.

Fazit zum Mitschreiben, Rekonstruktion ist Konstruktion, aber immer schon/erst en différance. Oder was man Darstellung - und mißverständlicherweise »Repräsentation« - nennt, oder anders: Repräsentation wäre zu denken als Präsentation ohne Präsenz, und sei sie vergangen.

Darstellung als und in Differenz zu dem, was ihr als vermeintlich Dargestelltes vermeintlich vorausging, muß daher auch und gerade in der Psychoanalyse entscheidend sein. Und hier setzt Freud an, horcht auf und schreibt nach, in Form von »Berichten«, wie er sagt: Er läßt sich Geschichten und Geschicke erzählen, schicksalhafte Zu- und Zusammenfälle - und das wäre die Übersetzung des Wortes Symptom, das in Geschichte als »Geschehnis« aber schon steckte.

Freud wird also lernen, dem Erzählen selbst und mehr noch dem darin nicht Erzählten in besonderer Weise zuzuhören, um es zu deuten. Soweit 
so mündlich. Wenn nicht deuten bereits einen Text unterstellt. Dann erst und nachträglich schreibt er auf und macht Geschichten über sogenannte Krankengeschichten von sogenannt Kranken. Er macht Geschichten zu Geschichte. So münden mündlich plurale Singulare zum schriftlichen Singular eines Namens, eines Werks und einer Geschichte, die die der Psychoanalyse ist. Singuläre Plurale führen gleichsam in den Singular ein. ${ }^{5}$

\section{Punkt: Stühle}

Daß die Psychoanalyse mit den Ohren sieht, nimmt nicht Wunder, wenn man ernst nimmt, wie die Grenze zwischen mündlichen Konversationen und schriftlichen Versionen eben gerade in ihrer différance zwischen ihren Fingern zerrinnt. Mit anderen Worten, wenn man ernst nimmt, wie die Grenze zwischen Mund und Hand(-Schrift) durchs Ohr hindurch den Text passiert und sich dekonstruiert haben wird. Denn nichts spricht dagegen, daß wer spricht, (nicht) vom Schreiben und Lesen spricht, liest und schreibt. Dazwischen und währenddessen, davor und danach: Weder das eine (nicht), noch das andere (nicht): das Deuten.

Freud sitzt noch in anderer Hinsicht zwischen den Stühlen: Was er hört und was er nicht sagen hört, schreibt er auf, erster Medienwechsel und Verdopplung der Darstellung. Sodann ist das genre, so es sich denn bestimmen ließe, nicht ohne »Wechsel« und ohne Spagat: Freud, der Arzt, Therapeut und Wissenschaftler, ist weder nur diese drei, noch hingegen stattdessen Schriftsteller oder Dichter.

Fast entschuldigend hatte er 1895 in den »Studien über Hysterie« geschrieben:

"[E]s berührt mich selbst noch eigentümlich, daß die Krankengeschichten, die ich schreibe, wie Novellen zu lesen sind, und daß sie sozusagen des ernsten Gepräges der Wissenschaftlichkeit entbehren. ${ }^{6}$

Anders formuliert: Was man vom Dichter zu erhalten gewöhnt sein mag, macht Freud sich als Novum für die Wissenschaft zu eigen, namentlich besagte »Novelle«. Genauer: das Novum, wenngleich immer NachRicht, kann als treibende Kraft oder Trieb des ersten und ehrgeizigen Aufklärers nicht des Unbewußten, wohl aber über das Unbewußte, genannt werden: Im hörbaren Tenor seiner Angst vor Nichtakzeptanz antizipiert Freud sein Stoßen auf Befremden und schreibt im Vorwort zu 
Dora defensiv dieses, nicht ohne Trotz: Die Rede ist vom Leser, der seine, Freuds Traumdeutung zu lesen, ach, versäumt hat:

»Er wird nur Befremden anstatt der gesuchten Aufklärung in ihr [der Lektüre, U.D.] finden und gewiß geneigt sein, die Ursache dieses Befremdens auf den für phantastisch erklärten Autor zu projizieren. In Wirklichkeit haftet solches Befremden an den Erscheinungen der Neurose selbst; [...]. Das Neue hat aber immer Befremden und Widerstand erregt« (90f.).

Nach Eckermann - dessen Passionen ich Ihnen leider ersparen muß ${ }^{7}$ halten wir fest, daß das Neue, wie Freud suggeriert, Neurose, Wiederholung und Übersetzung alles andere als ausschließt. Zurück zu Freuds Stühlen. Novelle gut und schön, ob neu, unerhört oder nicht. Denn mit Bedacht setzt Freud sich mitunter auch vom Dichterdasein ab. In einer der vielen Passagen, in denen er anläßlich Dora bezeichnenderweise das Problem seiner Darstellung thematisiert, schreibt er:

»lch muß nun einer weiteren Komplikation gedenken, der ich gewiß keinen Raum gönnen würde, sollte ich als Dichter einen derartigen Seelenzustand für eine Novelle erfinden, anstatt ihn als Arzt zu zergliedern. Das Element, auf das ich jetzt hinweisen werde, kann den schönen, poesiegerechten Konflikt, den wir bei Dora annehmen dürfen, nur trüben und verwischen; es fiele mit Recht der Zensur des Dichters, der ja auch vereinfacht und abstrahiert, wo er als Psychologe auftritt, zum Opfer. In der Wirklichkeit aber, die ich hier zu schildern bemüht bin, ist die Komplikation der Motive, die Häufung und Zusammensetzung seelischer Regungen, kurz die Überdeterminierung Regel« (VI, 132f.).

Überdeterminiert ist damit bei Freud hinwiederum das, was man ein genre nennt. Und zu einem solchen sind Freuds »Metapsychologie« im Besonderen und »Theorie« im Allgemeinen - von einer gewissen »French Theory« ganz zu schweigen - noch nicht einmal zu zählen. Die Darstellungen der Psychoanalyse darzustellen, wirft also ein Problem auf oder zwei. Wir bleiben bei denen, die die Anfänge oder »Einführungen in die Psychoanalyse« betreffen, und das heißt bei der Hysterie.

\section{Punkt: Verstimmungen}

Doras Symptome sind klassisch, ermangelt die Hysterie, die unter so vielen anderen auch »Suffocating Mother ${ }^{8}$ genannt wird, doch immer schon gewissermaßen der Luft und Lust, mehr noch und penibler: Es 
fehlt, im Maß des Leidens, nie an einem Exzeß: Weder an hysterischen Symptomen im »Wechsel«, noch aber, und zwar von Seiten der Theorie, an Theorien über und Namen für die Hysterie. Die Elastizität der Ironie besteht hier darin, daß der Exzeß an Theorien über die Hysterie wiederum einem Mangel an Erklärbarkeit oder Dingfestmachbarkeit geschuldet scheint. Hier die multiplen Theorien, da die ebenso zahllosen wie wechselhaften Symptome: Koinzidenzen und Korrespondenzen lassen, wenn sie sich häufen, Verdacht schöpfen und selbst Symptomcharakter erahnen.

Dora: Die Oberfläche sieht abgekürzt so aus: Sie konvertiert zeitweise in tussis nervosa, nervösen Husten also, zeitweise in nervöses Asthma, für das Freud das schönere Wort »Dyspnoe« in Umlauf hält. Da es bei Asthma nicht um einen Mangel an Luft geht, sondern um eine Verkrampfung, durch die ein Zuviel an gestauter Luft entsteht, ist die These vom Mangel im Exzeß - wenn nicht vom Exzeß als Mangel - so paradox nicht. Jene Dyspnoe wird bei Dora bis hin zur Aphonie »gelungen« sein. Daß ihr Wegfall der Stimme sie zum Schreiben brachte, fand Freud zwar logisch, dennoch stolpert er gerade hier. Im übrigen ist die Rede von einem gewissen Fuß, der, bar der Erklärbarkeit, einer Appendizitis auf eben diesem folgt. Kurzum, die Verstimmungen sind beachtlich und entsprechend nicht recht stillzustellen, also hörbar. Freud hört das so:

„Diese [...] Erzählung ist einem nicht schiffbaren Strom vergleichbar, dessen Bett bald durch Felsmassen verlegt, bald durch Sandbänke zerteilt und untief gemacht wird. Ich kann mich nur wundern, wie die glatten und exakten Krankengeschichten Hysterischer bei den Autoren entstanden sind« (VI, 95).

Kein Kommentar zu dieser singulären Metaphernflut, mit der Freud in seiner Erzählung die Erzählung der anderen - hier Dora - beschreibt. Oder aber in Performanz setzt. Diese drei Zeilen verdienten - unter Erstickungsgefahr - ein eigenes close reading. Ökonomisieren wir also: Die Hysterie gilt als »Krankheit durch Darstellung«, »maladie par représentation«. Angesichts der Konstellation von Hysterie und Theorie, respektive Dora und Freud, ist aber immer noch zu fragen, für wessen Darstellung, bzw. für wessen Symptomatik dieser Erzählgestus gilt. Und zwar ist genau so lange zu fragen, wie das Kreuz oder »X« der Übertragung - das X zwischen Dora und Freud - sich der Darstellbarkeit, mithin, der Theoretisierbarkeit sperrt, gerade so, als wäre dieses X die Hysterie »selbst«. Bleibt, mit »ihrer« Darstellung stimmt etwas nicht. Ihre Logik ist nicht stimmig. Freud bringt es auf den Punkt: 
»Die Unfähigkeit der Kranken zur geordneten Darstellung [...] ist nicht nur charakteristisch für die Neurose, sie entbehrt auch nicht einer großen theoretischen Bedeutsamkeit» (VI, 95f.).

Eben. Die Darstellung ist ungeordnet, verstimmt, bis hin zu zeitweiser Aphonie oder auch - Anna O. läßt grüßen - bis zum plötzlichen switch, mit dem im Fall der letzteren sogar gelten kann: French spoken only. Inwiefern aber entbehrt solche Unfähigkeit hinsichtlich der Darstellung "auch nicht einer großen theoretischen Bedeutsamkeit«, wenn nicht dahingehend, daß die Bedeutsamkeit der Theorie »in Wirklichkeit« an den, wie Freud sagte, »Erscheinungen der Neurose selbst [haftet]«, an dem »Neuen«, das Freuds Theorie darstellt?

Die Luftröhrenengpässe und Stimm-, Stimmungs- und Stimmbänderstörungen der Hysterie, die natürlich grundsätzlich weiblich ist - d.h. weiblich nicht nur konnotiert, sondern schlichtweg notiert - könnte indes auch ein Stimmrecht in Anschlag bringen, insofern es fehlt. Auf dem Spiel stünde dabei ein Stimmrecht, das das Zwischen der Geschlechter betrifft, den Zug ihrer Beziehung. Anders gefragt, was in diesem Kontext nichts ändert: $\mathrm{Ob}$ das Wuchern weiblicher Stimmbrüche im $\mathrm{Zu}$ sammenhang damit zu lesen ist, daß das Stimmrecht der Frauen zwar verbrieft, aber eben verbrieft ist. Etwas davon scheinen Freuds Patientinnen ihm zumindest mitteilen zu wollen. Diese ihre Darstellung stellt Freud wiederum dar, er schreibt über sie, über die Hysterie, über diese Krankheit ausgerechnet des exzessiven »Über«. Die Frage, wessen Geschichten oder Darstellungen »drüber« sind, über und unter welchen Tonlagen sie wann und wie zum Anschlag kommen, bleibt bestehen. Freud liefert ein wunderbares Beispiel für die Asymmetrie solcher A- und Polyphonien, die im Stimmrecht zwischen Lehrer und Schülerin wie in Korrespondenz scheinen. Freud ist hier der Dritte, nicht in der Mitte:

»Fräulein Rosalia H., dreiundzwanzig Jahre alt, seit einigen Jahren bemüht, sich zur Sängerin auszubilden, klagt darüber, daß ihre schöne Stimme ihr in gewissen Lagen nicht gehorcht. Es tritt ein Gefühl von Würgen und Schnüren in der Kehle ein, so daß der Ton wie gepreßt klingt; ihr Lehrer hat ihr darum noch nicht gestatten können, sich vor dem Publikum als Sängerin zu zeigen; obwohl diese Unvollkommenheit nur die Mittellage betrifft, so kann sie doch nicht durch einen Fehler ihres Organs erklärt werden; zuzeiten bleibt die Störung ganz aus, so daß sich der Lehrer für sehr befriedigt erklärt, andere Male, auf die leiseste Erregung hin, auch scheinbar ohne jeden Grund, tritt die schnürende Empfindung wieder ein, und die freie Stimmentfaltung ist behin- 
dert. Es war nicht schwer, in dieser belästigenden Empfindung die hysterische Konversion zu erkennen; ob tatsächlich eine Kontraktur in gewissen Muskeln der Stimmbänder eintrat, habe ich nicht feststellen lassen. ${ }^{9}$

Nicht gehorcht, nicht gestattet, nicht erklärt, nicht festgestellt, wohl aber erkannt. Freuds exzessive Frequenz von negativen Bestimmungen führt zu einer besonderen Stimmlage von Wissen: Wer das eine - den Körper mit seinen Insuffizienzen, hier: eine »Kontraktur« - gar nicht erst feststellen läßt, kann umso unschwerer »die hysterische Konversion erkennen«. D.h. das Erkennen der Konversion mag dann, schlicht mangels Alternative, noch ein Spiel des Erratens sein. Die spätere DoraAnalyse - ca. fünf Jahre nach den Studien über Hysterie - läßt den Eindruck von einem solchen Vorgehen nicht entstehen. Bevor wir auf das Zauberwort der »Konversion« zu sprechen kommen, sei folgendes hinzugefügt: Der obige Satz - »so kann sie doch nicht durch einen Fehler ihres Organs erklärt werden « - erfreut sich nämlich höchster Aktualität. Denn das offizielle Hauptkriterium für die Diagnose auf Hysterie, die inzwischen unter anderen Namen kursiert, lautet nach wie vor: »medically unexplainable $\ll$.

Reicht es aber zu sagen, daß die medizinische Unerklärbarkeit eben dazu dient, immer hübsch ein Rätsel zu haben, geklappt auf die Frau, die die sexuelle Beziehung, die es nicht gibt, aber auszutragen hat? Schachmatt der Wissenschaft, das und die mangels Erklärung Pathologisierungen zeitigt? Andererseits: Zurück zu Freud.

Und damit zurück zum Kreuz des Worts vom Rätsel ihrer Hieroglyphen. Freud lernt, hysterische Symptome als Metaphern singulärer Geschichten zu hören. Die rückwärtsvorwärts zu lesen sind, im besagten Modus des Hysteron-Proteron, steht doch zur Debatte, welches Verhältnis zum Wissen vor dem Wissen die Symptome unterhält. Es geht dabei um Symptome, die einen Ausfall, einen Bruch bezeugen, der sich nicht bündig und ordentlich sagen läßt. Kurz, wo die Sprache der Psyche Schiffbruch erleidet - oder, etwas ambivalenter: wo sie vom Gegenüber als »nicht schiffbarer Strom« zur Geltung gebracht wird -, springt im Fall der Hysterie, schreibt Freud, der Körper ein. Das nennt er Konversion, womit jener rätselhafte Sprung von psyche zu soma gemeint ist, bei dem sich eine Umkehrung oder Umdrehung, eine Wendung oder Version, wenn Sie so wollen, einstellt. Wenn es heißt, die Hysterie nähme die Metapher wörtlich, dann ist in dieser Wörtlich- oder Buchstäblichkeit der Körper, der von sich aus ohne Sinn ist, in Anschlag gebracht. Der 
Sinneffekt, den die Metapher auslöst, kommt hier dem somatischen Symptom zu, so daß der Abstand oder Riß, der Körper und Sinn teilt und trennt, kollabiert. Als stellten die Symptome der Konversion ein Supplement von Darstellung mangels Darstellbarkeit dar. Dieser Satz gilt für beide Seiten: die der Hysterie und die der Theorie, er gilt für die eine Seite, dieselbe: den Mangel, geteilt, von »Hystheorie «.

\section{Punkt: (Kon-)Versiert}

Freud hätte es vielleicht glühend interessiert, ob das von ihm neu gemünzte Wort, »Konversion«, auch in Konversationslexika anzutreffen war. Nun ist es aber nicht dieses Wort, sondern eher die Institution dieses genre von enzyklopädischem Wissenstext überhaupt, was Freud im Fall Dora insbesondere zu interessieren scheint. Denn die Frage nach den heimlichen »Quellen«, aus denen Dora ihr sexuelles Wissen schöpft, durchzieht Freuds Text wie ein hintergründiger Faden. Von dem Freud, wie es scheint, regelrecht gejagt ist. Es ist dabei auch nicht ganz ohne Ironie, daß man bis zur Encyclopedia Britannica vordringen muß, um zu erfahren, daß das Brockhaus Konversationslexikon ursprünglich Frauenzimmer-Lexikon heißen sollte. ${ }^{10}$ Indes hätte das Wort »Zimmer« für Freud längst genügt, um die Frau dazuzudenken.

Dora scheint standhafterweise nichts bis wenig darüber zu wissen, woher sie ihr Wissen hat. Freud verfolgt jede Spur. Peu à peu tauchen da Frauen auf, die etwas mehr, als vielleicht zu erwarten war, gelesen zu haben scheinen. Als hinge alles an dem Doppelfaden - Frauen und Lesen. Und damit an der Frage, ob Freuds wissenschaftliches Wissen, nota bene geknüpft an Schrift, am Ende womöglich nicht den Vorsprung hat, der die Distanz und die Position des Arztes als Instanz des unterstellten Wissens stützt. Freud scheint zu befürchten, zumindest ist er in diesem Punkt noch auffälliger wissenshungrig als in anderen, daß seine Wissensquellen womöglich nicht nur Dora, sondern auch Frau K., ja selbst dem Dienstmädchen, d.h., Ironie des Jargons, der »Gouvernante« zur Verfügung standen. Als die Deutung von Doras zweiten Traum sich zuspitzt, betont Freud den Unterschied, wenn es um bestimmte Vokabeln geht: »Im Hintergrunde des Bildes sah man Nymphen« (166), hatte es in Doras bzw. Freuds zweiter Traumerzählung geheißen. Freud gerät außer sich: 
"Das war symbolische Sexualgeographie! Nymphen nennt man, wie dem Arzte, aber nicht dem Laien bekannt, wie übrigens auch ersterem nicht sehr gebräuchlich, die kleinen Labien im Hintergrunde des sdichten Waldes [der im Traum vorkam] von Schamhaaren. Wer aber solche technische Namen wie 'Vorhof brauchte, der mußte seine Kenntnis aus Büchern geschöpft haben, und zwar nicht aus populären, sondern aus anatomischen Lehrbüchern oder aus einem Konversationslexikon« (166f.).

Freud nimmt Doras Kenntnisse überrascht, wenn nicht entgeistert, zur Kenntnis. Wenn hier ein Wanken der Differenz zwischen Arzt und Patientin, mithin, der Status der Wissensinstanz wenn nicht hysterisierend, so doch für Freud bedrohlich »unsicher« wird, dann könnte es durchaus und erneut um jene Differenz gehen, die sich immer schon sowohl als Geschlechterkampf als auch als Mündlichkeit versus Schriftlichkeit (in radikaler Differenz zu écriture, versteht sich) ausfocht. Was zur Komplikation der »Verbrieftheit« des Stimmrechts für Frauen beitragen mag, drängt sich doch der Eindruck auf, als dürfte ihr Lesendürfen und -können keinesfalls Effekte zeitigen. Es ginge, selbst wenn dieses »versus« sich vielleicht nirgendwo so deutlich wie in der Psychoanalyse als dekonstruiertes erweist, in diesem Fall dennoch - oder genau deshalb - am Ende vielleicht gerade darum: Denn die Frage des lesenden Lernens (»Kenntnis aus Büchern«) ist nicht nur eine Frage des wissenden Deutens der Hysterie von seiten der Theorie, sondern geht mindestens auch umgekehrt von der der Hysterie aus. Wenn also beide en différan$c e$, aber auf derselben Seite zu denken wären? Wie anders denn als Lesende könnte die Hysterie als »Kopistin« schlechthin gelten, als die, die ein anderes stets nach-ahmt und übersetzt, als die, die, histrionisch versiert, in ihrer Not sich windet und wendet, vertiert? Wie sonst könnte das, was die Ärzte im 21. Jh. - also relativ kurz nach der »wandernden Bestie« im Unterleib der Frau, von der Aristoteles sprach - unter sich und unter vorgehaltener Hand den »Affen der Krankheiten« nennen, so hartnäckig bestehen? Unmöglich, wenn die Hysterie nichts mit »Abgucken« zu tun hätte, kurzum mit dem, was Lesen, Rezipieren, Aneignen und Umarbeiten heißt? Lesen, versteht sich, nicht unbedingt im engen Sinn, wie Sie richtig erraten haben. Sondern ein Lesen vor, nach und in Konversation, vor, nach und in Geschichten und Lexika, ja selbst hysterische Blindheit kann noch ein Effekt von Lesen sein. 


\section{6. und letzter Punkt: Rätselraten}

»Lösen Sie Kreuzworträtsel!« Mit diesem Rat, der in Wahrheit vielleicht ein Radschlag war, wie wir schließlich sehen werden, wandte sich besagter Lacan also an sein psychoanalytisches Seminar. Der Grund nichts als Metaphern: Um dessen Fähigkeit zum Entziffern der »Hieroglyphen der Hysterie, der Wappen der Phobie, der Labyrinthe der Zwangsneurose « zu trainieren.

Nun ist es vielleicht nicht ganz ohne Ironie, daß man im Modus der Freudschen Nachträglichkeit gesagt haben können wird, daß vielleicht niemand mehr als Freud Lacans Rat, das zu lösen, was Worträtsel oder Wortfamilien zum Kreuz machen kann, gehört und sich zu Herzen genommen hat. Daß Freud die Sache mit dem Kreuzworträtsel also gleichsam avant la lettre ernst nahm, ja buchstäblich nahm, à la lettre, mehr noch: Buchstäblich am Fuß, also am Körper des Buchstabens nahm, au pied de la lettre, namentlich in einer Fußnote. Wie Sie wissen, gehören Fußnoten - genau wie Klammern, Interpunktion, Anführungszeichen und dergleichen rein Zeichenhaftes mehr - zu jenen Formen der Darstellung, die der Schrift im alltäglichen Sinn ebenso wie im Sinn der écriture - jene nichtpräsente Körperhaftigkeit einer eingeschriebenen Spur - vorbehalten ist. Soll man hier also noch einmal verraten, daß just Doras nachziehender Fuß eines ihrer hysterischen Konversionssymptome, also eine Darstellung war?

Kostprobe: Gegen Ende seines Nachworts zur Fallgeschichte Dora schreibt Freud, genauer: legt er Dora folgendes in den Mund, wenn nicht - per os, wie Freud sagt, also oral - gar in den Rachen. Denn genau ohne an dieser Stelle kenntlich zu machen, daß nicht sie, sondern er spricht, d.h. unter Ausfall gewisser Gänsefüßchen, führt Freud seine Deutung in seiner Schrift in folgender Weise ein:

"Die Ablehnung der Begleitung im Traume, sie wolle lieber allein gehen [...], hatte wohl den Sinn: Da alle Männer so abscheulich sind, so will ich lieber nicht heiraten. Dies ist meine Rache» (183f.).

Meine, will sagen Doras, Rache galt, so Freud, ihm, Freud. Ich merke es namentlich und doppelt an, denn nicht von ungefähr kann man hier in Verwirrung geraten. Genau hier - nachdem er obigen »Sinn« ihrer Ablehnung erkannt hat - setzt nun Freud, kurz hinter »lieber nicht heiraten«, nachträglich, fünf Jahre nach dem Fall, eine seiner Fußnoten. Sie resümiert eine Art abschließendes Geständnis, das ineins dem Scheitern 
dieser von Dora vorzeitig abgebrochenen Analyse Rechnung zu tragen versucht - oder aber eine Rechnung aufmacht:

"Je weiter ich mich zeitlich von der Beendigung dieser Analyse entferne, desto wahrscheinlicher wird mir, daß mein technischer Fehler in folgender Unterlassung bestand: Ich habe es versäumt [griechisch: hustereo, ich säume, verfehle, komme zu spät, U.D.], rechtzeitig zu erraten und der Kranken mitzuteilen, daß die homosexuelle (gynäkophile) Liebesregung für Frau K. die stärkste der unbewußten Strömungen ihres Seelenlebens war. Ich hätte erraten müssen, daß keine andere Person als Frau K. die Hauptquelle für ihre Kenntnis sexueller Dinge sein konnte [...].[...] An dieses Rätsel hätte ich anknüpfen müssen [...]. Der zweite Traum hätte es mir dann verraten. Die rücksichtslose Rachsucht, welcher dieser Traum den Ausdruck gab, war wie nichts anderes geeignet, die gegensätzliche Strömung zu verdecken, den Edelmut, mit dem sie den Verrat der geliebten Freundin verzieh und es allen verbarg [...]. Ehe ich die Bedeutung der homosexuellen Strömung bei den Psychoneurotikern erkannt hatte, bin ich oftmals in der Behandlung von Fällen steckengeblieben oder in völlige Verwirrung geraten« (184, Anm. 1, Herv. U.D.).

Wo die eine ein rätselhaftes Symptom vorführt, indem sie nach einem Blinddarmvorfall einen Fuß nachzieht, setzt der andere eine späte Fußnote, in der er sein früheres Scheitern verrät. Wenn es in den buchstäblich >narratierenden` Zeilen dieser Fußnote regelrecht von Rätseln, Raten, Erraten, Verraten und Geraten wimmelt, so vielleicht gerade deshalb, weil das angebliche Rätsel nicht aufgelöst werden konnte und Doras bzw. Freuds Analyse gescheitert war. Im Fall Dora blieb das Rätsel, "X», ein Kreuz. Erst im Maße der zunehmenden zeitlichen Distanz wird Freud gewahr, d.h. erst nachträglich und für diesen Fall $z u$ spät erkennt er, warum die Analyse oder Lösung des Rätsels mißraten war und warum Dora »mich um die Befriedigung gebracht, sie weit gründlicher von ihrem Leiden zu befreien« (185). Lacan hatte folglich recht.

Indes ist nicht auszuschließen, daß Freud hier mehr mitteilt, als das, was er in bewundernswerter Weise vorbuchstabiert: Daß nämlich Deuten ein Lesen und kein Lösen ist, daß es mit den Ohren sieht und sich mehr oder weniger blind zwischen Erraten und errata herumtasten muß. Und daß das Verb »lesen« nicht wissen heißt, sondern ein Raten impliziert, macht das englische Verb to read wunderbar deutlich und sichtbar. Fazit: Noch das beste Fingerspitzengefühl kann Errata nicht zu verhindern wissen, wenn es überhaupt so weit kommt. Denn, Sie ahnten es, was auf beiden Seiten überraschen und sich dafür seinerseits rächen kann, ist das Phänomen der Übertragung, und diese rätselhafte Dimension hatte Freud 
nicht erraten. Wenn seine Deutung - der zufolge Dora Herrn K. liebte und ihm die Nichtheirat nun heimzahlte, indem sie »Racheübertragung« an ihm, Freud, übte, statt an Herrn K. oder ihrem Vater -, wenn diese Lektüre also nicht griff und nicht fußte, dann womöglich deshalb, weil noch etwas anderes darunter lag, husteros. Ich unterstelle einmal, d.h. ich lese später, daß das Entscheidende gerade nicht nur Doras Liebe zu Frau K. war, also das, was Freud ihre »homosexuelle (gynäkophile) Strömung« nennt und die unterschätzt zu haben er eingesteht. Sondern ein weiteres, und zwar gemäß der Logik eines Zwischen, präzise im Schrägstrich zwischen »und« und »oder«: Und/oder das Weitere: Nämlich dasjenige, was zwei Männer, Doras Vater und jener Herr K., in dieser Geschichte wiederholt beteuern, nicht an ihrer Frau zu haben: »Sie wissen, ich habe nichts an meiner Frau«. Warum sollte das, was Dora alias Freud »an« Frau K. hat, kein Text sein, oder weniger noch, ein Buchstabe? Eben jener nämlich, der für Freud an Frau K. »ist«, und der sein, Freuds K., zu doppeln, wenn nicht auszuhebeln droht. Nicht D. wie Dora, sondern K. wie Z., jenes Zimmer- oder Konversationslexikon, das Dora an Frau K. hatte. Und somit über beachtlich mehr Wissen und Versiertheit verfügte, beachtlich mehr zu kopieren und zu träumen wußte, als Freud die längste Zeit erraten hatte.

$\mathrm{Zu}$ spät. Etwas war ihm durch die Lappen gegangen. Dasselbe gilt für meinen Text, ich komme zum Schluß: Frau K. wird der letzte Angelpunkt sein, um den oder an dem sich - das wäre zumindest mein Lesen statt Lösen - noch etwas anderes kristallisiert. Denn das Wort "gynäkophil« hob Freud im letzten Zitat auffällig hervor: Er fügte es, wie zur Erklärung oder um seine Offenheit in Sachen Katzen aus Säcken lassen noch einmal zu demonstrieren, zwischen »homosexuelle« und »Liebesregung« wie zur übersetzenden Erklärung zusätzlich griechisch und in Klammern ein, dazwischen versteht sich. Sie hören den Unterschied: Die Gynäkophilie auf der einen, der Gynäkologe auf der anderen Seite: Im Vorwort vor der Geschichte wird Freud seine Leser aufgeklärt und deutlich gemacht haben: »Ich nehme einfach die Rechte des Gynäkologen - oder vielmehr sehr viel bescheidenere als diese - für mich in Anspruch« (89). Warum also die zusätzliche Einfügung des Wortes »gynäkophil«? Hatte er es vergessen? Die Frau vergessen oder die philia, die eine Art von Zuneigung meint? Und warum das Bestehen auf diesem erudierten und im Gebrauch nurmehr der Schrift vorbehaltenen Fremdwort? Woanders, als er stark machen will, daß sexuelle Dinge, soweit dem Patienten bekannt, ganz unverblümt beim Namen zu nennen und 
diese Sache, das, was Sache ist oder (nicht) sein sollte, geradeheraus auszusprechen sei, da taucht nämlich in ähnlicher Weise, mitten im deutschen Text, völlig unvermittelt und in geradezu verschwindender Nähe zu Anna O.’s French only, ein Sprachenwechsel auf, wenngleich nicht wie hier ins Griechische, sondern ins lebendige und damit im Vergleich zum Altgriechischen eher mündliche Französisch: »»j'appelle un chat un chat « (ich nenne eine Katze eine Katze). Oder auch »pour faire une ommelette il faut casser des oeufs « (um ein Ommelette zu machen, muß man Eier aufschlagen). Soviel zu den Darstellungsformen der Rechte und Pflichten des Gynäkologen, der das griechische Wort »(gynäkophil)« wie einen verspäteten Zusatz zum Einsatz bringt. Und wenn es hier nicht nur um ein männliches Wissen um die Sache der Frauen ginge, der gunaika, sondern, im (maßlosen) Maß von eros und polemos zwischen den Geschlechtern, um die Logik der Differenz zwischen (Gynäko-)philie und (Gynäko-)logie, um die abgründige Differenz zwischen einem gewissen philein, diesem kaum zu übersetzenden »lieben, (sich be-) freunden, gönnen«, auf der einen und der Logik des logos auf der später dann - anderen Seite? ${ }^{11}$ Wenn Freud hier so explizit - wenngleich durch die Klammer subtil verschoben - beide Positionen besetzt, die mündlich-weibliche wie die schriftlich wissend männliche, dann markiert er eben diese Differenz, als suspendierte:

Kurzum, und Schluß mit den Unterstellungen: Gerade weil die Differenz zwischen mündlichem und schriftlichem Wissen in der Psychoanalyse keine stabile ist und nicht sein kann, kann die entscheidende Differenz zwischen Dora und Freud wie Tinte zu verlaufen drohen und in das ausufern, was als hysterische Identifizierung Schule gemacht hat. Freud, der im Vorwort länglich auf seine (im doppelten Wortsinn) »Auslassungen« eingeht, kann nach seiner Erfahrung mit Dora einen Text schreiben, der faßt, was es mit den Lücken im Erzählen, respektive im Wissen und Verdrängen, auf sich hat. Anders gesagt: Wo die Differenz zwischen mündlichem und schriftlichem Text sich als dekonstruiert erweist, mithin, wo der Zugang zu Text und Lektüre verrückt scheint und Metapher spielt, da ändert sich Freuds Schreibduktus plötzlich heftig. Denn Freuds Beteuerung seiner Unkenntnis bzw. Naivität in Sachen Homosexualität der Neurotiker erscheint - ebenso wie das angeblich so große Rätsel um die literaten Quellen der Frauen - plötzlich wie Freuds letzter Schutzwall. Dabei war es in Freuds Dora-Bericht längst - und die längste Zeit - um Schrift im alltäglichen Sinn gegangen: Zuhauf um Bücher, Briefe, Karten, die Dora interaktiv umgaben. Nicht zuletzt während der Zeit, als 
sie keine Stimme hatte. Und es muß sich längst um Lesen und Schreiben - um Schrift eben auch als Metapher - gehandelt haben, denn wie sonst wäre Freuds Frage an Dora anläßlich einer neuen Symptombildung (»Wen kopieren Sie damit?«) überhaupt möglich gewesen?

Angesichts der Frau als Körper als Text - es sind mindestens drei bricht etwas in Freuds Deutung von Doras zweitem Traum wie hinterrücks in seinen Text ein und sucht ihn ganz zum Schluß heim. Als Freud sich als Opfer von Doras Rache fühlt, wechselt, dreht, wendet und kehrt sich sein Text um, nämlich hin zu seiner Rache an Doras Rache. Er nennt sie »Übertragungsrache«, wie wahr. Das »Kreuz«, diesen buchstäblichen Chiasmus der Übertragung, die er »versäumt« hatte, »rechtzeitig« zu »erraten«, wird er später im Nachwort nicht lösen, wohl aber zu lesen geben. Hier ist der Gipfel:

»Es war ein unzweifelhafter Racheakt, daß sie in so unvermuteter Weise, als meine Erwartungen auf glückliche Beendigung der Kur den höchsten Stand einnahmen, abbrach und diese Hoffnungen vernichtete« (175).

Vielleicht liegt darunter noch, daß Freud, gerade durch sein Versäumnis, dem polemos zwischen philein und logos/legein aufsaß, der genau keine Novelle ist, wenngleich durchaus unerhört. Neu könnte vielmehr und vielleicht sein, daß die Hysterie sich ihre Geschichten immer schon und bei allem Leiden nicht ganz ohne Ironie - von der männlichen Philosophie« (!) erzählen ließ, sie also mündlich las, und seine Geschichte mit ihrem Körper kopierte, en différance. Erzählen und schreiben ließ von »dem« Philosophie also, dessen philein einen Vor- und Abhang bildet, weil es nicht präsent zu werden beliebt. Daß, mit einem Wort, sie, die Hysterie, in seiner Geschichte Philosophie las, aber Logosophie hörte. Wogegen sie mit ihrem Körper (an-)las und -schrieb, um das philein, auf das auch Freud sich nachträglich zurückbesann, insistierend rückzuübersetzen. Was der Logik einer gewissen Zeit entbehrt.

„Die philosophia ist mithin ein Suchen nach ... Sie kommt danach, verspätet, nach dem Verlust der Symphonie. Sie trauert um den ursprünglichen Einklang*. Diese Verspätung erotisiert das philosophische Suchen. Von ihr wird die eigentlich philosophische Frage angetrieben; sie läßt das philein zum Streben des Eros werden. Und mit dem Auftauchen dieses von Trauer erfüllten philosophischen Eros sind wir nicht weit entfernt von der Frage des Geschlechts", man könnte sogar sagen: von der Frage nach dem $\mathrm{Ge}^{-}$ schlecht" der Frage. ${ }^{12}$ 


\author{
Mit dem Rat, beim Lesen philosophia einmal durch hysteria (und philo- \\ sophisch durch hysterisch etc.) zu ersetzen, danke ich Ihnen für Ihre Ge- \\ duld.
}

\title{
Anmerkungen
}

1 Der vorliegende Text erscheint - vor oder nach diesem - in einer früheren Fassung auch in: RISS. Zeitschrift für Psychoanalyse. Freud. Lacan, No. 60, 2005 (demnächst).

2 Vgl. Jacques Derrida: »Die différance«, aus dem Französischen übersetzt von Eva Pfaffenberger-Brückner, in: ders., Randgänge der Philosophie, herausgegeben von Peter Engelmann, Wien 1988. Vgl. ders.: »Freud und der Schauplatz der Schrift«, in: ders., Die Schrift und die Differenz, aus dem Französischen übersetzt von Rodolphe Gasché, Frankfurt am Main 1976;

3 Vgl. Friedrich Kluge: Etymologisches Wörterbuch der deutschen Sprache, Berlin, New York 1989, 261 u. 631.

4 Sigmund Freud: »Bruchstück einer Hysterie-Analyse« (»Dora«) [1901/05], in: ders., Studienausgabe I-X Bde. u. Ergänzungsband [StA], Frankfurt am Main 1971, hier StA VI, 95. Alle folgenden Zitate mit Band- und Seitenangaben in Klammern beziehen sich, soweit nicht anders angegeben, auf diese Textausgabe.

5 Der Titel dieser Ringvorlesungsreihe - »Einführungen in die Psychoanalyse« - vollzieht eben diesen Gestus: Er führt vom unbestimmten Plural »Einführungen« - ohne Artikel, also indefinit - hin zum oder ein in den definiten Singular, in »die Psychoanalyse «. Und (v)ersetzt dabei all die Frauen, die sog. »Hysterika«, jene berühmten Anna O.s, Cäcilie M.s, Elisabeth von R.s (Dora kommt später), die doch ihn, Freud, in die Psychoanalyse einführten. Noch 1977 betrauert Lacan ihr Verschwinden mit der Frage, wo sie geblieben seien. Sie wurden ersetzt und verdichtet in einer Abstraktion (»Einführungen «), mithin, durch eine Metapher, die ein Ver- und Abdrängen verraten kann.

6 Sigmund Freud: »Elisabeth v. R...«, in: Josef Breuer, Sigmund Freud, Studien über Hysterie (1895), Frankfurt am Main 1970, 131 (=Gesammelte Werke Bd. I, 227).

7 Vgl. dazu Avital Ronell: Der Goethe-Effekt, übersetzt aus dem Amerikanischen von Ulrike Oudée Dünkelsbühler, München 1993.

8 Auf Deutsch: »[selbst und/oder andere] erstickende Gebärmutter«.

9 Freud, Breuer, Studien über Hysterie, 138, Herv. U.D.

10 Encyclopaedia Britannica: http://www.britannica.com/eb/article?eu=47101.

$11 »[$ Die Philosophie] ist eine Reaktion auf den Verlust [Herv. U.D. ] des ursprünglichen philein, des homologein, des Entsprechens, das im Einklang mit dem logos steht.« Jacques Derrida: Politik der Freundschaft, aus dem Französischen übersetzt von Stefan Lorenzer, Frankfurt am Main 2000, 454. Siehe hierzu insbes. auch 324-329 u. 452-460.

12 Ebd., 455. 


\section{Zum Mißverständnis der weiblichen Sexualität bei Freud}

\section{Kastrationswahrnehmung als symbolische Matrix}

\section{Vorbemerkung}

Es ist ziemlich lange her, daß ich mich mit dem Thema der Sexualität bei Freud und Lacan beschäftigt habe. ${ }^{1}$ Ich habe lange gebraucht, um es auf den Begriff zu bringen und sagen zu können, daß es keine Antwort auf Freuds Frage »Was will das Weib? « gibt. ${ }^{2}$ Daß das Seelenleben eine solche Lücke in seiner Konstruktion vorsehen kann und die Frage nach der Sexualität, speziell nach der weiblichen Sexualität, antwortlos, d.h. negativ ausfallen soll, brauchte für mich seine »Zeit zum Begreifen«. $\mathrm{Zu}$ meiner Entschuldigung könnte ich zwar anführen, daß Sexualität zu den schwierigeren Themen psychoanalytischer Theoriebildung gehört, dennoch war ich in der Folge kuriert davon. Nachdem ich in Universitätsseminaren trotzdem immer wieder damit zu tun bekam, habe ich mir deshalb irgendwann geschworen, das leidige Sujet beiseite zu legen. Ich hatte es satt, immer wieder dieselben Mißverständnisse auszuräumen, die lauteten, daß die Freudsche Sexualitätskonstruktion frauenfeindlich ist, Freud im besten Fall als Kind seiner Zeit deren geistesgeschichtlichen Vorurteilen aufgesessen ist oder Psychoanalyse wissenschaftstheoretisch nicht mehr als ein Konglomerat herrschender Ideologien darstellt. (Wenn dem so wäre, wäre sie zurecht überflüssig.) Irgendwann in den achtziger Jahren ist die Aufregung um das Thema dann verebbt und mittlerweile regt sich kaum noch eine Zuhörerin darüber auf, daß sie als Frau psychisch anders gebaut sein soll als ein Mann. Allenfalls der Penisneid, den Freud wie Lacan Frauen bescheinigen, reizt noch zum Widerspruch: Denn haben Frauen nicht genug Eigenes, sind sie denn 
nicht unabhängig von den Vergleichsmaßstäben, die das andere Geschlecht $\mathrm{zu}$ bevorzugen scheinen? Und schließlich, wen interessiert überhaupt noch das Eine? Ist Sexualität heute nicht vielmehr ein Pluralbegriff, d.h. sind nicht eher die Variationen von Transsexualismus und >gender trouble`, nicht eher Perversionen und die durch die sin vitro fertilisation` völlig undurchschaubar gewordenen Verwandtschaftsbeziehungen die sexuellen Themen der Zeit? Nach dem Motto: Mein Vater ist ein Samenfaden, bzw., wer ist der Vater des durch künstliche Befruchtung erzeugten Kindes, wer die Mutter eines Kindes, das in einer homosexuellen Ehe aufwächst? Die real-biologischen Erzeuger oder die sog. sozialen Elternteile? Das Reizthema »Sexualität« läuft also weiter, es artikuliert sich gegenüber den alten Diskussionen um das Phallushaben oder Phallussein heute nur anders. Doch, so meine Behauptung, grundsätzlich folgt es noch immer denselben Bahnen, denen nämlich, die Freud entdeckte, die Lacan dann strukturmäßig ausgeschrieben und wissenschaftstheoretisch aufgerüstet hat.

\section{Konstruktion der Geschlechterposition bei Freud}

In diesem Sinne möchte ich noch einmal die Positionen der Sexualitätskonstruktion von Freud und Lacan wiederholen und zeigen, daß sie keinesfalls nur veraltet sind. Ich werde dabei den Kastrationskomplex als einen Wahrnehmungskomplex vorstellen, ohne dabei auszusparen, daß Freuds Konstruktion der Weiblichkeit nicht frei von fragwürdigen Wertungen ist, bleibe trotzdem aber dabei, daß in der Freud-Lacanschen Sexualitätskonstruktion auch Gesetzmäßigkeiten des Seelenlebens vorgebracht sind, die, wie die aktuelle Hirnforschung unabsichtlich zeigt, auch weiterhin Gültigkeit besitzen.

Sehen wir uns also die Konstruktion der Geschlechter bei Freud an und lesen noch einmal im Untergang des Ödipuskomplexes und in Einige psychische Folgen des anatomischen Geschlechtsunterschieds. ${ }^{3}$ Freud stellt in diesen Texten von 1924 und 1925 die Behauptung auf, daß sich die Sexualität von Mädchen und Knabe unterschiedlich entwickelt, nicht auf dieselben Anstöße hin erfolgt, nicht demselben Zeitrhythmus gehorcht und, trotz gleicher Organisation durch die Wahrnehmung der Kastration, unterschiedliche affektive Folgen ergibt. Beim Mädchen äußern sie sich in Form von Enttäuschung und beim Knaben im Gefühl von Bedrohung und Angst. 
Wegen der leichteren Verständlichkeit und geringeren Komplexität setzt die Konstruktion der Geschlechter in der Regel mit der Darstellung der männlichen Entwicklung ein, d.h. mit dem männlichen Ödipuskomplex. Bekanntermaßen gilt der Ödipuskomplex als der mythisierte Komplex, in dem der Knabe seine Liebe zur Mutter entdeckt und den Vater als Feind und Rivalen empfindet. In dem Komplex wird weiters geschildert, wie der Knabe aufgrund der das Inzesttabu repräsentierenden Kastrationsdrohung schließlich von seiner Liebe zur Mutter abläßt.

Die Gründe seines Verzichts liegen für den Knaben sozusagen auf der Hand, es geht ihm um die eigene Haut, genauer darum, das narzißtisch besetzte Genitalorgan wenigstens teilweise zu retten. Doch, so Freuds Annahme, die Abkehr vom Liebesobjekt Mutter falle dem Knaben auch nicht übermäßig schwer, denn seine Liebe zum Vater und die davon gestützte Bildung der Gewissensinstanz des Über-Ichs federten seinen Verzicht sozusagen ab. Die Entwicklung der männlichen Sexualität soll darum theoretisch relativ glatt vonstatten gehen.

Die Entdeckung der weiblichen Geschlechtsbildung stellte Freud und die Psychoanalytiker der ersten Generation hingegen vor ungleich größere Schwierigkeiten. Das Diktum, wonach das Material an der Stelle des Mädchens » - unverständlicherweise - weit dunkler und lückenhafter« werde und »unsere Einsichten in diese Entwicklungsvorgänge beim Mädchen unbefriedigend, lücken- und schattenhaft« aussehen, gilt geradezu als Attribut der Freudschen Weiblichkeitskonstruktion. ${ }^{4}$ Die Schwierigkeiten mit der weiblichen Sexualität sind in dem Umstand begründet, daß der weibliche Ödipuskomplex in der Freudschen Theorie eine sekundäre Bildung darstellt. Die Lustverhältnisse sollen nämlich beim Mädchen umwegiger und komplizierter als beim Knaben liegen. Zwar orientiert sich auch das Mädchen bei ihren ersten Lustfindungsaktionen, ähnlich wie der Knabe, zunächst am eigenen Körper. Das Kleinwesen streckt geschlechtsunspezifisch die kleinen Lustfühler begierig in die Außenwelt und untersucht damit alles, dessen es habhaft wird, auf seine Lusttauglichkeit. Es steckt alles in den Mund, auch Teile des eigenen Körpers, weil der für ihn zunächst denselben Stellenwert wie die Umwelt, Außenwelt hat.

Doch mit der primären Lustsuche ist die Ähnlichkeit in der Lustentwicklung von Mädchen und Knabe auch schon zuende, denn für das Mädchen gestalten sich nach Freud die Liebesverhältnisse in der Folge gänzlich anders. Anders als der Knabe soll das Mädchen im Ödipusalter nämlich genötigt sein, vom ersten Liebesobjekt der Mutter zum Vater 
überzuwechseln. Während der Knabe an ein und demselben Lustobjekt, nämlich am Genital und zugleich an der Mutter festhalten kann, die er in der Säuglings- und Pflegeperiode anfangs noch mit nicht sexueller Libido besetzt hatte, soll das Mädchen nach klassisch-psychoanalytischer Auffassung einen Objektwechsel vollziehen.

An dieser Stelle ist ein kurzer Einschub notwendig. Denn, Freud mit Lacan gelesen, gehe ich davon aus, daß Psychoanalyse nicht nur auf die sog. klinische Theorie beschränkt ist, sondern $\mathrm{zu}$ einem wesentlichen Teil auch aus theoretischer Reflexion, d.h. aus Metapsychologie besteht. Ich gehe weiter davon aus, daß die Freudsche Metapsychologie nicht nur eine Begründung klinischer Phänomene liefert, sondern als eigenständige Aussageebene betrachtet werden muß. Bezogen auf die Freudschen Sexualitätskonstruktion ergibt sich damit die Auffassung, daß sie nicht als eine Objektbeziehungstheorie mißzuverstehen ist.

D.h. wenn im Ödipuskomplex von Mutter und Vater die Rede ist, sind damit nicht die konkret-empirischen Beziehungen der kleinen Subjekte und nicht reale Personen angesprochen, die für sie Objektstatus haben. Metapsychologisch betrachtet, sind mit Vater und Mutter vielmehr energetische, lustgeladene Triebkonstellationen und Vorstellungsrepräsentanten bezeichnet.

Ich nenne ein kurzes Beispiel. Eine junge Frau ist der Ansicht, daß sie ihren Freund instrumentalisiere, weil sie ihre Beziehung zu ihm rein sexuell versteht und den Freund auf seinen Organbesitz reduziert haben will. In ihrer Rede stellt sich jedoch heraus, daß sie nicht von dem Mann als Beziehungsobjekt spricht, sondern ihr Thema die Lust ist, die ihr mit ihm zuwenig ist. Ihre Mangelempfindung ist nicht auf den realen Mann beschränkt, sondern hängt an ihrer Vorstellung von einer Lust, die unendlich sein soll, die sie noch nie erlebt hatte und die ihr Phantasma darstellt.

In ähnlichem Sinne malt der Freudsche Ödipuskomplex eine Verschränkung zwischen Personen, phantasmatischen Objektvorstellungen und energetischen Strukturen von allgemeiner und grundsätzlicher Natur aus. Speziell den Gedanken von der überindividuellen Dimension hat Freud weiter mit seinem metapsychologischen Hauptbegriff des Unbewußten ausgearbeitet, mit dem er noch einmal grundlegend bekräftigt, daß auf der Ebene des Psychischen weder Individualität noch Personen die Hauptrolle spielen, sondern hier ein partiell unpersönliches Geschehen abläuft, das persönliche Absichten und Ziele unterläuft. 
Die Ausrichtung auf die unmenschliche Stelle im Anderen der Subjektivität finden wir dann auch im sekundären Ödipuskomplex des Mädchens wieder. Zwar heißt es, daß das Mädchen darin seinen Objektwechsel von der Person der Mutter zum Vaterobjekt vollzieht, wenn sie den Vater zum Liebesobjekt nimmt, weil die Mutter den kindlichen Liebesanspruch nicht erfüllte. Doch im Grunde lesen wir auch hier, daß es weder um die Mutter als Person, noch um sie als Geschlechtswesen geht. Es geht nur um dieses Andere an ihr, an dessen Platz die Mutter, wenn sie denn dazu in der Lage war, steht. Die Mutter als individuelle Objektperson und als Geschlechtswesen taucht erst nach dem Ödipuskomplex auf, erst nachdem sie, vom Vater als zweitem Anderen, symbolisch ersetzt worden ist. Der Systematik halber ist anzumerken, daß auch der Vater in seiner realen Person nicht besser als die Mutter davon kommt. Er tritt nur in einem anderen Moment der psychischen Bildungsgeschichte auf, wodurch er als Person die Position einnimmt, an der das Mädchen die Unerfüllbarkeit ihres Liebesanspruchs erfährt.

Auch an dieser Stelle ist wieder ein kurzer Einschub nötig. Bisher haben wir uns auf wenige Linien der sexuellen Bildung beschränkt, haben metapsychologische und unbewußte Wendungen zusammengetragen, die vielleicht sogar mehr verwirrt als erhellt haben. Trotzdem können wir mit Gewißheit herauslesen, daß die Sexualkonstruktion für die Geschlechter nicht gleich verläuft. In Freuds Beschreibung verläuft der Sexuierungsprozeß dissymmetrisch. 1925 formulierte Freud den Gedanken dahingehend, daß die feministische Forderung nach Gleichberechtigung der Geschlechter in der Sexualkonstruktion nicht weit trage, und er schon seit langem die Vorstellung eines Parallelismus aufgegeben habe. Das Stichwort des Parallelismus taucht auf, und, obwohl es im Ödipuskomplex die Rhythmen der Sexualitätsbildung anzeigen soll, verweist es auch auf Freuds Auffassung vom Verhältnis zwischen Körper und Seele, das in der Sexualität natürlich eine Hauptrolle spielt. Seit der Schrift über Das Unbewußte ${ }^{5}$ ist dieses Verhältnis neu definiert und hat sich Freud offiziell vom parallelistischen Denken verabschiedet.

Auch dieses Ergebnis müssen wir in den Ödipuskomplex eintragen, d.h. wir haben zu verstehen, daß auch im Ödipuskomplex Körper und Psyche nicht im Einklang miteinander stehen, sondern durch das Unbewußte auseinander gerissen sind. Anders gesagt, wir müssen vergegenwärtigen, daß Freuds irritierende Aussagen, wie die vom »morphologischen Unterschied der Geschlechter« oder der Anatomie, die Schicksal der weiblichen Sexualität sein soll, keine positiven Aussagen zur menschlichen 
Anatomie und zum Körper sind. Wo Freud von Morphologie, Anatomie oder von Körper spricht, geschieht das unter den Vorzeichen des Unbewußten, d.h. unter der Einschränkung, daß die Subjekte (ihren) Körper unter bestimmten Bedingungen wahrnehmen, nämlich unter der Bedingung von unbewußten Phantasmen und triebenergetischen Konstellationen. Genau darum dreht es sich auch im Kastrationskomplex.

\section{Der männliche Kastrationskomplex}

Greifen wir aber noch einen weiteren Komplex der Sexualitätskonstruktion heraus, den der Kastration. In Freuds Darstellung des männlichen Ödipuskomplexes hatten wir gesehen, wie die Kastrationsdrohung die anfängliche Lustsuche des Knaben, während der er die Mutter noch libidinös besetzt hält, unterbindet und umlenkt. Fügen wir hinzu, daß die Lustsuche des Knaben damit nicht nur energetisch betrachtet wird. Schon im Kastrationskomplex bekommt sie vielmehr auch einen Sinn zugewiesen. Mit dem Veto zur Kastration wird nämlich die Lust des Knaben von den Erwachsenen, in der Regel von der Mutter, als unpassend und störend deklariert. Sinngebung wird in Gestalt einer Drohung präsentiert. Das Schema ist bei Freud aus dem Zusammenhang des »fort-da«-Spiels ${ }^{6}$ bekannt, von dem aus wir ergänzen können, daß der Knabe mit seiner autoerotischen und ungerichteten Lustsuche bei den Erwachsenen einen wunden Punkt getroffen hat, eine Stelle, an der sie von Unlust markiert sind. Über die Unlust, den Ärger der Erwachsenen, bzw. darüber, daß sie ihrem Ärger Ausdruck verleihen, wird er als Lustwesen und Geschlechtssubjekt hervorgebracht.

Dabei zeigt sich im weiteren auch, daß Lust als psychischer Vorgang ein Verlustgeschäft ist. Lust wird erst da stabil, wo ein Verlust stattgefunden hat, etwas von ihr abgefallen, weggenommen worden ist oder wo, wie beim Knaben, zumindest die Drohung eines Verlustes besteht. Psychische Realität funktioniert als etwas, was das Subjekt von der Realität abzieht, das sich im Entzug konstituiert, heißt es in der Ethik der Psychoanalyse. $^{7}$

Die Verluste, die das Kleinkind in seiner Biographie schon aufzählen kann, Verlust der Mutterbrust bei der Entwöhnung und Verlust an analer Lust durch die Sauberkeitserziehung, haben den nun anstehenden großen Verlust an genitaler Lust schon vorbereitet und das Kleinkind bestenfalls schon gewarnt. Zunächst jedoch schenkt der Knabe der Kastrations- 
drohung noch keinen Glauben, sondern »benimmt [...] sich unschlüssig, zunächst wenig interessiert; er sieht nichts oder er verleugnet seine Wahrnehmung, schwächt sie ab, sucht nach Auskünften, um sie mit seiner Erwartung in Einklang zu bringen $« .{ }^{8}$ Erst nach der Beobachtung des weiblichen Genitals soll ihm der Realitätswert der Drohung glaubhaft werden. Doch selbst da noch sollen sich Dreijährige, wie mir eine Mutter erzählte, noch dazu verstiegen haben, die Schere aus dem Bad zu holen, weil sie wie die kleine Freundin aussehen wollten. Die Wahrnehmung des weiblichen Genitals hat also ihre Voraussetzungen, bis sie zur Schaltstelle des männlichen Kastrationskomplexes werden kann. Wenn dann jedoch die libidinösen Regungen intensiv genug sind und die Drohung entsprechend artikuliert ist, dann wird nach Freud die Wahrnehmung des weiblichen Genitals zum hauptsächlichen und wesentlichen Motor der männlichen Kastration. Die Realität der Kastration geht dann selbst in verschleierten Andeutungen auf und zeigt ihre Wirkungen. So genügte es beispielsweise dem kleinen Wolfsmann und seiner Schwester bereits, daß ihrer englischen Gouvernante der Hut vom Kopf flog, um ihnen die Geschlechtsdifferenz vor Augen zu führen und reicht es aus, daß die Gouvernante ein anderes Mal zu den Nachkommenden sagte: „Schauen Sie doch auf mein Schwänzchen! «9

Die Wirkungen des Kastrationskomplexes auf die Sexualität des Mannes bleiben weiterhin gültig: Abscheu vor dem wie auch immer verstümmelten Geschlecht und Geringschätzung prägen zu weiten Teilen das unbewußte Verhältnis des Mannes zur Frau. Nach dem Motto des auch im Seelenleben des erwachsenen Mannes immer noch regierenden magisch-mythischen Denkens: daß sie verdient haben muß, was man ihr ansieht. Die Strafe für eine ungeheuerliche Tat.

\section{Der weibliche Kastrationskomplex}

Gehen wir nun über zum weiblichen Kastrationskomplex. Nach Freud nimmt die Ausbildung des weiblichen Geschlechts einen gänzlich anderen Verlauf als die des Mannes. Freud geht von einem unterschiedlichen zeitlichen Verlauf der Geschlechtskonstruktion von Mann und Frau aus und macht den sexuellen Unterschied grundsätzlich von einem Wahrnehmungsvorgang abhängig. Im konkreten Fall des Mädchens soll das so aussehen, daß sie anders als der Knabe nicht in den Ödipuskomplex wie in einen Hafen einläuft und sich weder durch die narzißtisch- 
libidinöse Besetzung eines eigenen Körperorganteils, noch durch die Liebe zum gleichen Geschlecht geleitet und geschützt, in die ÜberIchbildung retten kann. Die psychische Ausgangslage des Mädchens ist radikaler und härter, sie sieht ganz und gar bodenlos aus. Denn Bedingung der weiblichen Sexualbildung ist nach Freud die Kastration. Weibliche Geschlechtsbildung nehme von der Kastration aus ihren Ausgang. D.h. von Anfang an soll das Mädchen mit der Wahrnehmung konfrontiert sein, daß sie im Vergleich mit dem anderen Geschlecht >zu kurz gekommen sei, daß es ihr fehle. Wir müssen diese, als reales Geschehen verstandene, unannehmbare Annahme dahingehend relativieren, daß es sich hier um Wahrnehmungsvorgänge handelt, in denen der Zugang zur Außenwelt und zu Außenobjekten im Blick steht. D.h. wir dürfen den Vorgang nicht als ein empirisch-phänomenales Geschehen mißverstehen. Trotzdem spielt sich der Wahrnehmungsvorgang da ab und malt Freud ihn konkret da auch aus. »Abgeschnitten?«, fragt der Bub das Mädchen, »Nein«, antwortet die, »immer so gewest! «.

Die Startbedingungen von Junge und Mädchen sind ungleich, in einem Punkt jedoch räumt Freud dem Mädchen einen Vorteil ein. In der Promptheit ihrer Reaktion auf die »unvermeidliche Tatsache« der Kastration überflügelt sie den Knaben bei weitem. Wo sich der Knabe zunächst unschlüssig benimmt, wenig interessiert, seine Wahrnehmung abschwächt oder abwartet, ob sie sich nicht doch noch mit seinen Erwartungen in Einklang bringen läßt, ist das Mädchen »im Nu fertig mit ihrem Urteil und ihrem Entschluß. Sie hat es gesehen, weiß, daß sie es nicht hat, und will es haben «. ${ }^{10}$

Im Hinblick auf Auffassungsgabe und Geschwindigkeit hängt das Mädchen den kleinen Knaben in der sexuellen Entwicklung deutlich ab, die Auswirkungen sind bekanntlich bis in die Pubertät hin spürbar. Erst danach sind Mädchen und Knabe im gleichen Takt und können gemeinsam das Lied von den trotzdem nicht gelingen wollenden Geschlechtsverhältnis singen.

Doch bis dahin hat die Annahme der Kastration das Mädchen vor ungleich größere Schwierigkeiten als den Knaben gestellt. Denn die Anerkennung ihrer Kastriertheit soll Freud und Lacan zufolge die Voraussetzung dafür sein, daß sich Weiblichkeit überhaupt entfaltet. Sofern es dazu denn kommt. Denn neben der Umsetzung dieser besten aller Möglichkeiten kennt die Freudsche Psychoanalyse auch die Versionen, in denen das Reale der Kastration auf weniger triebökonomische Weise umgesetzt wird. So gibt es den Fall, daß das Mädchen angetrieben von 
der Hoffnung auf Änderung der Bedingungen und getrieben von der Wut auf die Ungerechtigkeit ihres Schicksals aus dem phallischen Vergleichen nicht herauskommt und im sog. Männlichkeitskomplex stecken bleibt. Die Psychoanalyseliteratur kennt zahlreiche Beispiele dieser Art, man denke nur an die »Masken der Weiblichkeit«, in denen Joan Rivière in dem gleichnamigen Aufsatz ihr eigenes Triebschicksal schildert, d.h. ihr Schwanken zwischen der Konkurrenz mit dem Mann und ihrer Gewissensnot, weil sie es wagte, den Umstand der Kastration in Frage zu stellen. ${ }^{11}$

Als prekärste Form von Weiblichkeitskonstruktion gibt es dann auch den Fall, daß das Reale der Kastration als unerträglich wahrgenommen und darum verleugnet wird. Hier hat sich das kleine Mädchen in der Überzeugung versteift, wider allem Anschein doch einen Phallus zu besitzen, weshalb es dann gezwungen ist, sich zu benehmen, als ob sie ein Mann wäre. Sie spielt Mann, weiß aber, daß sie es nicht ist. Eine schizophrenisierte Situation, eine psychotische Situation.

Auffällig an Freuds Konstruktion ist der Raum, den die Kastration in der Sexualentwicklung des Mädchens einnimmt. Für das Mädchen soll die Kastration Ausgangspunkt und Scharnier der weiblichen Sexualbildung sein, der gegenüber der Ödipuskomplex eine nur untergeordnete Rolle spielt. Freud faßt den Ödipuskomplex in der weiblichen Geschlechtsentwicklung entsprechend als sekundäre Bildung auf.

Die Folgen für die Entwicklung der Geschlechtsidentität beim Mädchen sind beträchtlich. Denn die Vorgänge des Objektwechsels lassen das Mädchen affektiv und identifikativ ohne Handhabe. Anders als der Knabe hat das Mädchen nichts, womit sie ihre erste Liebesenttäuschung mit der Mutter mildern könnte. Zwar wird auch der Knabe in seinen Erwartung an die Mutter und deren phallische Macht enttäuscht, hat aber in der Identifizierung mit dem Vater als gleichem Geschlecht Rückendeckung und kann sich zudem mit dem Besitz des Organs trösten. Dem Mädchen hingegen bleibt nach Freudscher Auffassung nur ein zweiter Versuch. Sie muß sich an das andere Geschlecht, an den Vater als neuen Hoffnungsträger wenden, ohne bei ihrem Neustart bei der Mutter, dem gleichen Geschlecht, Unterstützung zu finden. Ganz im Gegenteil, die Beziehung zwischen Mutter und Tochter ist nach Freud vorrangig durch Feindschaft bestimmt, in den Augen des Mädchens bleibt die Mutter nämlich für seine Penislosigkeit mehr oder weniger lebenslang verantwortlich. Die Ausgangsbasis der weiblichen Sexualbildung, die Kastration, trifft das Mädchen also mit unvergleichlich größerer Härte als den 
Knaben. Auch der weitere Verlauf des Ödipuskomplexes soll daran nichts ändern, denn ihr Liebesanspruch findet auch bei dem zweiten Anderen, dem Vater, nicht die gewünschte Erfüllung. Das Reale der Kastration ist für das Mädchen unumgänglich. Die Anerkennung der narzißtischen Wunde, die Narben des Kastrationskomplexes bleiben ein Kennzeichen der weiblichen Sexualität. Sie müssen aber nicht ihr Stigma sein.

Angesichts solch abschreckender Sexualkonstruktion verwundert es nicht, daß schon in der Pionierzeit der Psychoanalyse Freuds Version von Weiblichkeit auf heftigen Widerspruch stieß. So verfochten E. Jones, M. Klein und die Londoner Schule die Gegenthese, wonach weibliche Sexualität primär vom Ödipuskomplex ausgehe und dieser keine sekundäre Bildung darstellt. Die Parallelentwicklung der Geschlechter sollte damit gerettet sein. Nicht so für Freud, für den die dissymmetrische Entwicklung das Schibboleth der Sexualkonstruktion bleibt und, wie ich meine, wegen des Unbewußten nicht anders lauten kann.

Betrachten wir noch einmal den Kastrationskomplex im allgemeinen. Kastration ist ein Vorgang, in dem durch die Wahrnehmung des Genitals des anderen Geschlechts Mädchen und Junge mit dem Körper des Anderen konfrontiert werden. Als ein Wahrnehmungskomplex eröffnet die Kastration, in Anlehnung an eine Bemerkung Freuds, die psychische Realität, wenngleich Wahrnehmung selbst bereits einen psychischen Vorgang darstellt und nicht die Annahme einer physischen Realität hinter dem Seelenleben erübrigt. ${ }^{12}$ Als Wahrnehmungskomplex ist Kastration mithin ein wesentlicher Baustein der Konstruktion von Geschlecht im psychischen Sinne, d.h. im Sinne des Unbewußten.

Mit dem Komplex sind wir tief in die Probleme von Körper und Seele, Psyche, Geist eingetaucht. Denn mit der Kastrationswahrnehmung beginnt das Subjekt innen und außen, physisch und psychisch zu unterscheiden, und zwar am Körper des Anderen. Das Innen/Außen-Schema als Differenzschema wird körperlich verankert und wirkt sich auf die Lustökonomie der kleinen Individuen aus. Die Grenzziehung bringt eine Umlenkung von Lust zustande. Lust wird nicht mehr unterschiedslos am eigenen Körper oder anhand von Außenobjekten erfahren, die polymorph-perverse Unentschiedenheit in der Lustempfindung hat ein Ende. Soweit wirkt sich der Komplex auf beide Geschlechter unterschiedslos aus.

Im Kastrationskomplex tragen sich aber auch die geschlechtsspezifischen Differenzen ein. Dabei kommen mehrere Faktoren zusammen; 
einerseits wirkt sich die visuelle Art der unbewußten Repräsentierung einer Objektvorstellung aus, andererseits die kulturellen Wertungen, die allein sichtbaren Objekten Existenz zubilligen. Das Resultat ist bekannt, im Hinblick auf sexuelle Identität, meint der Knabe, zu haben, was das Mädchen nicht hat, bzw. unterstellt, daß dem Mädchen fehle, was er objekthaft zu haben scheint. Vor dem Hintergrund der unbewußten Struktur und ihrer Gesetzmäßigkeit unterliegt er damit allerdings einer Täuschung, da seine Vorstellung vom Haben nur die Ebene der Phänomene berührt und im Psychismus dagegen das Gesetz des Verlustes herrscht, demzufolge die Habensposition denn auch unterminiert ist.

Die Kastrationswahrnehmung besagt also gleichzeitig, daß die imaginäre Wahrnehmung von Körper, von Geschlechtskörper im objekthaften Sinn, immer unter einem Teilverlust von realem Körper abläuft. Die hysterischen Patientinnen Freuds hatten von Anfang an vorgeführt, daß Körper nur in der Vorstellung, nur in der symbolischen Übersetzung existiert und nur unter dem Verlust von anatomischer, realer Grundlage psychisch repräsentierbar ist. Wie Frl. Elisabeth von R. aus den Studien über Hysterie verhielten sie sich schon immer, als ob Anatomie nicht existierte.

Sexualität, so lautet also die Quintessenz des Kastrationskomplexes, ist eine Konstruktion, die um körperliche Verluste herum angeordnet ist. Erst aufgrund von Verlusterfahrung wird auch der Körper von Mädchen und Knaben zum Lust- und Geschlechtskörper. Soweit in Andeutungen Freud und Lacan zum Aufbau der Sexualität.

\section{Kastration als Verlust}

Ich gebe zu, daß diese Konstruktion nicht unbedingt Sympathien erregt. Doch selbst wenn man nach gut zwanzig Jahren Lacan den Mangel satt haben könnte und das ganze Konfliktdenken zum Teufel wünscht, kommt man nicht an der Freudschen Verlustkonstruktion vorbei. Heute ist es die Neurophysiologie, die bekräftigt, daß Seele eine Verlustkonstruktion darstellt. In dem Sinne spricht zumindest der Bonner Neurophysiologe D. Linke davon, daß der Aufbau der Nervenzellen im Gehirn, dem mittlerweile ja die Gesamtleistung der Lebensvorgänge zugeschrieben wird, keineswegs kontinuierlich vorzustellen ist, als reine Anhäufung von Nervenzellen und deren Verschaltungen, sondern ein Vorgang ist, der unter Verlusten vor sich geht. Erstaunlicherweise soll ein 
Teil der Verluste genau in die Zeit fallen, in der laut psychoanalytischer Theorie der Ödipuskomplex und Kastrationskomplex ausgebildet werden. Neurophysiologen wollen jedenfalls herausgefunden haben, daß etwa zwischen dem dritten und fünften Lebensjahr, allerdings geschlechtsunspezifisch, ein Ausfall von Milliarden von Nervenzellen stattfindet und messen diesem Phänomen der sog. »neuronalen Verschwendung« konstruktive Bedeutung zu. Sie betonen weiters, daß sich dieser Nervenzellenverlust keineswegs als ein Defizit auswirke, sondern sind im Gegenteil der Auffassung, daß damit eine Ordnung hergestellt wird, die in der bis dahin gegebenen Nervenzellenkomplexität noch nicht möglich war. Es kommt Ordnung in die Vielfalt der Nervenzellen, anders gesagt, Selektion ermöglicht gutes Funktionieren. ${ }^{13}$ Auch für Neurophysiologen kommt also Ordnung durch Verlust von Körper zustande, Nervenzellen sind schließlich Körperelemente.

Ich habe nun keineswegs die Absicht, die Ergebnisse der Neurowissenschaft als Wahrheitsbeweis für die Psychoanalyse heranzuziehen. Im Gegenteil, ich bin der Meinung, daß die psychoanalytische Theorie darauf verzichten kann, daß sie nicht auf Verifikation durch fremde Wissenschaft angewiesen ist, und daß Beweise überhaupt nicht ihre Sache berühren. Trotzdem frappiert die neurologische Entdeckung, weshalb ich sie hier anführe, allein um damit zu sagen, daß es noch andere Wissenschaften gibt, die verlusthaft konstruieren und in denen eine Konstruktion durch Verlust nicht notwendigerweise defizitär aufgefaßt wird. Die Neurowissenschaft gibt aber noch einen anderen Hinweis. Die Kognitionspsychologie hat nämlich herausgearbeitet, daß Wahrnehmen keineswegs nur ein passiver Vorgang ist, sondern im Gegenteil höchst schöpferisch genannt zu werden verdient. Beim Wahrnehmungsvorgang wird ein Gegenstand nämlich nicht einfach abgebildet. Wahrnehmen setzt den Gegenstand überhaupt erst als solchen zusammen. Praktisch wie theoretisch kann man nicht davon ausgehen, daß die Dinge, so wie wir sie sehen, überhaupt existieren. Der Konstruktivist Ernst von Glasersfeld nennt die Annahme, daß es Dinge wirklich und tatsächlich gibt, geradezu die Tragik des neuzeitlichen abendländischen Denkens. Wir haben uns also zu vergegenwärtigen, daß die Dinge durch unsere Wahrnehmung überhaupt erst geschaffen werden.

Ganz in dem Sinne hatte auch schon der Neurobiologe J.Y. Lettvin 1959 herausgefunden, daß die Wahrnehmung eines Frosches auf nur drei spezifischen Eckdaten beruht: auf Größe, hell/dunkel-Kontrast und Bewegung. Sind diese Daten gegeben, erkennt der Frosch sein Beutetier, die 
Fliege, öffnet das Maul und schnappt zu. Dabei muß das Ding, die Fliege für den Frosch noch nicht einmal wirklich existieren, das Bild der Fliege oder eine Attrappe reichen schon aus, daß er das Maul öffnet und zu schnappen beginnt.

Was soll das im Zusammenhang mit dem Kastrationskomplex besagen? Der Kastrationskomplex ist mit Sicherheit kein vergleichbarer Vorgang, ist aber doch ein Vorgang, der zentral von Aktivität und Selektivität bestimmt wird, und er ist ein Vorgang, in dem im Resultat ein neues Ding, Objekt zustande kommt. Auch im Kastrationskomplex wird ein Objekt zusammengesetzt, das zuvor noch nicht existierte. Dieses Objekt entsteht, wie wir sahen, in der Außenwelt und zwar am Körper des anderen Geschlechts. Dieses Objekt ist nicht ganz und gar neu, denn auch vor der Kastrationswahrnehmung gab es für das Mädchen den Knaben als ein Gegenüber, als Spielgefährten oder Bruder vielleicht, ähnlich wie vielleicht der Knabe das Mädchen als kleinen >Nebenmensch` wahrgenommen hat. Doch im Kastrationskomplex ist die Wahrnehmung des anderen jetzt umkonstruiert worden. Das Mädchen sieht den Knaben nun in seiner sexuellen Gestalt, als sein Gegengeschlecht. Ähnlich wie bei dem Insekt verläuft auch der menschliche Wahrnehmungsvorgang dabei selektiv. Allerdings gibt bei der Gestaltwahrnehmung der kleinen Subjekte weder ein Hell/Dunkel-Kontrast, noch ein Bewegungskriterium den Ausschlag. Das Kriterium ist für sie vielmehr eines der schlechten Gestalt. Mädchen und Knaben nehmen wahr, daß zwischen ihnen ein Reales interveniert, störend ins Spiel gekommen ist, das weder die eine noch der andere besitzt. Wo der Knabe dieses Reale dem Anschein nach zu haben scheint, unterliegt das Mädchen erst gar nicht solchem Irrtum, zumal für sie die Identifizierung damit auch eine Gefahr darstellen würde. Denn anzunehmen, etwas zu sein, was sie phänographisch, als Phallus, nicht hat, d.h. entweder ganz Frau oder tatsächlich kastriert zu sein, würde sich für sie als nackte Katastrophe erweisen.

Streng genommen ist das Kriterium der Differenz etwas, was beiden Geschlechtern fehlt. Das menschliche Geschlechtswesen-Subjekt reagiert nicht wie die Fliege auf die Gestalt, die gut zum Essen, zum Fortpflanzen oder Lieben ist. Das menschliche Individuum, so jedenfalls Lacan, reagiert da, wo es hapert und antwortet vor allem auf das >Vallustding ‘ namens Phallus. Dieser Verlust ist angesprochen, wo den kleinen Subjekten der Körperverlust in Gestalt des Anderen gegenübertritt. Sei es dergestalt, daß das Mädchen wahrnimmt, daß sie nicht hat, was der Junge zu haben scheint, sei es, daß dieser kombiniert, daß der Körper des 
Mädchens dem gleichkommt, was man ihm angedroht hat. Im Rahmen des Kastrationskomplexes wird die Verlusterfahrung durch den Phallus verteilt und wird die Geschlechtszugehörigkeit nach der Wahrnehmung des Fehlenden etikettiert. ${ }^{14}$

Dabei fällt im weiteren auf, daß der Wahrnehmungsvorgang im Kastrationskomplex kein ausschließlich imaginäres Geschehen ist. Denn das Veto der Mutter zur autoerotischen Lustsuche des Knaben skizzierte gleichzeitig den Rahmen, der seine Wahrnehmung symbolisch abstützt. Anders als bei der Fliege ist der Wahrnehmungsvorgang beim kleinen Menschenindividuum von Anfang an symbolisch eingebettet. In diesem Rahmen gibt die Wahrnehmung der Kastration dann schließlich den Hinweis darauf, daß eine Dimension von Unerkennbarem im Spiel ist eine Dimension, die sich phänographisch und konkret aber nur am anderen Geschlecht manifestiert. An sich hat diese Dimension keinen Ort, an sich ist sie nur ein Teil des unsichtbar ablaufenden, energetisch getragenen Psychischen. D.h. im Kastrationsvorgang geht es auch um das Wahrnehmen eines ansonsten Unwahrnehmbaren, um die Wahrnehmung des Dings des Unbewußten eben. (Was die Psychoanalyse als Disziplin betrifft, so unterscheidet sie sich damit von der neurophysiologischen Konstruktion und ähnelt, wenn man sie erkenntnismäßig einordnen will, noch am ehesten einer ästhetischen Theorie.)

\section{Schlußbemerkung}

Ich komme zum Schluß. Ich hoffe ausreichend gekennzeichnet zu haben, daß Freuds Sexualitätskonzept keine Psychologie darstellt, d.h. nicht als Beschreibung von empirisch beobachtbaren Gegebenheiten oder Phänomenen gelesen werden kann. In der Psychoanalyse geht es weder um das volle, pralle Menschenleben, noch ausschließlich um die Subjekte. Die Annahme des Unbewußten besagt im Gegenteil, daß die Beziehungen zwischen den Individuen, insbesondere zwischen denen der Geschlechtswesen, ihrer Tendenz nach auf ein Scheitern zulaufen. Der Grund dafür ist in der Tendenz des psychischen Apparats angelegt und liegt am Unbewußten, mit dem dem menschlichen Individuum die Dimension eines Unpersönlichen und Unmenschlichen eingetragen ist, die individuelle Zielsetzungen unterläuft, einschließlich der, die dem eigenen Überleben dient. 
Eine narzißtische Kränkung zweifellos, was die Psychoanalyse den Gebildeten unter ihren Verächtern damit zumutet. Trotzdem war genau dieses die Botschaft, die mich an der Psychoanalyse immer fasziniert hat. Daran hat sich bis heute nichts geändert. Was mir mittlerweile allerdings fragwürdig erscheint, ist der Tenor der Freudschen Aussagen zur weiblichen Sexualität. So komme ich nicht mehr an der Feststellung vorbei, daß in der Geschlechtskonstruktion Freuds ein moralischer Ton mitschwingt. In Freuds Beschreibung heißen Frauen unvollständige, verkürzte und verstümmelte Geschöpfe. ${ }^{15}$ Freud spricht von den narzißtischen Wunden als den psychischen Folgen des Penisneids und verwendet vor allem in wertender Weise Attribuierungen des weiblichen Geschlechts. So nennt er den Ort der weiblichen Lust verkümmert und dann - er zögert selbst es auszusprechen, kann er sich der Idee aber doch nicht erwehren -: »daß das Niveau des sittlich Normalen für das Weib ein anderes « ${ }^{16}$ sei als für den Mann. Die Frau, die erst in zweiter Linie zum Ödipuskomplex kommt, hat nämlich keinen Grund ihn wieder zu verlassen. Die Kastration ist ja die Voraussetzung dafür, daß sie überhaupt ödipal strukturiert wird. Für die Bildung eines weiblichen ÜberIchs gibt es Freud zufolge also kein Motiv. Wenn in Fällen von Männlichkeitskomplex doch eine Gewissensinstanz zustande kommt, ist diese nie »so unerbittlich, so unpersönlich, so unabhängig von seinen affektiven Ursprüngen, wie wir es vom Manne fordern «. ${ }^{17}$

Der strukturellen Ebene seiner Aussagen zur Weiblichkeit zum Trotz, kommt Freud nicht daran vorbei, Frauen Charakterzüge zuzusprechen, die unabweisbar Wertungen sind. Daß das Weib weniger Rechtsgefühl zeige als der Mann, weniger Neigung zur Unterwerfung unter die großen Notwendigkeiten des Lebens und sich öfter von seinen Gefühlen leiten lasse. Freuds Abwertungen sind im Grunde verwunderlich, weil sein Urteil auf einer anderen Ebene, auf der Ebene des Intellekts sehr wohl positiv ausfällt. Für die geistigen Potenzen seiner Hysterikerinnen hatte Freud stets Lob und Respekt übrig. Ob bei Frl. von R., bei Frau Cäcilie oder Dora stets betonte er, daß ihre Symptome u.a. durch die Besonderheit ihrer Lebensumstände geschaffen waren, nämlich durch den Umstand, daß sie >andere geistige Nahrung gebraucht hätten`, die ihnen die Gesellschaft des 19. Jahrhunderts aber vorenthielt. Wertschätzung der weiblichen Intellektualität und moralische Entwertung ihrer Charakterstärken fallen bei Freud auseinander. Sagen wir, daß Freuds Position zum Ergebnis der eigenen Konstruktion zumindest zwiespältig ist. 
Und schließlich der Differenzmaßstab, der Phallus. Als Maß des Realen und als Libido ist er Teil der genialen Konstruktion der Freudschen Metapsychologie, hauptsächlich aber der Lacanschen Theorie des S-I-R. Er ist genial, weil unter nur seiner Bedingung die Möglichkeit besteht, Subjektivität überhaupt subjektiv zu denken.

Trotzdem weht von daher ein >odor del uomo<, den auch Lacans Aufsatz nicht verwischen kann, auch wenn er noch so sehr herausstreichen wird, daß der Phallus kein Objekt und kein Körperteil ist. Mir zumindest ist es ehrlich gesagt, immer noch nicht gelungen, einen Grund dafür zu finden, warum der Phallus am konkreten Mann dran hängen soll.

\section{Anmerkungen}

1 Der Aufsatz stützt sich u.a. auf einen Vortrag, den ich am 19. Januar 2004 im Kasseler Forum für die Psychoanalyse gehalten habe.

2 Edith Seifert: Was will das Weib? Zu Begehren und Lust bei Freud und Lacan, Weinheim 1987.

3 Sigmund Freud: »Der Untergang des Ödipuskomplexes«, in: ders., Studienausgabe [StA] Bde. I-X u. Ergänzungsband, Frankfurt am Main 2000, hier StA V, 243-251. Freud: »Einige psychische Folgen des anatomischen Geschlechtsunterschieds«, in: ders., StA V, 253-266.

4 Ebd., 249, 250.

5 Freud: »Das Unbewußte«, StA III, 119-173, Frankfurt am Main 1989.

6 Freud: »Jenseits des Lustprinzips«, StA III, 213-272, Frankfurt am Main 1989.

7 Jacques Lacan: Das Seminar Buch VII. Die Ethik der Psychoanalyse, Textherstellung Jacques-Alain Miller; Norbert Haas, Hans-Joachim Metzger (Hg.), übersetzt von Norbert Haas, Weinheim, Berlin 1996, 60.

8 Freud, »Einige psychische Folgen«, StA V, 260.

9 Freud: »Aus der Geschichte einer infantilen Neurose« (»Der Wolfsmann«), StA VIII, 139, Frankfurt am Main 2000.

10 Freud, »Einige psychische Folgen«, 261.

11 Joan Rivière: »Weiblichkeit als Maske«, in: Lili Gast (Hg.), Joan Rivière. Ausgewählte Schriften, Tübingen 1996.

12 Freud: »Brief an Juliette Boutonnier«, in: ders., Gesammelte Werke, Bde. I-XVIII, hier Nachtragsband 672, Frankfurt am Main 1987.

13 Detlef Linke: Einsteins Doppelgänger. Das Gehirn und sein Ich, München 2000.

14 Vgl. Lacans Bahnhofs-Apolog. Im Unterschied zu Freud argumentiert Lacan hier symmetrisch, denn Junge wie Mädchen nehmen gleichermaßen wahr, beim jeweils anderen angekommen zu sein. Die Symmetrie ist hier Ausdruck der topologischen Erörterung. Vgl. Jacques Lacan: »Das Drängen des Buchstabens im Unbewußten oder die Vernunft seit Freud«, in: Norbert Haas, Hans Joachim Metzger (Hg.), Jacques Lacan: Schriften II, übersetzt von Chantal Creusot, Nobert Haas, 15-55, hier 24f.

15 Freud, »Einige psychische Folgen«, $261 \mathrm{f}$.

16 Ebd., 265.

17 Ebd. 


\section{Zur Übertragung -}

\section{Der Analytiker als Schatzkästchen}

Beginnen möchte ich, indem ich von einem Ereignis spreche, das mich und andere als einen großen, traurigen Verlust getroffen hat, das ist der Tod von Jutta Prasse. Jutta Prasse war eine feinsinnige, mutige Psychoanalytikerin, die zu den ersten gehörte, die sich in Deutschland für die Psychoanalyse Lacans eingesetzt haben, für ihre Praxis und ihre Weitergabe, und sie hat ihren Einsatz über mehr als 25 Jahre bis zu ihrer schweren Krankheit gehalten. Die Schriften, die sie hinterlassen hat, empfehle ich Ihnen zur Lektüre, es sind intensiv gearbeitete Aufsätze zur Psychoanalyse ${ }^{1}$, literarische Übersetzungen aus dem Italienischen, Französischen und dem Englischen sowie Übersetzungen psychoanalytischer Arbeiten (Jacques Lacan, Lou Andreas-Salomé). In der Nacht zum 27. Mai ist Jutta Prasse gestorben, ihr möchte ich meinen Vortrag widmen.

Zur Übertragung - der Analytiker als Schatzkästchen, so mein Titel. Warum ist mir wohl diese Metapher eingefallen, die den Analytiker/die Analytikerin ein Schatzkästchen nennt? Vielleicht habe ich, ohne daß es mir selbst ganz bewußt gewesen wäre, an ein >Sesam, öffne Dich` gedacht, das auf seine Weise in der Analyse bedeutsam ist, ein >Sesam, öffne Dich` des Mundes, ein `Sesam, öffne Dich` des Unbewußten. Vielleicht habe ich auch an das geheimnisvolle Kästchen gedacht, das ich als Mädchen einmal geschenkt bekam, als Liebesgabe meines ersten Verehrers. Ob etwas von dieser Gabe, die mir damals voll unergründeter, lustvoll lockender, aber auch unheimlicher Versprechen schien, sich für mich in der Psychoanalyse fortgesetzt hat? Die Analyse als ein Ort, 
an dem Schätze geborgen werden, an dem die flüchtigen Worte bewahrt und beschützt werden sollen? In der die Sprache als eine Gabe, die uns vom Anderen her kommt, betrachtet wird, und die dem Vermögen, aber auch den Mißgeschicken und dem Scheitern des Sprechens Raum gibt. Und wahrscheinlich habe ich auch an dieses kleine Kästchen, das Geheimversteck oder die Hosentasche gedacht, in der Kinder ihre Fundstücke als kostbaren Schatz aufbewahren, die kleinen, schmuddeligen Dinge, die sie auflesen: 1 Stück Bindfaden, tote Regenwürmer, eine Murmel, ein Schnipsel Silberpapier, den entstellten Vers eines Reimes oder ein paar schmutzige Wörter. Ich möchte heute abend dieses Kästchen ein wenig öffnen ${ }^{2}$, um auch Ihnen Lust und Neugier zu machen auf ... die Psychoanalyse. Oder ist es die Büchse der Pandora, mit der wir es zu tun bekommen, und das Kästchen vielmehr Ort des Unheimlichen?

Ich werde also zur Übertragung in der analytischen Situation sprechen: über ihren Rahmen, als das, was sie begrenzt, aber auch erst ermöglicht, über ihre Bedingungen, wie sie zustande kommen kann, ferner wird von dem die Rede sein, was die Analyse in Gang hält und was in ihr geschieht, und nicht zuletzt werde ich einige Fäden aus der Geschichte der Psychoanalyse aufnehmen.

Beginnen möchte ich, zum zweiten Mal, indem ich Ihnen den Ball zuspiele, und Sie bitte, darüber nachzudenken, mit welcher Frage sich ein Subjekt wohl an einen Analytiker wendet? Vordergründig wird die Frage durch den Wunsch oder den Anspruch bestimmt, eine Analyse zu machen, es gibt verschiedene Klagen, Leiden, Symptome, vielleicht auch einen aktuellen Anlaß - das alles ist ernst zu nehmen, ist aufmerksam zu hören, aber es ist noch nicht das, was ich im Sinn habe. Mir geht es bei meiner Frage an Sie nicht um diese verschiedenen Artikulierungen, sondern im Sinn habe ich gewissermaßen die eine Frage - es mögen zwei, vielleicht sogar drei Fragen sein, die eine Frage verzweigt sich im Verlauf ... -, die unbewußt am Anfang einer jeden Psychoanalyse steht. Welche Frage also trägt das Subjekt, das sich an einen Analytiker wendet, in sich - zumeist ohne sie zu wissen, ohne sie formulieren $\mathrm{zu}$ können? Sie lautet etwa so: >Ich komme zu Dir, Analytiker, weil Du ein Schatzkästchen für mich bist. Ich komme zu Dir, Analytiker, weil ich in Dir etwas vermute, ein Wissen, vielleicht auch ein Vermögen, das mir bei meinem Weg hilft, mein Stolpern/mein Leiden anzuerkennen, meine Wahrheit zu suchen und zu erfinden, und, vielleicht, etwas MehrGenießen (plus-de-jouir, Lacan) leben zu können.く 
Natürlich ist meine Frage an Sie eine rhetorische, denn ich werde Ihnen einige Gedanken dazu vortragen, zu denen ich bei der Vertiefung in diese Frage gekommen bin. Aber nicht nur. Denn die Überlegung, was Sie wohl auf mich, d.h. auf mein Thema heute abend ebenso wie auf die Themen meiner Vorredner übertragen haben, also welche Frage, welcher Wunsch Sie dazu gebracht haben mag, in diese Vorlesung zur Psychoanalyse zu kommen, hat mich bewegt. >Was, oder vielleicht besser: wovon möchte jemand wohl hören, der etwas über die Psychoanalyse hören möchte , habe ich mich gefragt, und ich vermute, daß dieses Interesse an der Psychoanalyse, also am Unbewußten, zugleich ein Interesse an Ihrem eigenen Unbewußten ist. >Was hat es auf sich mit diesem Unbewußten, mit meinem Unbewußten, mit meinem unbewußten Begehren`, so etwa könnte Ihre Frage lauten. Und dann ist dieses Interesse nicht so fern von demjenigen, das den einen oder anderen zum Analytiker gehen läßt. Sie sehen also, mein Vortrag heute abend ist eine Antwort auf Ihre Frage, die Sie allerdings gar nicht gestellt haben. Und damit sind wir mitten im Thema der Übertragung, die ebenfalls häufig eine Antwort des Subjekts auf eine Frage darstellt, die erst im Laufe der Analyse herausgearbeitet werden kann.

Die Hoffnung, die sich an den Analytiker richtet, die zugleich das ist, was dem Analytiker unterstellt wird, wäre also: >Kannst Du mir sagen, Analytiker, wer ich bin? Manchmal hat die Frage eine etwas andere Betonung: >Kannst Du mir sagen, Analytiker, warum ich leiden muß?< Und vielleicht noch: >Kannst Du mir sagen, Analytiker, was mein Begehren ist und wie ich es in meinem Leben (meinem Leben als Sprachwesen und damit als einem Mangelwesen), wie ich es in meinem Leben mehr-genießen kann?^Dies sind, wie ich meine, die Grundformen der Frage, die jemanden in eine Psychoanalyse bringen. Und ich möchte diese Fragen stark machen gegenüber einer Tendenz, die die Psychoanalyse nur noch als analytische Therapie ansehen möchte (so anerkennenswert das in anderer Hinsicht auch sein mag), in der die Psychoanalyse also nur noch der Krankenversorgung im Rahmen der Bereitstellung von Richtlinienbehandlungen dient. Wohlgemerkt, es muß keinen grundsätzlichen Widerspruch zwischen beiden Möglichkeiten geben, Freud sah sogar die allgemeine Anerkennung und Bereitstellung der Psychoanalyse als einer von der Allgemeinheit finanzierten Behandlungsmethode als eine gewisse Utopie an, aber er war sich der damit verbundenen Gefahren bewußt, nennen möchte ich nur die wiederum 
sehr aktuell gewordene Medizinalisierung der Psychoanalyse, die Freud schon damals als größte Gefahr für sie betrachtete.

Die Fragen aber, die das Subjekt bewegen, die es möglicherweise zu einer Analyse bewegen, sind in erster Linie und in vollem Sinne Fragen, die das Rätsel der eigenen Existenz und das Begehren betreffen. Es sind Fragen, mit denen wir alle uns herumzuschlagen haben, weil es Fragen sind, die unsere Existenz als Sprachwesen, parl'-être ${ }^{3}$, sagt Lacan, uns auferlegt. Indem wir zu Sprachwesen geworden sind und jedes Mal wieder, wenn wir Sprechwesen sind, uns also in die Sprache, ins Sprechen hineinbegeben, reißt die Sprache in uns einen Mangel, einen Mangel an Sein auf ${ }^{4}$, der ein grundlegender, nicht zu stillender und nicht stillzustellender Mangel ist, der das menschliche Subjekt konstituiert. Dieser Mangel ist cause de la désir ${ }^{5}$, Ursache des Begehrens, er nimmt das Subjekt in eine unabschließbare Bewegung von einem Objekt zum nächsten hinein, um dieses Begehren zu erfüllen - was nicht mit einer Befriedigung gleichzusetzen ist - oder, zumindest und vielleicht sogar mehr noch, um ihm Antwort zu geben.

Gewiß, die Antworten auf das Begehren und den ihm zugrundeliegenden Mangel fallen in unterschiedlicher Weise neurotisch, auch psychotisch oder autistisch oder noch anders aus und sind mit je unterschiedlichem Genießen, aber auch mit Leid verknüpft - und dort ist dann möglicherweise der Ort, an dem ein Subjekt sich an einen Analytiker wendet -, sofern es dem Analytiker oder der Psychoanalyse als solcher seinen Wunsch zuträgt, anträgt, überträgt. Der Analytiker wiederum darf an diesem »Treffpunkt $\aleph^{6}$ nicht fehlen oder taub sein, d.h. dieser Frage des Subjekts gegenüber haben wir als Analytiker vor allem anderen Verantwortung.

Dem, was uns vom Unbewußten des anderen her angetragen wird, haben wir analytisch zu begegnen, das bedeutet, daß wir darauf mit unserem Begehren zu antworten haben: der existentiellen Frage des Subjekts nach seinem Begehren, die es in die Analyse hineinträgt, geben wir Resonanz mit unserer Antwort, die im aufmerksamen Hören und in dem Begehren zu analysieren besteht. Griechisch analysis bedeutet: Auflösung, auch: Befreiung, Erlösung; im Blick auf die Psychoanalyse also auch: sich von etwas lösen können.

Wie nun wird die analytische Situation eingeleitet? Es gibt, das ist bekannt, ein bestimmtes Setting. Der Analysant/die Analysantin liegt auf einer Couch, der Analytiker sitzt hinter dieser, der Blickkontakt ist unterbunden, denn die Aufmerksamkeit ist auf das Hören, das Sprechen 
und das Gesprochene gerichtet. >Sagen Sie alles, was Ihnen durch den Sinn geht $\iota$, lautet die Grundregel für das Subjekt, das auf der Couch Platz genommen hat (Peter Müller hat sie Ihnen in seinem Vortrag eingeführt und den Schub, den das >alles` auslöst, kommentiert ${ }^{7}$ ). Ich werde in meinem Vortrag den Akzent auf das `Sagen Sie legen, um zu betonen, daß es in der Analyse um eine Sprechbeziehung geht, um ein Band zwischen Analysant und Analytiker, das sich durch das Sprechen knüpft und durch es Bestand erhält - das Sprechen, das unauflöslich mit dem Schweigen verbunden ist. Ich nenne damit auch die Sprache als das dritte Element der analytischen Situation, sie strukturiert die Beziehung. Die Übertragung ist dieses Sprechen, spitzt Lacan zu. Sie ist aber ebenso auch das, wodurch der Rand des Unsagbaren berührt wird. Sie spielt sich im Sprechen eines Analysanten zu einem Analytiker ab, insofern er ihm ein unbewußtes Wissen unterstellt, ein Wissen vom Unbewußten, das, Sie haben es nun schon mehrfach in dieser Vorlesungsreihe gehört, immer ein sexuelles ist, das mit dem Eros, dem Begehren des Subjekts zu tun hat. Lacan schreibt: "Sowie man annimmt, der Analytiker wisse, nimmt man auch an, er nehme teil an der Begegnung mit dem unbewußten Begehren ${ }^{8}{ }^{8}$ Als dieses Subjekt, dem Wissen unterstellt wird, ermöglicht er ein Sprechen desjenigen, der in die Analyse kommt, Sprechen, das von einem unbewußten Begehren getragen ist. In diesem Sprechen wird als Übertragung das aufgefaßt, was sich vom Unbewußten hören läßt.

Die Übertragung ist ein zentrales Konzept der Psychoanalyse, verschiedene psychoanalytische Schulen haben jedoch divergierende Konzeptionen der Übertragung ausgearbeitet. Die Übertragung ist keineswegs nur ein theoretisches Konzept, sondern hat unmittelbarste Auswirkungen auf die Handhabung der Praxis der Analyse, sie wendet beide, Theorie und Praxis, einander zu wie ein Scharnier. Die unterschiedlichen Übertragungstheorien haben daher unterschiedliche Gestaltungsweisen der analytischen Praxis und der analytischen Beziehung zur Folge.

In Lacans Übertragungsbegriff ist der Bezug zum Unbewußten des Analysanten wesentlich, nicht so sehr der zur Person des Analytikers. Er nimmt damit Freuds Übertragungsbegriff, wie er ihn in der Traumdeutung ausgearbeitet hat, auf und arbeitet ihn weiter aus. Wie kann uns etwas Unbewußtes überhaupt bewußt werden, da doch die unbewußte Vorstellung grundsätzlich nicht bewußtseinsfähig ist, fragt Freud dort, und antwortet: die unbewußte Vorstellung »[vermag] dort [im Vorbewußten, Verf.] nur eine Wirkung zu äußern [...], indem sie sich mit einer 
harmlosen, dem Vorbewußtsein bereits angehörigen Vorstellung in Verbindung setzt, auf sie ihre Intensität überträgt und sich durch sie decken läßt. Es ist dies die Tatsache der Übertragung [...] «. ${ }^{9}$ Die unbewußte Vorstellung kann durch die Assoziation mit einer bewußtseinsfähigen, sie deckenden, zum Bewußtsein passieren und so eine Wirkung äußern. (Veranschaulichen läßt sich diese Übertragungsbewegung leicht am Beispiel der Spinnenphobie: Möglicherweise kennen Sie jemanden, der sich vor Spinnen schrecklich fürchtet, oder haben es gar am eigenen Leib erfahren. Dem Bewußtsein allerdings ist keinerlei Grund erkennbar, warum jemand vor diesem harmlosen kleinen Tierchen Furcht haben sollte, allein die Frage, was durch die Spinne gedeckt wird, welche unbewußten Vorstellungen sich ihr assoziiert haben, kann die Furcht erhellen und auflösen.)

Die Grundform der Übertragung läßt sich gemäß Freud in einer zweifachen Bewegung beschreiben, sie besteht zum einen in der Aktualisierung von etwas Unbewußtem (Vergangenem), indem es sich mit einer bewußtseinsfähigen Vorstellung alliiert, assoziiert; zum anderen geschieht eine Verschiebung auf die Person des Analytikers, indem sich die Rede des Analysanten an diesen wendet. Wohlgemerkt: es geht bei Freud und auch bei Lacan um eine Verschiebung auf den Analytiker, der Übertragungsbegriff aber macht nicht seine Person selbst zum Inhalt. Andere Übertragungskonzeptionen rücken die Person des Analytikers ausdrücklich in den Mittelpunkt; seine Wahrnehmungen und Gefühle werden als Reaktionen auf die Übertragung verstanden, diese sogenannte >Gegenübertragung ` gilt als Erkenntnisinstrument und Diagnostikum für die unbewußte Psychodynamik. Lacans sehr fruchtbare, kritische Auseinandersetzung mit bestehenden Übertragungskonzeptionen führte ihn u.a. dazu, einen Schnitt vorzunehmen, der etwa die Register des Symbolischen, des Realen und des Imaginären voneinander zu unterscheiden erlaubt; oder anders, wie der Dichter »schied er zwischen der Struktur und dem Gefühl. Der Dichter nannte die Struktur >Poesie` und das Gefühl nannte er $>$ Liebe $\ll{ }^{10}$

Das, was übertragen wird, ist nicht das Unbewußte selbst, sondern es macht Wirkungen, vornehmlich in der Rede des Analysanten, manchmal auch in seinem Verhalten. In der Analyse haben wir es mit diesen Effekten des Unbewußten zu tun, und um Ihnen eine Vorstellung von der angesprochenen Intensität zu geben, die bei der Übertragung unbewußter Vorstellungen oder Wünsche mitverschoben wird, d.h. von der Quantität der psychischen Libido sowie der energetischen Betrach- 
tungsweise psychischer Vorgänge, zitiere ich Ihnen die bei Freud sich anschließende Stelle:

"Diese unbewußten Wünsche betrachte ich [...] als immer rege, jederzeit bereit, sich Ausdruck zu verschaffen, wenn sich innen Gelegenheit bietet, sich mit einer Regung aus dem Bewußten zu alliieren, ihre große Intensität auf deren geringe zu übertragen. Sie teilen diesen Charakter der Unzerstörbarkeit mit allen anderen wirklich unbewußten, d.h. dem System Ubw angehörigen seelischen Akten. Diese sind ein für allemal gebahnte Wege, die nie veröden und den Erregungsvorgang immer wieder zur Abfuhr leiten, so oft die unbewußte Erregung sie wiederbesetzt." ${ }^{11}$

Ich komme zurück zur analytischen Situation: Ebenso wie um die Sprechbeziehung zwischen Analysant und Analytiker geht es in der analytischen Situation um die Beziehung zum Sprechen überhaupt, zum eigenen Sprechen, das in der Analyse aufgrund der ihr eigenen Regeln sowie der Arbeit des Analytikers auf eine andere Weise aufgenommen und zu Gehör gebracht wird als in der >normalen Unterhaltung geschieht, indem das Gesagte vom Analytiker durch die Arbeit des Hörens und des Entzifferns des unbewußten Textes dem-/derjenigen, der/die auf der Couch liegt, als etwas anderes zurückerstattet wird. Darin, daß wir das Gesprochene ein wenig anders hören, eine kleine Verschiebung vornehmen - oder vielleicht zurücknehmen, und damit einen anderen Sinneffekt oder auch, dem Witz, dem Traum vergleichbar, einen Un-Sinn-Effekt hervorbringen, etwas vom Anderen des Subjekts, von seinem Unbewußten hören lassen, liegt die Möglichkeit, etwas aufzulösen, zu öffnen, etwas Neues auch in dem, was wiederholt wird, zu hören. Was nun will die Analyse erreichen, was sind ihre Ziele? Es geht ihr um die Erinnerung von Verdrängtem, um das, was bisher nicht erinnert werden konnte, weil es zu schmerzhaft oder zu unangenehm oder zu obszön usw. war. Es geht der Analyse aber noch um einen weitergehenden Schritt, der vielleicht weniger bekannt ist, nämlich um das, was Lacan die reconnaissance ${ }^{12}$, Anerkennung, genannt hat, durch die sowohl die Produktion wie auch der Wunsch nach solchen unbewußten Phantasien bei sich selbst angenommen und anerkannt werden kann. Das bedeutet dann auch, daß solche Phantasien nicht weiterhin abgewehrt werden müssen, also etwa projektiv vermeintlich beim anderen entdeckt oder somatisiert werden müssen etc., sondern als eigene betrachtet und eben anerkannt werden können. Die Anerkennung ist sogar der schwierigere Teil der analytischen Arbeit; in dem Text Erinnern, Wiederholen und Durcharbeiten beschreibt Freud einen ähnlichen Zusammenhang, er 
nennt ihn »durcharbeiten«: »Es ist aber jenes Stück der Arbeit, welches die größte verändernde Einwirkung auf den Patienten hat und das die analytische Behandlung von jeder Suggestionsbeeinflussung unterschei$\operatorname{det}^{13}{ }^{13}$ - also etwa der Hypnose.

Die `Abstinenz « und die >gleichschwebende Aufmerksamkeit` bestimmen die Haltung des Analytikers, das ist das règlement zwischen beiden an der Analyse Beteiligten. Ich lese bei Freud:

"Das kranke Ich verspricht uns volle Aufrichtigkeit, d.h. die volle Verfügung über allen Stoff, den ihm seine Selbstwahrnehmung liefert, wir sichern strengste Diskretion zu und stellen unsere Erfahrung in der Deutung des vom Unbewussten beeinflussten Materials in seinen Dienst. Unser Wissen soll sein Unwissen gutmachen, soll seinem Ich die Herrschaft über verlorene Bezirke des Seelenlebens wiedergeben. In diesem Vertrag besteht die analytische Situation. (14 $^{14}$

Interessanterweise spricht Freud hier von einem (mündlichen) Vertrag, der Form nach also dem juristischen Bereich zugehörig, den die beiden Subjekte miteinander schließen, mit dem sie sich selbst und auch wechselseitig an Verpflichtungen und einzuhaltende Regeln binden. Seinem Inhalt nach ist dieser Vertrag dem Bereich des Rechts allerdings vollkommen fremd. In der analytischen Situation aber stellt sich, trotz der miteinander getroffenen Übereinkunft und entgegen dem ausgesprochenen Wunsch des Subjekts, seine Analyse zu unternehmen, etwas ein, was diesen Vertrag stört, wodurch er gebrochen wird. Dieser Vertragsbruch stellt sich regelmäßig ein, er fehlt in keiner Analyse; wovon ich spreche, ist der Widerstand gegen die Psychoanalyse. Er gehört offenbar zu ihrer eigenen Struktur. Der Widerstand macht sich ganz wesentlich an der Schwierigkeit, die Grundregel einzuhalten, bemerkbar, das heißt, als Störung, als Unterlaufen des frei assoziierenden Sprechens; die Einfälle stocken oder Assoziationen stellen sich zwar ein, werden aber abgewiesen, Phantasien und Gedanken werden aus mancherlei Gründen und Rücksichtnahmen verschwiegen. Freud erklärt die Grundregel seinen Patienten folgendermaßen:

»hre Erzählung soll sich doch in einem Punkte von einer gewöhnlichen Konversation unterscheiden. Während Sie sonst mit Recht versuchen, in Ihrer Darstellung den Faden des Zusammenhanges festzuhalten und alle störenden Einfälle und Nebengedanken abweisen, um nicht, wie man sagt, aus dem Hundertsten ins Tausendste zu kommen, sollen Sie hier anders vorgehen. Sie werden beobachten, daß Ihnen während Ihrer Erzählung verschiedene Gedanken kommen, welche Sie mit gewissen kritischen Ein- 
wendungen zurückweisen möchten. Sie werden versucht sein, sich zu sagen: Dies oder jenes gehört nicht hierher, oder es ist ganz unwichtig, oder es ist unsinnig, man braucht es darum nicht zu sagen. Geben Sie dieser Kritik niemals nach und sagen Sie es trotzdem, ja gerade darum, weil Sie eine Abneigung dagegen verspüren. ${ }^{15}$

Angesprochen ist hier die Selbstkritik, genauer: die (unbewußte) psychische Zensur, die sich regelmäßig einschaltet, wenn wir uns bemühen, diese Grundregel wahr zu machen, und zwar um sie zu unterlaufen. Im Text Freuds folgt eine schöne, berühmte, auch wissenschaftstheoretisch interessante Stelle, auf die ich nicht näher eingehen kann, die ich Ihnen aber nicht vorenthalten möchte: »Sagen Sie also alles, was Ihnen durch den Sinn geht. Benehmen Sie sich so, wie zum Beispiel ein Reisender, der am Fensterplatz des Eisenbahnwagens sitzt und dem im Inneren Untergebrachten beschreibt, wie sich vor seinen Blicken die Aussicht verändert«. ${ }^{16}$

Was aber unterscheidet den Analytiker etwa vom weltlichen Beichtvater, fragt Freud weiter, der doch auch aufmerksam zuhört und dem Beichtenden Erleichterung bringen möchte. Der Unterschied ist groß, denn - und hier wird es spannend - nun gibt Freud eine nähere Bestimmung dessen, was er unter Aufrichtigkeit in der psychoanalytischen Situation versteht: »wir wollen von ihm nicht nur hören, was er weiß und vor anderen verbirgt, sondern er soll uns auch erzählen, was er nicht weiß $\ll^{17}$.

Um ein Paradox wie dieses - daß, wer eine Analyse machen will, erzählen soll, was er nicht weiß - wird es noch mehrmals gehen, und zwar nicht nur aus Spaß an der witzigen Logik des Paradoxes, sondern auch notwendigerweise, denn die Logik des Unbewußten kann am ehesten mittels eines Paradoxes, eines Witzes, einer Andeutung oder einer poetischen Formulierung zur Sprache kommen. Mittels der analytischen Grundregel kommen also Analysant und Analytiker zu dem, was - beide - nicht wissen:

"Er soll uns nicht nur mitteilen, was er absichtlich und gern sagt, was ihm wie in der Beichte Erleichterung bringt, sondern auch alles andere, was inm in den Sinn kommt, auch wenn es ihm unangenehm zu sagen ist, auch wenn es ihm unwichtig oder sogar unsinnig erscheint. Gelingt es inm, nach dieser Anweisung seine Selbstkritik auszuschalten, so liefert er uns eine Fülle von Material, Gedanken, Einfällen, Erinnerungen, die bereits unter dem Einfluß des Unbewußten stehen. ${ }^{18}$ 
Die > freie Assoziation $<$ zeigt dann, daß wir eben nicht frei sind in unserem Sprechen, sondern daß es unbewußt determiniert ist. In den hörbar werdenden Assoziationen überträgt das Subjekt im Sprechen seine unbewußten Signifikanten, seine unbewußten Strukturierungen, und das bedeutet sich selbst. Die >Assoziation< führt mithin direkt zum Subjektbegriff Lacans.

Wiederholt diskutiert Freud die verschiedenen Schwierigkeiten bei der Einhaltung der Grundregel, insbesondere »unter der Herrschaft der Widerstände versagt der Gehorsam gegen sie, und für jeden kommt irgend einmal die Zeit, sich über sie hinauszusetzen. Man muß sich aus seiner Selbstanalyse daran erinnern«, so Freud, »wie unwiderstehlich die Versuchung auftritt, jenen kritischen Vorwänden zur Abweisung von Einfällen nachzugeben. Von der geringen Wirksamkeit solcher Verträge, wie man sie durch die Aufstellung der psychoanalytischen Grundregel mit dem Patienten schließt, kann man sich regelmäßig überzeugen, wenn sich zum erstenmal etwas Intimes über dritte Personen zur Mitteilung einstellt $\ll .{ }^{19}$ Freud bezieht sich hier auf einen hohen Regierungsbeamten, der zu ihm kam, um eine Analyse zu machen. Er gab aber immer wieder Diskretion und die Wahrung von Dienstgeheimnissen als Grund an, um bestimmte Einfälle nicht auszusprechen, - die Analyse ist unter solchen Umständen nicht möglich. »Der Patient weiß, daß er alles sagen soll, aber er macht aus der Diskretion gegen andere eine neue Abhaltung « er möchte seine Einfälle nicht sagen, oder es will ihm nichts einfallen -, dies ist eine Form des Widerstandes also, und Freud ist in diesem Punkt streng: »Was immer die Fortsetzung der Arbeit stört, ist ein Widerstand «. ${ }^{20}$ Anders gesagt, alles kann zum Widerstand verwendet werden, auch oder sogar gerade Verhaltensweisen, die wir gemeinhin als anständig oder rücksichtsvoll anderen gegenüber empfinden. Freuds Strenge steht hier, ganz wie er versprochen hat, >im Dienste` des Unbewußten des Analysanten, die Analyse soll ihm verlorene Bezirke des Seelenlebens wiedergeben: »Die psychoanalytische Behandlung muß sich über alle Rücksichten hinaussetzen, weil die Neurose und ihre Widerstände rücksichtslos sind «. ${ }^{21}$ Hinzufügen möchte ich, daß es, wenn ich von der Strenge der Psychoanalyse spreche, nicht um das Bild einer strengen Person geht, sondern um eine Notwendigkeit, die sich aus der Sache ergibt, der >Chose`, die Lacan an den Grund der Ethik gestellt hat.

Was ist das Rücksichtslose der Neurose und ihrer Widerstände, das sie gegen die Einhaltung der Grundregel, gegen ein "frei assoziierendes« oder »volles Sprechen $\aleph^{22}$, wie Lacan es ausdrückt, richtet? Und sollte 
man diesen Widerständen nicht doch einen Platz einräumen? »Es ist sehr merkwürdig«, fährt Freud fort, »daß die ganze Aufgabe unlösbar wird, sowie man die Reserve an einer einzigen Stelle gestattet hat. Aber man bedenke, wenn bei uns ein Asylrecht, zum Beispiel für einen einzigen Platz in der Stadt, bestände, wie lange es brauchen würde, bis alles Gesindel der Stadt auf diesem einen Platz zusammenträfe «. ${ }^{23}$ Von welchem Gesindel ist hier die Rede, dem, unerbittlich, nicht ein einziger Platz und keinerlei Asylrecht zugestanden wird? In meiner Lesweise wird hier in zweierlei Hinsicht von Gesindel gesprochen; zum einen drückt diese Metapher selbstverständlich nicht eine politische Meinung Freuds aus, sondern sie zeigt - die Umgehensweise des Analysanten mit sich selbst, sie zeigt das Rücksichtslose der Neurose, d.h. sie spricht davon, wie die psychische Zensur bestimmte Einfälle und Zusammenhänge durch ihre kritische Bewertung zu Gesindel werden läßt. Gesindel-Wünsche, auch Geschwindel-Gedanken also, mit denen er oder sie am liebsten nichts zu tun haben möchte, um nicht unversehens selbst in die Nähe solchen Gesindels zu rücken. Zum anderen zeigt Freud, wie der psychische Apparat in solchem Fall verfährt: Er bewertet den entsprechenden Einfall, als verbrecherisch etwa, als sexuell-obszön, er zensiert oder bestraft ihn, weist ihn vom Zugang zum Bewußtsein ab, er unterdrückt, isoliert oder verdrängt ihn. Im Blick auf das Wissen, von dem eben die Rede war, das gesagt werden soll, obwohl es nicht gewußt wird, zeigt sich so, daß es ein Wissen ist, von dem man nicht wissen will. Von dem man sich sogar, wie Lacan formuliert, mit Abscheu abwendet.

Wer wird mit dieser Frage, worin die Rücksichtslosigkeit der Neurose bestehe und ob ihren Widerständen nicht doch ein Platz eingeräumt werden solle, besonders angesprochen? Gewiß, es ist der Analysant/die Analysantin, davon haben Sie eben gehört. Es ist aber mindestens so auch der Analytiker, insofern er signalisiert, daß »Reserve gestattet ist $\ll$. Aus diesem Grund liegt die Betonung der Grundregel auf dem »alles«: Der Rücksichtslosigkeit der Neurose hat der Analytiker seine Strenge entgegenzusetzen. Worin besteht die Strenge des Analytikers? Dem Gesindel auch bei sich selbst kein Asyl, keine Reserve, einzuräumen. Das heißt, Freud spricht an dieser Stelle die Ethik des Analytikers an, dessen Begehren in der psychoanalytischen Praxis geradezu auf dieses Gesindel gerichtet ist, von diesem möchte er hören.

Das psychische Gesindel zu isolieren, es von anderen psychischen Bildungen fernzuhalten, etwa durch Pausen und Unterbrechungen der Rede aus seinem Zusammenhang zu reißen, ist das Eigentümliche und Rück- 
sichtslose der Zwangsneurose. Unsere `normale〈, konzentrierte Denktätigkeit tut allerdings genau dies. Ich zitiere dazu eine längere Passage aus Freuds Aufsatz Hemmung, Symptom und Angst:

"Was so auseinandergehalten wird, ist gerade das, was assoziativ zusammengehört, die [...] Isolierung soll eine Garantie für die Unterbrechung des Zusammenhanges im Denken geben. Einen Vorwand für dies Verfahren der Neurose gibt der normale Vorgang der Konzentration. Was uns bedeutsam als Eindruck, als Aufgabe erscheint, soll nicht durch die gleichzeitigen Ansprüche anderer Denkverrichtungen oder Tätigkeiten gestört werden. Aber schon im Normalen wird die Konzentration dazu verwendet, nicht nur das Gleichgültige, nicht Dazugehörige, sondern vor allem das unpassende Gegensätzliche fernzuhalten. Als das Störendste wird empfunden, was ursprünglich zusammengehört hat und durch den Fortschritt der Entwicklung auseinandergerissen wurde, z.B. die Äußerungen der Ambivalenz des Vaterkomplexes [ich werde gleich darauf zurückkommen, Verf.] [...] oder die Regungen der Exkretionsorgane in den Liebesregungen. So hat das Ich normalerweise eine große Isolierungsarbeit bei der Lenkung des Gedankenablaufes zu leisten, und wir wissen, in der Ausübung der analytischen Technik müssen wir das Ich dazu erziehen, auf diese sonst durchaus gerechtfertigte Funktion zeitweilig zu verzichten. [...] Indem es aber Assoziationen, Verbindung in Gedanken, zu verhindern sucht, befolgt es eines der ältesten und fundamentalsten Gebote der Zwangsneurose, das Tabu der Berührung. Wenn man sich die Frage vorlegt, warum die Vermeidung von Berührung, Kontakt, Ansteckung in der Neurose eine so große Rolle spielt und zum Inhalt so komplizierter Systeme gemacht wird, so findet man die Antwort, daß die Berührung, der körperliche Kontakt, das nächste Ziel sowohl der aggressiven wie der zärtlichen Objektbesetzung ist. Der Eros will die Berührung, denn er strebt nach Vereinigung, Aufhebung der Raumgrenzen zwischen Ich und geliebtem Objekt. Aber auch die Destruktion, die vor der Erfindung der Fernwaffe nur aus der Nähe erfolgen konnte, muß die körperliche Berührung, das Handanlegen voraussetzen. Eine Frau berühren ist im Sprachgebrauch ein Euphemismus für ihre Benützung als Sexualobjekt geworden. Das Glied nicht berühren ist der Wortlaut des Verbotes der autoerotischen Befriedigung. Da die Zwangsneurose zu Anfang die erotische Berührung, dann nach der Regression die als Aggression maskierte Berührung verfolgte, ist nichts anderes für sie in so hohem Grade verpönt worden, nichts so geeignet, zum Mittelpunkt eines Verbotssystems zu werden. Die Isolierung ist aber Aufhebung der Kontaktmöglichkeit, Mittel, ein Ding jeder Berührung zu entziehen [...]. r $^{24}$

Auch die Worte können zu solchen Dingen werden, die nicht mehr berührt, nicht in den Mund genommen werden dürfen, damit, schließlich, das Subjekt selbst nicht mehr berührt wird - von dem, was in ihm ist, was es bedrängt und was in ihm drängt. 
Was geschieht dann, wenn etwas nicht ausgesprochen werden kann, aus Scham oder weil es Schuldgefühle verursacht, oder weil es unbewußt ist? Wo bleibt das? Es drängt sich - denn das Unbewußte hat die Tendenz, sich zu reproduzieren - in anderer Form an die psychische Oberfläche. Es äußert sich dann beispielsweise im Handeln des Subjekts, in seinem Benehmen dem Analytiker gegenüber.

Freud hat dieses Verhalten mühsam lesen lernen müssen. Wie bedeutungsvoll die Übertragung die Beziehung zwischen Analysant und Analytiker prägt, hat Freud erfahren, als eine Analysantin von ihm, der er den Namen Dora ${ }^{25}$ gab, die Analyse plötzlich abbrach. Dieses Abbrechen geschah an einer signifikanten Stelle der Analyse, und es geschah, weil Freud etwas sehr Wesentliches, was Dora ihm unbewußt übermitteln wollte, nicht gehört hat, vielleicht nicht wahrhaben wollte, nämlich Doras homosexuelle Neigung und das Gewicht, das ihre Bindung an ihre Mutter für sie besaß. Freud hatte demgegenüber einen Widerstand, der ihn in dieser Hinsicht >taub< sein ließ, und Dora hatte kein anderes Mittel, zu bedeuten, daß sie in ihrem besonderen Begehren >ungehört geblieben war, als Freud >sitzenzulassen bringen. Bemerkenswert an Freud aber und analytisch ist, daß er dieses Scheitern ernstgenommen, es nicht einfach Doras >Psychopathologie< zugeschrieben hat, sondern seinen >verstopften Ohren`, seinem eigenen Unvermögen, einen Teil ihres unbewußten Begehrens anzuerkennen. Ihr Abbrechen der analytischen Kur hat er nachträglich als eine >Botschaft< aufgenommen, ein >Sagen tragung ausgearbeitet. Vielleicht ist es so, daß überhaupt erst da, wo eine/r sich irritieren lassen kann, etwas - anderes - auftauchen, entstehen, im `Zwischen` gehört werden kann, was einer Frage, einem Fragen ähnlich ist, - zumindest kann dort, wo Gewißheit herrscht und keine Frage, nichts gehört werden. Die beiden Elemente der Aktualisierung und der Verschiebung auf die Person des Analytikers finden Sie hier wieder.

Eine grundlegende Erkenntnis der Psychoanalyse besteht in der Auffassung, daß das Handeln (etwa Doras) etwas zu bedeuten hat, daß es für etwas steht, was - noch - nicht gesagt, was anders nicht symbolisiert werden kann, das aber selbst symbolisch verfaßt ist. Aus diesem Grunde kann es auch gedeutet werden. Eine solcherart verschlüsselte, im Verhalten ausgedrückte unbewußte Botschaft nennen wir im Zusammenhang einer Analyse >Agieren`. Ich möchte dieses >Agieren` in der Übertragung an einer der großen Fallgeschichten Freuds, dem sogenannten Rattenmann ${ }^{26}$ deutlich machen: Es handelt sich um einen Analysanten 
mit starken Zwangsvorstellungen, die sehr quälend für ihn sind, ihn zudem von wichtigen Entscheidungen - wen er heiraten soll - und von seiner Berufstätigkeit abhalten. Sein Vater ist früh gestorben, er hat ihn einzig in liebevoller Erinnerung. Nun taucht in der Analyse eine Kindheitsszene auf, die nicht als solche erinnert wird, aber deren Erzählung von der Mutter, aus früherer Zeit auch vom Vater. Freud sieht in dieser Szene die Krankheitsveranlassung, denn sie ist für starke feindselige Affekte und Einstellungen gegenüber dem Vater verantwortlich, die jedoch verdrängt sind. Aus dieser verdrängten Ambivalenz leiten sich die leidvollen Symptome des Patienten ab. Erzählt wird ihm, daß er, als er noch sehr klein war, etwas »Arges $\ll^{27}$ angestellt habe, wofür ihn der Vater prügelte. Der kleine Kerl sei daraufhin selbst in schreckliche Wut geraten und habe seinen Vater mit allen Worten, die ihm einfielen, beschimpft, »du Lampe, du Handtuch, du Teller«, weil er zu der Zeit noch keine Schimpfworte gekannt habe. Der Vater hielt erschüttert über diesen elementaren Ausbruch im Schlagen inne. Der Patient meint, diese Szene sei für beide ein bleibend wirksamer Eindruck gewesen, der Vater habe ihn nie wieder geprügelt, er selbst aber führt seine Charakterveränderung darauf zurück, aus Angst vor der Größe seiner Wut sei er von da an feige geworden.

Freud vermutet, daß dies Arge etwas Sexuelles im Zusammenhang mit der Onanie des Kindes gewesen ist. Diesen Genuß hatte ihm der Vater untersagt, ihn hart dafür bestraft und so einen unauslöschlichen Groll gegen den Vater hinterlassen. In der Analyse gelingt es dem Rattenmann nicht, die Bedeutung dieser Szene, d.h. die verdrängte Wut gegen den Vater anzuerkennen; er erzählt die Szene, isoliert sie aber aus ihrem Zusammenhang und von den entsprechenden Affekten, er kann diese nicht erinnern, das Erzählte bewirkt daher nicht viel. Freud fährt fort:

"Er mußte sich also die Überzeugung, daß sein Verhältnis zum Vater wirklich jene unbewußte Ergänzung [die verdrängte Wut, Verf.] erforderte, erst auf dem schmerzhaften Weg der Übertragung erwerben. Es kam bald dazu, daß er mich und die Meinigen in Träumen, Tagesphantasien und Einfällen aufs gröblichste und unflätigste beschimpfte, während er mir doch mit Absicht niemals etwas anderes als die größte Ehrerbietung entgegenbrachte. Sein Benehmen während der Mitteilung dieser Beschimpfungen war das eines Verzweifelten. 'Wie kommen Herr Professor dazu, sich von einem schmierigen, hergelaufenen Kerl wie ich so beschimpfen zu lassen? Sie müssen mich hinauswerfen; ich verdiene es nicht besser.ı Bei diesen Reden pflegte er vom Diwan aufzustehen und im Zimmer herumzulaufen, was er zuerst mit Feinfühligkeit motivierte; er 
bringe es nicht über sich, so gräßliche Dinge zu sagen, während er behaglich daliege. Er fand aber bald selbst die triftigere Erklärung, daß er sich meiner Nähe entziehe, aus Angst, von mir geprügelt zu werden. Wenn er sitzen blieb, so benahm er sich wie einer, der sich in verzweifelter Angst vor maßlosen Züchtigungen schützen will [...]. Er erinnerte, daß der Vater jähzornig gewesen war und in seiner Heftigkeit manchmal nicht mehr wußte, wie weit er gehen durfte. In solcher Schule des Leidens gewann er allmählich die inm mangelnde Überzeugung [...]; dann war aber auch der Weg zur Auflösung der Rattenvorstellung frei. Eine Fülle von bisher zurückgehaltenen tatsächlichen Mitteilungen wurde nun auf der Höhe der Kur zur Herstellung des Zusammenhanges verfügbar. ${ }^{28}$

Der Zwangsneurotiker isoliert, dichtet ab, um nichts durchzulassen vom Verdrängten. Das, was er in der analytischen Situation erinnert oder phantasiert, reißt er aus dem Zusammenhang, der dem Erinnerten seine Bedeutungen, sein Gewicht und die dazugehörenden Affekte zurückgeben könnte. Er agiert so aus Angst, Angst vor einem strafenden und mißbilligenden Analytiker, auf den er die eigene Strenge und Ablehnung projiziert hat. Der Widerstand gegen den Fortgang der Analyse zeigt sich vor allem im Modus des Sprechens, in der Art und Weise, wie mit bedeutsamen Zusammenhängen und den dazugehörigen Affekten umgegangen wird.

Der Analytiker ist für den Zwangsneurotiker häufig ein Objekt, dem er mißtraut, dem er nicht glauben will, von dem er sich kritisiert oder auch abgelehnt fühlt. Diese Einstellung wird gemeinhin als negative Übertragung bezeichnet. Am Beispiel des Rattenmannes aber haben wir gesehen, daß es keine entscheidende Rolle spielt, ob die Übertragungstönung negativ oder positiv ist, auch die vom Rattenmann in dem Analyseabschnitt als negativ erlebte Übertragung beinhaltet wertvolle, ja entscheidende Hinweise.

Das eindrucksvoll beschriebene Agieren in der Übertragung des Rattenmannes, jene stumme Kommunikation macht deutlich, warum Freud es als Wiederholung bezeichnet. Der Rattenmann sträubt sich innerlich vehement dagegen, der Erinnerung an seinen Vater negative Aspekte hinzuzufügen; wohl möchte er sich auch nicht an das, was er als Kind "Arges« getrieben hat mit der damit verbundenen Beschämung, erinnern. Das, was in der Übertragung wiederholt wird, ist immer etwas, was in der Kindheit unbefriedigt, traumatisch, ungelöst geblieben ist. Die Erinnerung bezieht sich in der Psychoanalyse nie auf das >Faktischeく, sondern auf das Phantasieleben, auf die psychische Realität. 
Für den Rattenmann hat es seit der Szene keine lösenden Worte für seine Einstellung und Affekte gegen den Vater gegeben, sie blieben von da an verdrängt. Er hat Angst vor seiner Wut entwickelt, die Zwangsvorstellungen und Hemmungen bildeten sich als ihr Ausdruck. Die ins Unbewußte verdrängten Repräsentationen seiner negativen Einstellungen und Affekte drängen - der dem Unbewußten eigenen Dynamik zufolge - danach, sich zu reproduzieren; in der Analyse ist die Darstellung des Verdrängten in entstellter Form möglich, durch die Assoziation bzw. Allianz mit einer bewußtseinsfähigen Vorstellung. Das Subjekt überträgt also mit Notwendigkeit, denn das Verdrängte als solches ist - zunächst nicht sagbar.

Ein weiteres Motiv der Übertragung ist, daß sie auch dem Widerstand dem Widerstand gegen das Erinnern und ins-Sprechen-bringen - Genüge tut. Der Rattenmann schützt sich mit dem Übertragungseinfall, so peinlich ihm die Beschimpfung seines Analytikers Freud auch ist, gegen die noch schmerzhaftere Erkenntnis, daß diese Rede sich >eigentlich einen anderen, an seinen Vater als Instanz des Gesetzes und der Strafe, richtet. Ich knüpfe nochmals an Erinnern, Wiederholen und Durcharbeiten an:

"[...] der Analysierte erinnere überhaupt nichts von dem Vergessenen und Verdrängten, sondern er agiere es. Er reproduziert es nicht als Erinnerung, sondern als Tat, er wiederholt es, ohne natürlich zu wissen, daß er es wiederholt. [...] Solange er in Behandlung verbleibt, wird er von diesem Zwange zur Wiederholung nicht mehr frei; man versteht endlich, dies ist seine Art zu erinnern«. [Und, etwas weiter unten: ] "Wir merken bald, die Übertragung ist selbst nur ein Stück Wiederholung und die Wiederholung ist die Übertragung der vergessenen Vergangenheit [...].. ${ }^{29}$

Welche Haltung nimmt die Psychoanalyse gegenüber diesem Agieren als Wiederholung ein? Das, was der Analysant als Reales und Aktuelles erlebt, etwa seine (positive oder negative) Einstellung zum Analytiker, oder Impulse, die so stark sind, daß die Grundregel oder das Setting gebrochen werden wie beim Rattenmann, versteht die Psychoanalyse seit Dora - nicht mehr als bloße Störung, sondern als eine stumme Mitteilung. Voraussetzung für dies Verständnis ist die Einsicht in die sprachliche Struktur des Verhaltens.

>Ein Wort für ein anderes $\measuredangle$, das ist die einfachste und grundlegendste Definition der Metapher; so läßt sich auch eine Geste, ein Verhalten für, anstelle von Worten übersetzend lesen. Analog der Struktur der Metapher also ersetzt das Handeln - des Rattenmannes etwa - seine unbe- 
wußte Rede, bzw. die Erinnerungen, die er nicht wahrhaben will; es, das Handeln, das Agieren ersetzt - und übersetzt - diesen unbewußten Text. Die Ersetzung kann aber nicht geschehen, ohne daß Spuren dessen, was ersetzt wird, weiterwirken. Ein Handeln in der Übertragung läßt sich daher lesen, da auch es sprachlich determiniert ist. Es geschieht anstelle des Sagens, aber es selbst ist gleichfalls artikuliert. Ohne die linguistischen Bedingungen der Struktur der Sprache gekannt zu haben, hat Freud gleichwohl diese Übersetzungsarbeit leisten können: „Wir verstehen schließlich«, sagt Freud, »dies [das Agieren, Verf.] ist seine Form der Erinnerung«. Die analytische Deutung gibt ihrerseits eine neuerliche Übersetzung des Handelns, des Agierten, d.h. sie substituiert dem Handeln wiederum Worte oder Signifikanten. Das Agieren findet nicht nur im Handeln, es findet ebenso in der Rede statt; ich nehme diesen $\mathrm{Zu}$ sammenhang weiter unten nochmals auf.

Dem, was das Subjekt für sein Gesindel hält, möchte die Analyse also gewissermaßen volles >Einbürgerungsrecht`zuerkennen, es soll seinen Ort nicht in der Verschwiegenheit oder der Stummheit behalten, sondern einen solchen in der Rede, im Zusammenhang des Sprechens bekommen - ja, sie legt dem sprechenden Subjekt nahe, sich dem Tabu der Berührung zu widersetzen und sich dieses Gesindels anzunehmen, es anzusprechen, bei sich aufzunehmen, schließlich seine Sprachen zu lernen: den genauen Wortlaut der Zwangsideen, die Sprache des Darmes, den Dialekt der Hysterie etc.

Insofern kann Freud sagen, die Übertragung sei der »Tummelplatz, auf dem ihm [dem Wiederholungszwang, Verf.] gestattet wird, sich in fast völliger Freiheit zu entfalten, und auferlegt ist, uns alles vorzuführen, was sich an pathogenen Trieben im Seelenleben des Analysierten verborgen hat «. ${ }^{30}$ Die Übertragung eröffnet ein »Zwischenreich«, zugleich ist sie »ein Stück des realen Erlebens [...] und von der Natur eines Provisoriums «. ${ }^{31}$ Auf diesem Feld kann und wird die Wiederholung eine Deutung erfahren, - und daß die Deutung eine ganz eigenständige, mit metamorphotischer Kraft begabte Kategorie ist, die seit dem Mittelalter aus dem europäischen Denken verdrängt war und erst durch Freud wieder eingeführt worden ist, darauf weist Pierre Legendre mit Nachdruck hin. ${ }^{32}$ Die Deutung des Analytikers hat verändernde Wirkung auf das, was wiederholt wird; zunächst einmal, da es vom Analysanten symbolisiert, und das bedeutet auch, metaphorisiert wird, dann, weil es einem anderen mitgeteilt, d.h. sozialisiert wird. Im Sprechen wird etwas bisher nicht Mitteilbares der Sprache - als dem Anderen - und dem konkreten 
anderen - der/die ja zugleich Platzhalter des Anderen ist -, anvertraut, es wird so der Möglichkeit der Verwandlung übergeben. Die Deutung weist schließlich auf den unbewußten Wunsch und dessen Abkömmlinge, die unbewußten Phantasien. Der Widerstand gegen die Psychoanalyse stellt also möglicherweise einen Widerstand gegen das eigene Andere dar, mit dessen Vergegenwärtigung und vielleicht auch Realisierung ein gewisses Anderswerden einhergeht.

>Répétition〈 ist der französische Ausdruck für >Wiederholung〈. Lacan fügt dem psychoanalytischen Nachdenken über die Wiederholung den Ausdruck »hâler « ${ }^{33}$ hinzu, dessen Konnotationen auch zu >schleppend, ermüdend holen, wieder-holen, heranholen, einholen (wie ein Fischernetz), das setzt eine etwas andere Betonung, nämlich auf die Arbeit der Erinnerung, die das Erinnerte, Vergangene in einen aktuellen, also anderen Kontext einläßt. Mit dieser Akzentuierung kann das Neue, das in jede Wiederholung auch eingetragen ist, besonders wenn sie ins Sprechen gebracht werden konnte, hervortreten. Die Wieder-holung, als Übertragung, trägt somit bereits etwas in sich, das à-part ist von der Wiederholung des Selben, sie gibt etwas zu hören, das etwas anderes möchte, oder etwas anderes möchte als die Starre des Wiederholungszwanges. Diese Akzentsetzung hält den Entwurf des Subjekts offen.

Ist ein Gegenstück zu der sogenannten >negativen` Übertragung vorstellbar? Eine Übertragung also, die so beschaffen wäre, daß sie ermöglicht oder sogar den Wunsch wachruft, dem Analytiker/der Analytikerin »alles« zu sagen? Sie würde auf der Annahme beruhen, vom Analytiker geliebt zu werden, ihn zu lieben, endlich jemanden gefunden zu haben, dem man uneingeschränkt vertrauen, dem man »alles« sagen kann - bis hin zu dem, was man sogar vor sich selbst verborgen hat, »die tiefsten Geheimnisse«, wie Freud es ausdrückt, und auch dann noch liebenswert zu sein und geliebt zu werden. Der Analytiker wird durch eine solche Übertragung zu einer Person, die sogar noch den 〉Mist`, der ja auch produziert wird, durch seine Deutungen in Gold verwandeln kann, oder mit dessen Zutun z.B. die Wunschphantasie, ein vollständiges Wesen mit einer vollständigen Geschichte zu sein, wahrgemacht werden könnte, indem die fehlenden Erinnerungsstücke der Kindheit wiedergefunden und zusammengesetzt werden könnten, um so dem Mangel an Sein abzuhelfen. Kein »alles« aber vermöchte dies, er bleibt, läßt dem Subjekt sein Wünschen. Auch das »alles« ist in der Psychoanalyse nicht sub- 
stantiell zu verstehen, das heißt, es darf verschiedenes heißen, etwa: >alles mögliche`, Gesindel, Ges(t)ammel, Sammelsurium, irgendetwas ... In der psychoanalytischen Praxis kommt die >positive « Übertragung täglich vor, d.h. die Beziehung ist getragen von Sympathie, Wertschätzung, Vertrauen, von positiven Erwartungen an den Analytiker und die Analyse. Dies sind, darauf weist Freud immer wieder hin, abgemilderte Formen der Sexualtriebe, sie haben sich durch »Abschwächung des Sexualzieles aus rein sexuellen Begehrungen entwickelt, so rein und unsinn lich sie sich auch unserer bewußten Selbstwahrnehmung darstellen mögen «. ${ }^{34}$ Diese Form der positiven Übertragung ist für das Ingangkommen und die Fortsetzung der Analyse unabdingbar, sie bringt den Analysanten überhaupt erst zum Analytiker, dem er ja ein Wissen unterstellt und dem er vertraut. Ohne sie läuft nichts. Sie tritt aber auch weniger abgeschwächt auf, zeigt sich dann als Verliebtheit in den Analytiker/ die Analytikerin. Und, so wunderbar, so ersehnt, einmalig und besonders das Verliebtsein sonst ist, so regelmäßig, ja sogar >unvermeidlich ‘ tritt sie in der psychoanalytischen Situation auf. Die Liebesübertragung entsteht strukturell, sie tritt notwendig auf, ist eine $»$ mit Sicherheit eintreffende Tatsache ${ }^{35}$ Sie kommt allerdings auch überall anders als in der Psychoanalyse vor, in der Psychiatrie, dem Krankenhaus, der Uni etc., nur wird sie dort nicht als solche erkannt und analysiert, und tritt daher teilweise in den demütigendsten Formen der Hörigkeit und Abhängigkeit, etwa der Patienten gegenüber dem Arzt, auf.

Lacan weist daraufhin, ich habe es bereits gesagt, daß die Übertragung strukturell in dem Moment auftritt, in dem einem anderen Subjekt Wissen unterstellt wird, und zwar ein Wissen, das mit dem Eros, mit dem Begehren zu tun hat. Die Übertragung ist also Übertragung des Begehrens des Analysanten, aber - und das unterschlägt Freud, so Lacan - in der Begegnung mit dem Begehren des Analytikers. ${ }^{36}$ Die Übertragung ist mithin die Frage, so läßt sich auch formulieren, nach dem Verhältnis des Begehrens des Analysanten und dem des Analytikers, sie ist geradezu dieses Verhältnis des Begehrens zum Begehren des anderen. Im strukturellen Sinne gibt es mithin nur ein Subjekt der Übertragung.

Ebenso wenig wie die Übertragung nur in der psychoanalytischen Situation geschieht, ist sie auch keine Erfindung der Psychoanalyse. Lacan zeigt im Seminar XI, das er 1964-65 gehalten hat, an Platons Symposion (Sie wissen, daß in diesem Text Das Gastmahl zu einem üppigen Gelage eingeladen wird, um Reden zu Ehren des Eros zu halten), in diesem Text 
also, so Lacan, ist die Übertragung in »vollendeter und strengster Form $\ll^{37}$ artikuliert.

Einer der Redner, Alkibiades, hält eine Lob- und Liebesrede auf Sokrates, und er verlangt in seiner Rede etwas von Sokrates, etwas, von dem er nicht weiß, was es ist, er nennt es agalma ${ }^{38}$, griech.: Schmuckstück, Prachtstück; zweite Bedeutung: Bildsäule, Götterbild. Dieses agalma stellt für Alkibiades genau das dar, was kostbarer und begehrenswerter ist als alle Güter, es stellt für ihn den höchsten Wert dar, es ist, psychoanalytisch gesprochen, das unbewußte Objekt seines Begehrens.

Selbstverständlich werden wir diese Stelle hier nicht ausreichend lesen und auslegen können, lediglich auf zwei, drei Aspekte, die die Psychoanalyse betreffen, möchte ich Bezug nehmen. ${ }^{39}$ Ich setze bei der Rede des Alkibiades ein, er spricht in Bildern von seiner Liebe zu Sokrates: »Ich behaupte nämlich, er sei äußerst ähnlich jenen Silenen in den Werkstätten der Bildhauer, welche die Künstler mit Pfeifen oder Flöten vorstellen, in denen man aber, wenn man die eine Hälfte wegnimmt, Bildsäulen von Göttern erblickt [...]. « ${ }^{40}$ Als Subjekt, das sich seiner Vereinzelung bewußt ist, als ein einziges Subjekt von sich allein her, spricht Alkibiades dann: »Ob aber jemand, wenn er ernsthaft war und sich auftat, die Götterbilder gesehen hat, die er [Sokrates, Verf.] in sich trägt, das weiß ich nicht. Ich habe sie aber einmal gesehen, und so göttlich und golden und überaus schön und bewundernswürdig kamen sie mir vor, daß ich glaubte, auf der Stelle alles tun zu müssen, was nur Sokrates wünschte «. ${ }^{41}$ Diese Stelle formuliert die Liebesübertragung, aber auch die - strukturelle - Bereitschaft des Subjekts zu Unterwerfung und Gehorsam. Sie gibt die psychische Dynamik an, an der etwa der Hypnotiseur, die Suggestion also, ansetzt; psychoanalytisch nennen wir diesen psychischen Vorgang Idealisierung; sie beschreibt den psychischen Vorgang, durch den der Hypnotiseur mit Autorität und Macht ausgestattet wird, während das Subjekt zu einer gewissen Hingabe und Gehorsam bereit ist. Sie gibt ebenso den Abzweig an, der besagt, daß unser Begehren sich grundsätzlich nur über das Begehren des Anderen konstituiert.

Was vergöttert Alkibiades da wohl in Sokrates? Was diese Vergötterung bewirkt, ist augenfällig: sie macht aus Sokrates etwas anderes: einen Silenen - ein Mischwesen, Menschen mit Pferdeohren, -schwanz und -hufen, Begleiter des Dionysos, Gott des Rausches und der Ekstase. Diese Statuen wurden im antiken Griechenland von Künstlern gefertigt. Aus Sokrates nun macht sie etwas Säulenhaftes, Starres, vielleicht auch 
Phallisches, vor allem aber etwas Vieldeutiges, ein Rätsel. Zudem legt dieser psychische Vorgang etwas in ihn hinein, eben die »bewundernswürdigsten, überaus schönen, goldenen Götterbilder«, und diese rufen Alkibiades' Liebe hervor, wie sie jene auch erst erschaffen hat.

Jedoch nicht allein dem Aussehen des Sokrates schreibt Alkibiades diese bezaubernde Kraft zu, sondern sie geschieht kraft seiner Rede: »durch bloße Worte « richte er dies aus ${ }^{42}$,ja, »seine Reden [seien] jenen aufzuschließenden Silenen äußerst ähnlich $\aleph^{43}$, auch »sie sind inwendig ganz göttlich«.

Nicht unähnlich wird die Deutung des Analytikers hin und wieder aufgenommen wie das Orakel von Delphi etwa oder auch wie sgoldene Worte $\iota$, die seinem Inneren entströmen. Die >Vergoldung $\triangleleft$, die in der Liebesübertragung geschieht, ist so etwas wie ein Täuschungsmanöver; Lacan legt die sich überschneidenden Felder der Liebe und des Begehrens auseinander: »Das Subjekt, das dem Begehren des Analytikers unterworfen, assujettiert ist, will diesen über die Unterwerfung/ assujettissement dadurch hinwegtäuschen, daß es sich von ihm lieben läßt, daß es von sich aus ihm diesen Trug, der Liebe heißt, anbietet. Die Übertragungswirkung besteht in diesem Effekt der Täuschung, der sich hier und jetzt wiederholt. ${ }^{44}$

»Ich liebe Dich,

Weil aber, unerklärlich,

Ich in Dir etwas liebe,

das mehr als Du -

das Objekt a,

Muß ich Dich verstümmeln«,

formuliert Lacan ${ }^{45}$, - und Alkibiades nimmt in der Tat den zum Silenen gewordenen Sokrates gewissermaßen auseinander, zerlegt ihn in zwei Hälften, öffnet die Statue, um in ihrem Inneren etwas zu entdecken - die Worte, die Stimme, den Blick? -, das er sucht und das ihn erfüllen soll, das Objekt seines Verlangens, sein agalma. Die Liebe bzw. die Liebesübertragung entsteht dort, wo wir im anderen etwas zu finden vermeinen, was uns fehlt, erfüllt, was unseren Mangel schließt. Diese Einsicht in die Dynamik der Übertragung auf der Ebene des Objekts arbeitet Lacan mit dem Konzept des phantasmatischen Objekts, das Objekt (a) des Triebs, heraus, abgekürzt: der andere scheint das zu haben, was mir fehlt, und das ich begehre. Um dieses begehrte, phantasmatische Objekt kreist die Übertragung. 
Auch diese Einsicht ist keineswegs nur der Psychoanalyse zugänglich, Platon etwa hat sie mit analytischer Treffsicherheit benannt: »Denn er nötigt mich einzugestehen«, so Alkibiades, »daß mir selbst noch gar vieles mangelt $\aleph^{46}$ - und, fügen wir hinzu, er scheint $\mathrm{zu}$ sein oder zu haben, was mir fehlt. In der Analyse geht es nicht zuletzt darum, die Verkennung, méconnaissance ist Lacans Ausdruck, aufzulösen, die in der Liebesübertragung liegt. Solange das Subjekt beim anderen das zu finden vermeint, was seinen Mangel schließen würde, solange es erhofft, der/die andere könne überhaupt haben und geben, was ihm - fundamental - fehlt, kann es nicht zur Anerkennung des grundsätzlichen Mangels gelangen. In radikaler Weise bestimmt sich das Subjekt des Unbewußten von hier: »Hier, an diesem Punkt eines Mankos, soll das Subjekt sich wiedererkennen, anerkennen. ${ }^{47}$ Diesen Mangel anzuerkennen bedeutet Trauerarbeit, von der womöglich ein Rest bleibt, - Zeuge dessen, daß es sich mit diesem Mangel leben läßt, ohne stets nach Ausgleich oder Auffüllung zu streben, denn jener allein vermag es, daß wir Subjekt des Spiels unseres Wunsches sein können.

Alkibiades übrigens, im antiken Text Platons, wendet seine Liebe, seine Sehnsucht und sein Sprechen dem Sokrates in einem Zustand zu, von dem auch das moderne Subjekt auf der Couch des Analytikers häufig spricht: Sein Leiden, die innere Not, in der er sich befindet, läßt ihn so zu Sokrates sprechen: »Meine Seele gerät in Unruhe darüber und in Unwillen, daß ich mich in einem knechtischen Zustand befinde. ${ }^{48}$

Ich komme auf das Agieren zurück, das wir als Widerstand aufgenommen haben, das sich im Handeln etwa, aber auch in der Rede selbst ausdrücken kann. Wir sind von der Frage ausgegangen, ob nicht die Liebesübertragung die besten Voraussetzungen bietet, um das »alles« der Grundregel ins Werk zu setzen? Überraschenderweise öffnet auch die Liebesübertragung nicht den Mund. Sie verhilft vielleicht dazu, schöne, verführerische Reden zu führen, nicht aber, die Grundregel einzuhalten, frei zu assoziieren, alles zu sagen, was in den Sinn kommt, im Gegenteil. Sie bewirkt vielmehr eine Auswahl dessen, was gesagt wird, denn der Analysant/die Analysantin möchte ja geliebt werden, also auch liebenswert erscheinen, wird also beginnen, sich als besonders klug, gehorsam oder gerade ungehorsam, witzig oder phantasievoll etc. darzustellen, um den Analytiker auf diese Weise für sich einzunehmen. Er/sie wird auch versuchen, seine Erlebnisse so darzustellen, daß sie eine bestimmte Reaktion im Analytiker hervorrufen sollen, Mitleid etwa oder Distanznahme oder eine gewisse Schonung etc. Auch die Liebesübertragung also ist 
ein Widerstand, sie will die Liebe leben, agieren, und nicht erinnern. Freud macht allerdings deutlich, daß die Analyse nur in der Übertragung, d.h. mit einem Aspekt des Widerstandes verlötet, stattfinden kann. Analytisch fassen wir die Liebe als einen `Einfall« auf - wie alle anderen - und lösen sie, indem wir uns nicht mit dem Objekt der Übertragung verwechseln, sie vielmehr deutend immer wieder von uns ablösen, sie auf ihre Bahnungen, auf ihre Ursprünge in der Kindheit veweisen. Der Rattenmann hatte seine Wut und Feindseligkeit gegenüber dem Vater verdrängt; die Liebe und das Begehren, die das Kind sowohl auf den Vater wie auf die Mutter richtet, sind ebenso Gegenstand der Verdrängung, die die Analyse durch die Erinnerung wieder-holen möchte.

Ich komme zum Schluß. Sokrates also ist Alkibiades' Schatzkästchen, so scheint es. Ist der Analytiker auch ein solcher Schatz, ein solches Schatzkästchen für den Analysanten, der es in sich hat - dieses Es des Unbewußten? Der Analytiker ist durchaus so etwas wie ein Kästchen allerdings ein leeres, einem Resonanzraum vergleichbar: Er/sie gibt Raum zu sprechen und sorgt dafür, diesen offen zu halten, damit die Effekte des Unbewußten ins Sprechen gebracht, gehört und aufgenommen werden können. Der Analytiker birgt, bewahrt etwas auf, hebt etwas hervor, etwas von der Flüchtigkeit der Worte, so daß der Sprachschatz, der trésor, i.e. der Schatz der unbewußten Signifikanten des Analysanten, hervortreten kann. Dies sind keineswegs alles Schätze, denn ebenso wie die Signifikanten, die für ein Subjekt sein Lust-Genießen repräsentieren, finden wir dort jene der Traumata, des Leidens, dessen, was unerträglich war oder ist für ein Subjekt.

Dennoch aber ist nicht nur Leere im Kästchen. Es ist allerdings nicht so sehr ein Wissen, das den Analysanten hier erwartet, auch wenn er es zu finden hofft. In der Psychoanalyse geht es überhaupt nicht so sehr um Wissen. Wir interessieren uns viel mehr für das, was er/sie nicht wissen will, für die »unerhörte Botschaft«, wie Lucien Israël es ausdrückt, für das, was Anstoß und Kluft des Wissens ist. Und wir zielen, wir deuten auf ein anderes Register, das der psychischen Realität, der subjektiven Wahrheit; diese gilt es zu erkennen, vor allem aber anzuerkennen. Das, was der Analytiker offen hält und wofür er Verantwortung hat, ist die Möglichkeit für das Aufnehmen und die Anerkennung der besonderen Wahrheit eines einzigen Subjekts. Das Begehren des Analytikers ist auf dieses radikal Singuläre des jeweiligen Subjekts gerichtet - und wenn überhaupt, so ist das der `Schatzı, den es erhalten kann.

Vielen Dank für Ihr Ohr. 


\section{Anmerkungen}

1 Jutta Prasse: Sprache und Fremdsprache. Psychoanalytische Aufsätze, herausgegeben von Claus-Dieter Rath, Bielefeld 2004.

2 Auch Freuds Überlegungen zum Motiv der Kästchenwahl wären zu nennen, vgl. Sigmund Freud: »Das Motiv der Kästchenwahl«, in: ders., Gesammelte Werke [GW], Bde. I-XVIII, Frankfurt am Main 1968, hier: GW X, 24-37; ebenso ders., Studienausgabe [StA] Bde. I-X u. Ergänzungsband, Frankfurt am Main 1969, hier: StA X, 181-193.

3 Jacques Lacan: Écrits. Herausgegeben von Jacques Alain Miller, Paris 1966, hier 254, übersetzt in ders., Schriften I, 92f., Norbert Haas (Hg.), übersetzt von Rodolphe Gasché, Norbert Haas et al., Weinheim, Berlin 1991.

4 Nicht nur reißt die Sprache im Subjekt diesen manque-à-être auf, sie liefert es auch dem Überschuß des Sprachlichen aus, dem Überschuß an Bedeutung, an Homophonien, Assonanzen, Anagrammen, der Metonymie und der Metapher etc., die auf das Subjekt eine öffnende wie auch irritierende Wirkung ausüben. Vgl. Lacans Konzept der lalangue, etwa in: Jacques Lacan: Seminar Buch XX. Encore, Textherstellung Jacques Alain-Miller; Norbert Haas, Hans-Joachim Metzger (Hg.), übersetzt von Norbert Haas, Vreni Haas, Hans-Joachim Metzger, Weinheim, Berlin 1986, 150ff.; ebenso aber auch Freuds Unterscheidung von manifester und latenter Bedeutung, etwa in der Traumdeutung, der Witztheorie oder der Psychopathologie des Alltagslebens; vgl. auch den Vortrag in dieser Vorlesungsreihe von Max Kleiner: »Die Bildungen des Unbewußten «, in: Karl-Josef Pazzini, Susanne Gottlob (Hg.), Einführungen in die Psychoanalyse. Einfühlen, Unbewußtes, Symptom, Hysterie, Sexualität, Übertragung, Perversion, Bielefeld 2005, 29-46.

5 Vgl. Anmerkung 4.

6 Jacques Lacan: Seminar Buch XI. Die vier Grundbegriffe der Psychoanalyse, Textherstellung Jacques Alain-Miller; Norbert Haas, Joachim Metzger (Hg.), übersetzt von Norbert Haas, Weinheim, Berlin 1978, 247.

7 Vgl. Peter Müller: »Was sagt das Symptom?«, in: Karl-Josef Pazzini, Susanne Gottlob (Hg.), Einführungen in die Psychoanalyse. Einfühlen, Unbewußtes, Symptom, Hysterie, Sexualität, Übertragung, Perversion, Bielefeld 2005, 47-68.

8 Lacan, Die vier Grundbegriffe, 247.

9 Freud, »Traumdeutung«, GW II/III, 568, StA II, 536.

10 Hervé Le Tellier: »Die Genesis nach Sankt Paul zum Thor«, in: Jürgen Ritte, Hans Hartje (Hg.), Oulipo. Affensprache, Spielmaschinen und allgemeine Regelwerke, übersetzt von Eugen Helmlé, Werner Schmitz, Ernest Wicher und den Herausgebern, Berlin 1996.

11 Freud, »Traumdeutung«, GW II/III, 558 und die Fußnote, StA II, 527.

12 Vgl. dazu auch Freuds interessante kleine Arbeit »Über fausse reconnaissance (déjà raconté) während der psychoanalytischen Arbeit«, GW X, 115ff., StA Ergänzungsband, 231ff. Vgl. Lacan, Écrits, 343, 353, 623f; übersetzt in ders., Schriften I, 214f; vgl. Lacan, Écrits, 815, übersetzt in ders., Schriften II, 190, Norbert Haas (Hg.), übersetzt von Chantal Creusot, Wolfgang Fietkau et al., Weinheim, Berlin 1991.

13 Freud, »Erinnern, Wiederholen und Durcharbeiten«, GW X, 136, StA, Erg.bd., 215.

14 Freud, »Abriss der Psychoanalyse «, hier Kapitel: Die psychoanalytische Technik, GW XVII, 98, StA Erg.bd., 412.

15 Freud, »Zur Einleitung der Behandlung«, GW VIII, 468, StA Erg.bd., 194f.

16 Ebd.

17 Freud, »Abriss der Psychoanalyse«, GW XVII, 99, St.A. Erg.bd., 413.

18 Ebd.

19 Freud, »Einleitung der Behandlung«, GW VIII, 469, FN StA Erg.bd., 195 FN.

20 Freud, »Traumdeutung«, GW II/III, 521, StA II, 495.

21 Freud, »Einleitung der Behandlung«, GW VIII, 469FN, StA Erg.bd., 195 FN.

22 Vgl. Lacan, Écrits, 247ff., übersetzt in ders., Schriften I, 85ff.; vgl. ders., Écrits, 616ff., übersetzt in ders., Schriften I, 206f.; ders., Seminar. Buch I, 141.

23 Freud, »Einleitung der Behandlung«, GW VIII, 469FN, StA Erg.bd., 195 FN.

24 Freud, »Hemmung, Symptom und Angst«, GW XIV, 150f, StA VI, 264ff.

25 Vgl. Freud, »Bruchstück einer Hysterie-Analyse«, GW V, 161-286, StA VI, 83-186.

26 Freud, »Bemerkungen über einen Fall von Zwangsneurose«, GW VII, 379-438, StA VII, 31-103. 
27 Ebd., GW VII, 426ff., StA VII, 71ff. Die folgenden Zitate beziehen sich auf diese Textpassagen.

28 Ebd.

29 Freud, »Erinnern«, GW X, 129f., StA Erg.bd. $209 f$.

30 Ebd., GW X 134f., StA Erg.bd. 214f.

31 Ebd.

32 Pierre Legendre: Das Verbrechen des Gefreiten Lortie, übersetzt von Clemens Pornschlegl, Freiburg 1999. Vgl. bes. 40ff.

33 Lacan, Die vier Grundbegriffe, 73, vgl. den Hinweis des Übersetzers Norbert Haas, daß auch das deutsche Wort >holen schleppen, ziehen« hatte; ebd., 294.

34 Freud, »Zur Dynamik der Übertragung«, GW VIII, 371, StA Erg.bd., 165.

35 Freud, »Bemerkungen über die Übertragungsliebe«, GW X, 308, StA Erg.bd., 220.

36 Lacan, Die vier Grundbegriffe, 267.

37 Ebd., 243.

38 Ebd., 268

39 Ich lege im Folgenden meine eigene, auf diese `Einführung hin vorgenommene Lektüre dar. Für eine intensivere Auseinandersetzung mit dem Thema der Übertragung sei neben den Kapiteln aus dem Seminar Buch XI auf Lacans Seminar Buch VIII (196061) hingewiesen, das ganz der Übertragung gewidmet ist und einen Kommentar zum Symposion enthält, vgl. Jacques Lacan: Le Séminaire, livre VIII. Le transfert. JacquesAlain Miller (Hg.), Paris 1991; dazu auch die Sammlung der beigebrachten Errata: Le Transfert dans tous ses errata. Actes du colloque proposé par kécole lacanienne de psychanalyse, Paris 1991.

40 Platon: »Das Gastmahl«, in: ders., Werkausgabe in 8 Bänden, Gunther Eigler (Hg.), übersetzt von Friedrich Schleiermacher, Darmstadt 1974, hier Bd. III, 215 b.

41 Ebd., 217a.

42 Ebd., 215d.

43 Ebd., 221e.

44 Lacan, Die vier Grundbegriffe, 267.

45 Ebd., 277 und 282.

46 Platon, »Gastmahl«, 216a.

47 Lacan, Die vier Grundbegriffe, 284.

48 Platon, »Gastmahl«, 216a. 

Günther X. Frank

\title{
Perversion: Savoir-faire und Monotonie
}

\author{
Versuch einer Strukturanalyse
}

Sehr geehrte Damen und Herren, liebe Kolleginnen und Kollegen, liebe Freundinnen und Freunde,

die Perversionen sind das letzte ... [Pause] Thema unserer Vorlesungsreihe »Einführungen in die Psychoanalyse« in diesem Sommersemester. Eine Schwierigkeit dieses Vortrages wird darin liegen, daß hier sowohl Kolleginnen und Kollegen sitzen, die sich seit vielen Jahren mit der Psychoanalyse beschäftigen, als auch solche Zuhörerinnen und Zuhörer, die vielleicht noch keinen Text von Freud gelesen haben. Erstgenannte bitte ich um Verständnis, wenn Ihnen vieles von dem, was ich vortragen werde, längst geläufig ist, Letztgenannte bitte ich, Verständnisfragen sofort zu stellen, mich also gerne immer zu unterbrechen, wenn Sie merken, daß der Faden reißt und Sie nicht mehr folgen können. Diskussionsbeiträge bitte ich für das Ende aufzusparen, aber unterbrechen Sie mich bitte bei Unklarheiten.

Um sich dem Thema zu nähern, ist es, wie immer bei psychoanalytisch zu betrachtenden Begriffen, sehr fruchtbar, zunächst bei Freud den Ausgang zu nehmen. Meist findet sich in seinen Texten bereits mehr, als spätere Autoren und Autorinnen zu denken vermochten. Daher werde ich versuchen, mit Ihnen eine Freud-Lektüre zu betreiben, ich werde also viel zitieren und mich eng am Text bewegen. Dabei gehe ich chronologisch vor und stelle Ihnen Freuds Auseinandersetzungen mit dem Thema an einigen mir zentral erscheinenden Texten vor. Drei Texte 
werden besonders im Mittelpunkt stehen: die Drei Abhandlungen zur Sexualtheorie von 1905, >Ein Kind wird geschlagen . Beitrag zur Kenntnis der Entstehung sexueller Perversionen von 1919 sowie Fetischismus von $1927 .{ }^{1}$ Die psychoanalytische Betrachtung versucht, ich hoffe dies wird deutlich werden, sich dem Thema so weit wie möglich ohne Bewertungen, egal ob moralischer oder sonstiger Art, zu nähern.

Die Bemühungen einer Lektüre Freuds zu dem Thema führten mich u.a. an einen Punkt, an dem in diesen Texten ein Ringen um einen Zugang erkennbar wird, welcher von verschiedenen Hemmnissen verstellt ist. Dazu gehört zentral die Frage nach dem, was Perversion überhaupt sein kann angesichts der Erkenntnisse der Psychoanalyse, welche uns u.a. auffordert, uns im perversen Feld verortet zu sehen und die Frage nach dem >Normalen $`$ nicht recht zu beantworten weiß mit der Konsequenz, Definitionsversuche immer wieder kritisch zu befragen und letztlich die Definition anderen Diskursen zu überlassen. Freud ist hier sehr weit gegangen, kam aber nicht an dem Punkt an, an dem er die Fragestellungen hätte zuspitzen wollen dahingehend, im analytischen Diskurs die Begrifflichkeiten an die Theorie anzupassen und, was denkbar wäre, den Perversionsbegriff aufzugeben und von Sexualitäten zu sprechen. Vielleicht wird bei der folgenden Lektüre erkennbar, was damit gesagt sein soll.

Ich möchte beginnen mit einem Zitat aus der Schrift Bruchstück einer Hysterie-Analyse von 1905, wo Freud bzgl. der Abwertungen, die die Perversionen im wissenschaftlichen Diskurs oft erfahren, bemerkt,

»daß solche Leidenschaftlichkeit im Verurteilen dem Arzte nicht ansteht. Ich finde es auch unter anderem überflüssig, daß ein Arzt, der über die Verirrungen der sexuellen Triebe schreibt, jede Gelegenheit benutze, um in den Text den Ausdruck seines persönlichen Abscheus vor so widrigen Dingen einzuschalten. Hier liegt eine Tatsache vor, an die wir uns, mit Unterdrückung unserer Geschmacksrichtungen, hoffentlich gewöhnen werden. Was wir die sexuellen Perversionen heißen, die Überschreitungen der Sexualfunktion nach Körpergebiet und Sexualobjekt, davon muß man ohne Entrüstung reden können. Schon die Unbestimmtheit der Grenzen für das normal zu nennende Sexualleben bei verschiedenen Rassen und in verschiedenen Zeitepochen sollte die Eiferer abkühlen «. $^{2}$

Festzuhalten ist, daß sich, je nach Stand der gesellschaftlichen Entwicklungen, natürlich die Einstellungen im Hinblick auf Akzeptanzen von sogenannten perversen Ausdrucksformen von Sexualitäten verändern. Festzuhalten ist aber auch, daß es eine je subjektive Beziehung zu 
Partialtrieben gibt und das Thema Perversionen also schwer zu behandeln ist, ohne stärkere Affekte hervorzurufen. Klar ist auch, daß je nach gesellschaftlicher Entwicklung die sogenannten Perversionen zum Teil dem juristischen Diskurs unterworfen sind. Schließlich: In der Alltagssprache ist das Wort Perversion, pervers, zu einer Metapher der Abwertung geworden, auch auf Feldern, die zunächst nicht deutlich sexuell besetzt sind.

Ich komme zu den Drei Abhandlungen zur Sexualtheorie von 1905. Unter »I. Die sexuellen Abirrungen« definiert Freud zwei »Abweichungen [...], deren Verhältnis zur angenommenen Norm eingehende Untersuchung fordert« $(\mathrm{V}, 34)$, nämlich bezüglich Sexualobjekt und Sexualziel. Die Norm wird hier »angenommen«, wobei wir die Annahme, das Annehmen als >Übernahme`, wie z.B. >ich nehme das Paket an >ich übernehme eine Aufgabe ‘ oder aber als >Vermutung`, wie etwa in dem Satz >angenommen, das und das passiert`, lesen können. Der weitere Text enthält öfter »Norm« und »normal«; es ist dabei wichtig, das »angenommen« immer mit zu denken. Freud führt nun unter »A) Die Inversion« bezüglich der Homosexualität aus, daß weder von »Degeneration« (V, 36ff.), hier verweist er auf die Leistungen Homosexueller wie auch auf alte Kulturen, noch von »Angeborensein« gesprochen werden kann. Er verfolgt verschiedene Sichtweisen anderer Forscher und kommt immer wieder zu Einwänden, die letztlich den aus seiner Sicht mannigfaltigen Variationen des Phänomens geschuldet sind. Eine Schlußfolgerung ist, keine wie auch immer gegebene Verknüpfung zwischen Sexualtrieb und Sexualobjekt anzunehmen, sondern zwischen Trieb und Objekt lediglich eine fast zufällige, recht lose Verbindung zu sehen. In der späteren Schrift Triebe und Triebschicksale ${ }^{3}$ von 1915 beschreibt Freud den Trieb durch vier Elemente, Quelle, Drang, Ziel und Objekt, wobei er betont, daß das Objekt das Element ist, das am leichtesten zu verändern sei im Sinne einer Ersetzung. Zurück zu den Drei Abhandlungen zur Sexualtheorie, wir lesen:

„Die Erfahrung an den für abnorm gehaltenen Fällen lehrt uns, daß hier zwischen Sexualtrieb und Sexualobjekt eine Verlötung vorliegt, die wir bei der Gleichförmigkeit der normalen Gestaltung, wo der Trieb das Objekt mitzubringen scheint, in Gefahr sind zu übersehen. Wir werden so angewiesen, die Verknüpfung zwischen Trieb und Objekt in unseren Gedanken zu lockern. Der Geschlechtstrieb ist wahrscheinlich zunächst unabhängig von seinem Objekt und verdankt wohl auch nicht den Reizen desselben seine Entstehung» (V, 46f). 
Wieder auffällig scheint mir hier die vorsichtige Formulierung »für abnorm gehalten«. Trieb und Objekt sind also verlötet, keineswegs legt die Existenz des Triebes das Objekt fest. Und: Die »für abnorm gehaltenen Fälle« sind es, bei denen dies deutlich wird. Die »Gleichförmigkeit der normalen Gestaltung « zeigt dies nicht, wirkt verschleiernd, verführt zu übersehen. Bevor wir weitergehen, sei ein Ausschnitt aus der berühmten Anmerkung von 1920 zitiert, der zeigt, wie weit Freud blickte, und wie wenig er sich von scheinbaren Gegebenheiten blenden ließ:

„Die psychoanalytische Forschung widersetzt sich mit aller Entschiedenheit dem Versuche, die Homosexuellen als eine besonders geartete Gruppe von den anderen Menschen abzutrennen. Indem sie auch andere als die manifest kundgegebenen Sexualerregungen studiert, erfährt sie, daß alle Menschen der gleichgeschlechtlichen Objektwahl fähig sind und dieselbe auch im Unbewußten vollzogen haben. Ja die Bindungen libidinöser Gefühle an Personen des gleichen Geschlechtes spielen als Faktoren im normalen Seelenleben keine geringere, und als Motoren der Erkrankung eine größere Rolle als die, welche dem entgegengesetzten Geschlecht gelten. Der Psychoanalyse erscheint vielmehr die Unabhängigkeit der Objektwahl vom Geschlecht des Objektes, die gleich freie Verfügung über männliche und weibliche Objekte, wie sie im Kindesalter, in primitiven Zuständen und frühhistorischen Zeiten zu beobachten ist, als das Ursprüngliche, aus dem sich durch Einschränkung nach der einen oder der anderen Seite der normale wie der Inversionstypus entwickeln. Im Sinne der Psychoanalyse ist also auch das ausschließliche sexuelle Interesse des Mannes für das Weib ein der Aufklärung bedürftiges Problem und keine Selbstverständlichkeit, der eine im Grunde chemische Anziehung zu unterlegen ist» ( $V, 44, F N 1)$.

Es klingt hier an, daß eine Offenheit der Objektwahl als ursprünglich anzunehmen ist und von dort aus hetero- wie auch homosexuelle Ausprägungen durch Einschränkungen entstehen. Das erklärte Forschungsinteresse betrifft auch die Heterosexualität.

Wir kommen zum zweiten Abschnitt »B) Geschlechtsunreife und Tiere als Sexualobjekte« $(\mathrm{V}, 47)$. Freud erörtert kurz die sexuelle Gewalt an Kindern und die Sodomie und kommt zu dem Schluß, daß »bei überraschend viel Individuen die Art und der Wert des Sexualobjektes in den Hintergrund treten« $(\mathrm{V}, 48)$. Abgesehen von der unangemessen anmutenden Zusammenfassung von Kindern und Tieren in diesem kurzen Abschnitt ist die zuletzt zitierte Aussage meines Erachtens zu kurz gedacht; möglicherweise trägt Freud hier die Verzerrbrille der Normierung. Aus meiner Arbeit mit pädosexuell orientierten bzw. fixierten Männern kann ich sagen, daß die Objektwahl von diesen zwar gerne als 
zufällig dargestellt wird, eine längere Arbeit mit den Betroffenen aber eher eine Überdeterminierung der Objektwahl erkennen läßt. In einer anderen bekannten Anmerkung konstatiert Freud, daß die Antike den Akzent auf den Trieb gelegt habe, wir jedoch auf das Objekt: »Die Alten feierten den Trieb und waren bereit, auch ein minderwertiges Objekt durch ihn zu adeln, während wir die Triebbetätigung an sich geringschätzen und sie nur durch die Vorzüge des Objektes entschuldigen lassen« (V, 48, FN 1). Ich lasse es dahingestellt, ob dies eine zutreffende Beschreibung der Einstellungen zu Trieb und Objekt in der Antike und Neuzeit ist. Wichtig erscheint mir, ob nicht beide Einstellungen in der Neuzeit nebeneinander existieren und je nach subjektiver Ausrichtung die jeweils andere mit einem perversen Charakter versehen erscheint.

Wir kommen nun zu dem Kapitel »2) Abweichungen in Bezug auf das Sexualziel« $(\mathrm{V}, 48)$. Scharfsinnig zeichnet Freud hier nach, daß, wenn das normale Sexualziel als »die Vereinigung der Genitalien [...] zur Lösung der sexuellen Spannung « definiert ist, hier bereits die Perversionen erkennbar werden, sofern diese Definition gehalten wird. Er nennt als Beispiele für Abweichungen vom Sexualziel Betasten, Beschauen und Küssen. Vielleicht können Sie bei folgendem Zitat mit mir schmunzeln: »Eine bestimmte dieser Berührungen, die der beiderseitigen Lippenschleimhaut, hat ferner als Kuß bei vielen Völkern (die höchstzivilisierten darunter) einen hohen sexuellen Wert erhalten, obwohl die dabei in Betracht kommenden Körperteile nicht dem Geschlechtsapparat angehören, sondern den Eingang zum Verdauungskanal bilden« (V, 49). Auf diesem Weg kommt Freud zu einer Definition der Perversionen: Es handelt sich entweder um anatomische Überschreitungen oder um Verweilungen bei den intermediären Relationen zum Sexualobjekt. Geebnet werden diese durch die sogenannte `Sexualüberschätzung «. Gemeint ist eine umfassende Wertschätzung des Sexualobjektes mit der »Tendenz, alle vom Sexualobjekt ausgehenden Sensationen mit einzubeziehen «. Auf psychischer Ebene ist dabei eine »logische Verblendung (Urteilsschwäche) angesichts der seelischen Leistungen und Vollkommenheiten des Sexualobjektes sowie [...] gläubige Gefügigkeit gegen die von letzterem ausgehenden Urteile« (V, 49f.) festzustellen. Allerdings wird eine wichtige Einschränkung gemacht: Die Erforschung des Liebeslebens gelingt besser beim Mann, bei Frauen findet Freud letzteres »in ein noch undurchdringliches Dunkel gehüllt« $(\mathrm{V}, 50)$.

Ein Kriterium für die Zuordnung von Sexualzielen zu den Perversionen ist der Ekel, den viele bei diesen Sexualzielen empfinden. Freud merkt 
zurecht an, daß dieses Kriterium ein rein konventionelles ist. Er deutet an, daß bei den anatomischen Überschreitungen neben der Sexualüberschätzung ein weiteres Moment auftaucht, wobei speziell die Mund- und die Afterschleimhaut quasi wie Genitalien behandelt werden. Gemeint ist hier seine Entdeckung der Organisation der kindlichen Sexualität im sogenannten Anlehnungstypus, was er in einem anderen Teil der Drei Abhandlungen zur Sexualtheorie, überschrieben mit »II. Die infantile Sexualität« (V, 73), entfaltet.

Nun kommt Freud auf den Fetischismus zu sprechen. Das Phänomen hat für Freud einen herausragenden Wert in der Beschreibung der Perversionen, er wird ihm 1927 einen eigenen Artikel widmen, den ich später ansprechen werde. Der Fetischismus wurde bei den Abweichungen bezüglich des Sexualobjektes in einem früheren Kapitel der Drei Abhandlungen zur Sexualtheorie nicht erwähnt, da das Moment der Sexualüberschätzung als Erklärungsmöglichkeit noch nicht eingeführt war. Jetzt beschreibt Freud die Tatsache von Übergängen zum Fetischismus in Fällen, wo »eine fetischistische Bedingung am Sexualobjekt erfordert wird, wenn das Sexualziel erreicht werden soll« (V, 52f). Beispiele sind Haarfarbe, Kleidung oder Körperfehler. Er stellt fest:

„Die Anknüpfung ans Normale wird durch die psychologisch notwendige Überschätzung des Sexualobjektes vermittelt, welche unvermeidlich auf alles mit demselben assoziativ Verbundene übergreift. Ein gewisser Grad von solchem Fetischismus ist daher dem normalen Lieben regelmäßig eigen, besonders in jenen Stadien der Verliebtheit, in welchen das normale Sexualziel unerreichbar oder dessen Erfüllung aufgehoben erscheint."

Wir sehen für die Frage nach den Perversionen hier also einen quantitativen Faktor erscheinen. Jetzt definiert Freud den Übergang von bloßen Variationen des Geschlechtstriebes ins Pathologische allgemein anhand des konkreten Beispiels am Fetischismus so:

- Der Fetisch setzt sich an die Stelle des normalen Sexualziels (Fixierung).

- Der Fetisch wird von der Person abgelöst zum alleinigen Sexualobjekt.

Zur Frage der Entstehung des Fetischismus entwickelt Freud hier einige Gesichtspunkte, die ich nicht referiere, da wir später noch einen Blick in Freuds Aufsatz zu dem Thema werfen werden. Erwähnt sei lediglich, daß der Fetisch bei den Betroffenen in deren frühesten Erinnerungen, welche nach dem 5. Lebensjahr datieren, bereits sexualisiert ist. Hinter 
dieser Erinnerung steckt eine vergessene Phase der Sexualentwicklung, die durch den Fetisch gleichsam wie eine Deckerinnerung repräsentiert wird.

Damit kommen wir zu »b) Fixierungen von vorläufigen Sexualzielen« $(\mathrm{V}, 55)$. Freud ist sich im klaren, daß diese Abweichungen allesamt beim »normalen Sexualvorgang angedeutet sind«. Für die Schaulust beschreibt er den Übergang zur Perversion durch drei Merkmale:

- Einschränkung ausschließlich auf die Genitalien,

- Verbindung mit der Überwindung des Ekels (Beispiel: Voyeur als Zuschauer bei der Exkretion),

- das normale Sexualziel wird nicht vorbereitet, sondern verdrängt.

Er stellt fest, daß im Paar Voyeurismus - Exhibitionismus das Sexualziel in aktiver und passiver Form ausgebildet ist, was bei zwei anderen oft zusammen genannten Perversionen wieder auftaucht: Sadismus und Masochismus, Begriffe, die Krafft-Ebing 1886 nach literarischen Vorbildern in die Sexualwissenschaft eingeführt hat. Auch hier taucht wieder ein qualitativ-quantitatives Moment in der Bestimmung der Perversion auf: Freud konstatiert: »Der Sadismus entspräche dann einer selbständig gewordenen, übertriebenen, durch Verschiebung an die Hauptstelle gerückten aggressiven Komponente des Sexualtriebes« (V, 57). Den Masochismus hält Freud für die »häufigste und bedeutsamste aller Perversionen« (V, 56). 1905 hält Freud den Masochismus noch für eine Umbildung des Sadismus im Sinne einer Wendung gegen die eigene Person, später erkennt er einen >primären Masochismus` an. In seiner Schrift Das ökonomische Problem des Masochismus ${ }^{4}$ von 1924 entwikkelt er dann als Formen des ১sekundären Masochismus` den ১femininen und den >moralischen Masochismus. Für Freud haben Sadismus und Masochismus insofern eine Sonderstellung, als »der ihnen zugrunde liegende Gegensatz von Aktivität und Passivität zu den allgemeinen Charakteren des Sexuallebens gehört« $(\mathrm{V}, 58)$. Für ihn gruppieren sich Sadismus und Masochismus allerdings um ein Gemeinsames, den Schmerz, und insofern sind sie eng verbunden. Freud sieht sie sogar regelhaft, wenngleich unterschiedlich stark ausgeprägt, in derselben Person vereinigt und sieht diese Sichtweise in der klinischen Literatur bestätigt.

Wir kommen zu »3) Allgemeines über alle Perversionen« (V, 59). Hier wird deutlich, wie problematisch für den Entdecker des Unbewußten die Frage nach dem Krankheitswert der Perversionen ist. Einerseits zeigt 
sich, daß die Perversionen generell einen Bestandteil des Sexuallebens darstellen:

"Bei keinem Gesunden dürfte irgendein pervers zu nennender Zusatz zum normalen Sexualziel fehlen und diese Allgemeinheit genügt für sich allein, um die Unzweckmäßigkeit einer vorwurfsvollen Verwendung des Namens Perversion darzutun. Gerade auf dem Gebiete des Sexuallebens stößt man auf besondere, eigentlich derzeit unlösbare Schwierigkeiten, wenn man eine scharfe Grenze zwischen bloßer Variation innerhalb der physiologischen Breite und krankhaften Symptomen ziehen will« $(V, 60)$.

Andererseits findet Freud zwei Kriterien, die Perversionen zu krankhaften Symptomen machen können: 1. Die Entfernung vom Normalen: Der Sexualtrieb vollführt »in der Überwindung der Widerstände (Scham, Ekel, Grauen, Schmerz) erstaunliche Leistungen (Kotlecken, Leichenmißbrauch)«. Interessant ist, daß die psychoanalytische Sichtweise in der Entstehung dieser extremen Ausprägungen die darin enthaltene Leistung betont und würdigt, so als wäre die Kategorisierung als >krankhaft $\iota$, im Text an dieser Stelle übrigens mit Anführungszeichen geschrieben, eher ein Zugeständnis an einen affektiven Vorgang als das bestechende Ergebnis einer Analyse. Freud fügt noch hinzu, daß die betreffenden Personen in ihrem sonstigen Sein als normal gelten und sich auch so verhalten, sie also als krank nur im Feld der Sexualität gelten.

2. Wenn die Perversion »das Normale unter allen Umständen verdrängt und ersetzt hat« $(\mathrm{V}, 61)$, wenn also eine Ausschließlichkeit und Fixierung vorliegt, dann »sehen wir zu allermeist die Berechtigung, sie als ein krankhaftes Symptom zu beurteilen«. Interessant ist hier abermals die Vorsicht, mit der Freud in der Wendung »zu allermeist« eine Einschränkung vornimmt. Es sei hier angemerkt, daß dieses Kriterium einer absoluten Ausschließlichkeit in den mir bekannten Kasuistiken wie auch in meiner Praxis so nie auftritt. Zumindest in Phantasien tauchen bei allen Subjekten mit starker Fixierung bzgl. des Sexualobjekts und -ziels auch andere Elemente auf.

Freud kommt wieder auf die »abscheulichsten Perversionen« zu sprechen und die gerade bei diesen geleistete seelische Arbeit, welcher er »den Wert einer Idealisierung des Triebes nicht absprechen kann. Die Allgewalt der Liebe zeigt sich vielleicht nirgends stärker als in diesen ihren Verirrungen«. Nach dieser Erkenntnis des Wertes der Perversionen im Hinblick auf ihre Entwicklung kommt Freud zu zwei Ergebnissen des Nachdenkens über diese Phänomene: Die Mächte, gegen die der Sexualtrieb ankämpft, vornehmlich Ekel, Scham und Moralität, sind daran 
beteiligt, »den Trieb innerhalb der als normal geltenden Schranken zu bannen«. Dies zeigt deutlich die gesellschaftliche Konstruktion der Perversionen, da sowohl das als >normal Geltende als auch die Entwicklung von Ekel, Scham und, am deutlichsten, Moralität, von gesellschaftlichen Gegebenheiten geprägt sind.

Die Perversionen werden nicht als Entitäten, sondern im Zusammenwirken von mehreren Motiven verständlich. Freud entnimmt dieser Tatsache den Hinweis, »daß vielleicht der Sexualtrieb selbst nichts Einfaches, sondern aus Komponenten zusammengesetzt ist, die sich in den Perversionen wieder von ihm ablösen« (V, 61f). Damit ist Freud nahe an dem die Sexualitäten der Menschen treffend beschreibenden Diktum Jacques Lacans: »Jeder Trieb ist Partialtrieb «. ${ }^{5}$

Das folgende Kapitel »4) Der Sexualtrieb bei den Neurotikern« (V, 62) bringt wenig zur Erhellung der Perversionen, sondern beschäftigt sich mit dem Verhältnis von Neurose und Perversion und ist ergiebiger für die Felder der Neurose und der Paranoia. Hier findet sich auch die berühmte Bestimmung, »die Neurose ist sozusagen das Negativ der Perversion « $(\mathrm{V}, 65)$, welche auf der Annahme beruht, daß hinter jeder Neurose ein verdrängter Aspekt aus dem Sexuellen steckt. Dazu später mehr.

Ergiebiger für uns ist das Kapitel »5) Partialtriebe und erogene Zonen« (V, 67). Freud führt hier die Perversionen auf eine Reihe von Partialtrieben zurück, welche allerdings selbst nicht als primär, sondern als zerlegbar angesehen werden. Es ist interessant, daß Freud hier von "positiven« und »negativen Perversionen« spricht, d.h. er reiht die Neurosen - hier Hysterie und Zwangsneurose sowie eigentlich auch psychotische Phänomene, er nennt Dementia praecox und Paranoia - insofern als negative Perversionen unter die sexuellen Besonderheiten ein, als er sie allesamt als wesentlich sexuell motiviert sieht. Dann definiert Freud Trieb »als die psychische Repräsentanz einer kontinuierlich fließenden, innersomatischen Reizquelle, zum Unterschiede vom 〉Reiz`, der durch vereinzelte und von außen kommende Erregungen hergestellt wird. Trieb ist so einer der Begriffe der Abgrenzung des Seelischen vom Körperlichen«. Hier wird deutlich, daß in der Psychoanalyse ein Triebbegriff gedacht wird, der nicht biologisch ist. Bei Lacan findet sich in der sprachlichen Strukturierung von Trieb dieser Gedanke am konsequentesten weiter gedacht, denn die von Freud angenommene »psychische Repräsentanz«, die den Trieb darstellt, ist nicht anders als sprachlich strukturiert zu denken. 
Freud beschreibt den Trieb an sich als qualitätslos, als beschreibbar eher als Maß von Arbeitsanforderung für das Seelenleben. Die qualitative Unterscheidung von Trieben ist möglich durch ihre Beziehungen zur Quelle und zum Ziel. Die Triebquelle ist der somatische Abhang am Begriff als erregender Vorgang in einem Organ, das Triebziel wäre die Aufhebung dieses Organreizes. Hier merkt Freud in den 20er Jahren an, daß die Trieblehre zugleich das bedeutsamste wie auch das unfertigste Stück in der psychoanalytischen Theorie bilde. Zur Zeit der Niederschrift der Drei Abhandlungen zur Sexualtheorie hat er die Theorie vom Todestrieb noch nicht entwickelt, welche ihn zu obiger Anmerkung veranlaßt hat, da er in ihr u.a. auf Jenseits des Lustprinzips von 1921 verweist.

Freud führt aus, daß die Partialtriebe von verschiedenen Organen, bevorzugt auch von Schleimhäuten, ausgehen können. Die jeweils besetzten Organe nennt er »erogene Zone« (Hervorhebung i.O., V, 68). Die Analyse von Neurosen hat ihm gezeigt, daß mehr (im Fall der Hysterie) oder weniger (im Fall der Zwangsneurose) deutlich erkennbar ist, daß erogene Zonen »als Nebenapparate und Surrogate der Genitalien« fungieren.

Im folgenden Kapitel »6) Erklärung des scheinbaren Überwiegens perverser Sexualität bei den Psychoneurosen« (V, 69) nimmt Freud zunächst den Akzent der perversen Sexualität im neurotischen Geschehen zurück. Er schwankt in der Einschätzung, ob bei Neurosen dem »übergroßen Maß von Sexualverdrängung und einer übermächtigen Stärke des Sexualtriebes eine ungewöhnliche Neigung zur Perversion im weitesten Sinne« beigeordnet werden kann. Er stellt fest, daß bei den meisten Psychoneurotikern »die Erkrankung erst nach der Pubertätszeit [...] unter der Anforderung des normalen Sexuallebens« auftritt. Interessant ist hier, daß das als >normal einnimmt. Ferner scheint in dem Wort »Anforderung« etwas auf, was nicht das Genießen des Körpers im Sexuellen betont, sondern an eine wie auch immer geartete Leistung denken läßt. Hier, ein wenig weiter gedacht, könnte das >Normale sich als Ideal erweisen, dem sich die Einzelnen in ihren jeweils verschieden strukturierten Sexualitäten unterwerfen. Pervers wäre dann die Person, die sich auf ihre jeweilige sexuelle Struktur (sexuellen Genießens) besinnt, mit dieser zu genießen versucht und jedenfalls die Unterwerfung unter das Diktat des >Normalen` verweigert. So könnten wir Freud lesen. Schwierig wäre dann le- 
diglich die Frage, warum die Perversionen etwas mit Krankheitsgeschehen zu tun haben sollten ...

Sehen wir, was Freud hier weiter entwickelt. Er führt für das beschriebene Geschehen eine Metapher ein: Die Libido verhalte sich »wie ein Strom, dessen Hauptbett verlegt wird; sie füllt die kollateralen Wege aus, die bisher vielleicht leer geblieben waren« (V, 69f). Denken wir nicht an Elektrizität, sondern an Wasser. Strom, nicht Bächlein oder Rinnsal. Da schwingt etwas sehr Kraftvolles mit, ein Strom hat auch etwas gewaltig-gewalttätiges, ein Strom kann auch tödlich sein, denken wir an zu starke Strömungen, hohe Wellen oder Strudel. Die Libido erscheint in dieser Metapher materiell wie Wasser vorgestellt: Ein Strom versiegt nicht, fließt permanent, kann je nach Witterung lediglich weniger oder mehr Wasser führen. Wie ein Strom also fließt die Libido gemäß gewisser Gesetze. Die Gravitation läßt in eine Richtung fließen, nämlich bergab. Die Materialität läßt Widerstände meiden, sie werden umflossen. Auch in dieser Metapher scheinen die Fragen und Widersprüche auf, die die Beschäftigung mit der Frage des Normalen und des Perversen begleiten: Warum fließt der Strom entweder im Hauptbett oder in den kollateralen Wegen? Ist es nicht eher so, daß ein Hauptbett gelegentlich zu zwei Flußarmen werden kann, ist es nicht eher so, daß Flußnebenläufe auch immer fließen, gibt es nicht tote Arme neben Flüssen, in denen das Wasser steht statt zu fließen? Es wird noch komplizierter. Direkt nach dem metaphorischen Satz lesen wir: »Somit kann auch die scheinbar so große (allerdings negative) Perversionsneigung der Psychoneurotiker eine kollateral bedingte, muß jedenfalls eine kollateral erhöhte sein« $(\mathrm{V}, 70)$. Wir haben gesehen, daß Freud die Neurose als das Negativ der Perversion bezeichnet hat, was hier wieder auftaucht. Die >negative Perversionsneigung « wäre dann also eigentlich zu verstehen als Neurose, die entstanden ist durch Sexualverdrängung. Hier schwankt Freud zwischen der >Neurose als Negativ der Perversion` und der Möglichkeit, bei neurotischen Subjekten eine Perversionsneigung neben der Neurose anzunehmen.

Auf die offene Frage aus dem letzten Kapitel bietet Freud unter »7) Verweis auf den Infantilismus der Sexualität« (V, 71) eine Lösung. Er sieht die perversen Regungen bei den Psychoneurosen «als Symptombildner« an. Die perverse Neigung selbst kann also als die verdrängte Sexualstrebung angesehen werden, welche das neurotische Symptom hervorbringt. Damit allerdings findet Freud »die Anzahl der Menschen, die man den Perversen zurechnen könnte, in ganz außerordentlicher 
Weise gesteigert«. Aus psychoanalytischer Sicht ist also eine verdrängte, mithin unbewußte Perversionsneigung ausreichend, eine Perversion zu definieren, es ist also in keiner Weise nötig, manifest pervers zu handeln, um pervers zu sein, z.B. als HysterikerIn. Damit verschwindet eine ohnehin nie wahrnehmbare Grenze zwischen >normal` und spervers doppelter Weise, einmal insofern »die Neurosen von allen ihren Ausbildungen her in lückenlosen Reihen zur Gesundheit abklingen«, also bei dem Paar >neurotisch` versus >gesund k kein Gegensatz, sondern ein Kontinuum vorliegt; zum anderen »werden wir durch die außerordentliche Verbreitung der Perversionen zu der Annahme gedrängt, daß auch die Anlage zu den Perversionen keine seltene Besonderheit, sondern ein Stück der für normal geltenden Konstitution sein müsse«. Hier fällt zweierlei auf: Einmal ist der Antipode des Wortes >pervers« nicht >gesund «, sondern >normal«, womit, wie bereits mehrfach erwähnt, die gesellschaftlichen Normen als wesentlicher Bestandteil jeder Perversionstheorie die Relativität und zeitliche Begrenztheit der Definitionsversuche unterstreichen, zum anderen verschwimmt in der Formulierung der Gegensatz von >normal« und >pervers $\triangleleft$, so daß die Linearität eines Kontinuums, wie es zwischen >neurotisch de, aufgegeben wird zugunsten eines eher gekrümmt vorzustellenden Gebildes, einer Ellipse oder eines Kreises etwa. Es ließe sich auch, im wahrsten Sinne des Wortes, auf den Punkt bringen.

Freud erkennt, daß das Potential perverser Entwicklung eine allgemein menschliche Konstitution ist.

Es handelt sich um angeborene, in der Konstitution gegebene Wurzeln des Sexualtriebes, die sich in der einen Reihe von Fällen zu den wirklichen Trägern der Sexualtätigkeit entwickeln (Perverse), andere Male eine ungenügende Unterdrückung (Verdrängung) erfahren, so daß sie auf einem Umweg als Krankheitssymptome einen beträchtlichen Teil der sexuellen Energie an sich ziehen können, während sie in den günstigsten Fällen zwischen beiden Extremen durch wirksame Einschränkung und sonstige Verarbeitung das sogenannte normale Sexualleben entstehen lassen."

Bleibt anzumerken, ob der letzte Fall eine Chance hat, allzu häufig zu entstehen; ich glaube, es wird ihn in reiner Form kaum geben. Jedenfalls ist es u.a. eine >wirksame Einschränkung ${ }^{6}{ }^{6}$, welche die Voraussetzung für das >sogenannte normale Sexualleben eigenen Einschätzung überlassen werden, ob hier sich vielleicht eine Gegenüberstellung andeutet, die bedeutet: >beschränkt und normal< versus >weniger beschränkt und pervers $`$. 
Im Text folgen nun zwei weitere Abschnitte, »II. Die infantile Sexualität« (V, 73) sowie »III. Die Umgestaltungen der Pubertät« (V, 108), welche hier nicht mehr vorgestellt werden können, die ich Ihnen aber gleichwohl sehr zur Lektüre empfehle, da besonders die Ausführungen über die kindliche Sexualität den Charakter der Partialtriebe erhellen. Es sei angemerkt, daß die berühmte Äußerung Freuds, die kindliche Sexualität sei »polymorph-pervers« $(\mathrm{V}, 91)$ angelegt, hier gemacht wird.

1913 veröffentlicht Freud in Australien einen Text unter dem Titel »On Psycho-Analysis« (Nachtragsband, 723), dessen deutsches Original 1911 geschrieben wurde und nicht erhalten ist. Ich möchte nun ein Zitat aus der Rückübersetzung des Textes von Anna Freud, welcher unter dem Titel Über Grundprinzipien und Absichten der Psychoanalyse veröffentlicht wurde, einbeziehen. Dort lesen wir:

"Unsere wichtigste Entdeckung war vielleicht, daß es so etwas gibt wie eine infantile Sexualitätı, daß der Sexualtrieb aus einer Reihe von Partialtrieben zusammengesetzt ist und daß er eine komplizierte Entwicklung durchmacht, ehe nach vielen Einschränkungen und Umformungen am Ende die snormales erwachsene Form des Sexuallebens zustande kommt. Die bisher rätselhaften sexuellen Perversionen des Erwachsenen erklären sich in diesem Zusammenhang als sexuelle Entwicklungshemmungen, als Fixierungen an infantile Entwicklungsstufen oder als abwegige Entwicklungsprodukte. Die Neurosen sind nichts anderes als das Negativ der Perversionen« (Nachtragsband, 726).

Daß der Sexualtrieb als aus Partialtrieben bestehend zu verstehen ist, hatten wir schon gesehen. Auch daß die >normale` Form des Sexuallebens aus `Einschränkungen` und ১Umformungen` entsteht, ist ein Stück weit schon in den Drei Abhandlungen zur Sexualtheorie entwickelt worden. Für die Entwicklung der Perversionen bietet Freud hier drei Erklärungen. Die »sexuelle[n] Entwicklungshemmungen« setzen allerdings ein Ziel einer Entwicklung voraus, möglicherweise ist hier an das >Primat der Genitalien` zu denken, eine in der Psychoanalyse verbreitete Vorstellung, die allerdings hinter die Entdeckungen von 1905 zurückfällt. Die »Fixierungen an infantile Entwicklungsstufen« werfen abermals die Frage der Quantität auf, es ist schwer vorstellbar, daß die orale oder anale Stufe ohne Fixierungen der einen oder anderen Ausprägung durchlaufen werden können. Schließlich verrät uns Freud nicht, was er unter »abwegige[n] Entwicklungsprodukte[n]« versteht. Ohne Lektüre des zum Stellvertreteroriginal gewordenen englischen Textes ist nicht zu entscheiden, inwiefern diese Formulierung eine annafreudianische sein könnte. 
1915 verfaßt Freud einen Entwurf für einen abschließenden Beitrag einer auf zwölf Teile angelegten Metapsychologie ${ }^{7}$ mit dem Titel Übersicht der Übertragungsneurosen, welcher erst 1983 entdeckt und 1985 veröffentlicht wurde. Hier definiert Freud die »nicht zur Kinderzeugung führenden Befriedigungen« (Nachtragsband, 645) als pervers. Übrigens taucht hier auch der bereits erwähnte »Primat der Genitalien« auf. Jedenfalls ist mit dieser Definition von >pervers $₫$ die Perversion eher als das Regelhafte im Sexualleben zu verstehen, das andere, welches Freud hier nicht bezeichnet, ist als seltene Ausnahme sexueller Handlungen zu sehen, die »Befriedigung, die zur Kinderzeugung führt«. In den Vorlesungen zur Einführung in die Psychoanalyse von 1917 nimmt Freud in der »XX. Vorlesung. Das menschliche Sexualleben« (XI, 313ff.) diesen Faden wieder auf. Es ist

»der gemeinsame Charakter aller Perversionen, daß sie das Fortpflanzungsziel aufgegeben haben. In dem Falle heißen wir eine Sexualbetätigung eben pervers, wenn sie auf das Fortpflanzungsziel verzichtet hat und die Lustgewinnung als davon unabhängiges Ziel verfolgt. Sie verstehen also, der Bruch und Wendepunkt in der Entwicklung des Sexuallebens liegt in der Unterordnung desselben unter die Absichten der Fortpflanzung. Alles was vor dieser Wendung vorfällt, ebenso alles, was sich ihr entzogen hat, was allein dem Lustgewinn dient, wird mit dem nicht ehrenvollen Namen des 'Perversen` belegt und als solches geächtet» (XI, 327).

Freud bietet hier wieder eine sehr enge bzw. eigentlich sehr weite Definition von Perversion an; er nennt jede Sexualbetätigung pervers, die ausschließlich der Lustgewinnung statt der Fortpflanzung dient. Daß er damit die nicht-perverse Sexualität zu einer recht seltenen Ausnahme im Feld des Sexuellen macht, verdeutlicht, wie prekär Definitionsversuche sind. Man könnte mit den Worten des Psychoanalytikers Lutz Mai, sozusagen mit Freud gegen Freud, das Verhältnis von Fortpflanzung und menschlicher Sexualität nicht nur als ein gänzlich voneinander abgelöstes, sondern als ein hemmendes bestimmen: »Die menschliche Sexualität ist das, was der Fortpflanzung im Wege steht. ${ }^{8}{ }^{7}$ Freud relativiert selbst in der folgenden »XXI. Vorlesung. Libidoentwicklung und Sexualorganisationen« (XI, 331): »Vergessen Sie nicht, wir sind derzeit nicht im Besitze eines allgemein anerkannten Kennzeichens für die sexuelle Natur eines Vorganges, es sei denn wiederum die Zughörigkeit zur Fortpflanzungsfunktion, die wir als zu engherzig ablehnen müssen.« Die Fortpflanzungsfunktion reicht nicht aus, weil es die Perversen gibt. Freud fährt weiter unten fort: „Um ihretwillen allein sind wir zur Be- 
hauptung berechtigt, daß Sexualität und Fortpflanzung nicht zusammenfallen [...]« (XI, 332). Wir sehen: Die Beschäftigung mit den Perversionen gestattet es der Psychoanalyse, die menschliche Sexualität genauer zu erkennen. Die einfache Gleichung `sexuell = genital $८$ gilt aus psychoanalytischer Sicht nicht. Das konstituierende Moment der Perversionen für die menschlichen Sexualitäten, die Tatsache, daß perverse Anteile allgegenwärtig zu sein scheinen, wie wir gesehen haben auch in neurotischen und psychotischen Symptomen, wirft eine Frage auf: Wieso dieses allgemein menschliche Phänomen mit einer so despektierlichen Bezeichnung belegen? Freud findet als einen Grund für die abwehrende Haltung den Perversionen gegenüber »geheimen Neid«, den die empfinden, die ihre perversen Neigungen nicht manifest ausleben.

„Wenn aber die Existenz der sexuellen Perversionen ein so zwingendes Argument in dieser Frage ist, warum hat es nicht bereits längst seine Wirkung getan und diese Frage erledigt? Ich weiß es wirklich nicht zu sagen. Es scheint mir daran zu liegen, daß diese sexuellen Perversionen mit einer ganz besonderen Acht belegt sind, die auf die Theorie übergreift und auch ihrer wissenschaftlichen Würdigung in den Weg tritt. Als ob niemand vergessen könnte, daß sie nicht nur etwas Abscheuliches, sondern auch etwas Ungeheuerliches, Gefährliches sind, als ob man sie für verführerisch hielte und im Grunde einen geheimen Neid gegen die sie Genießenden niederzukämpfen hätte, etwa wie ihn der strafende Landgraf in der berühmten Tannhäuserparodie eingesteht:

>Im Venusberg vergaß er Ehr' und Pflicht!

- Merkwürdig, unser einem passiert so etwas nicht.«

Freud stellt fest, »daß dem Sexualleben der Normalen nur selten der eine oder andere perverse Zug abgeht« (XI, 333). Er hält es hier für sinnlos, diese sich auch pervers betätigenden Personen als Perverse zu bezeichnen, sondern bestimmt eine Perversion erst dann als gegeben, wenn sie einen Status von Ausschließlichkeit in der Sexualität erlangt hat. Er setzt also wieder einen quantitativen Unterschied, der in eine Qualität, hier die Ausschließlichkeit, umschlägt. Ob diese Einschränkung des Begriffes trägt oder nicht, Freud ist jedenfalls klarsichtig genug, zu erkennen, daß diese klar fixierten Perversionen einer Zentrierung unterliegen, die genauso organisiert ist wie die genitale Zentrierung. Wir lesen:

»n dieser Hinsicht ist zwischen der perversen und der normalen Sexualität kein anderer Unterschied, als daß die herrschenden Partialtriebe und somit die Sexualziele verschiedene sind. Es ist sozusagen hier wie dort eine gut organisierte Tyrannis, nur daß hier die eine, dort eine andere Familie die Herrschaft an sich gerissen hat» (XI, 334). 
Sowohl die/der im Normalen Gefangene wie auch die/der in einer Perversion Fixierte teilen also das Schicksal, in ihrer Genußfähigkeit arg beschränkt zu sein.

Um die Entwicklung im Denken Freuds bezüglich der Perversionen nachzeichnen zu können, ist ein weiterer Text wichtig, es geht um $>$ Ein Kind wird geschlagen $<$ Beitrag zur Kenntnis der Entstehung sexueller Perversionen (XII, 197), ein Text von 1919. Im Titel fällt auf, daß das Wort »Perversionen« durch »sexuell« präzisiert ist, also offenbar ein Gebrauch auch außerhalb des sexuellen Feldes nahegelegt wird. Sehen wir die für unsere Fragestellung wichtigsten Passagen der Schrift an. Freud findet bei überraschend vielen Personen, die wegen einer Hysterie oder Zwangsneurose die psychoanalytische Behandlung aufgesucht hatten, die Phantasievorstellung mit dem Inhalt »ein Kind wird geschlagen«. Es fällt auf, daß Freud den wortwörtlichen Inhalt einer sexualisierten Phantasie als Titel wählt, also den Akzent auf die Signifikanten legt und nicht auf eine klinische Klassifizierung des Phänomens. Die Phantasie selbst umfaßt drei Personen: das Subjekt, eine schlagende Person und das geschlagene Kind.

Freud merkt auch an, daß seine Explorationen keine nähere Beschreibung dieser Phantasien brachten, d.h. es gibt eine Stockung, ein Hindernis beim In-die-Sprache-Bringen sexueller Phantasien, ein Phänomen, das allen gelegentlich auf dem Gebiet des Sexuellen Explorierenden sehr geläufig sein dürfte. Die nämliche Phantasie ist mit Lustgefühlen verbunden und wird, teilweise mit Zwangscharakter, bei der Selbstbefriedigung eingesetzt. Freud findet in den Analysen der betreffenden Personen, daß diese Phantasien sehr früh, schon in der Vorschulzeit, gepflegt und von da aus weiter entwickelt und beibehalten wurden. Reale Schlageszenen aus der Schulzeit riefen bei den zuschauenden Kindern allerdings kein Genießen hervor, sondern »ein eigentümlich aufgeregtes, wahrscheinlich gemischtes Gefühl, an dem die Ablehnung einen großen Anteil hatte« (XII, 198f). Die real beobachteten Schlageszenen wurden zum Teil auch als unerträglich empfunden. Freud berichtet ferner, daß auch in den entwickelteren Phantasien späterer Jahre wichtig ist, »daß den gezüchtigten Kindern kein ernsthafter Schaden zugefügt werde« (XII, 199). In den Analysen stellt Freud fest, daß die Betroffenen in ihrer Kindheit selbst eher selten geschlagen worden sind. Fragen nach der Identität des geschlagenen Kindes wie nach der der schlagenden Person können die Betroffenen nicht beantworten, die Frage nach dem Geschlecht des geschlagenen Kindes bringt insofern keine weiterführende 
Antwort, als es keine konstanten Beziehungen zwischen dem Geschlecht des/der phantasierenden Analysanten/Analysantin und dem des geschlagenen Kindes gibt. So weiß Freud die an der Schlagephantasie haftende Lust nicht als sadistische oder masochistische zu bezeichnen.

Im zweiten Kapitel erklärt Freud, daß die Entstehung einer solchen »zur autoerotischen Befriedigung festgehaltenen Phantasie« (XII, 200) durch das Vorauseilen einer Komponente der Sexualfunktion in Verbindung mit einer Fixierung, welche sie späteren Entwicklungen entzieht, zu verstehen ist. Dann allerdings kommen die Fragen. Warum verfällt diese infantile Perversion nicht der Verdrängung? Weshalb können oft recht banal erscheinende Eindrücke das Sexualstreben fixieren? Freud führt aus, daß die psychoanalytische Forschung ergeben hat, daß eine sadistische Sexualkomponente, die später verdrängt wird, eine Disposition zur Zwangsneurose bildet. Für die sechs Fälle, vier Frauen und zwei Männer, welche die Grundlage für diese Schrift bilden, war nicht bei allen der Grund für die Analyse eine Zwangsneurose. Freud mag sich nicht damit zufrieden geben, daß die Schlagephantasien »meist abseits vom übrigen Inhalt der Neurose bleiben und keinen rechten Platz in deren Gefüge einnehmen« (XII, 202).

Im nun folgenden dritten Kapitel verfolgt Freud die Entwicklung der Phantasien. Da die Schlagephantasien der Analysantinnen bzw. Analysanten erst mit ca. fünf Jahren auftauchen, geht Freud davon aus, daß die berichtete Phantasie eher »einem Endausgang, nicht einer Anfangsäußerung entsprechen« (XII, 203), sie also eine Entwicklung hinter sich haben, »in deren Verlauf sich das meiste an ihnen mehr als einmal ändert: ihre Beziehung zur phantasierten Person, ihr Objekt, Inhalt und ihre Bedeutung«. Freud beschränkt sich nun zur Vereinfachung der Darstellung auf das Material der vier Analysantinnen. Zunächst stellt er fest, daß »das geschlagene Kind [...] nie das phantasierende, regelmäßig ein anderes Kind, zumeist ein Geschwisterchen, wo [...] vorhanden, ist «. Die Phantasie ist also keine masochistische, aber sie scheint auch keine sadistische zu sein, da die schlagende Person, welche zunächst unbestimmt bleibt, sich im Laufe der Analyse als der Vater des Mädchens erweist. So lautet die erste Phase der Schlagephantasie: »Der Vater schlägt das Kind « (diese und die folgenden Hervorhebungen i.O., XII, 204) oder genauer: »Der Vater schlägt das mir verhaßte Kind«. Die zweite Phase, welche in keinem Fall erinnert wurde und eine Konstruktion der Analyse ist, allerdings eine notwendige, wie Freud betont, »ist in hohem Grade lustbetont und [...] hat unzweifelhaft masochistischen Charakter«. Sie 
lautet: »Ich werde vom Vater geschlagen«. Die dritte Phase ähnelt wieder der ersten; die schlagende Person ist nie der Vater, sondern durch einen Vatervertreter, z.B. einen Lehrer besetzt. Die eigene Person kommt nicht mehr zum Vorschein, wenn, dann als Zuschauerin. Das eine geschlagene Kind ist jetzt durch viele Kinder ersetzt, die meist männlichen Geschlechts und der Phantasierenden nicht bekannt sind. Wichtig ist: »die Phantasie ist jetzt der Träger einer starken, unzweideutig sexuellen Erregung und vermittelt als solcher die onanistische Befriedigung« (XII, 205). Hier gesteht Freud, »daß Zusammenhang und Aufeinanderfolge der drei Phasen der Schlagephantasie [...] bisher ganz unverständlich geblieben sind «. Im nun folgenden vierten Kapitel zeigt die Analyse, daß das kleine Mädchen »zärtlich an den Vater fixiert» (XII, 206) ist. Die Geschwisterkinder, zumal wenn es jüngere sind, wie bei drei der vier analysierten Frauen der Fall, ziehen Liebe und Zärtlichkeit vom Vater auf sich, wofür das Kind sie haßt. Das Geschlagenwerden ist zu verstehen als »eine Absage der Liebe und eine Demütigung«. Die erste Phase also, »der Vater schlägt das verhaßte Kind «, heißt: »der Vater liebt dieses andere Kind nicht, er liebt nur mich«. Die sexuelle Erregung ist in dieser ersten Phase schon angelegt, aber noch diffus. Es handelt sich um eine interessante Variante des ödipalen Komplexes, den Freud hier für Mädchen und Jungen recht parallel konstruiert und bei dem sich die Haß- und Konkurrenzeinstellung nicht an die Mutter, sondern an das Geschwisterkind knüpft. Das Schicksal der ödipalen Objektwahl ist bekannt, sie wird vollständig verdrängt, wirkt im Unbewußten fort und bringt so das Schuldbewußtsein hervor. Dieses findet Ausdruck in der zweiten Phase, die masochistisch geworden ist und lautet: »)Nein, er liebt dich nicht, denn er schlägt dich«" (XII, 208). Im Geschlagenwerden findet Freud ein Zusammentreffen von Schuldbewußtsein und Erotik. Das Geschlagenwerden »ist nicht nur die Strafe für die verpönte genitale Beziehung, sondern auch der regressive Ersatz für sie, und aus dieser letzteren Quelle bezieht es die libidinöse Erregung, die ihm von nun anhaften und in onanistischen Akten Abfuhr finden wird« (XII, 209). Daß die Phantasie der zweiten Phase in der Regel unbewußt bleibt, kann an der Intensität der Verdrängung liegen. Die Phantasie der dritten Phase kann dann als Ersatz der unbewußten zweiten Phase gelesen werden. Von der Formel der ersten Phase: »Der Vater schlägt das andere Kind, er liebt nur mich« (XII, 211), scheint der zweite Teil verdrängt worden zu sein, der Akzent ist auf den ersten Teil zurückgewichen. Die Phantasie scheint wieder ins Sadistische gewendet, 
ist dies aber nur formal, da die vielen unbestimmten Kinder, die von der den Vater ersetzenden Person wie z.B. dem Lehrer geschlagen werden, Ersetzungen der eigenen Person sind. Die libidinöse Besetzung des verdrängten Anteils ( $>$ er liebt mich $২$ ) ist übernommen worden und damit »auch das am Inhalt haftende Schuldbewußtsein«.

Für die Entstehung der Perversionen folgert Freud im nun folgenden fünften Kapitel aus dem Vorausgegangenen, daß sie, wie jede Konstituierung des Sexuellen, eine enge Verbindung mit dem Ödipuskomplex hat. Wir lesen: »Die Perversion steht nicht mehr isoliert im Sexualleben des Kindes, sondern sie wird in den Zusammenhang der uns bekannten typischen - um nicht zu sagen: normalen - Entwicklungsvorgänge aufgenommen. Sie wird in Beziehung zur inzestuösen Objektliebe des Kindes, also zum Ödipuskomplex des Kindes gebracht, tritt auf dem Boden dieses Komplexes zuerst hervor, und nachdem er zusammengebrochen ist, bleibt sie, oft allein, von ihm übrig, als Erbe seiner libidinösen Ladung und belastet mit dem an ihm haftenden Schuldbewußtsein« (XII, 212). Freud ist hier schon sehr nahe an dem später von ihm entwickelten Strukturelement der Perversion, einem spezifischen Umgang mit der Kastration. Er fügt noch an, daß »Menschen, die eine solche Phantasie bei sich tragen, [...] eine besondere Empfindlichkeit und Reizbarkeit gegen Personen, die sie in die Vaterreihe einfügen können« (XII, 216), entwickeln und leicht von diesen Vaterfiguren gekränkt werden. Dies als Hinweis darauf, daß die Spezifika, die ein Subjekt im sexuellen Feld entwickelt, nicht isoliert betrachtet werden sollten, da vielfältige Effekte aus der Sexualkonstitution hervorgehen. Ich verlasse den Text Ein Kind wird geschlagen an dieser Stelle und wende mich einer anderen Untersuchung Freuds zu.

1927 veröffentlicht Freud eine Abhandlung mit dem Titel Fetischismus (XIV, 311). Er hat eine Reihe von Männern in Analyse gehabt, »deren Objektwahl von einem Fetisch beherrscht war«, bei denen sich durchweg dieselbe analytische Aufklärung bzgl. Sinn und Absicht des Fetischs ergaben. Vorab sei bemerkt, daß das Wort >Perversion $८$ in dieser Arbeit nicht auftaucht. Dann ist bemerkenswert, daß Freud die betreffenden Analysanten nicht wegen deren Fetischismus in Analyse hatte, sondern der Fetischismus spielte nur eine Nebenrolle; die Betroffenen zeigten sich mit ihrer Objektwahl, dem Fetisch, meist »zufrieden oder loben sogar die Erleichterungen, die er ihrem Liebesleben« ermöglichte. Freud stößt hier auf ein Phänomen, das bei verschiedenen Perversionen $\mathrm{zu}$ beobachten ist, nämlich daß die betroffenen Personen häufig froh 
über ihre sexuelle Verfaßtheit und Orientierung sind, da diese Garanten ihres Genießens zu sein scheinen. Natürlich gibt es auch bei den Perversionen ein Leiden am Symptom, dies scheint jedoch sehr viel seltener der Fall zu sein und in seinem Ausmaß letztlich bei genauerer Analyse oft von der gesellschaftlichen Bewertung der jeweiligen Orientierung abzuhängen.

Freud erwähnt einen besonders merkwürdigen Fall, es geht um einen jungen Mann, der »einen gewissen `Glanz auf der Nase` zur fetischistischen Bedingung erhoben hatte«. Für diesen Fetisch fand Freud folgende Aufklärung: Der Signifikant `Glanz« ist durch die Verschiebung vom Englischen in das Deutsche entstanden, wobei der Signifikant persistierte, also nicht übersetzt wurde. Es war eigentlich das englische Wort für 〉Blick«, also >glance〈, das der Ausgangspunkt für 〉Glanz « war, da der Betroffene als Kind anglophon aufwuchs. Der Fetisch war also die Nase, nicht `Glanz auf der Nase`, sondern ein 〉Blick auf die Naseく. Wofür die Nase wiederum stehen kann, überläßt Freud unserer Phantasie.

Freud fand nun in allen analysierten Fällen, daß der Fetisch ein Ersatz war für den Phallus der Frau, eigentlich der Mutter. Der Knabe weigert sich also, »die Tatsache seiner Wahrnehmung, daß das Weib keinen Penis besitzt, zur Kenntnis zu nehmen« (XIV, 312). Ließe er die Wahrnehmung zu, dann wäre sein eigener Penisbesitz bedroht, was letztlich die Kastrationsangst befördert. Zunächst beschreibt Freud den Vorgang als Verdrängung, kommt dann aber dazu, die Vorstellung, hier die Kas tration, vom Affekt, hier Angst und Panik, zu trennen. Der Affekt würde dann der Verdrängung anheimfallen, für die Vorstellung, welche wir auf der Ebene der Signifikanten lesen könnten, wählt Freud die Bezeichnung $»$ Verleugnung«. Mit der Verleugnung ist die unerwünschte Wahrnehmung nicht verschwunden, sie bleibt weiter wirksam. »[...] im Konflikt zwischen dem Gewicht der unerwünschten Wahrnehmung und der Stärke des Gegenwunsches ist es zu einem Kompromiß gekommen, wie es nur unter der Herrschaft der unbewußten Denkgesetze - der Primärvorgänge - möglich ist « (XIV, 313). Was Freud hier u.a. zum Ausdruck bringt ist die Tatsache, daß es im Unbewußten kein Nein, keine Negation gibt, d.h. der Penis der Frau ist vorhanden, allerdings in ersetzter Form. Dieser Penisersatz erbt das Interesse, das zuvor dem Penis der Frau galt, und steigert es noch, da er auch ein »Denkmal«»der Abscheu vor der Kastration« ist. Der Fetisch »bleibt das Zeichen des Triumphes über die Kastrationsdrohung und der Schutz gegen sie«. Freud räumt 
ein, sich hier mit der Erklärung dessen, was geschehen ist, zufrieden zu geben und nicht erklärt zu haben, warum es geschehen ist. Es folgt eine Reihe von Beispielen, bevor Freud noch einen weiteren Vorgang beschreibt, der neben dem der Verleugnung eine wichtige Rolle beim Fetischismus spielt, nämlich die Spaltung. Freud definiert hier Spaltung so, daß »die wunschgerechte wie die realitätsgerechte Einstellung [...] nebeneinander « (XIV, 316) bestehen. ${ }^{9}$ Dies ist insofern eine bemerken swerte Struktur, als dem nebeneinander Bestehen zweier sich eigentlich widersprechenden Einstellungen etwas zutiefst Primärprozeßhaftes innewohnt.

Mit der Darlegung dieser Strukturelemente der Perversion bei Freud verlassen wir die Texte des Begründers der Psychoanalyse und werfen noch einen Blick auf einige markante Punkte im Denken Lacans zu dem Thema. Es sei zunächst bemerkt, daß Lacan den Perversionen keinen allzu hohen Stellenwert für das psychoanalytische Denken eingeräumt zu haben scheint, er erwähnt sie zwar gelegentlich und liefert auch einige interessante Beiträge, aber er macht sie, im Gegensatz etwa zu den Psychosen $^{10}$ oder der Angst ${ }^{11}$, nie zu einem plakativen Thema seiner Jahresseminare. Beginnen wir mit einem längeren Zitat aus dem IV. Seminar zur Objektbeziehung von 1956/1957. Dort sagt Lacan:

"Was ist Perversion? Innerhalb ein und derselben psychoanalytischen Gruppierung hört man dazu die zwiespältigsten Stimmen. Die einen glauben, sie folgten Freud, und behaupten, daß man schlicht und einfach auf die Annahme des Fortbestehens einer Fixierung zurückgehen muß, die sich auf einen Partialtrieb bezieht. Dieser würde gewissermaßen schadlos die gesamte Dialektik des Ödipus durchlaufen, die dabei ist sich herzustellen. Er würde nicht die Schicksale erleiden, die die anderen Partialtriebe zu reduzieren und in einer Bewegung zu vereinen trachten, die sie letzten Endes in den Geschlechtstrieb einmünden läßt, der der vereinigende ideale Trieb ist. Demnach wäre die Perversion ein Unfall in der Entwicklung der Triebe. Indem diese Analytiker in klassischer Weise Freuds Annahme ausdrücken, wonach die Perversion das Negativ der Neurose $^{12}$ sei, wollen sie die Perversion schlicht und einfach zu einer Größe machen, in der der Trieb sich nicht ausgearbeitet hat. Andere jedoch, die im übrigen nicht zwangsläufig deshalb die Schlaueren oder die Besseren sind, die aber gewitzt sind durch die Erfahrung und durch eine Offensichtlichkeit, die sich in der analytischen Praxis wahrhaftig ausprägt, versuchen zu zeigen, daß die Perversion recht weit davon entfernt ist, jenes reine Element zu sein, das fortbesteht, und daß auch sie durchaus Anteil hat an dem, was sich durch die ganzen Krisen, die dramatischen Verschmelzungen und Entschmelzungen, die eine Neurose durchquert, hindurch realisiert hat und 
was denselben Reichtum an Dimensionen wie diese, denselben Überfluß, dieselben Rhythmen und dieselben Etappen aufweist. Sie versuchen daraufhin zu erklären, daß die Perversion das Negativ der Neurose ist, indem sie eine Formel wie die folgende in den Vordergrund rücken, zu der sie die gesamten Spiele inspirieren, durch die hindurch sich eine Analyse der Reduktion der Abwehrformen verfolgen läßt - es geht in der Perversion um die Erotisierung der Abwehr. Ich habe nichts dagegen, das macht ein schönes Bild. Doch, ehrlich gesagt, warum kann diese erotisiert werden? Das ist die ganze Frage. Woher kommt diese Erotisierung? Wo hat die unsichtbare Macht ihren Ort, die das projizieren würde, was dort scheinbar wie etwas Überflüssiges kommt, diese Färbung, dieser Eigenschaftswandel, diese libidinöse Befriedigung? In Wahrheit ist die Sache nicht undenkbar, aber das wenigste, was man sagen könnte, ist, daß sie nicht gedacht wird. ${ }^{13}$

Mir scheint Lacan hier eine gute Zusammenfassung zweier grundlegender Sichtweisen zur Problematik zu gelingen, wobei das meiste der vorgetragenen Gedanken bei Freud bereits zu finden ist und sein immer wieder wahrnehmbares Schwanken bei der Theoretisierung der Perversionen mitbedingt. Zugleich, so hoffe ich deutlich gemacht zu haben, hatte schon Freud die reduktionistischen Sichtweisen, die Lacan hier referiert, zumindest im Ansatz, überwunden. In Lacans Seminar zur Objektbeziehung finden sich eine Fülle von Ansätzen zur Theoretisierung der Sexualitäten, vornehmlich auch zur Bestimmung der Rolle des Phallus. Dies würde einen ganzen Vortrag füllen, ich komme zu einem anderen Schlaglicht auf das Thema der Perversionen, das Lacan in einer Schrift von 1963 geworfen hat. Lacan definiert das Begehren als das Begehren des Anderen, die sprachlich vermittelte Struktur des Begehrens ist immer als ein Begehren nach einem Begehren zu verstehen. In Kant mit Sade führt Lacan nun die Funktion der Wahrheit ein. Die Praxis der Psychoanalyse erkennt »in der Begierde die Wahrheit des Subjekts «. ${ }^{14}$ Ein Verzicht im Hinblick auf die Begierde »wird [...] damit erkauft, daß der Mensch seine Wahrheit preisgibt «. ${ }^{15}$ Bemerkenswert ist, daß Lacan hier die Wahrheit nicht nur als die Wahrheit des Subjekts des Unbewußten bestimmt, sondern eine eher ontologische Bestimmung vornimmt als $>$ Wahrheit des Menschen $<$. Damit ist u.a. gesagt, daß das Begehren weit mehr umfaßt als das triebhafte Geschehen, es wird zur wichtigen Dimension des Menschseins. Es sei erwähnt, daß im französischen Text »désir« steht, was hier interessanterweise mit »Begierde« übersetzt wurde und nicht, wie sonst üblich, mit »Begehren«. Möglicherweise ist diese Verschiebung in der Bedeutung ein Hinweis auf die 
Tragweite der Bestimmung des Verhältnisses von Begehren, Wahrheit und Menschsein, wenngleich dieses im strengen Sinne auch freudianisch genannt werden könnte. Vielleicht ist diese Verschiebung aber auch im Hinblick auf de Sade zu verstehen. Jedenfalls umfaßt das Begehren oder die Begierde natürlich auch das sogenannte perverse Begehren und wir halten fest, daß Lacan keinen Unterschied macht bzgl. des Verhältnisses zur Wahrheit. Im Seminar von 1964 über Die vier Grundbegriffe der Psychoanalyse entwickelt Lacan im XIV. Kapitel »Der Partialtrieb und seine Kreisbahn « ${ }^{16}$, ausgehend von Freuds Schrift Triebe und Triebschicksale von 1915, seine Formel »Jeder Trieb ist Partialtrieb «. ${ }^{17}$ Lacan führt aus, daß die Triebe an einen ökonomischen Faktor gebunden sind, der von Bedingungen abhängt, die er mit dem Terminus Real-Ich versieht und dem die Funktion des Lustprinzips unterstellt ist. Vorläufig sieht Lacan im Real-Ich »ein System, das eine gewisse Homöostase der inneren Spannungen gewährleisten soll «. ${ }^{18}$ Wir lesen:

„Um der Realität dieses homöostatischen Systems willen tritt die Sexualität nur in Form der Partialtriebe auf. Der Trieb ist in genauem Sinne jene Montage, mit deren Hilfe die Sexualität am psychischen Leben partizipiert, und zwar auf eine Weise, die der Struktur eines Aufklaffens $\sim$ structure de béance angepaßt sein muß, die die Struktur des Unbewußten ist ${ }^{19}$

Der Trieb kann nur als Partialtrieb in Erscheinung treten, da er die Sexualität, ausgehend vom Unbewußten, in Form einer permanenten Kreisbahn im Seelenleben repräsentiert, als Beimengung in wahrscheinlich allen seelischen Regungen. Für die Entwicklung der Partialtriebe geht Lacan nicht von einer Art »Erzeugung von einem der Partialtriebe zum nächsten $\aleph^{20}$ aus, es gibt kein Verhältnis deduktiver oder genetischer Art. Damit wird auch die Vorstellung sexueller Entwicklung als Abfolge von Partialtrieben, die quasi aufeinander aufbauen und sich auf ein Ziel wie z.B. die >genitale Reife hin entwickeln, als psychoanalytisches Konzept abgelehnt. ${ }^{21}$ Das Verhältnis von Trieb und Perversion ist bei Lacan zu verstehen als zu unterscheidendes im Hinblick auf die Situierung des Subjekts. Trieb sieht er mit Freud als »eine radikale Struktur [...], in welcher dem Subjekt noch kein Ort angewiesen ist «. ${ }^{22}$ Die Perversion hingegen definiert sich gerade »durch die Art und Weise, wie das Subjekt seinen Platz in ihr findet«. ${ }^{23}$ Im Hinblick auf das Subjekt könnte man den Trieb also als fast äußerlich, jedenfalls eher daneben oder dem Subjekt fremd bestimmen, die Perversion wäre dann eher so etwas wie eine Heimstatt, in der das Subjekt sich einrichten kann. Für den Trieb 
hebt Lacan, abermals mit Freud, auch die Eigenschaft einer »konstanten Kraft $«{ }^{24}$ hervor, etwas, das in dem Signifikanten >Trieb (anklingt und bei Übersetzungen desselben gerne unterschlagen wurde.

Ich schließe diese Auszüge aus dem Seminar XI mit einem Zitat, in dem Lacan den Trieb beschreibt als »etwas, das von einem Rand ausgeht, das dessen geschlossene Struktur verdoppelt, einer Bewegung folgend, die eine Wiederkehr darstellt und dessen Konsistenz durch nichts anderes garantiert erscheint, als durch das Objekt, und zwar im Namen von etwas, das eingekreist werden soll «. ${ }^{25}$

In seinem Seminar XX mit dem Titel Encore von 1972/1973 führt Lacan seine These aus, daß das Geschlechtsverhältnis nicht existiert. Mit dieser Annahme wird abermals deutlich, daß jeder Art von Zentrierung menschlicher Sexualitäten auf Genitalität im Licht der Psychoanalyse eine Absage erteilt werden muß: Es geht nicht. Ich möchte schließen mit einem vorletzten Zitat von Lacan - es soll noch ein letztes geben zur Überleitung in die Diskussion. Ich lasse dieses vorletzte Zitat unkommentiert. Lacan schreibt: »Es gibt kein Geschlechtsverhältnis, weil der Genuß des Anderen, aufgefaßt als Körper, stets inadäquat ist - pervers auf der einen Seite, sofern der Andere sich reduziert auf das Objekt $a-$ und auf der anderen, ich würde sagen, verrückt, rätselhaft «. ${ }^{26}$

Es wird kolportiert, Lacan habe bei einer wissenschaftlichen Tagung der französischen psychoanalytischen Vereinigung nach einem Vortrag von Jean Clavreul über das Thema Perversion bemerkt: »Nur die Perversen können angemessen über die Perversion sprechen«. Dies als Ermutigung zum Einstieg in die Diskussion.

\section{Anmerkungen}

1 Vgl. Sigmund Freud: »Drei Abhandlungen zur Sexualtheorie«, in: ders., Gesammelte Werke [GW] Bde. I-XVIII, London 1940, Frankfurt am Main ${ }^{2}$ 1999, hier GW V, 27 145. Die römische Ziffer verweist auf den Band, die lateinische gibt die Seite an. Wird im Text ohne Zitatangabe zitiert, bezieht sich das Zitat auf die vorangegangene, ausgewiesene Textstelle. Vgl. ders., »)Ein Kind wird geschlagen<. Beitrag zur Kenntnis der Entstehung sexueller Perversionen«, GW XII, 195-226. Vgl. ders., »Fetischismus«, GW XIV, 309-317.

2 Freud: »Bruchstück einer Hysterie-Analyse«, GW V, $209 \mathrm{f}$.

3 Vgl. Freud: »Triebe und Triebschicksale«, GW X, 209-232.

4 Vgl. Freud: »Das ökonomische Problem des Masochismus«, GW XIII, 369-383.

5 Jacques Lacan: Das Seminar Buch XI. Die vier Grundbegriffe der Psychoanalyse, Textherstellung Jacques-Alain Miller; Norbert Haas, Hans Joachim Metzger (Hg.), übersetzt von Norbert Haas, Weinheim, Berlin 1980, 182 (Hervorhebung i.O.).

6 Freud nennt in der Zusammenfassung "Scham, Ekel, Mitleid und die sozialen Konstruktionen der Moral und Autorität« (GW V, 132). 
7 Sechs Teile gelten als verschwunden, die anderen erhaltenen sind: »Das Unbewußte« (1913), »Triebe und Triebschicksale« (1915), »Die Verdrängung« (1915), »Metapsychologische Ergänzung zur Traumlehre« (1916), »Trauer und Melancholie« (1916).

8 So Lutz Mai in einem seiner Hamburger Seminare zu Totem und Tabu aus den 1990er Jahren.

9 Freud nimmt diesen Gedanken später wieder in der Arbeit »Die Ichspaltung im Abwehrvorgang" von 1938 auf, vgl. GW XVII, 57-62.

10 Vgl. Jacques Lacan: Das Seminar Buch III (1955-1956). Die Psychosen, Textherstellung Jacques-Alain Miller (Hg.), übersetzt von Michael Turnheim, Weinheim, Berlin 1997.

11 Vgl. Jacques Lacan: Das Seminar Buch X (1962/1963). Die Angst, übersetzt von Gerhard Schmitz, Lacan Archiv, Bregenz.

12 Bei Freud ist die Neurose das Negativ der Perversion!

13 Jacques Lacan: Das Seminar Buch IV (1956-1957). Die Objektbeziehung, Textherstellung Jacques-Alain Miller, übersetzt von Hans-Dieter Gondek, Wien 2003, $131 \mathrm{f}$.

14 Jacques Lacan: »Kant mit Sade«, in: ders., Schriften II. Norbert Haas, Hans-Joachim Metzger (Hg.), übersetzt von Norbert Haas, Hans-Joachim Metzger, Weinheim, Berlin 1986, 156.

15 Ebd., 157.

16 Lacan, Die vier Grundbegriffe, 182.

17 Ebd.

18 Ebd., 184.

19 Ebd.

20 Ebd., 189.

21 Eine genau genommen von Freud angedachte Sichtweise, vgl. Freud: »Zeitgemäßes über Krieg und Tod«, GW X, 337.

22 Lacan, Die vier Grundbegriffe, 190.

23 Ebd.

24 Ebd., 189.

25 Ebd.

26 Jacques Lacan: Das Seminar Buch XX (1972-1973). Encore, Textherstellung Jacques Alain Miller; Norbert Haas, Joachim Metzger (Hg.), übersetzt von Norbert Haas, Vreni Haas, Joachim Metzger, Weinheim, Berlin 1986, 157. 



\section{Autorinnen und Autoren}

Johanna Drobnig-Naumann (Dipl.-Psych.), Studium und Forschungsaufenthalte in Hamburg, Paris und Jerusalem. Verschiedene Lehr- und Vortragstätigkeiten. Lebt als Psychoanalytikerin und Übersetzerin psychoanalytischer und wissenschaftstheoretischer Texte (Julia Kristeva, Jacques Lacan, Jean-Bertrand Pontalis, Bernard Baas, Hans-Jörg Rheinberger) in Hamburg. Mitbegründerin vom Lehrhaus der Psychoanalyse Hamburg.

Ulrike Oudée Dünkelsbühler (Dr. phil., M.A.), Studium der Komparatistik, Romanistik und Anglistik in Konstanz, Berkeley, Siegen und Montréal. Freiberufliche Praxis für Fremdsprachen- u. Kommunikationstraining, Kulturtheorieseminare und Übersetzung in Hamburg (http://www.phillingua.de). Arbeitsschwerpunkte und Veröffentlichungen zu Dekonstruktion, Psychoanalyse, Übersetzung, Kultur- und Theoriekritik; Forschungsprojekt »Schrift und Symptom: Theorien der Hysterie und umgekehrt «.

Günther X. Frank (Dipl.-Psych.), Psychoanalytiker und Psychotherapeut. Studium der Psychologie und Theologie in Hamburg. Tätig in der AIDS- und Sexualberatungsstelle im Fachdienst Gesundheit des Kreises Stormarn, freiberuflich psychoanalytisch tätig in eigener Praxis und als Honorarmitarbeiter der pro familia Schleswig-Holstein zur Therapie familiär gewalttätiger Personen sowie im Bereich beruflicher Weiterbildung. Mitbegründer vom Lehrhaus der Psychoanalyse Hamburg und Mitarbeit in demselben. Arbeitsschwerpunkte: Sexualität, HIV/AIDS, STD/STI, Arbeit mit Sexualstraftätern, Arbeit mit von illegalen Suchtstoffen Abhängigen, Sexualpädagogik, Projektarbeit.

Susanne Gottlob (Dr. phil.), Studium der Literaturwissenschaft und Kunstgeschichte in Hamburg und Italien. Lehrtätigkeiten und Veröffentlichungen, u.a. »Stimme und Blick«, transcript Verlag 2002. Verschiedene Lektorate. Mitarbeit im Lehrhaus der Psychoanalyse Hamburg 
seit 1998. Arbeitsschwerpunkte: Lesbarkeit und Einschreibungen von Geschichtlichkeit (Die Gesetze der Gastfreundschaft, Pierre Klossowski; Atemwende, Paul Celan; Der Naturvertrag, Michel Serres), Widerstand und Psychoanalyse (u.a. Seminar mit Susanne Moll).

Max Kleiner (Dipl.-Psych.), Studium der Psychologie in Trier, Montpellier und Hamburg. Psychotherapeut und Psychoanalytiker, Übersetzer von Lacan-Seminaren. Gründungsmitglied vom Lehrhaus der Psychoanalyse Hamburg; Arbeitsschwerpunkte: Psychosen, Topologie.

Peter Müller (Dr. med.), Psychoanalytiker in eigener Praxis seit 1979. Facharzt für psychotherapeutische Medizin. Veröffentlichungen zur Praxis der Psychoanalyse; Mitherausgeber des Jahrbuchs für klinische Psychoanalyse. Supervisor in verschiedenen Einrichtungen. Gründungsmitglied von: Fondation Européenne pour la Psychoanalyse (1991), Assoziation für die Freudsche Psychoanalyse (1994), Psychoanalytisches Kolleg (2004).

Karl-Josef Pazzini (Prof. Dr. phil.), Studium der Philosophie, Theologie, Erziehungswissenschaften, Mathematik, Kunstpädagogik. Psychoanalytiker in eigener Praxis. Mitbegründer von: Assoziation für die Freudsche Psychoanalyse (1994); Psychoanalytisches Kolleg (2004). Professor für Erziehungswissenschaft. Didaktik der Bildenden Kunst, Universität Hamburg. Arbeitsschwerpunkte: Psychoanalyse, Pädagogik, Museum; Bildung, Lehre und Lernen in Bezug auf Kunst, Aggressivität der Lehre. Dazu verschiedene Veröffentlichungen, zuletzt (mit Marianne Schuller und Michael Wimmer) »Wahn - Wissen - Institution«, transcript Verlag 2005.

Claus-Dieter Rath (Dr. rer. soc.), Psychoanalytiker in Berlin. Gründungsmitglied von: Fondation Européenne pour la Psychoanalyse (1991); Assoziation für die Freudsche Psychoanalyse (1994); Freud-LacanGesellschaft. Psychoanalytische Assoziation Berlin (1997); Psychoanalytisches Kolleg (2004). Veröffentlichungen über Fragen der psychoanalytischen Praxis, der Geschichte der Psychoanalyse und über die Massenpsychologie des Alltagslebens. Mitherausgeber von: (mit Jutta Prasse) Lacan und das Deutsche. Die Rückkehr der Psychoanalyse über den Rhein. Freiburg im Breisgau 1994; (mit André Michels, Peter Müller, Achim Perner): Jahrbuch für klinische Psychoanalyse. Tübingen 
1998ff. Herausgeber der Textauswahl $>$ Jutta Prasse: Sprache und Fremdsprache. Psychoanalytische Aufsätzer. Bielefeld 2004.

Edith Seifert (Dr. phil.), Studium der Romanistik und Soziologie. Verlagsredakteurin, Dozentin am Goethe-Institut, wissenschaftliche Mitarbeiterin an der Freien Universität Berlin, Gastprofessorin und Lehrbeauftragte an der Universität Wien und Innsbruck. Psychoanalytikerin in Berlin. Mitbegründerin von: Psychoanalytischer Salon Berlin, Psychoanalytisches Kolleg (2004). Arbeitsschwerpunkte: Weibliche Sexualität. Das Verhältnis zwischen Neurowissenschaft und Psychoanalyse. Dazu verschiedene Veröffentlichungen. 


\section{Titel zur Psychoanalyse}

Karl-Josef Pazzini,

Susanne Gottlob (Hg.)

Einführungen in die

Psychoanalyse I

Einfühlen, Unbewußtes,

Symptom, Hysterie, Sexualität, Übertragung, Perversion

April 2005, 160 Seiten,

kart., $16,80 €$,

ISBN: 3-89942-348-8

Karl-Josef Pazzini,

Marianne Schuller,

Michael Wimmer (Hg.)

Wahn - Wissen - Institution

Undisziplinierbare Näherungen

(unter Mitarbeit von Jeannie

Moser)

Februar 2005, 376 Seiten,

kart., $29,80 €$,

ISBN: 3-89942-284-8

Jutta Prasse

\section{Sprache und Fremdsprache}

Psychoanalytische Aufsätze

(herausgegeben von

Claus-Dieter Rath)

2004, 212 Seiten,

kart., $22,80 €$,

ISBN: 3-89942-322-4
Manfred Riepe

Intensivstation Sehnsucht

Blühende Geheimnisse im Kino

Pedro Almodóvars.

Psychoanalytische Streifzüge

am Rande des Nervenzusam-

menbruchs

2004, 26o Seiten,

kart., zahlr. Abb., 25,80 €,

ISBN: 3-89942-269-4

Peter Widmer

Angst

Erläuterungen zu Lacans

Seminar X

2004, 176 Seiten,

kart., $18,80 €$,

ISBN: 3-89942-214-7

Marianne Schuller,

Gunnar Schmidt

Mikrologien

Literarische und

philosophische Figuren

des Kleinen

2003, 182 Seiten,

kart., $24,80 €$,

ISBN: 3-89942-168-X

Manfred Riepe

Bildgeschwüre

Körper und Fremdkörper im

Kino David Cronenbergs.

Psychoanalytische Filmlektüren nach Freud und Lacan

2002, 224 Seiten,

kart., zahlr. SW-Abb., 24,80 €,

ISBN: 3-89942-104-3

Leseproben und weitere Informationen finden Sie unter: www.transcript-verlag.de 